\title{
ENHANCED OIL RECOVERY OF VISCOUS OIL BY INJECTION OF WATER-IN- OIL EMULSION MADE WITH USED ENGINE OIL
}

\author{
A Dissertation \\ by \\ XUEBING FU \\ Submitted to the Office of Graduate Studies of \\ Texas A\&M University \\ in partial fulfillment of the requirements for the degree of \\ DOCTOR OF PHILOSOPHY
}

Approved by:

Chair of Committee, Robert H. Lane

Committee Members, Maria A. Barrufet

David E. Bergbreiter

Akhil Datta-Gupta

A. Daniel Hill

Head of Department, A. Daniel Hill

December 2012

Major Subject: Petroleum Engineering

Copyright 2012 Xuebing Fu 


\begin{abstract}
Solids-stabilized water-in-oil emulsions have been suggested as a drive fluid to recover viscous oil through a piston-like displacement pattern. While crude heavy oil was initially suggested as the base oil, an alternative oil - used engine oil was proposed for emulsion generation because of several key advantages: more favorable viscosity that results in better emulsion injectivity, soot particles within the oil that readily promote stable emulsions, almost no cost of the oil itself and relatively large supply, and potential solution of used engine oil disposal.
\end{abstract}

In this research, different types of used engine oil (mineral based, synthetic) were tested to make W/O emulsions simply by blending in brine. A series of stable emulsions was prepared with varied water contents from $40 \sim 70 \%$. Viscosities of these emulsions were measured, ranging from $10^{2} \sim 10^{4} \mathrm{cp}$ at low shear rates and ambient temperature. Then an emulsion made of $40 \%$ used engine oil and $60 \%$ brine was chosen for a series of coreflood experiments, to test the stability of this emulsion while flowing through porous media. Limited breakdown of the effluent was observed at ambient injection rates, indicating a stability of the emulsion in porous media. Pressure drops leveled off and remained constant at constant rate of injection, indicating steady-state flows under the experimental conditions. No plug off effect was observed after a large volume of emulsion passed through the cores.

Reservoir scale simulations were conducted for the emulsion flooding process based on the emulsion properties tested from the experiments. Results showed 
significant improvement in both displacement pattern and oil recovery especially compared to water flooding. Economics calculations of emulsion flooding were also performed, suggesting this process to be highly profitable. 


\section{DEDICATION}

To Daulat D. Mamora 


\section{ACKNOWLEDGEMENTS}

I would like to thank Dr. Daulat Mamora, for bringing me into the heavy oil area and getting me started with my research project. I also want to thank my committee chair, Dr. Robert Lane for continually challenging me and always having time for discussions, and my committee members, Dr. Maria Barrufet, Dr. Akhil Datta-Gupta, Dr. Daniel Hill, and Dr. David Bergbreiter for their generous support for me in completing this project.

Thank you to my lab mates for making my research possible and enjoyable, especially Matt Wiese and Hamid Rahnema. Many thanks to my friends, Xinwei Li, Cui Song, Hongqian Nie and Guohua Ann for their constant support and encouragement. I would also like to thank my parents, Zengchun $\mathrm{Wu}$ and Haitao Fu for their love and understanding and my cousin, Qinghua Li for always believing in me.

Finally, thank you to everyone who has helped me to learn and grow over the last six years at Texas A\&M University. 


\section{TABLE OF CONTENTS}

Page

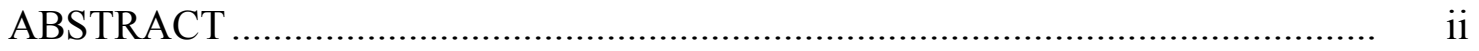

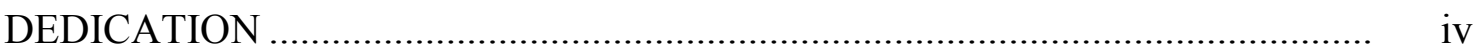

ACKNOWLEDGEMENTS ................................................................

TABLE OF CONTENTS .............................................................................. vi

LIST OF FIGURES .......................................................................... viii

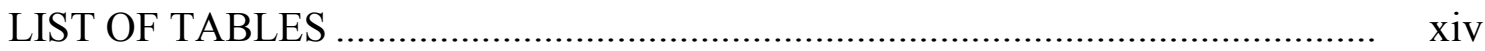

\section{CHAPTER}

I INTRODUCTION ............................................................ 1

1.1 Statement of Problem ............................................................ 1

1.2 Objectives of Research ...................................................... 2

1.3 Background and Literature Review .................................... 2

II EXPERIMENTAL METHODS ............................................... 15

2.1 Chemicals and Fluids ....................................................... 15

2.2 Experimental Apparatus ........................................................ 15

2.3 Experimental Procedures.......................................................... 21

III EXPERIMENTAL RESULTS ................................................. 27

3.1 Emulsion Generation........................................................ 27

3.2 Bench Tests .................................................................. 28

3.3 Corefloods ...................................................................... 41

IV SIMULATION STUDIES ...................................................... 78

4.1 General Description.............................................................. 78

4.2 Water Flooding ..................................................................... 81

4.3 Emulsion Flooding ............................................................. 87 
CHAPTER Page

4.4 Sensitivity Analyses ............................................................... 97

4.5 Emulsion Flooding in a Water-flooded Reservoir ................... 110

V ECONOMICS CALCULATIONS ............................................ 117

5.1 Model Description.......................................................... 117

5.2 Input Values ........................................................... 118

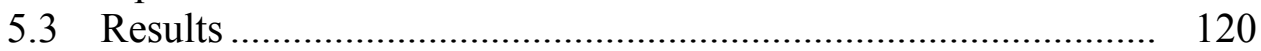

5.4 Sensitivity Analyses ..................................................... 122

5.5 Emulsion Flooding in a Water-flooded Reservoir ................... 137

VI SUMMARY AND CONCLUSIONS.......................................... 141

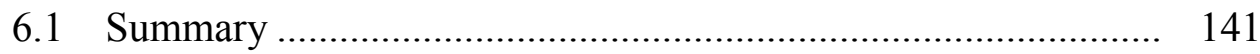

6.2 Conclusions ............................................................... 142

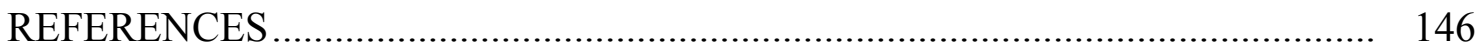

vii 


\section{LIST OF FIGURES}

FIGURE Page

2.1 Silverson L4RT laboratory homogenizer ....................................... 16

2.2 Coreflood system.......................................................................... 20

2.3 Snapshot of the emulsification process ............................................. 22

2.4 Setup for packing a slimtube with sand ......................................... 25

3.1 Used engine oil (Pennzoil 5W-30) and W/O emulsions at different brine volume fractions ...................................................................... 28

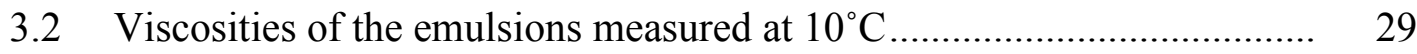

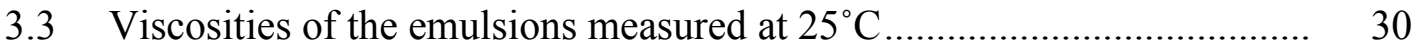

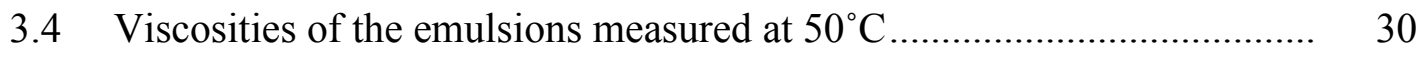

3.5 Microscopic images of a W/O emulsion (60 vol\% water), taken right after made (left) and 6 months later (right) ................................ 32

3.6 Densities of the emulsions............................................................. 33

3.7 Interfacial tensions between used engine oil/fresh engine oil and brine... 34

3.8 Particle Size distribution of the soot particles within used engine oil ..... 36

3.9 Microscopic images of emulsions generated with brine A, B and C (from top to bottom) ..................................................................... 38

3.10 Viscosities of emulsions generated with brine A, B and C ................... 39

3.11 Viscosities of emulsions generated with brine A, B and C, after 6 months

3.12 Bentheimer sandstone, Idaho sandstone and Boise sandstone from to $\mathrm{t} o$ ott om of si e 1

3.13 Emulsion effluents collected at injection rate $1 \mathrm{ft} / \mathrm{d}, 3 \mathrm{ft} / \mathrm{d}, 10 \mathrm{ft} / \mathrm{d}$ and $100 \mathrm{ft} / \mathrm{d}$ (from left to right). 
3.14 ressure rof ile for emulsion in ection

daho sandstone. 46

$3.15 \mathrm{f}$ fecti e is cosit of the emulsion daho sandstone

3.16 ressure rof ile for emulsion in ection

oise sandstone

3.17 Effective viscosity of the emulsion

oise sandstone 50

3.18 ressure rof ile for emulsion in ection entheimer sandstone 51

$3.19 \mathrm{f}$ fecti e is cosit of the emulsion entheimer sandstone

3.20 Viscometer-measured is cosit of the emulsion effluents Bentheimer sandstone I

3.21 Relative permeability curves

3.22 Mobility factor curves in two phase flow

3.23 ressure rof ile for emulsion in ection 12 entheimer sandstone $\quad . . . \quad 56$

$3.24 \mathrm{f}$ fecti e is cosit of the emulsion 12 Bentheimer sandstone I......... 57

3.25 Viscometer-measured viscosity of the emulsion and effluents:

12 entheimer sandstone

3.26 ressure rof ile for emulsion in ection 12 entheimer sandstone $\quad \ldots \quad 61$

3.27 Effective viscosity of the emulsion: 12 entheimer sandstone $\quad \ldots \ldots . . .62$

3.28 Bentheimer sandstone core right after emulsion flow experiment........... 63

3.29 ressure rof ile for emulsion in ection entheimer sandstone $\quad . . . .64$

$3.30 \mathrm{f}$ fecti $\mathrm{e}$ is cosit of the emulsion entheimer sandstone II .......... 65

3.31 ressure rof ile for emulsion in ection 12 entheimer sandstone . 66

$3.32 \mathrm{f}$ fecti e is cosit of the emulsion 12 entheimer sandstone $\quad \ldots \ldots . .66$

3.33 ressure rof ile for emulsion in ection $\quad$ entheimer sandstone $\quad \ldots \quad 67$ 
$3.34 \mathrm{f}$ fecti e is cosit of the emulsion entheimer sandstone $\quad \ldots . . . . .68$

3.35 ressure rof ile for emulsion in ection $3^{\prime}$ sand a cked slimtu e ......... 71

$3.36 \mathrm{f}$ fecti e is cosit of the emulsion $3^{\prime}$ sand a cked slimtu e .............. 72

3.37 Viscometer-measured viscosity of the emulsion effluents:

$3^{\prime} \quad$ sand acked slimtu e ............................................................... 73

3.38 ressure rof ile for emulsion in ection ${ }^{\prime}$ sand a cked slimtu e ........ 74

$3.39 \mathrm{f}$ fecti e is cosit of the emulsion ' ${ }^{\prime}$ sand a cked slimtu e .............. 75

3.40 Viscometer-measured viscosity of the emulsion effluents:

, sand acked slimtu e ................................................................... 76

4.1 (a) $2 \mathrm{D}$ view of the gridblocks from top; (b) 3D view of the gridblocks ... 79

4.2 Liquid rates and well BHPs in water flooding ................................. 81

4.3 Water cut in water flooding ........................................................ 82

4.4 Cumulative oil production in water flooding .................................... 83

4.5 Recovery performance for water flooding ….................................... 84

4.6 Oil saturation after two years of water flooding ................................. 85

4.7 Liquid rates and well BHPs in emulsion flooding ............................. 89

4.8 Comparison between emulsion flooding and water flooding:

oil production rate ....................................................................... 91

4.9 Comparison between emulsion flooding and water flooding: liquid injection rate..................................................................... 92

4.10 Comparison between emulsion flooding and water flooding: water cut... 92

4.11 Comparison between emulsion flooding and water flooding:

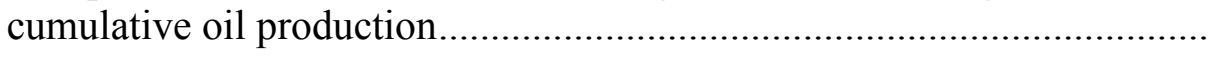


4.12 Comparison between emulsion flooding and water flooding: oil recovery performance.

4.13 Crude oil fraction after two years in emulsion flooding...

4.14 Oil production rates under different emulsion viscosities.

4.15 Water cut under different emulsion viscosities

4.16 Cumulative oil productions under different emulsion viscosities ...... 100

4.17 Injection and production rates at different emulsion breakdown 102

4.18 Water cut in the produced fluids at different emulsion breakdown.

4.19 Oil production rates for reservoirs with different crude oil viscosities 104

4.20 Cumulative oil productions for reservoirs with different crude oil viscosities

4.21 Oil production rates for reservoirs with different porosities 107

4.22 Cumulative oil productions for reservoirs with different porosities ....... 108

4.23 Oil production rates for reservoirs with different permeabilities 109

4.24 Cumulative oil productions for reservoirs with different permeabilities .. 110

4.25 Oil rate and water cut at the production well for emulsion flooding after water flooding

4.26 Total liquid rate and BHP at the injection well for emulsion flooding after water flooding

4.27 Emulsion rate at the production well for emulsion flooding after water flooding

4.28 Cumulative oil production at the production well for emulsion flooding after water flooding.....

4.29 Recovery performance for emulsion flooding after water flooding 
FIGURE Page

5.1 Monthly liquid rates in water flooding ............................................ 119

5.2 Monthly liquid rates in emulsion flooding .................................... 120

5.3 Cash flow for water flooding and emulsion flooding .......................... 121

5.4 NPV for water flooding and emulsion flooding .............................. 121

5.5 Sensitivity analyses of capital costs on cash flow ............................ 123

5.6 Sensitivity analyses of capital costs on NPV ..................................... 123

5.7 Sensitivity analyses of water price on cash flow in water flooding ......... 125

5.8 Sensitivity analyses of water price on NPV in water flooding ............... 125

5.9 Sensitivity analyses of emulsion price on cash flow in emulsion flooding................................................................... 127

5.10 Sensitivity analyses of emulsion price on NPV in emulsion flooding ...... 127

5.11 Sensitivity analyses of water disposal cost on cash flow in water flooding

5.12 Sensitivity analyses of water disposal cost on NPV in water flooding ..... 129

5.13 Sensitivity analyses of water disposal cost on cash flow in emulsion flooding.

5.14 Sensitivity analyses of operating cost on cash flow in water flooding ..... 130

5.15 Sensitivity analyses of operating cost on cash flow in water flooding ..... 131

5.16 Sensitivity analyses of operating cost on cash flow in emulsion flooding.

5.17 Sensitivity analyses of operating cost on NPV in water flooding........... 132

5.18 Sensitivity analyses of operating cost on NPV in emulsion flooding ....... 133

5.19 Sensitivity analyses of annual interest rate on NPV in water flooding ..... 134 
FIGURE $\quad$ Page

5.20 Sensitivity analyses of annual interest rate on NPV in emulsion flooding......................................................................... 134

5.21 Sensitivity analyses of emulsion viscosity on cash flow in emulsion flooding .......................................................................... 135

5.22 Sensitivity analyses of emulsion viscosity on NPV in emulsion flooding.......................................................................... 136

5.23 Monthly liquid rates during emulsion flooding in a water-flooded reservoir ............................................................. 138

5.24 Cash flow for emulsion flooding in a water-flooded reservoir ............... 138

5.25 NPV for emulsion flooding in a water-flooded reservoir ...................... 139 


\section{LIST OF TABLES}

TABLE $\quad$ Page

4.1 Reservoir and fluid properties .................................................... 79

4.2 Reservoir fluid quantities in water flooding ........................................ 86

4.3 Reservoir fluid barrels in water flooding ..................................... 87

4.4 Reservoir fluid quantities in emulsion flooding ................................ 96

4.5 Reservoir fluid barrels in emulsion flooding........................................ 96

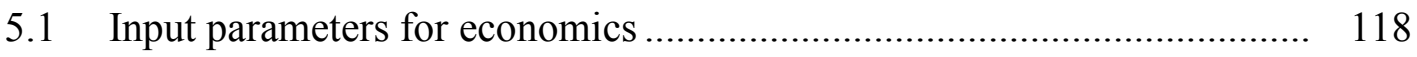




\section{CHAPTER I}

\section{INTRODUCTION}

\subsection{Statement of Problem}

Heavy oil constitutes a large proportion of worldwide oil reserves (Chopra and Lines, 2008). Cold production of such reserves is attractive in a number of locations for economic or technical reasons, due to thin formation that would lead to excessive heat loss or proximity to permafrost that could be melted during thermal recovery (Gondouin and Fox III, 1991; Selby et al., 1989). Primary production recovers usually less than five percent of heavy oil, while water flooding may add only another $5-10 \%$ recovery (Mai et al., 2009) — the mobility ratio is very unfavorable in water flood recovery of heavy oils, leading to high water cuts early in the process.

Polymer flooding is the most widely used EOR method for light to medium viscous oil recovery (Du and Guan, 2004), but this process may not be suitable for heavy oil having viscosity of $200 \mathrm{cp}$ or higher, due to the uneconomically high concentration of polymers required (Bragg, 1999). Alkali flooding or alkali-surfactant flooding is perhaps a more promising approach than polymer flooding in cases where an emulsion may form spontaneously in situ to mobilize heavy oil or divert flow to improve the recovery of heavy oil (Bryan and Kantzas, 2007). However, high cost of chemicals and high reaction/retention in the reservoir again limits their applications. Other methods include

the use of solvents, $\mathrm{CO}_{2}$, or inert gas to lower the viscosity of crude oil, but only with very limited success (Selby et al., 1989). 
A relatively recent approach involves generating high water percentage water-inoil crude oil emulsions by adding solid nanoparticles as a stabilizer (Bragg, 1999, 2000). This crude oil emulsion is proven to be an effective drive fluid that displaces in-situ oil through a piston-like displacement pattern and triples the net oil recovery of a water flooding process. However, this crude oil emulsion system has its shortcomings. Besides the requirement of adding nanoparticles, the viscosity of a crude oil emulsion is usually much higher than the original crude and thus too far beyond the purpose of mobility control and results in poor injectivity. Therefore, development of new non-thermal methods or improvement of existing methods is required for enhanced recovery of viscous oil that has viscosity of a few hundred to a few thousand centipoises.

\subsection{Objectives of Research}

The objectives of this research are the following:

- Explore the possibility of generating stable emulsions from used engine oil

- Characterize the stability and rheological behavior of used engine oil emulsions with both bench tests and coreflood experiments

- Evaluate the possibility of using this new emulsion system as a displacement fluid for heavy oil EOR based on simulations and economics calculations

\subsection{Background and Literature Review}

Heavy oil deposits in Canada, Venezuela and the United States comprise several trillion barrels (Chopra and Lines, 2008). Compared to light oil, the principal difficulty 
of the recovery of heavy oil is the high oil viscosity that impedes its flow. Thermal methods target at lowering oil viscosity by application of hot water (Harmsen, 1971), steam (Liebe and Butler, 1991; Owens and Suter, 1965) or in situ combustion (Joseph N. Breston, 1958). Among those methods, steam injection is the most successful and has been widely applied in heavy oil fields. However, many reservoirs are not suitable for thermal methods due to thin formation $(<10 \mathrm{~m})$ or large depth $(>1000 \mathrm{~m})$ which would lead to excessive heat loss (Selby et al., 1989). For such reservoirs, non-thermal recovery methods may be employed.

\subsubsection{Overview of Non-thermal Methods}

Water flooding is the most commonly used technique after primary recovery even in heavy oil reservoirs. The primary recovery from heavy oil reservoirs is generally low and water flooding is usually quite inefficient due to unfavorable mobility ratio which results in severe channeling and early water breakthrough. In the Lloydminster area the primary recovery was estimated to be $3-8 \%$ of the original oil in place (OOIP), and water flooding, which was carried out in most major reservoirs in this area, only added up an additional $1-2 \%$ of OOIP to the primary recovery (Adams, 1982). Because of the simplicity and low cost of water flooding, it is still widely applied despite its poor performance.

Carbon dioxide flooding was also suggested for heavy oil recovery and has been tested in different fields, with varied extent of success (Khatib et al., 1981; Picha, 2007; Reid and Robinson, 1981; Saner and Patton, 1986). Carbon dioxide can be applied to 
recover oil by various techniques: carbonated water flooding, $\mathrm{CO}_{2}$ cyclic stimulation, and immiscible $\mathrm{CO}_{2}$ flooding (Selby et al., 1989). The major mechanisms for improved oil recovery by $\mathrm{CO}_{2}$ are: oil viscosity reduction, oil swelling, interfacial tension reduction and emulsification (Selby et al., 1989). So far $\mathrm{CO}_{2}$ flooding is only applied to limited number of reservoirs.

Polymer flooding consists of adding polymers into injection water to increase its viscosity and thus to lower the water-oil mobility ratio. It has been successfully applied to many light to medium light (approximately $<200 \mathrm{cp}$ ) oil fields in the world (Kang et al., 2011; Leonard, 1986). Comparatively fewer attempts were made for heavy oil recovery using polymers. It was once considered that very high concentrations of polymer were required for highly viscous oils: the cost of chemical together with increased difficulty of injection would make this process uneconomical. However, polymer flooding for heavy oil recovery has become more promising in recent years due to the wide application of horizontal wells in heavy oil production and higher oil prices (Wassmuth et al., 2009; Wassmuth et al., 2007; Zaitoun, 1998).

Alkali flooding or caustic flooding involves injection of alkaline solutions into the reservoir, which react with the organic acids within heavy oil and form in situ surfactants, thus lowering the interfacial tension (IFT) and forming emulsions (Selby et al., 1989). Johnson (Johnson Jr., 1976) proposed four different mechanisms by which caustic flooding may improve oil recovery: (1) emulsification and entrainment, (2) wettability reversal (oil-wet to water-wet), (3) wettability reversal (water-wet to oil-wet), and (4) emulsification and entrapment. The actual mechanisms of this process depend on 
reservoir conditions and rock/fluid properties and may include a few of them at the same time. Although much success has been observed in laboratory experiments (Farouq Ali et al., 1979; Jennings Jr. et al., 1974; Scott et al., 1965; Xie et al., 2008) and certain fields reported promising results with this process (Edinga et al., 1980; Xie et al., 2008), a majority of field applications of alkali flooding were unsuccessful (Alikhan and Farouq Ali, 1983; Leonard, 1984; Selby et al., 1989). Caustic flooding usually does not outperform polymer flooding but its price is much lower and thus may be considered in certain cases.

Surfactant may be added to the injected alkali solutions and constitute a process called Alkali-surfactant (AS) flooding. In alkali flooding the minimum IFT is often achieved at very low concentrations of alkali. However, higher concentrations of alkali are often injected due to large consumption by the rock (Drillet and Defives, 1991; Mohnot et al., 1987; Novosad and Novosad, 1984), which leads to conditions that alkali floods do not perform at optimal conditions. By adding surfactants the floods can be stabilized by allowing higher concentrations of alkali to achieve minimum IFT (Bryan and Kantzas, 2009; Nelson et al., 1984). Improved recovery of heavy oil by AS flooding was observed in the lab (Bryan and Kantzas, 2009; Bryan and Kantzas, 2008; Mai et al., 2009) but applications were rarely seen in the fields, likely due to the high cost of surfactants especially in contrast to the low crude prices. Also, heavy oil itself may contain asphaltene which is surface active, thus reduces the requirement for artificial surfactants. Unlike chemical flooding of light oil, polymer is usually not part of the 
formulation, as polymer would be less effective in heavy oil cases and mobility control can come from emulsification.

Emulsion flooding is closely related to alkali or AS flooding. Sometimes the term "emulsion flooding" ma indicate a chemical flooding $\mathrm{r}$ ocess that in ol e $\mathrm{s}$ in situ emulsification (Kumar et al., 2010). Another category of emulsion flooding refers to an emulsified fluid prepared above the ground, by which means the composition and quality of emulsion can be better controlled. The emulsion flooding we focus on is under the second category through this dissertation. As an emulsion is composed of both water and oil (and often a small amount of stabilizer), injecting such a fluid means injecting a fraction of oil into the reservoir. This type of risk makes an emulsion flooding process unattractive and so far field applications are very limited. However, more frequent applications may be seen in future as crude oil price increases and cheaper/better emulsion systems are being developed.

\subsubsection{Emulsion Flooding}

Crude oil is the most common candidate for oil in generating emulsions because of its availability in the field. Generally two types of emulsions could be generated depending on the phase distribution: water-in-oil (W/O) or oil-in-water $(\mathrm{O} / \mathrm{W})$. In $\mathrm{O} / \mathrm{W}$ emulsions water is the continuous phase and oil exists as small droplets suspended in water. This type of emulsion has viscosities closer to water. On the contrary, W/O emulsions are mixtures of oil and water within which oil is the continuous phase. The viscosity of a $\mathrm{W} / \mathrm{O}$ emulsion would be closer to that of oil, and it increases as the water 
fraction goes up (Isaacs and Chow, 1992). Both types of emulsions have been suggested as displacement fluids for heavy oil recovery.

McAuliffe (McAuliffe, 1973b) conducted laboratory studies with oil-in-water emulsions by injecting an $\mathrm{O} / \mathrm{W}$ emulsion made with crude oil and dilute solutions of sodium hydroxide into sandstone cores. Reduced water permeability was observed even after many pore volumes of water being injected after the emulsion injection. Then a field test (McAuliffe, 1973a) was reported by the same author, indicating positive responses of flood pattern and incremental oil recovery from emulsion flooding. The major cause was attributed to improvement of heterogeneity of reservoir by the oil droplets plugging off higher permeability zones of the reservoir. The mechanism of this $\mathrm{r}$ ocess is com a ra le to the "emulsification and entra ment" mechanism in caustic flooding.

It has long been noticed that the $\mathrm{pH}$ of water has an effect on the type of emulsion to be formed. Farouq Ali et al. (Farouq Ali et al., 1979) generated stable W/O and $\mathrm{O} / \mathrm{W}$ emulsions by using low $\mathrm{pH}(\mathrm{pH}=2)$ and high $\mathrm{pH}(\mathrm{pH}=10)$ water, respectively. The emulsions were injected as slugs to recover crude heavy oil in coreflood experiments. The results were compared with acid flooding and caustic flooding cases, indicating higher efficiency of heavy oil recovery for the emulsion flooding cases. Also W/O emulsion slugs were found to be more effective than $\mathrm{O} / \mathrm{W}$ emulsions.

Similar adjustment of $\mathrm{pH}$ to generate stable emulsions was reported by D'Elia-S and Ferrer-G (D'Elia-S and Ferrer-G, 1973). In their research, stable W/O emulsions were made by mixing a heavy oil, a refined oil and low $\mathrm{pH}$ water without using any 
commercial surfactant. The refined oil was added simply to lower viscosity of the mixture. Then this emulsion was injected into a core as a slug to displace heavy oil, indicating a high recovery of $75 \%$ of the original oil in place.

More recently, nanoparticles were used as stabilizers to generate stable emulsions for the purpose of enhanced oil recovery (Bragg, 1999, 2000; Bragg and Varadaraj, 2006). In their patents, hydrophilic or oleophilic solid particles were used to promote $\mathrm{O} / \mathrm{W}$ and $\mathrm{W} / \mathrm{O}$ emulsions, respectively. The low viscosity $\mathrm{O} / \mathrm{W}$ emulsion can be used to enhance production of oil from subterranean reservoirs, or the transportation of oil through a pipeline. On the other hand, the high viscosity $\mathrm{W} / \mathrm{O}$ emulsion was suggested as a drive fluid for displacing hydrocarbons from the formation or to produce a barrier for diverting flow of fluids in the formation. An W/O emulsion consisted of $58 \%$ water and $42 \%$ crude heavy oil stabilized by proposed oleophilic nanoparticles was used as a drive fluid to recover the same crude oil in coreflood experiments, and a nearly $100 \%$ recovery was obtained at unit pore volume injection, indicating a piston-like flooding pattern.

Kaminsky et al. (Kaminsky et al., 2010) reported a successful field test on using $\mathrm{W} / \mathrm{O}$ emulsions to recover heavy oil after lab testing and reservoir modeling. The emulsion was generated on site using produced crude oil (3000 cp) and water. Small amounts of added mineral fines were used to stabilize the emulsion. Propane was dissolved into the oil to adjust the viscosity of the injected emulsion to be similar to that of the in situ oil. Emulsion fluid displaced viscous oil in a miscible-like manner with favorable mobility, which lead to improved displacement and recovery. The field 
piloting confirmed the ability to generate and sustain injection of a solids-stabilized emulsion in the field and to propagate stabilized emulsions in the reservoir.

All previous research came to the same conclusion on the high recovery efficiency of $\mathrm{W} / \mathrm{O}$ emulsions as displacement fluid to recover crude oil. As mentioned above, the oil external nature of the emulsion enables a semi-miscible process, and the high viscosity of emulsion allows sufficient mobility control during displacement. The two factors together can promote piston-like flood pattern in ideal conditions. Therefore for $\mathrm{W} / \mathrm{O}$ emulsions of high water fractions $(>50 \%)$, their efficiency as displacement fluids is so high that the net oil recoveries could be close to the water fraction. Even though oil is being injected into the reservoir (in the form of emulsion), the net oil recovery of this process is much greater than that from water flooding and at smaller amount of fluid injection. However, problems are associated with high water fraction $\mathrm{W} / \mathrm{O}$ emulsions.

First of all, the viscosity of $\mathrm{W} / \mathrm{O}$ emulsions increases quickly as the water fraction gets higher. A $60 \%$ emulsion can be $20 \sim 50$ times more viscous than the original oil used for creating this emulsion. Since crude oil is the common option for emulsion generation, the emulsion viscosity is usually unfavorably high for displacing the same crude, which will result in low injectivity. To solve this problem, both D'Elia-S (D'Elia-S and Ferrer-G, 1973) and Bragg (Bragg, 1999, 2000) suggested mixing in light hydrocarbon components to lower the emulsion viscosity. This would add up cost as light hydrocarbons are expensive, and may also complicate the emulsion generation process if the added hydrocarbon is gas. 
Secondly, some crude oil will not form stable emulsions just by adding solid particles (Bragg, 1999, 2000) or adjusting the pH (Farouq Ali et al., 1979). As heavy oil contains varied amount of asphaltene and other surface active agents, some may require more effective stabilizers than nanoparticles or acid to form emulsions that are stable enough for injection. Therefore this process will be limited by the chemical composition of heavy crude produced from the reservoir. Also the solid nanoparticles may be somewhat costly although less expensive than surfactants.

One possible solution for these problems is finding another candidate oil that is moderately viscous, and can emulsify easily without too much additives. It also has to be cheap and available in large quantities. Lead by those thoughts, we decided used engine oil would be a good candidate for generating W/O emulsions.

Engine oil is mainly composed of hydrocarbons. Because it is used under high temperatures and frequent frictions in engines, oil oxidation will occur. Oxidized compounds like organic acids can reduce the IFT, and soot (organic carbon) in used engine oil provides great oleophilic nanoparticles to stabilize the emulsion when water is mixed in. Engine oil is also good in that it has moderate viscosities, ranging from 30 $\sim 100 \mathrm{cp}$ at ambient temperature.

Large quantities of used engine oil are produced in the US every year. As waste products, they have to be recycled to avoid polluting the environment. Nowadays almost every mechanic shop serves as a used engine oil recycling center. Most of the collected oil is simply burned as fuel for energy. Used engine oil seems to be more of a pollution concern nowadays than being a useful material. All these facts added up and brought 
about our motivation in finding the possibility of generating $\mathrm{W} / \mathrm{O}$ emulsions with used engine oil for heavy oil EOR purposes.

\subsubsection{Used Engine Oil}

Used engine oil is a complex mixture of low and high $\left(\mathrm{C}_{15}-\mathrm{C}_{50}\right)$ molecular weight aliphatic and aromatic hydrocarbons (Kaplan et al., 2001). It also contains additives, metals, and various organic and inorganic compounds (T-Taissi and Raminsky, 2007). The additives are to minimize oxidation, control foaming, and resting or improving viscosity of the oil (Mashava et al., 1989). Due to the toxins and heavy metals contained in the oil, it is very harmful to the environment if not recycled properly. It is estimated that one gallon of used engine oil can contaminate 1 million gallon of water (http://www.recycleoil.org/). Recycling of used engine oil is required by law (http://www.dallascityhall.com/html/used_motor_oil_text.html).

About 2.7 billion gallons of engine oil are sold annually in the United States and about half of this oil becomes used oil (http://prose.eng.ua.edu/ed/pdf_file/tguide.pdf). The other half is either burned or leaked from the engine. It was estimated that about $70 \%$ of the used engine oil was generated from automotive, and the rest from industrial and other sources (http://prose.eng.ua.edu/ed/pdf_file/tguide.pdf) based on a study in Alabama. The exact amount of used engine oil reported varies among different websites, but a typical number is about 1.4 billion gallons per year.

Within the 1.4 billion gallons of used oil produced, about 780 million gallons are used as fuel, 160 million gallons re-refined and 200 million gallons end up being 
illegally dumped (http://www.americanrecycler.com/0110/used002.shtml). Estimated by a long-time executive in the used oil business, over $50 \%$ of the oil goes to industrial burning for energy, about $20 \%$ is re-refined into base lubricants, and another $15 \sim 18 \%$ is used for on-site heating. Another website states that up to $74 \%$ of all oil recycling in the U.S. is for burning in turbines, incinerators, power plants, cement kilns or manufacturing facilities, and an additional $11 \%$ of used motor oil is burned in specifically designed industrial space heaters (http://earth911.com/recycling/automotive/motor-oil/the-manyuses-of-recycled-motor-oil/). Another interesting article about used engine oil in California (http://www.cawrecycles.org/issues/used_motor_oil states that "more than half of the used oil collected in California is shipped out of state or offshore to be burned as fuel, resulting in toxic air pollution (such as phosphates, sulfur, and heavy metals including zinc, cadmium, copper, lead and benzene) and $\mathrm{CO}_{2}$ being released into the atmosphere. California's strict air emissions standards do not allow the burning of used oil "Those descri tio ns can lead us to the conclusion that used engine oil is more of a pollution concern nowadays than being a useful material.

The price of used engine oil is also found in literatures. Lam et. al (Lam et al., 2012) described used engine oil to be readily available at low cost and produced in high volumes. T-Raissi (T-Taissi and Raminsky, 2007) stated used engine oil was available at a relatively low cost of 10 cents/gallon delivered, and at the amount of 45 million gallons per year in Florida. Breslin (Breslin, 2010) mentioned used oil from large generators was sold to dealer at approximately 25 cents per gallon. Therefore it seems 
reasonable to assume a price of 10 to 25 cents per gallon for used engine oil, if there were no additional benefit from the government for the performance of recycling.

To relate to our research, for the purpose of heavy oil displacement, some calculations are made below:

1. In the US, daily heavy oil production is $0.5 \mathrm{Mb} / \mathrm{d}$ (Huc, 2011), which amounts to about $180 \mathrm{Mb} /$ year. The annual production of used engine oil is 1.4 billion gallons, which equals to $35 \mathrm{Mb} /$ year. If all the used engine oil is used for generating emulsions (60\% water), then about $90 \mathrm{Mb} /$ year can be supplied. This may not be a proper assumption, but it at least demonstrates the similar scale of the amount of used engine oil emulsion supply and the amount of heavy oil production, especially considering this emulsion flooding method to be a complementary method for thermal methods.

2. About 100 million gallons of used engine oil is produced in California each year (http://www.cawrecycles.org/issues/used_motor_oil). Assuming half of this oil is used for generating emulsions of $60 \%$ water cut, then about 3 million barrels of used engine oil emulsions can be generated annually for the purpose of heavy oil displacement. This could recover roughly the same amount of heavy crude oil -3 $\mathrm{Mb} /$ year. For the type of reservoir studied in our simulations, this amount of used engine oil emulsion could support heavy oil production from a field of 80 acres.

3. The price of used engine oil is 10 to 25 cents per gallon, which equals to $\$ 4.2 / \mathrm{bbl}$ to $\$ 10.5 / \mathrm{bbl}$. This price is low compared to the used engine oil price assumed in our economics calculations $(\$ 10 / \mathrm{bbl}$ to $\$ 20 / \mathrm{bbl})$. However, used engine oil 
recycling seems to be constantly developing these days, and the price and availability of used engine oil may vary as new recycling methods come into play. Injecting used engine oil back into the reservoir (in the form of emulsions) to displace crude may provide an alternative solution to used engine oil recycling besides improved recovery of heavy oil. 


\section{CHAPTER II}

\section{EXPERIMENTAL METHODS}

\subsection{Chemicals and Fluids}

Used Engine Oil I: a mineral based oil, Pennzoil 5W-30, collected from a 2003 Ford Focus engine after 3000 miles of use.

Used Engine Oil II: a synthetic engine oil, Mobil1 5W-20, collected from a 2006 Ford F-150 engine after 5000 miles of use.

Used Engine Oil III: a mixture of used engine oil (different brands) coming directly from a recycling tank (mostly mineral based because of the same oil type provided in the oil change center).

Brine: synthetic brine was prepared by adding sodium chloride and potassium chloride into water. Total dissolved solids are $30,000 \mathrm{mg} / \mathrm{kg}$ brine, with $20,000 \mathrm{ppm}$ sodium chloride and 10,000 ppm potassium chloride included.

All measurements and results for part 3.1 and 3.2 were conducted with emulsions made with Oil I, unless otherwise specified. All measurements and results for part 3.3 were conducted with emulsions made with Oil III.

\subsection{Experimental Apparatus}

Our experiments included emulsion generation, bench tests and coreflood experiments, so the apparatus associated with these experiments were shown under the same categorization. 


\subsubsection{Emulsification}

All the emulsions were generated by SILVERSON model L4RT laboratory homogenizer, shown in Figure 2.1.

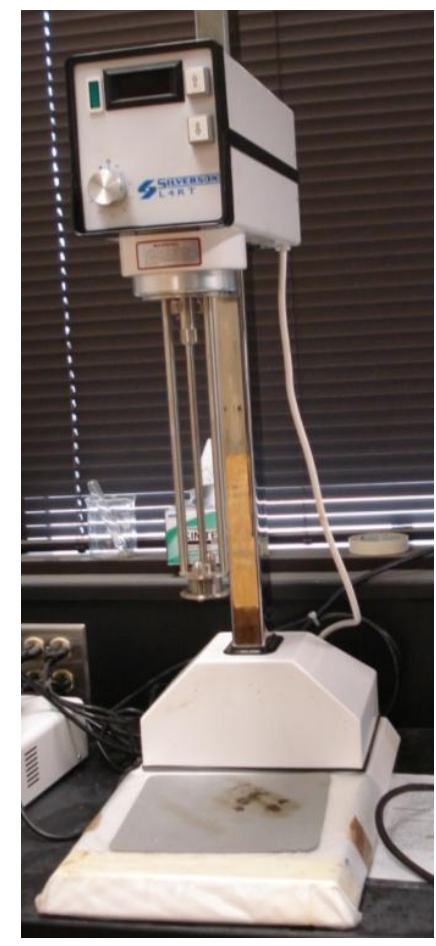

Fig. 2.1-Silverson L4RT laboratory homogenizer.

This homogenizer functions by rotating rotor blades under high speed, thereby drawing liquid upward from the bottom of vessel and into the center of the workhead. Centrifugal force then drives the liquid toward the periphery of the workhead where the 
fluids meet a static screen An "emulsor" screen was used for the ur o se of emulsification. When the liquid is forced through the screen under high rate, fine droplets are created and one phase of fluid gets dispersed in another. Then the fluids flow toward the sides of vessel and downward to replace the fluid sucked up in the workhead. Therefore the fluids get cycled in the vessel and forced through the screen thousands of times to create high quality emulsions with fine liquid droplets.

\subsubsection{Bench Test Devices}

After the emulsion was generated, a number of instruments were used to characterize the properties of this emulsion. The devices involved in those measurements are listed as follows.

\subsubsection{Rheometer}

Viscosity measurements were conducted by Brookfield digital rheometer Model DV-III+. The operation principle of the rheometer is to drive a spindle (which is immersed in the test fluid) through a calibrated spring at a certain shear rate. The shear stress of fluid against the spindle can be measured by the spring deflection which is further detected with a rotary transducer. Then the viscosity is obtained by dividing the shear stress over the shear rate. Two spindles, CPE- 40 and CPE-52 were used to measure the viscosities of the samples at different ranges. A water bath was coupled to the rheometer so that different temperatures could be applied. 


\subsubsection{Microscope}

The microscopic images of the emulsions were taken by Meiji Polarizing Microscope Model MT9920. A trinocular head was installed to replace the original binocular head of this model. The head is composed of $10 \times$ Widefield High Eyepoint eyepieces, and a CCD camera, by which the live images can be transferred to computer and seen from the computer screen. Three objective lenses with $10 \times, 40 \times$ and $100 \times$ magnifications are linked to the headpiece, thereby generating images of $100 \times, 400 \times$, and $1000 \times$ magnifications. All measurements from the microscopic images were calibrated with a stage micrometer, which was also provided by Meiji.

\subsubsection{Density meter}

Densities of fluids were measured by a high precision Anton Parr digital density meter Model DMA 4100M. Only $1 \mathrm{ml}$ of sample is required for density measurement. The accuracy of this density meter is up to $0.0001 \mathrm{~g} / \mathrm{ml}$.

\subsubsection{Tensiometer}

Interfacial tension (IFT) measurements were conducted by a drop shape analysis de ice Model SA30 Krüss For FT measurements of a dark nontrans a rent oil, an oil bubble has to be forced through an inverted needle to enter the water phase and form a drop upward. The shape of the drop depends on the IFT between the oil and water. By taking an image of the drop and fitting the shape by the Laplace-Young equation, the IFT can be calculated automatically by the software provided with the instrument. 


\subsubsection{Particle size analyzer}

The sizes of soot particles in the used engine oil were measured by a particle size analyzer Model 90Plus by Brookhaven. Particle sizes are measured by dynamic light scattering method. A dilute solution of the fine particles needs to be prepared before measurement and transferred into the sample cuvette. When the laser of the instrument turns on, a laser light goes through the solution, and the scattered light is collected from $90^{\circ}$ angle Small a rticles in the solution undergo Brownian motion, as a result the scattered light intensity will fluctuate. Based on the time dependence of the intensity fluctuation, the diffusion coefficient of the particles can be obtained. Knowing the diffusion coefficient and the viscosity of the medium, the size (hydrodynamic radius) of the particles can be calculated by the Stokes-Einstein equation.

\subsubsection{Coreflood System}

Our coreflood system consisted of several major components, shown in Figure 2.2. An ISCO pump was used to pump fluids, and an accumulator filled with emulsion was connected to the pump. These two parts constituted the injection system. When brine was the injectant, the accumulator was removed from the system and brine was directly forced into the coreflood cell from the pump.

A house designed and fabricated coreflood cell was connected to the injection system so that fluids can be pumped through. The coreflood cell was fabricated with aluminum and can withhold pressure up to 3000 psi. It accommodated cores measuring 1 inch diameter and 1 foot in length. When setting up the experiment, a core has to be 
placed in a nitrile sleeve and fit into the cell with both ends secured to the end plugs for the cell. Then the annulus between the sleeve and the coreflood cell wall will be filled with hydraulic oil, through which a confinement pressure is applied to the core sleeve by a hydraulic pump.

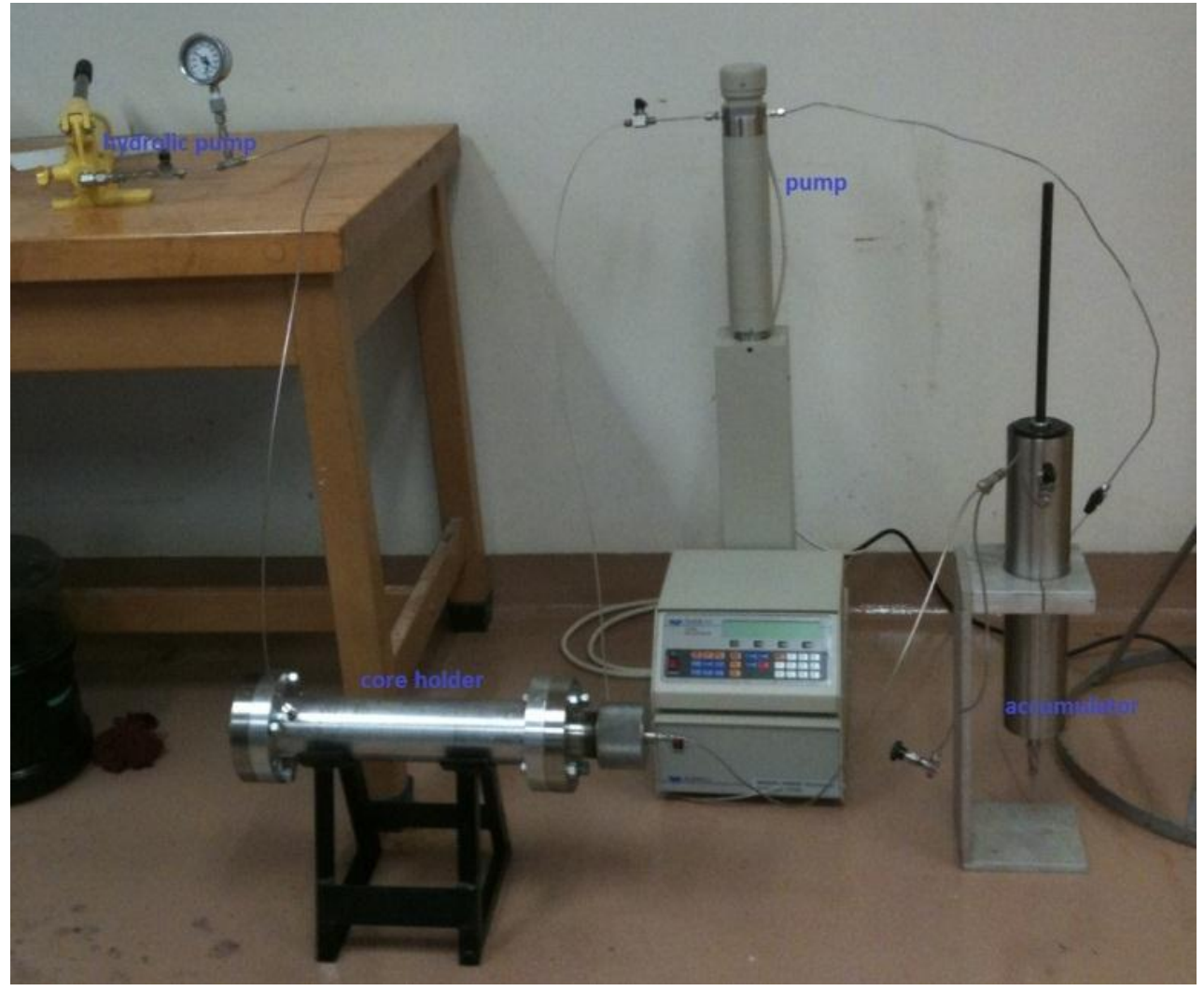

Fig. 2.2- Coreflood system.

The production system was kept simple: no back pressure regulator was used as the fluid system consisted of only liquid. A digital pressure gauge was connected to the 
inlet of the coreflood cell so the pressure can be recorded during the experiments. As the outlet pressure - atmospheric pressure was set to be 0 on the pressure gauge, the pressure value read at the inlet would be equal to the pressure drop between the inlet and outlet.

In our late experiments, sand-packed slim tubes of longer lengths were used to take the place of the coreflood cell. No confinement pressure was applied on the slim tubes. Preparation of these slimtubes will be introduced in the experimental procedures.

\subsection{Experimental Procedures}

The procedures on how to generate emulsions, how to prepare sand-packed slimtubes and how to conduct coreflood experiments are specified below. Bench measurements on the emulsion properties were rather straightforward thus not detailed here. All tests and measurements were conducted at am i ent tem e rature $23 \pm 05{ }^{\circ} \mathrm{C}$ unless otherwise specified.

\subsubsection{Emulsion Generation}

Used engine oil was first placed in a container, then brine was added into the oil in small amounts, while the high shear mixer (Silverson L4RT) was functioning to homogenize the fluids at 5,000 RPM to emulsify the system. Figure 2.3 indicates a snapshot of the emulsification process. After certain amount of brine was added, the emulsion was blended for an additional 5-10 minutes before the sample was collected. 


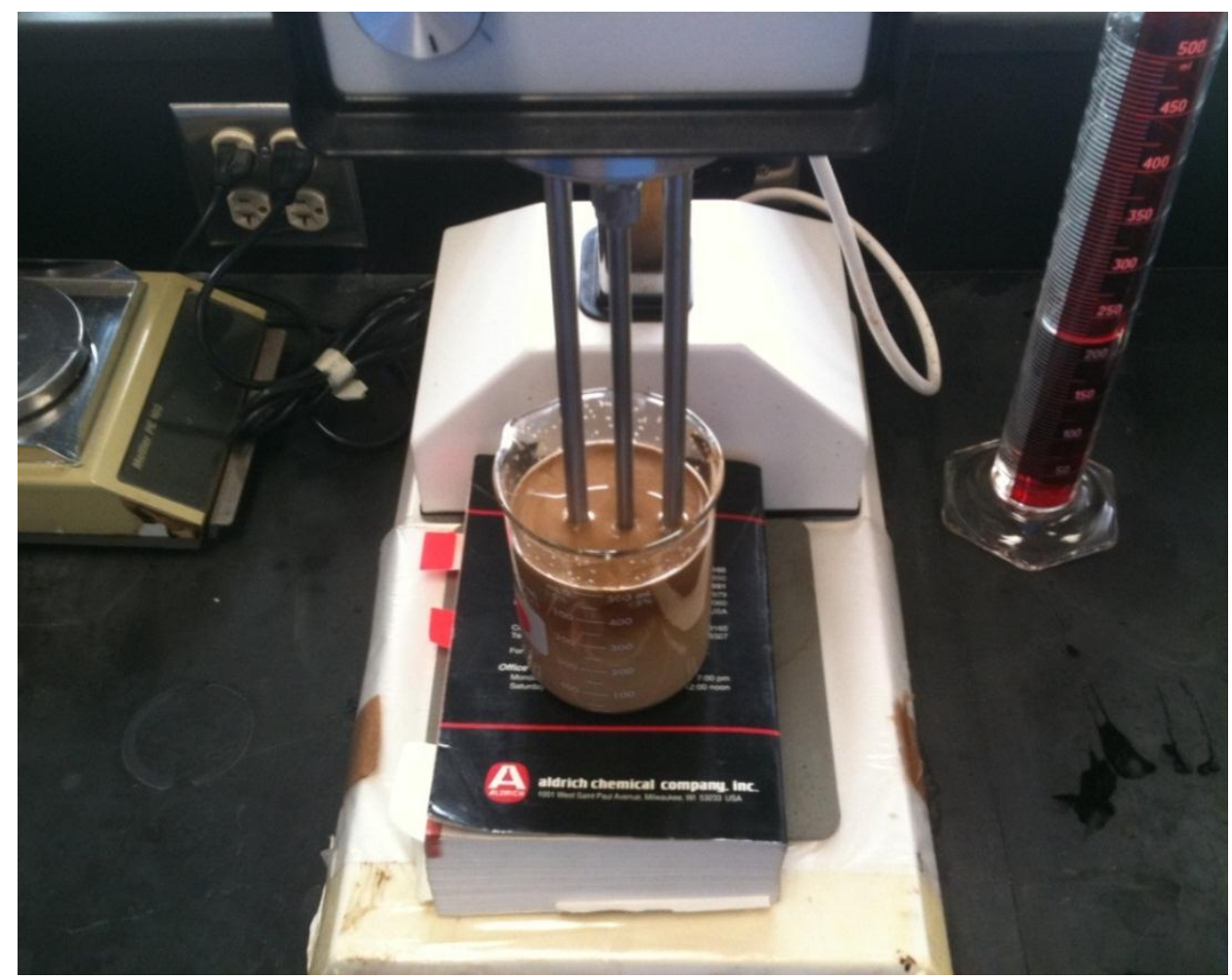

Fig. 2.3 - Snapshot of the emulsification process.

\subsubsection{Coreflood Experiments}

The main purposes of coreflood experiments were testing the emulsion stability and rheological properties in porous media. Different types of sandstone cores were used to test the emulsion under a variety of conditions. The porosity and permeability of rock were characterized before emulsion injection. The main steps for conducting coreflood experiments were set as follows: experiments were set as follows:

1. Select a clean sandstone core. 
2. Put the core in oven to remove any moisture, then measure the dry weight of the core $\left(m_{d}\right)$.

3. Saturate a core with brine by leaving core in solution for a few days (use vacuum pump to remove any air if necessary), then measure the weight of the brinesaturated core $\left(m_{b}\right)$, from which the amount of water within the core could be found. The volume of water is equal to the pore volume (PV) of the core. Given the dimensions of the core, its porosity can be calculated.

4. Put the core into a core-holder and set up the coreflood system. A confinement pressure of 1800 psi was applied through the hydraulic pump.

5. $\mathrm{n}$ ect $\mathrm{r}$ ine at a certain flow rate $5 \mathrm{ml} / \mathrm{min}$ until the $\mathrm{r}$ essure dro $\Delta$ stabilizes, then record the this value. From the injection rate, pressure drop, and dimensions of the core, the e rmea il it of the core can e estimated arc 's law.

6. Connect the accumulator that stores the emulsion into the injection system and start injecting emulsions through the core. Inject over 2 PVs of emulsion to ensure no more original free water is left in the core.

7. Set a certain flow rate at the pump. Record the pressure drop along the process and collect the effluent in small vials. Keep injecting at least 1 PV after the pressure drop stabilizes and save the effluent from this period of time for further analysis.

8. Repeat step 7 at other injection rates. 
The emulsion effluents were further characterized for free water breakout. Some samples were tested with viscometer for viscosity measurements. The stabilized pressure drop at any flow rate was taken to calculate the effective viscosity of the emulsion, under that particular condition. Detailed calculations on effective viscosity of the emulsion as well as other parameters during the coreflood experiment will be shown in the experimental results.

\subsubsection{Slimtube Preparation}

Our coreflood cell accommodates cores with maximum length of 1 foot, so slimtubes of greater lengths were prepared to test the emulsion while traveling longer distances through porous media. $1 / 4 " \mathrm{OD} \times 0.035^{\prime \prime}$ Wall stainless steel tubing of 3 feet and 6 feet lengths were used as slimtubes for sand packing. Silica sand of 100 mesh in size was chosen to pack these tubes. An electrical shaker was used to help the sand packing in the tube tightly. $1 / 4 "$ OD to $1 / 8 "$ OD tube fittings were used to connect the slitube to the coreflood system. Glass wool was applied on the end of the slimtube to keep the sand from escaping. 


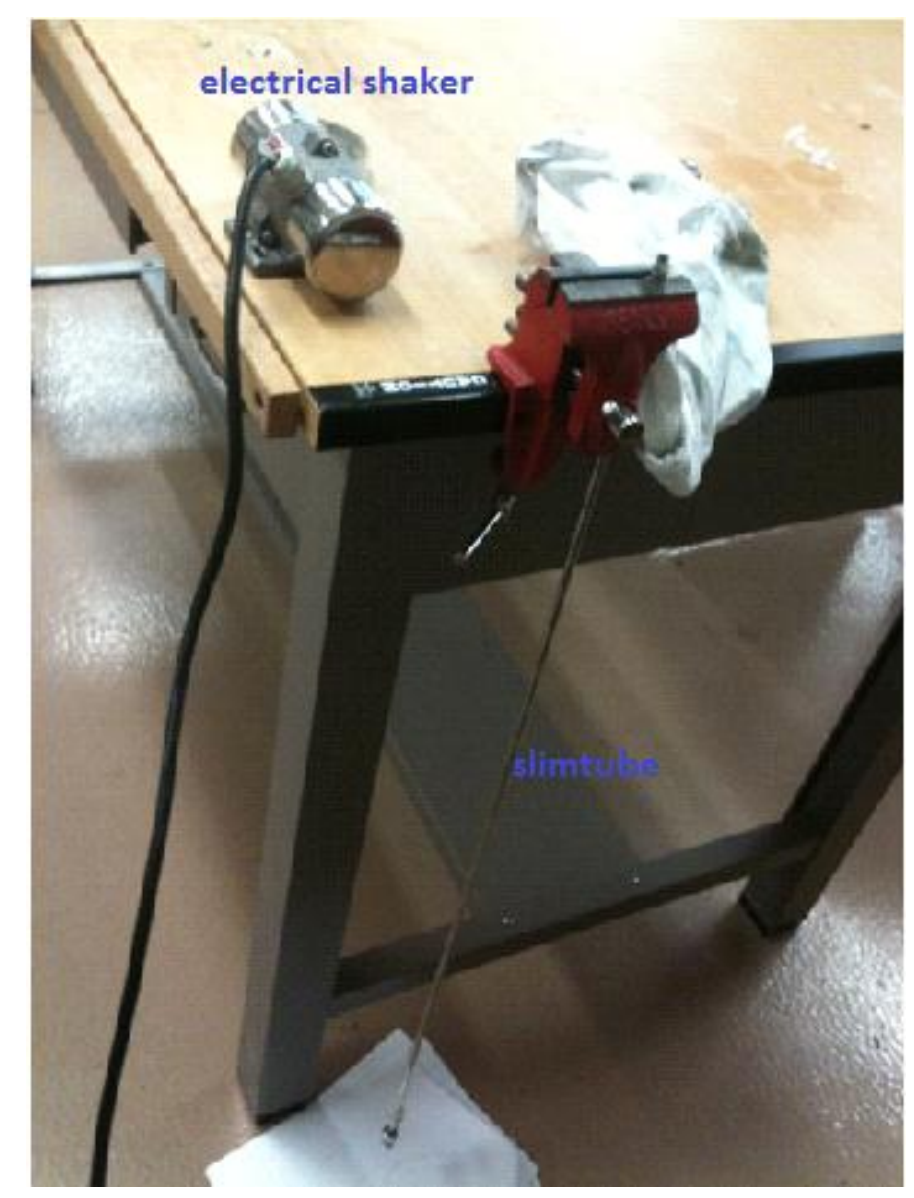

Fig. 2.4- Setup for packing a slimtube with sand.

Detailed procedures of preparing these slimtubes are as follows:

1. Pick a slimtube and make sure it is straight in shape.

2. Insert 1/4" nuts on both ends of the tube.

3. Put glass wool into a $1 / 4 "$ OD to $1 / 8$ " OD tube fitting, and then connect the fitting to one end of the tube. This way one end of the tube is sealed. 
4. Fix the tube to a table vertically (the sealed end down), and fix an electrical shaker close to the tube onto the same table

5. Start filling sand into the tube from top (the open end), while keeping the electrical shaker on to shake the system for better packing. A picture of the setup for sand packing is shown in Figure 2.4.

6. When the tube is filled up with sand, shake long enough time to make sure that the sand line no longer fall below the top of the tube.

7. Apply another $1 / 4 "$ OD to $1 / 8$ " OD tube fitting to the top of the tube. Again place glass wool into the fitting before doing so.

During the preparation of a sand packed slimtube, it is also important to characterize the porous media before injecting emulsion through. Similar concepts to those in making coreflood cells were used in measuring and calculating the porosity and permeability of the sand packed slimtubes. All measurements and calculations will be shown in the experimental results. 


\section{CHAPTER III}

\section{EXPERIMENTAL RESULTS}

\subsection{Emulsion Generation}

As mentioned earlier, used engine oil and brine were mixed together by a high shear mixer functioning at 5,000 RPM. Under this blending speed, brine was easily emulsified into the used engine oil. The color of mixture quickly changed from black to light brown.

A series of $\mathrm{W} / \mathrm{O}$ emulsion samples with water concentration (volume fraction) of $20 \%, 40 \%, 50 \%, 60 \%$ and $70 \%$ were obtained, shown in Figure 3.1 . The $20 \%$ emulsion "se a rated" into two la ers of liquid an u e $r$ la er of a darker color and a lower la er of a lighter color This indicates that the water dro lets could " $\mathrm{r}$ eci i tate" when the water concentration is low. It has to be noted that no water segregation was observed even though those two layers were recognized. The division was simply due to gravitational difference but not phase separation. At higher water concentrations, the emulsions tend to be more stable in terms of apparel unity: only a thin layer of black oil appeared on top of the $40 \%$ water content emulsion. No visible separation was recognized for the $50 \%, 60 \%$ and $70 \%$ cases. All these emulsions last for months without any visible water segregation.

As more brine was added and emulsified into the oil, the viscosity of the emulsion increased significantly. Up to $75 \%$ of the brine could be added to the used engine oil to form stable $\mathrm{W} / \mathrm{O}$ emulsions. Beyond that point, brine could hardly be 
blended into the system, and water would exist as a separate phase, with little or no oil droplets in it. The emulsion did not invert into a water continuous phase $(\mathrm{O} / \mathrm{W})$ as more brine was added. This indicates that used engine oil has a high tendency to be the external phase while forming emulsions with brine.
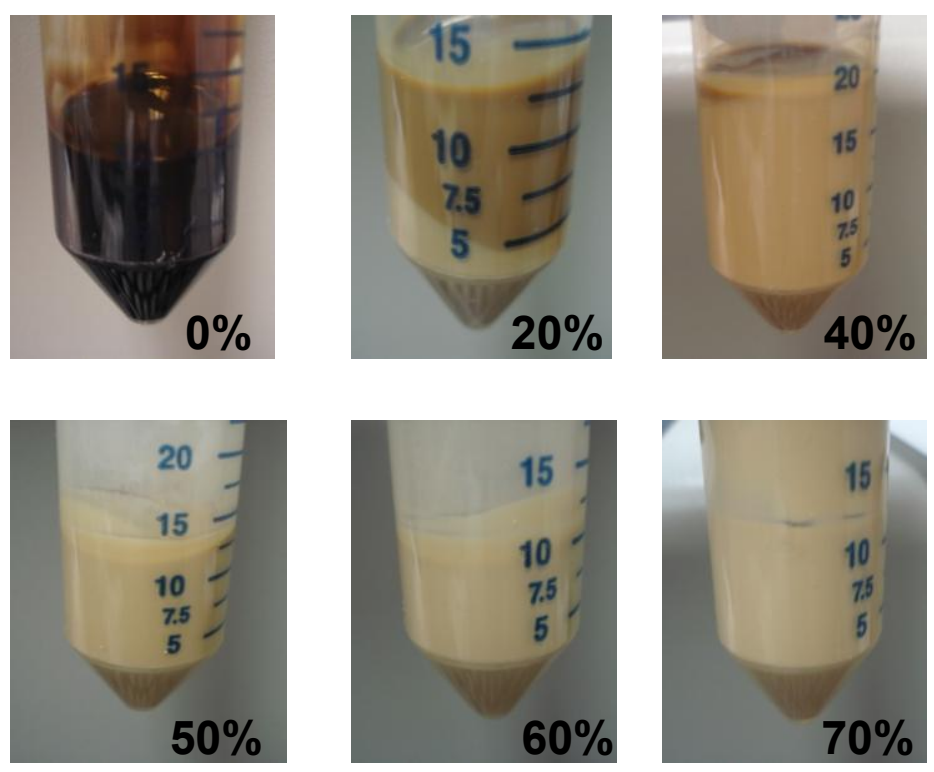

Fig. 3.1-Used engine oil (Pennzoil 5W-30) and W/O emulsions at different brine volume fractions.

\subsection{Bench Tests}

Bench tests included microscopic imaging, viscosity measurement and density measurement for the emulsions. Interfacial tension (IFT) measurements and soot particle size analysis for used engine oil were also conducted to better understand the stability of 
the emulsion system. Major measurements were repeated for Emulsions made with synthetic based oil, indicating very similar results to mineral based oil emulsions. Emulsions made with different brine solutions were also tested to reveal the effect of brine salinity and hardness on emulsion stability. All tests and measurements were conducted at am i ent tem er ature $23 \pm 05{ }^{\circ} \mathrm{C}$ unless otherwise s e cified

\subsubsection{Viscosity Measurement}

Viscosity measurements of these emulsions were conducted at three different tem e ratures $10{ }^{\circ} \mathrm{C}, 25{ }^{\circ} \mathrm{C}$, and $50{ }^{\circ} \mathrm{C}$, shown in Figures $32-3.4$. The percentages indicate the water volume fractions of the emulsion samples.

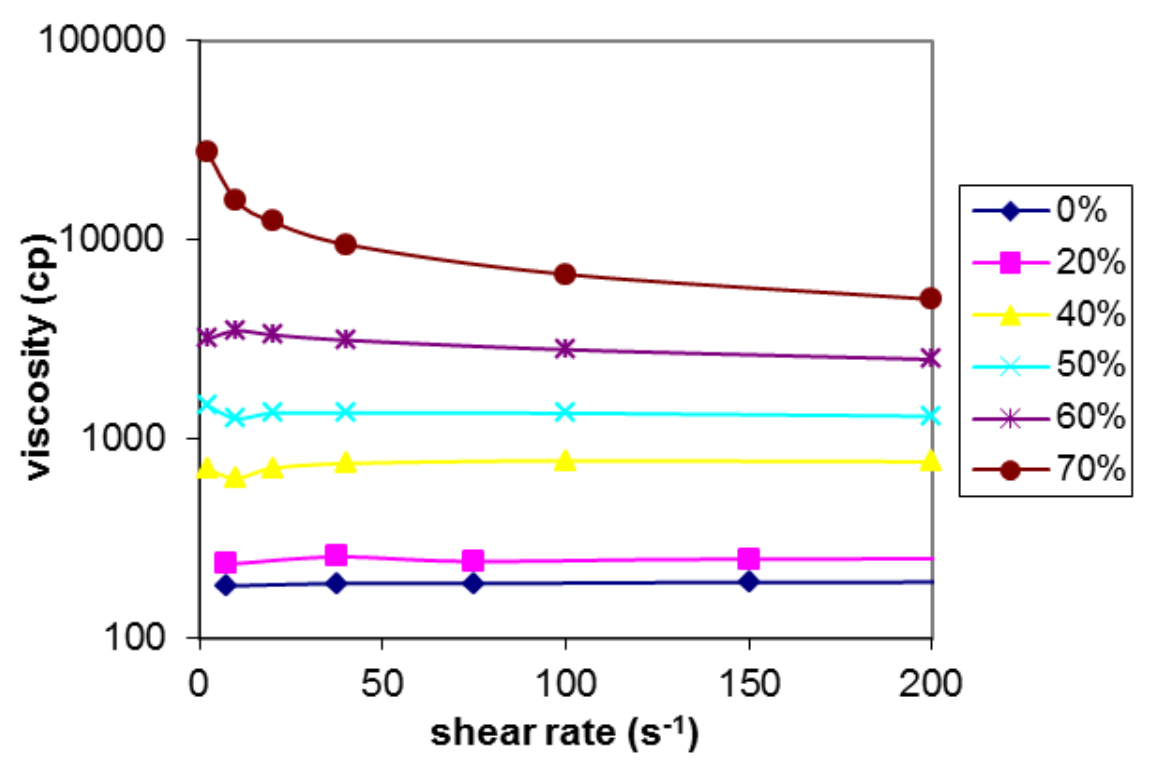

Fig. 3.2- Viscosities of the emulsions measured at $10^{\circ} \mathrm{C}$ 


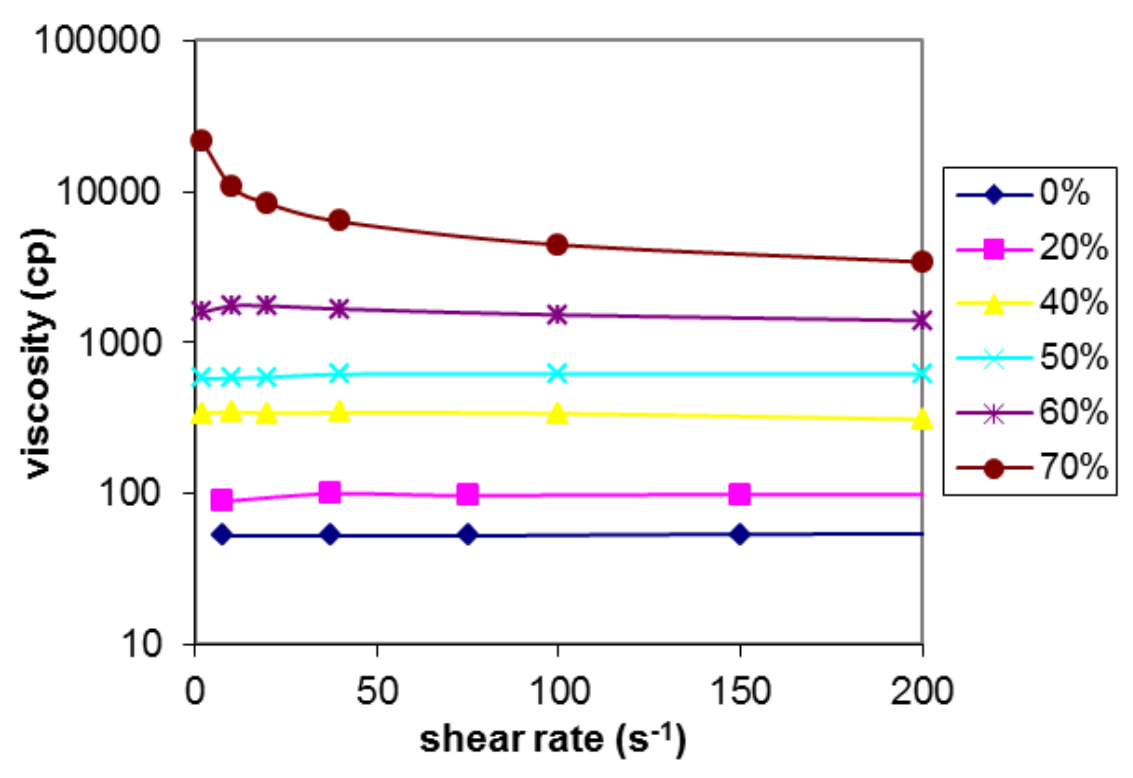

Fig. 3.3- Viscosities of the emulsions measured at $25^{\circ} \mathrm{C}$

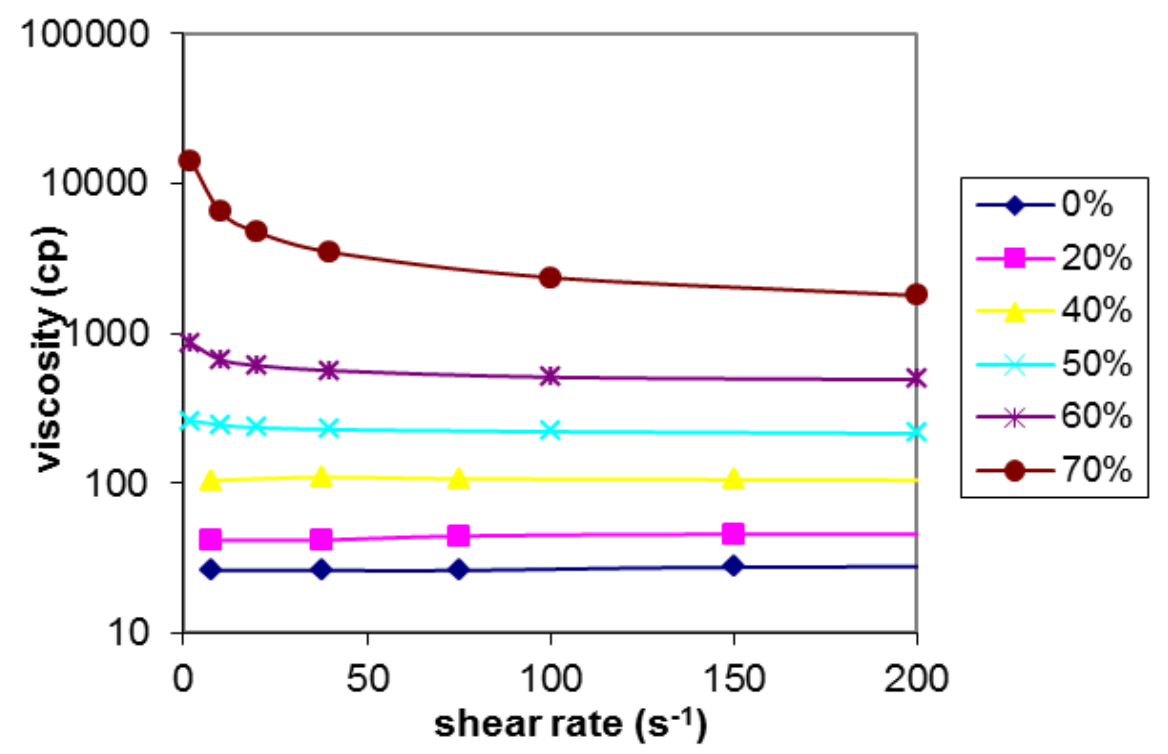

Fig. 3.4- Viscosities of the emulsions measured at $50^{\circ} \mathrm{C}$ 
Very similar patterns were obtained for all three cases: the viscosity of the emulsion increased with increasing water concentration, and a wide viscosity range from $10^{2}$ to $10^{4}$ was covered. At low water concentration, the viscosity of the emulsions remained constant under different shear rates - the fluids were Newtonian. Beyond a certain point (around 40\% from the figures), the emulsions demonstrated more pseudoplastic or shear thinning behavior, i.e. the viscosity decreased with increasing shear rate. The rheological property of a fluid is important because the fluid will experience shear going through porous media. It is generally believed that at a normal injection rate, the shear rate within a sandstone core ranges from $7 \mathrm{~s}^{-1}$ to $10 \mathrm{~s}^{-1}$ (Wassmuth et al., 2009). An emulsion that contains $50-60 \%$ water had viscosities of a few hundred to a few thousand centipoises at ambient temperature (about $10-40$ times more viscous than the original used engine oil), and was considered to be good candidates for displacing heavy oil of the same viscosity range.

\subsubsection{Microscopic Imaging}

The used engine oil emulsions we made were macroemulsions. They are not thermodynamically stable. Although no visible phase separation was observed for over 6 months, certain amount of breakdown (coalescence among water droplets) must have occurred. The drop sizes of the dispersed phase in a macroemulsion are larger than the wavelengths of visible light, so macroemulsions are usually not transparent, and the suspended droplets are large enough to be seen by a microscope. 


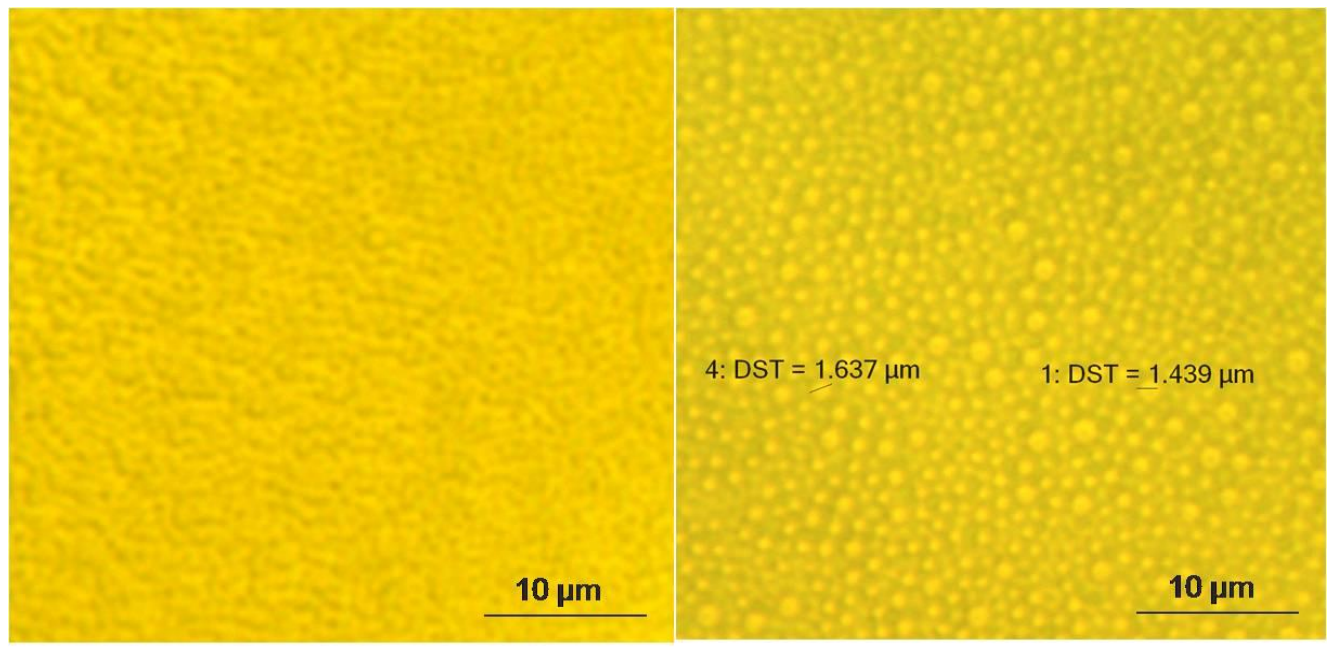

Fig. 3.5- Microscopic images of a W/O emulsion (60 vol\% water), taken right after made (left) and 6 months later (right).

Microscopic images of a $60 \%$ water content emulsion are shown in Figure 3.5. The left picture was taken right after the emulsion was made, while the right picture was taken after the emulsion remained stationary for 6 months. Very limited amount of coalescence among water droplets occurred within the 6 months duration. When the emulsion was first made, the water droplets were mostly around $1 \sim 1.5$ micrometers in diameter. After 6 months, larger droplets of 2 micrometers in diameter were formed. Similar results were obtained for the emulsions of different water contents. The small average size and narrow distribution of water droplets, and the long breakdown time scale both indicated that the $\mathrm{W} / \mathrm{O}$ emulsions made with the used engine oil were very stable. 


\subsubsection{Density Measurements}

The densities of the emulsions were measured and plotted against the volume percentage of water, shown in Figure 3.6. Taking into account the density of used engine oil $(0 \%$ water $)$ and brine $(100 \%$ water $)$, all the data points follow a straight line relationship very well. Basically the density of an emulsion can be easily calculated from the oil and brine density, given the volume percentage of each phase. An equation of "emulsion densit $=0001$ Water ercentage +0828 " was o taine d, with the fluids used in this measurement. In this case, the density of used engine oil and brine was measured to be $0.864 \mathrm{~g} / \mathrm{ml}$ and $1.020 \mathrm{~g} / \mathrm{ml}$, respectively.

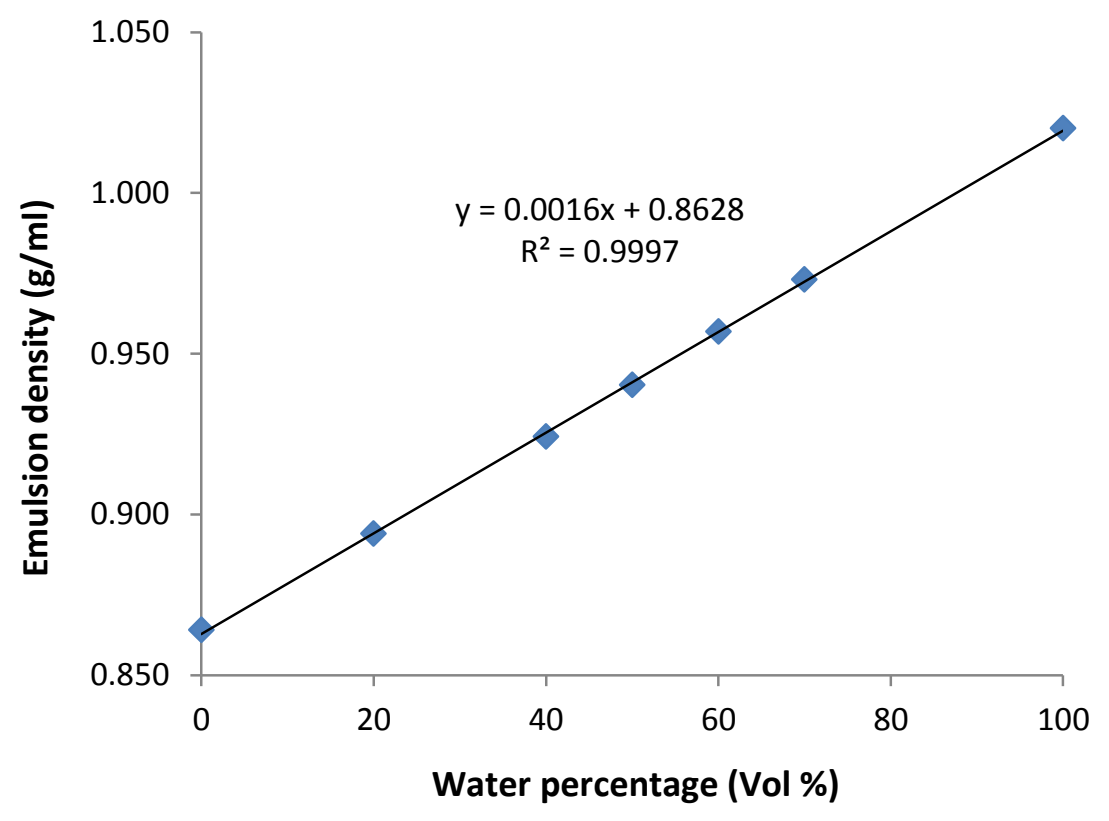

Fig. 3.6- Densities of the emulsions. 


\subsubsection{Interfacial Tension Measurements}

To understand the stability of the emulsions, the IFT was measured between the used engine oil and the brine, shown in Figure 3.7.

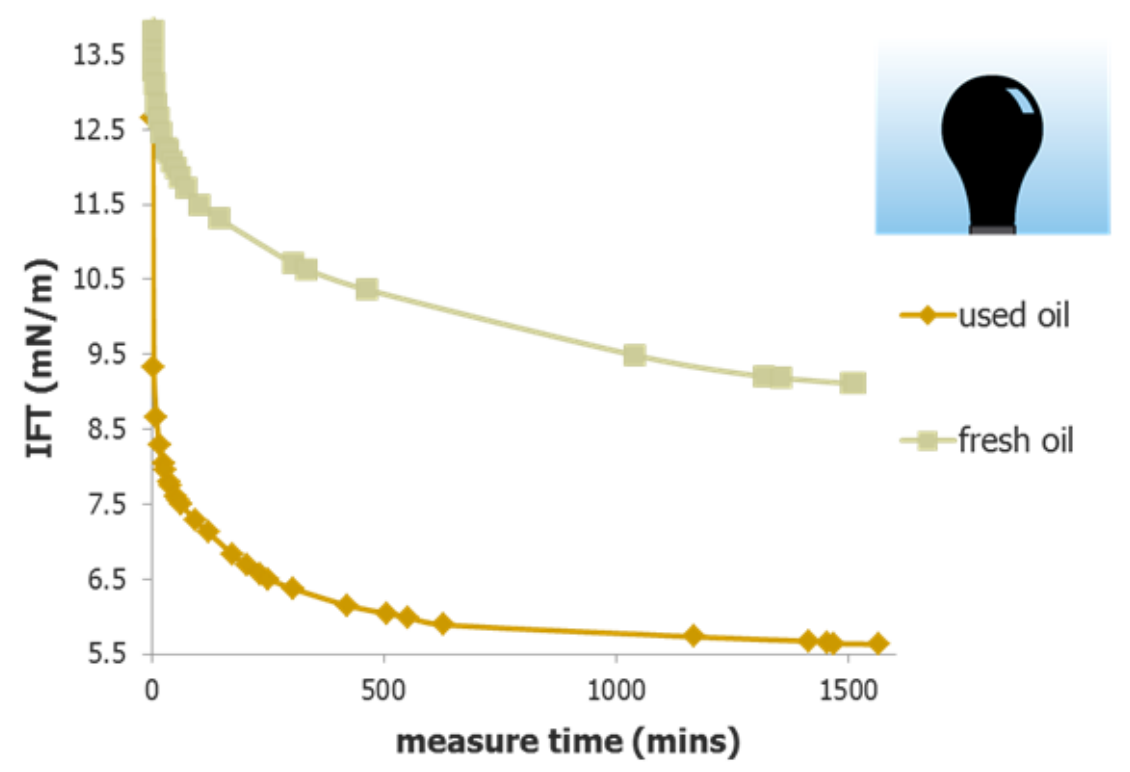

Fig. 3.7- Interfacial tensions between used engine oil/fresh engine oil and brine.

Measured by the pendant drop method, the IFT decreased with time. During the measurement, after an oil drop was created, the surface active agents in the oil would migrate toward the interface and gradually accumulated at the interface to lower the IFT. An hour after the pendent drop was created (starting point of the measurement), the IFT was about $7.5 \mathrm{mN} / \mathrm{m}$. This value kept on decreasing until it reached about $5.5 \mathrm{mN} / \mathrm{m}$. 
For comparison, the IFT between a fresh engine oil (the same Pennzoil 5W-30) and the brine was also tested and plotted on Figure 3.7. Similar trend of IFT drop with time was also observed. The IFT value was measured to be $11.8 \mathrm{mN} / \mathrm{m}$ at one hour after the pendant drop was created and this value decreased to about $9 \mathrm{mN} / \mathrm{m}$ after a day. Apparently the IFT between the used engine oil and the brine was much lower than that between the fresh engine oil and the brine.

\subsubsection{Soot Particle Size Characterization}

Lowered IFT was not the only reason for the stability of the emulsions. Rigid or solid interfacial films could also be important in stabilizing macroemulsions. A term interfacial viscosity is associated with this phenomenon (Kokal, 2005). When high molecular weight polar molecules or fine solid particles are adsorbed at the interface, they could behave like an insoluble skin on the water droplets, and prevent the water droplets from coalescing into each other during collision.

Soot particles are abundant in any used engine oil. Soot is composed of heterocyclic compounds that are produced from partial burning of hydrocarbons. They are mostly oleophilic but can be partially hydrophilic because of the oxidation. The size of the soot particles was measured to be around $200 \mathrm{~nm}$, shown in Figure 3.8. These particles are perfect oleophilic nanoparticles to promote relatively stable $\mathrm{W} / \mathrm{O}$ emulsions. Because of the functioning mechanism of the particle size analyzer, the sizes tend to be overestimated due to less scattering of light from smaller sized particles. 


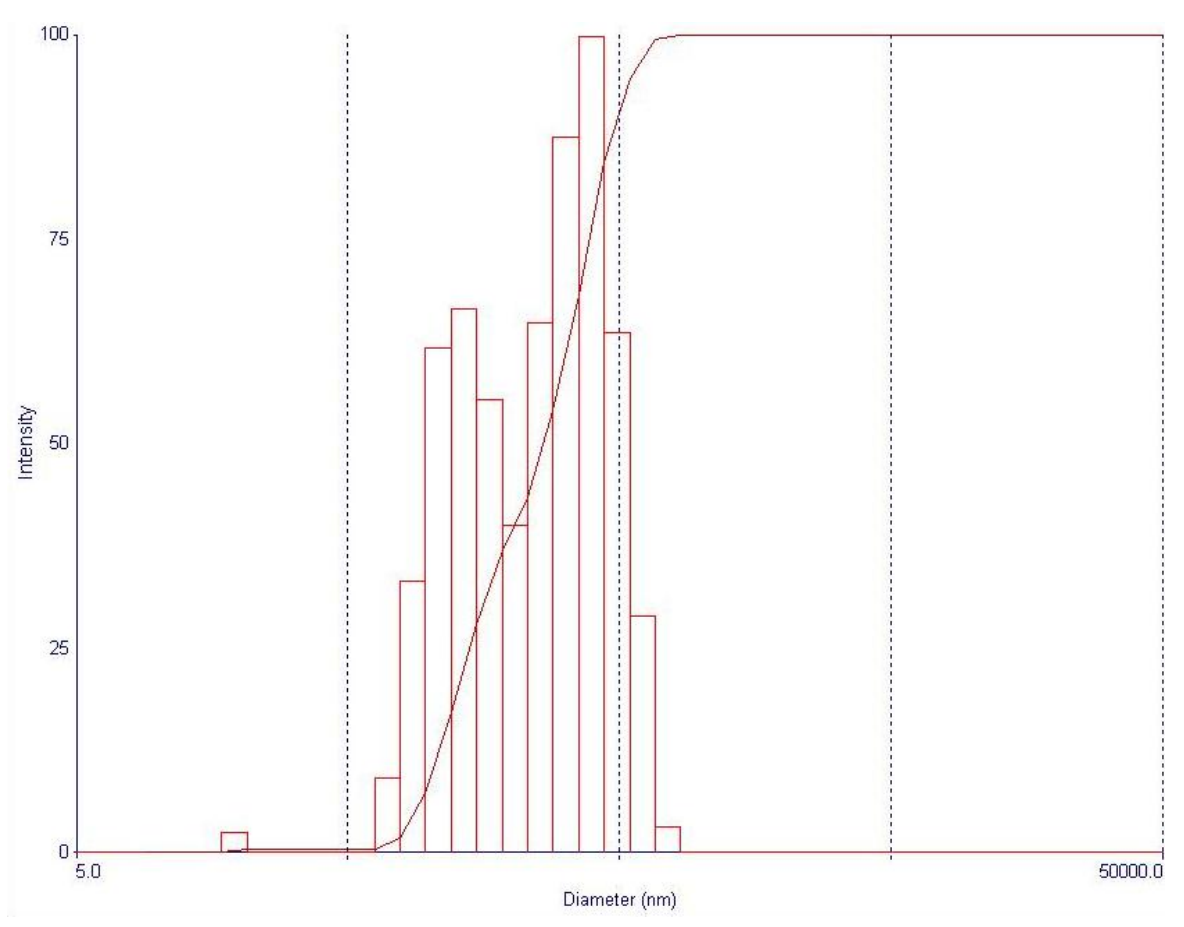

Fig. 3.8 - Particle Size distribution of the soot particles within used engine oil.

To better understand the cause of good stability of this emulsion system, we also generated emulsions with fresh engine oil emulsions and made comparison with used engine oil emulsions. Results indicated that fresh engine oil also formed relatively stable W/O emulsions with brine, but the stability was found lower than the used engine oil case, from much larger droplet sizes in microscopic images. Given the same amount of shear, smaller droplet sizes normally imply better stability. Fresh engine oil contains detergents, which are surface active, and then by functioning in the engine more surface active agents are created (oxidized components and soot particles), so the used engine oil became even more favorable toward forming emulsions with water. 
The Total Acid Number (TAN) of the 5W-30 used engine oil was also measured, which was found to be $0.4 \mathrm{mg} \mathrm{KOH} / \mathrm{g}$ oil. The acidity of oil may also be beneficial to the formation of Water-in-Oil emulsions.

\subsubsection{Salinity Effect on Emulsion Stability}

To study the effect of brine salinity and hardness on the stability of emulsion, three different solutions were used to generate emulsions, following the same procedures as described in 2.1 .2 , and with the same water content ( $60 \%$ by volume). The three solutions are:

A. 30,000 ppm brine made with $\mathrm{NaCl}(20,000 \mathrm{ppm})$ and $\mathrm{KCl}(10,000 \mathrm{ppm})$;

B. 33,000 ppm brine made with $\mathrm{NaCl}(20,000 \mathrm{ppm}), \mathrm{KCl}(10,000 \mathrm{ppm})$ and $\mathrm{CaCl}_{2}$ $(3,000 \mathrm{ppm}) ;$

C. Fresh water.

The microscopic images of the three emulsions are shown in Figure 3.9. Emulsions made with A and B had similar water droplet sizes, which were much smaller than the droplet size in emulsion made with C. This indicates that the brine solutions produced higher-quality emulsions than fresh water - certain amount of salinity is beneficial for generating stable emulsions. Also, the 3,000 ppm $\mathrm{CaCl}_{2}$ had negligible effect on the droplet size, indicating the emulsion system is not sensitive to the hardness of brine solutions. 

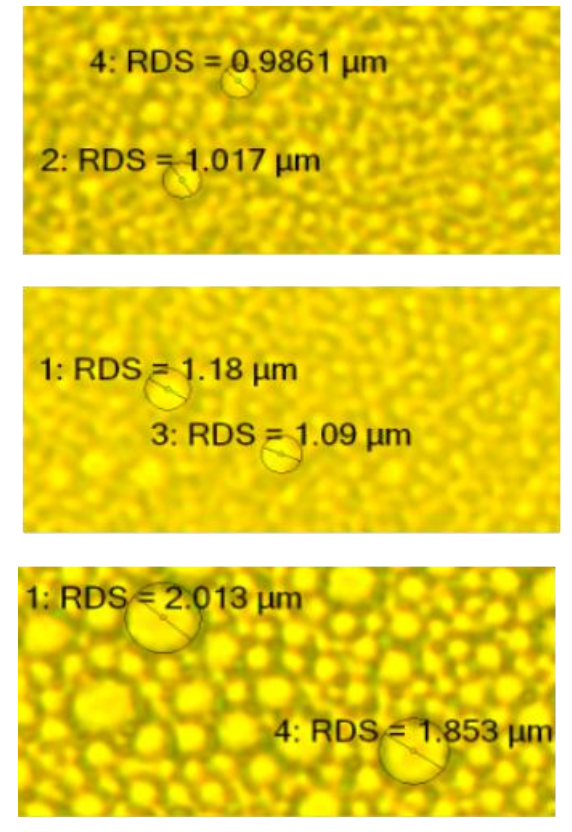

Fig. 3.9- Microscopic images of emulsions generated with brine A, B and C (from top to bottom).

The stability of the emulsions could also be revealed from viscosity measurements. The better the water phase is dispersed in the oil phase, the higher the viscosity the emulsion will be. Figure 3.10 indicates the viscosity of emulsions made with the three different solutions. The lower viscosity of the emulsion made with fresh water lead to the same conclusion that certain amount of salinity is beneficial for emulsion generation. The similar viscosities of the two brine solutions confirmed the similar stabilities of emulsions made with/without calcium ion. The fact that the stability of used engine oil emulsion is not sensitive to brine hardness, on the other hand, 
indicates the benefits of having soot particles as stabilizer, as an emulsion stabilized by surfactants alone is usually very sensitive to the concentration of hard ions.

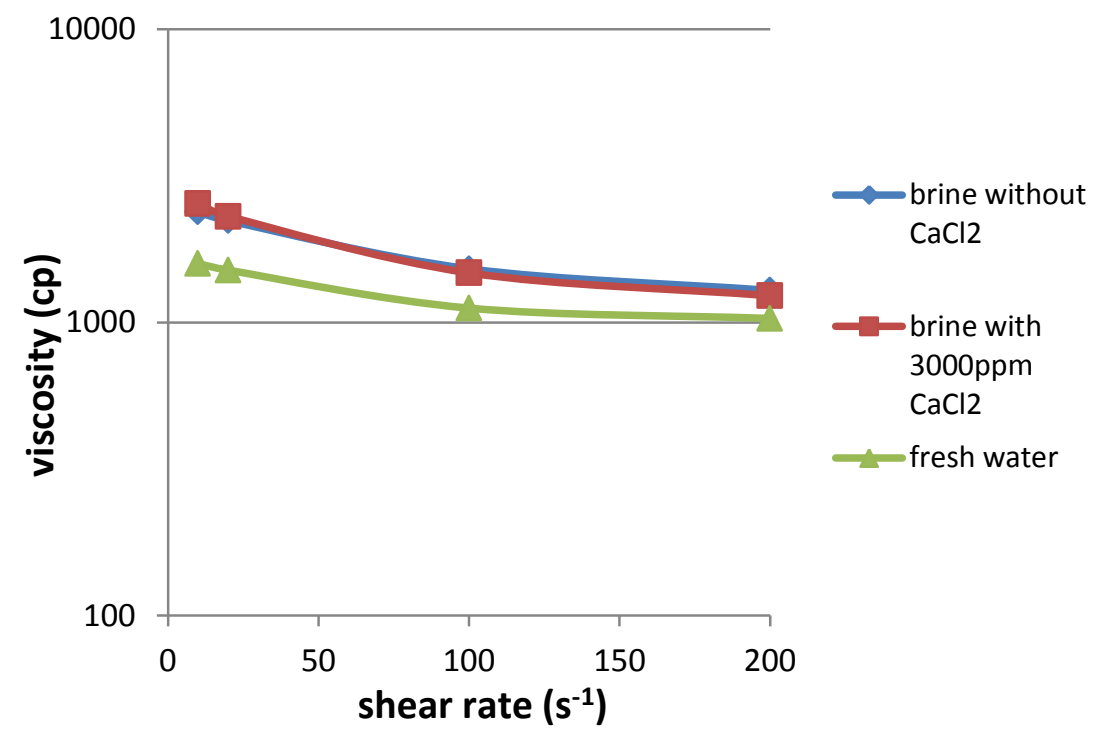

Fig. 3.10- Viscosities of emulsions generated with brine A, B and C.

\subsubsection{Time Effect on Emulsion Viscosity}

As the water droplets coalesce and their sizes increase, the viscosity of emulsion will get lower. Figure 3.11 shows the viscosities measured for the same emulsions as those in the previous part 3.2.6, only after six months on shelf. 


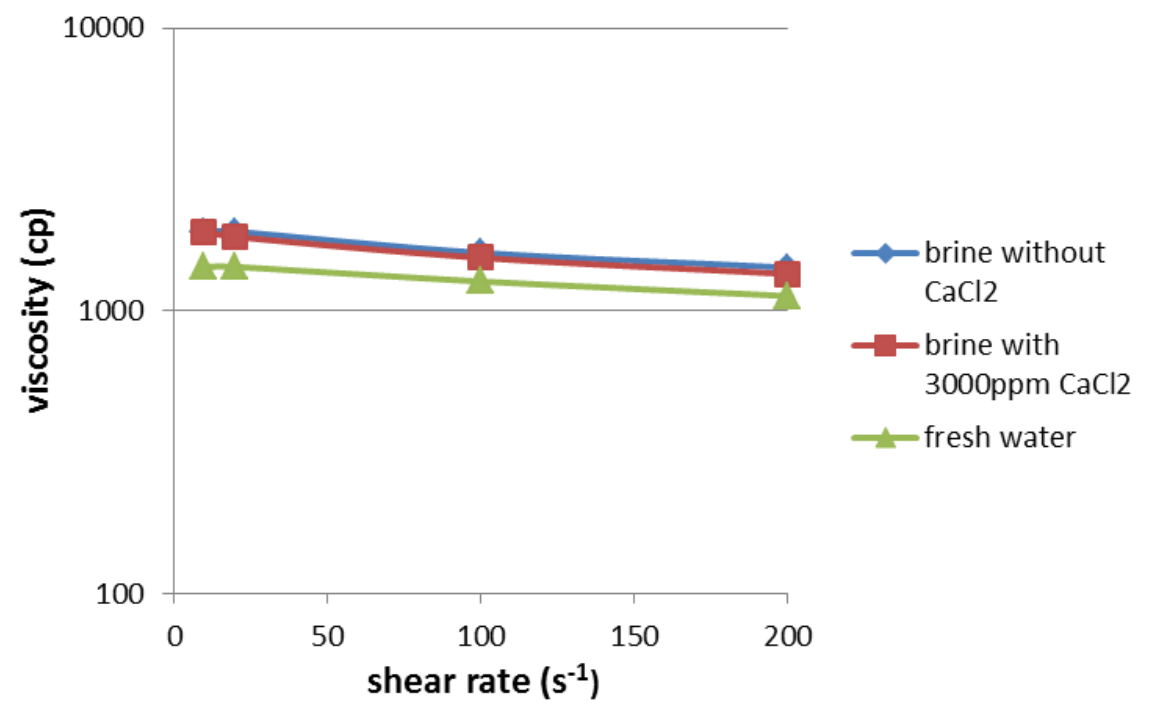

Fig. 3.11 - Viscosities of emulsions generated with brine A, B and C, after 6 months.

Among these three emulsion samples, the one made with fresh water still had the lowest viscosity, and the emulsions made with the two brines remained very similar. Compared to the viscosities in Figure 3.10, the viscosities measured after six months (Figure 3.11) decreased from $2381 \mathrm{cp}, 2540 \mathrm{cp}$ and $1588 \mathrm{cp}$ to $1905 \mathrm{cp}, 1905 \mathrm{cp}$ and $1429 \mathrm{cp}$, for the emulsions made with brine A, B and C, restpectively, at the shear rate of $10 \mathrm{~s}^{-1}$. Roughly $20 \%$ of the viscosity was lost after six months, as measured at this shear rate. Interestingly, the shear thinning effect seemed to diminish with time - the shape of the curves became flatter. As a matter of fact for the viscosities measured at a high shear rate of $200 \mathrm{~s}^{-1}$, they even increased after six months. The values went from $1286 \mathrm{cp}$, $1234 \mathrm{cp}$ and $1032 \mathrm{cp}$ to $1421 \mathrm{cp}, 1349 \mathrm{cp}$ and $1127 \mathrm{cp}$, respectively for the emulsions made with brine $\mathrm{A}, \mathrm{B}$ and $\mathrm{C}$. What caused this interesting rheological behavior with time 
is not clear, but it may have to do with the size distribution evolution of the water droplets.

\subsection{Corefloods}

After the bench tests proved the stability of used engine oil emulsions, a number of coreflood experiments were conducted, to test the stability of the emulsions while passing through porous media, and to obtain their flow behavior. Early experiments focused on using different cores to see the porosity/permeability effect on emulsion breakdown, later the experiments were conducted with a single type of sandstone core, focusing on the effect of traveling distance on emulsion properties. Finally, two sandpacked slimtubes were used to test the emulsion properties at much longer travelling distances.

\subsubsection{Fluids}

Used Engine Oil III: A mixture of used engine oil (different brands) coming directly from a recycling tank (mostly mineral based type because of the oil provided in the oil change center).

Brine: Synthetic brine was prepared by adding sodium chloride and potassium chloride into water. Total dissolved solids are $30,000 \mathrm{mg} / \mathrm{kg}$ brine, with $20,000 \mathrm{ppm}$ sodium chloride and 10,000 ppm potassium chloride included.

Emulsion: Emulsions in coreflood tests were generated with used engine oil III and brine with similar procedures described in 2.1.2. As the emulsions were made in 
larger batches, relatively longer time (about 10 minutes) of shear was applied to ensure the quality of mixing. The volume fraction of brine was set to be $60 \%$. This particular value was somewhat arbitrarily chosen, but the idea is to generate emulsions of moderately high viscosity and to keep a relatively large fraction of brine.

\subsubsection{Early Corefloods}

In the early experiments, three types of sandstone cores were used to test the emulsion properties. These cores are Idaho sandstone, Boise sandstone and Bentheimer sandstone, shown in Figure 3.12.

All the cores used were of the same diameter -1 inch, to match the core holder we had. Two different lengths of cores were tested: 6 inches and 12 inches. As the length of the core holder was 1 foot, aluminum spacers were utilized to fulfill the whole length when 6-inch cores were tested.

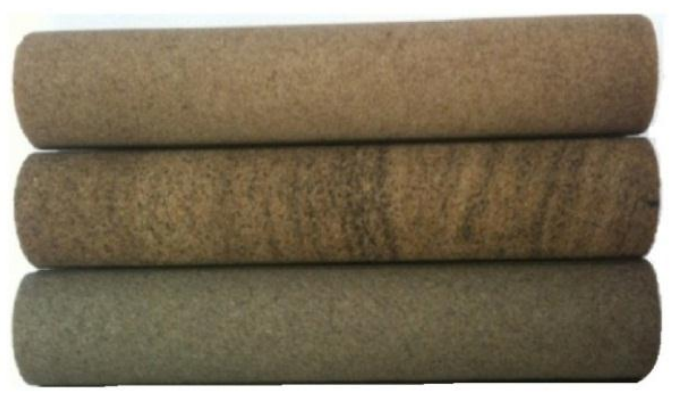

Fig 3 12- entheimer sandstone, daho sandstone and oise sandstone from to to ott om of si e 1 
Early corefloods followed the same procedures as introduced in 2.3.2. The injection rates were set to be $1 \mathrm{ft} / \mathrm{d}, 3 \mathrm{ft} / \mathrm{d}, 10 \mathrm{ft} / \mathrm{d}$ and $100 \mathrm{ft} / \mathrm{d}$, to observe the emulsion flow behavior within a wide range of flow rates. The results and analyses for these early corefloods are listed by core types in the subsections below.

\subsubsection{Idaho sandstone}

The dry and brine-saturated weight was measured to be $137.98 \mathrm{~g}$ and $156.12 \mathrm{~g}$, respectively. Knowing the density of brine and the bulk volume of the core, the porosity of the rock could be obtained:

$\phi=\frac{\operatorname{Vol}(\text { pore })}{\operatorname{Vol}(\text { bulk })}=\frac{\left(m_{b}-m_{d}\right) / \rho_{b}}{\pi r^{2} l}=\frac{(156.12 \mathrm{~g}-137.98 \mathrm{~g}) /\left(1.02 \mathrm{~g} / \mathrm{cm}^{3}\right)}{3.1416 \times(1.27 \mathrm{~cm})^{2} \times 15.24 \mathrm{~cm}}=\frac{17.78 \mathrm{~cm}^{3}}{77.2 \mathrm{~cm}^{3}}=0.230$

After the core was put into the core holder and the brine was injected through, the pressure drop would stabilize at any fixed rate of injection. At the injection rate of 5 $\mathrm{ml} / \mathrm{min}$, the pressure drop stabilized around $9.8 \mathrm{psi}$. Therefore the water permeability of the rock could be estimated:

$$
\begin{aligned}
& k=\frac{q \mu l}{A \Delta p} \\
& =\frac{\left(5 \mathrm{ml} / \mathrm{min} \times 10^{-6} \mathrm{~m}^{3} / \mathrm{ml} \times 1 / 60 \mathrm{~min} / \mathrm{s}\right) \times\left(1 \times 10^{-3} \mathrm{~Pa} \cdot \mathrm{s}\right) \times\left(15.24 \times 10^{-2} \mathrm{~m}\right)}{3.1416 \times\left(1.27 \times 10^{-2}\right)^{2} \times(9.8 \mathrm{psi} \times 6894 \mathrm{~Pa} / \mathrm{psi})} \\
& =3.7 \times 10^{-13} \mathrm{~m}^{2}=370 \mathrm{md}
\end{aligned}
$$

Before the injection of our emulsion, the injection rates had to be calculated for the pump. As the proceeding rates along the core were set to $1,3,10$ and $100 \mathrm{ft} / \mathrm{d}$, the pump rates could be calculated correspondingly (ignoring irreducible water saturation): 
$1 \mathrm{ft} / \mathrm{d}=\frac{\left(3.1416 \times 1.27^{2}\right) \mathrm{cm}^{2} \times 30.48 \mathrm{~cm} \times 0.23}{24 \times 60 \mathrm{~min}}=0.025 \mathrm{~cm}^{3} / \mathrm{min}$

$3 \mathrm{ft} / \mathrm{d}=0.074 \mathrm{~cm}^{3} / \mathrm{min}$

$10 \mathrm{ft} / \mathrm{d}=0.247 \mathrm{~cm}^{3} / \mathrm{min}$

$100 \mathrm{ft} / \mathrm{d}=2.467 \mathrm{~cm}^{3} / \mathrm{min}$

The injection rates followed a step-wise increase. The emulsion was first injected at the lowest rate $1 \mathrm{ft} / \mathrm{d}$, until the movable brine originally in the core was completely displaced by emulsion, which could be judged from fixed percentage of water in the effluent, and stable pressure drop along the core. Afterwards the second lowest rate 3 $\mathrm{ft} / \mathrm{d}$ was set for the pump until the new pressure stabilized and another effluent sample was collected. Then the pump rate was set to be $10 \mathrm{ft} / \mathrm{d}$, and finally $100 \mathrm{ft} / \mathrm{d}$, following the same logic. Effluents were collected carefully at each injection rate after the emulsion flow stabilized at that rate, and tall glass vials were used to keep them. The vials that contained the effluents from each rate were shown in Figure 3.13.

The emulsion broke down to some extent while passing through the core. This phenomenon was also observed by earlier researchers (Kaminsky et al., 2010). In our research, the percentage of water breakout was simply estimated by the height of water layer divided by the total height of the fluid in the vial. This free water percentage remained stable for months through the observation time, indicating well-maintained stability of the emulsion above free water, and also proved the validity of this simple method of emulsion breakdown characterization. 
The free water content were found to $3 \%, 4 \%, 8 \%$ and $18 \%$, respectively at injection rate of $1 \mathrm{ft} / \mathrm{d}, 3 \mathrm{ft} / \mathrm{d}, 10 \mathrm{ft} / \mathrm{d}$ and $100 \mathrm{ft} / \mathrm{d}$. The higher the flow rate, the higher intensity of shear the emulsion experienced, and the more free water broke out of the emulsion.

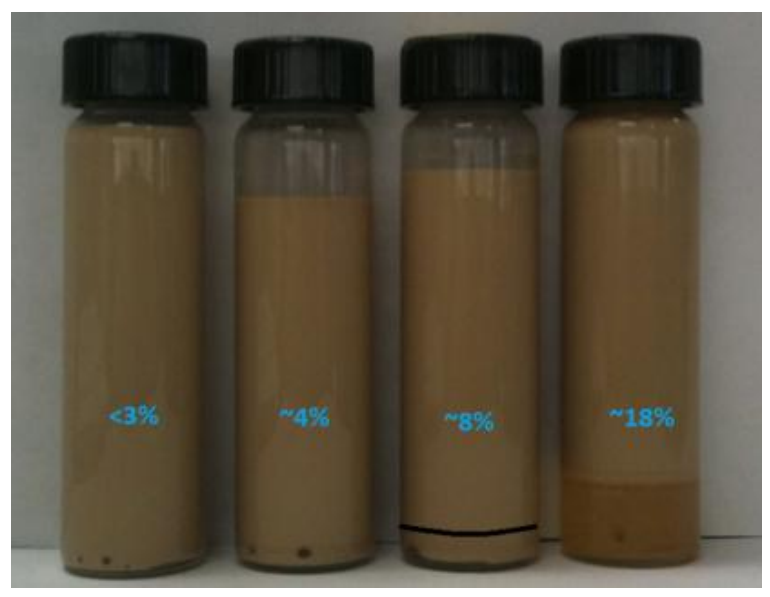

Fig. 3.13 - Emulsion effluents collected at injection rate $1 \mathrm{ft} / \mathrm{d}, 3 \mathrm{ft} / \mathrm{d}, 10 \mathrm{ft} / \mathrm{d}$ and $100 \mathrm{ft} / \mathrm{d}$ (from left to right).

The pressure profile during the injection was also obtained, shown in Figure 3.14. The pressure drop along the core leveled off at any fixed rate of injection. Steadystate flow was achieved at this stage and the emulsion breakdown also became constant. No plug-off effect from soot particles was observed as the pressure drop remained unchanging as more emulsion flooded through the core at any particular rate. 


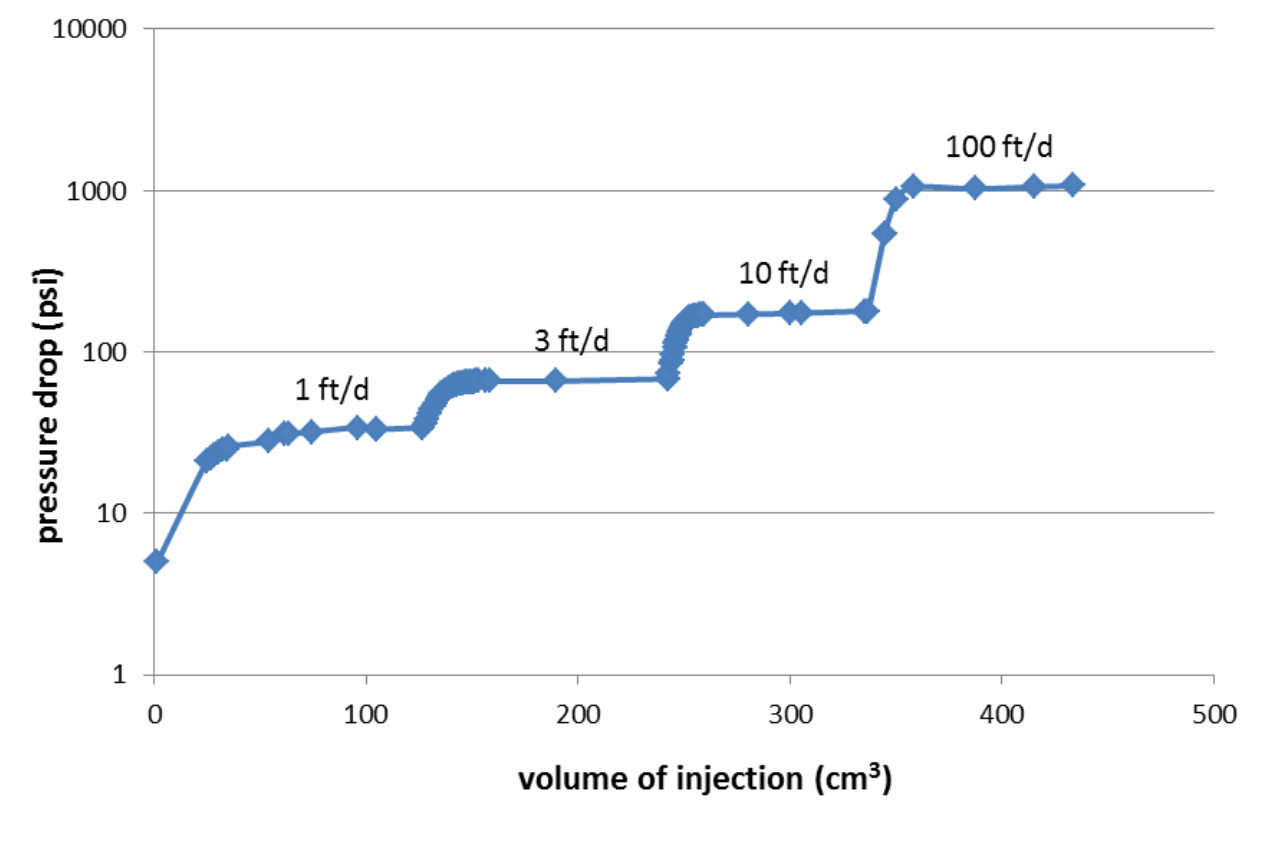

Fig 31 - ressure rofile for emulsion in ection daho sandstone

By taking a value of the pressure drop at any flat part, and the corresponding flow rate at this oint, the effecti e iscosit can e estimated a rc 's law, assuming single phase flow. For example, the pressure drop was found to stabilize around $34 \mathrm{psi}$ at injection rate of $1 \mathrm{ft} / \mathrm{d}$, so the effective viscosity was calculated as follows:

$$
\begin{aligned}
& \mu_{e f f}=\frac{k A \Delta P}{q l} \\
& =\frac{3.7 \times 10^{-13} \mathrm{~m}^{2} \times 3.1416 \times 0.0127^{2} \mathrm{~m}^{2} \times 34 \mathrm{psi} \times 6895 \mathrm{~Pa} / \mathrm{psi}}{\left(0.025 \times 10^{-6} \mathrm{~m}^{3} / \mathrm{min}\right) /(60 \mathrm{~s} / \mathrm{min}) \times 15.24 \times 10^{-2} \mathrm{~m}} \\
& =0.692 \mathrm{~Pa} \cdot \mathrm{s}=692 \mathrm{cp}
\end{aligned}
$$


It has to be noted that single phase flow assumption is not good for conditions of higher flow rates, under which a larger amount of water breaks down from the emulsion system. Also in the equation above, the permeability used for viscosity calculation should be the relative permeability of emulsion, which is difficult to obtain from experiments. As a result the absolute permeability measured with brine was used instead, to roughly estimate the effective viscosity of the emulsion. Therefore the absolute value of $\mu_{\text {eff }}$ is not accurate and comparison of this value among different cores may not be very meaningful.

The effective viscosity of the emulsion was estimated to be $701 \mathrm{cp}, 453 \mathrm{cp}, 356$ cp and $217 \mathrm{cp}$, at corresponding injection rate of $11 \mathrm{ft} / \mathrm{d}, 3 \mathrm{ft} / \mathrm{d}, 10 \mathrm{ft} / \mathrm{d}$ and $100 \mathrm{ft} / \mathrm{d}$, respectively, shown in Figure 3.15.

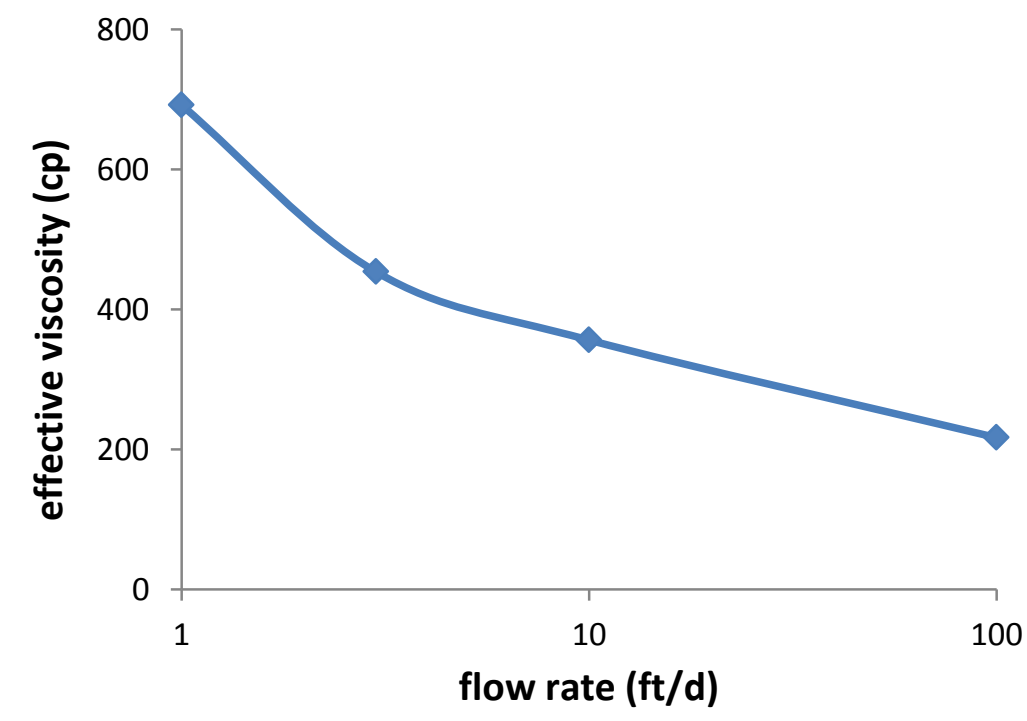

Fig 315 - $\mathrm{f}$ fecti e is cosit of the emulsion daho sandstone 
The effective viscosity of the emulsion decreased at increasing injection rate. To understand the flow behavior of this emulsion, the origin of shear thinning in corefloods need to be clarified. This seemingly reasonable trend has its complex origins: at least three factors could have caused this trend. First of all, the higher injection rate the more free water breaks out from the emulsion and thus the water fraction in the emulsion gets lower, and the emulsion viscosity gets lower. Secondly, as more free water coexists with the emulsion while passing through the core, a bigger effect of two-phase flow will take place, the influence of which will be discussed in more details later. Finally, the emulsion itself is shear thinning, so the higher the flow rate, the higher shear it experiences in the core, and the less viscosity will appear.

\subsubsection{Boise sandstone}

The porosity and permeability of the Boise sandstone core was measured to be 0.206 and $510 \mathrm{md}$, respectively. After the injection rates were translated into pump rates and the emulsion flow experiments were conducted, the effluents were analyzed. The free water contents of the effluents were found to be $7 \%, 15 \%, 16 \%$ and $32 \%$ at injection rate of $1 \mathrm{ft} / \mathrm{d}, 3 \mathrm{ft} / \mathrm{d}, 10 \mathrm{ft} / \mathrm{d}$ and $100 \mathrm{ft} / \mathrm{d}$, respectively.

The pressure profile was also obtained, shown in Figure 3.16. Similar to the Idaho sandstone case, step-wise increases of pressure drops were obtained at increasing rates of injection. Stabilized pressure drops were realized at each fixed rate of injection. Smaller values of pressure drops were achieved at any identical rate of injection compared to the Idaho sandstone case, due to the higher permeability of the Boise 
sandstone and higher amount of water breakouts. From the stabilized pressure drop values at each rate, the effective viscosity of the emulsion was also calculated, shown in Figure 3.17.

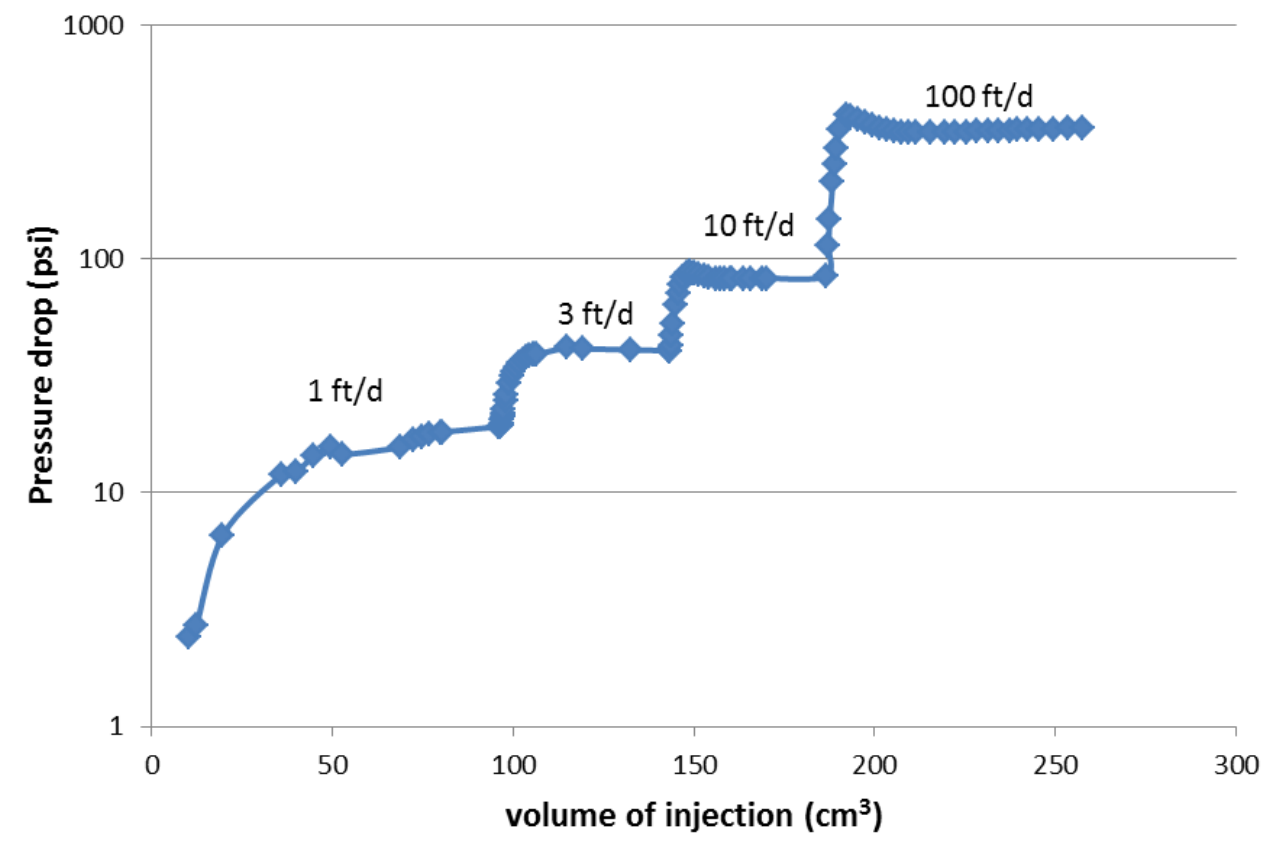

Fig.3 1 - ressure rofile for emulsion in ection oise sandstone 


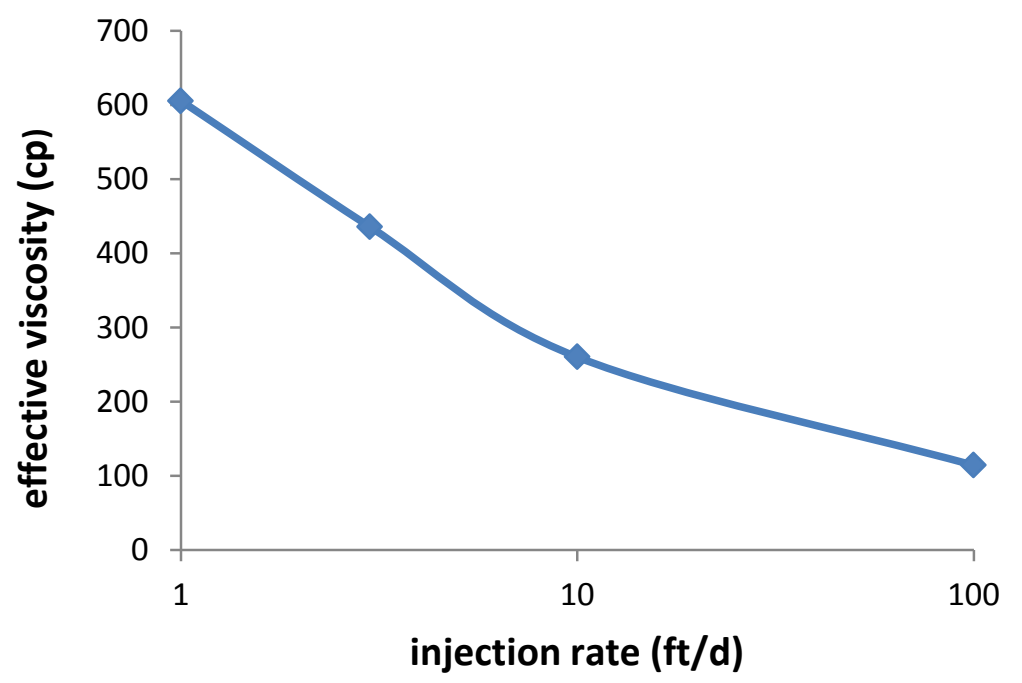

Fig 31 - f fecti e is cosit of the emulsion oise sandstone

\subsubsection{Bentheimer sandstone}

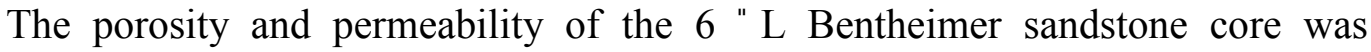
characterized to be 0.172 and $1650 \mathrm{md}$, respectively. After the injection rates were translated into pump rates and the emulsion flow experiments were conducted, the effluents were analyzed. The free water content of the effluents were found to be $2 \%$, $3 \%, 3 \%$ and $13 \%$ at injection rate of $1 \mathrm{ft} / \mathrm{d}, 3 \mathrm{ft} / \mathrm{d}, 10 \mathrm{ft} / \mathrm{d}$ and $100 \mathrm{ft} / \mathrm{d}$, respectively. The pressure profile was also obtained, shown in Figure 3.18. From the stabilized pressure drop values at each rate, the effective viscosity of the emulsion was also calculated, shown in Figure 3.19. 


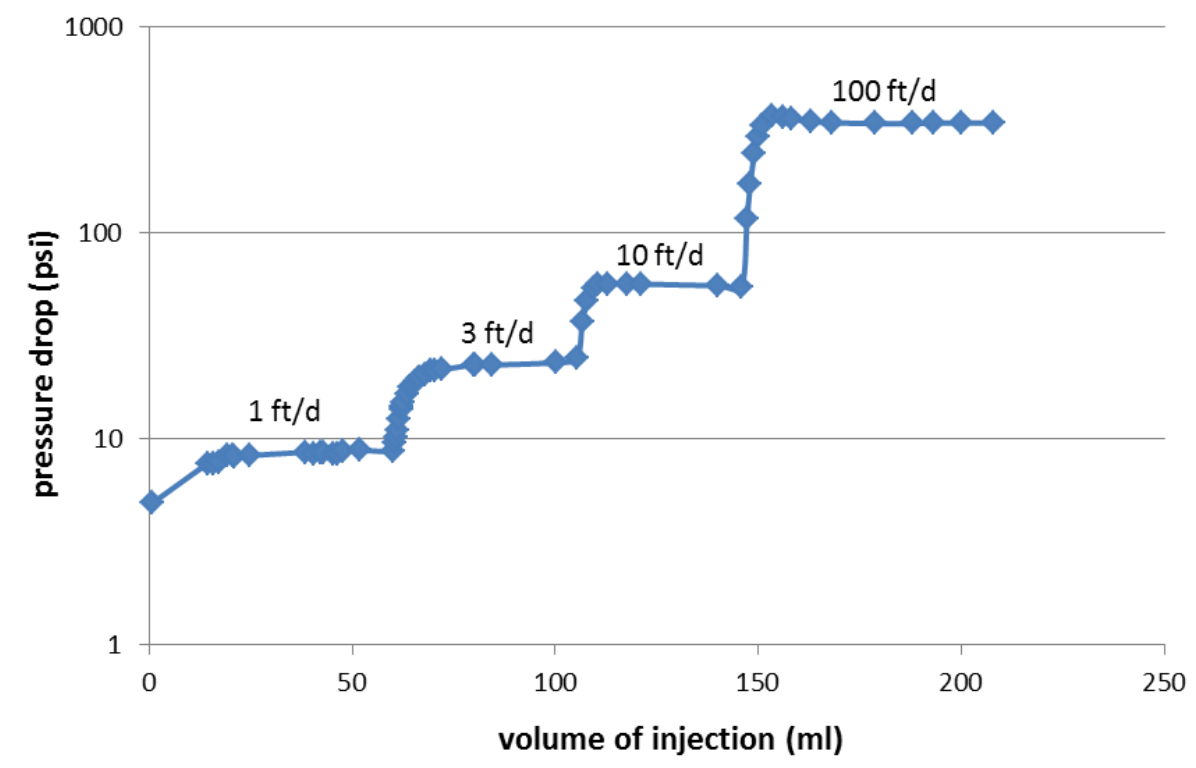

Fig 318 - r essure rof ile for emulsion in ection entheimer sandstone

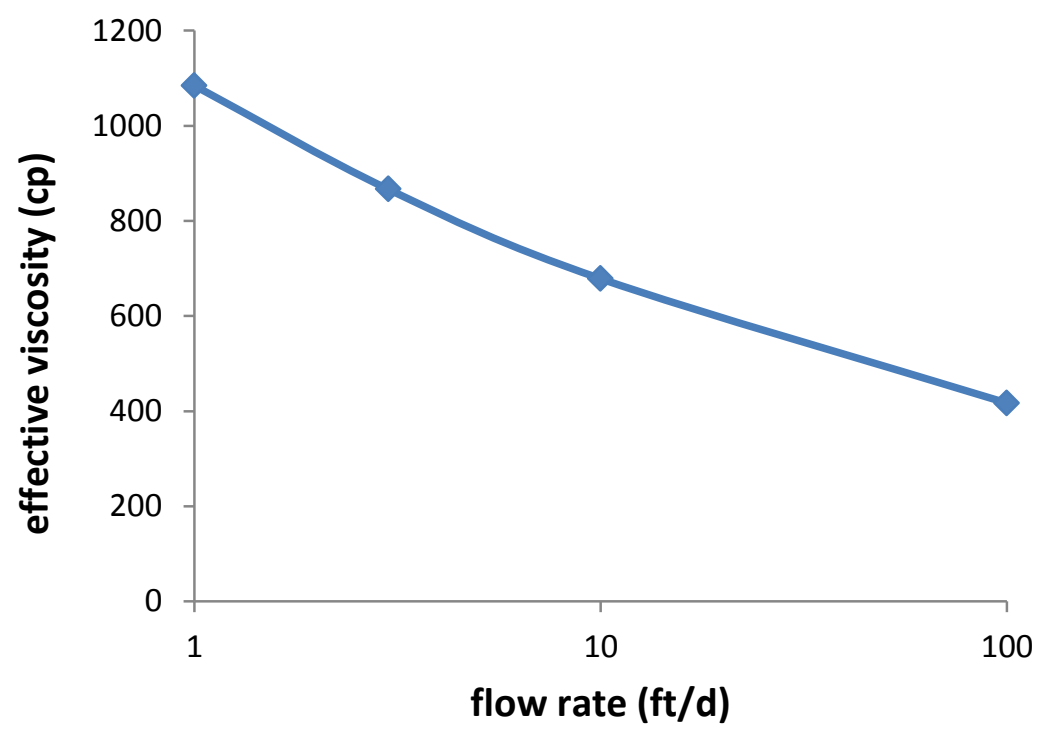

Fig. 3.19- Effective viscosity of the emulsion entheimer sandstone 
In this case, the viscosities of the emulsion effluents were also measured by viscometer. As the emulsion was separated into two layers after passing through the core, and the volume ratio between these two fluids remained unchanged for months, the sample was simply taken from the top layer. The viscometer-measured viscosities of the emulsion effluents are shown in Figure 3.20. The original emulsion before injection was also measured by viscometer at the same time and shown in this figure. Because the effluents at $1 \mathrm{ft} / \mathrm{d}, 3 \mathrm{ft} / \mathrm{d}$ and $10 \mathrm{ft} / \mathrm{d}$ had similar amount of water breakdown, their viscosity profiles were very similar. Compared to the original emulsion, these three effluents lost about $35 \%$ of the original viscosity. The effluent at $100 \mathrm{ft} / \mathrm{d}$ had the lowest viscosity, due to higher water breakdown from the emulsion. About $60 \%$ of the original viscosity was lost compared to the original emulsion, measured at shear rate $10 \mathrm{~s}^{-1}$.

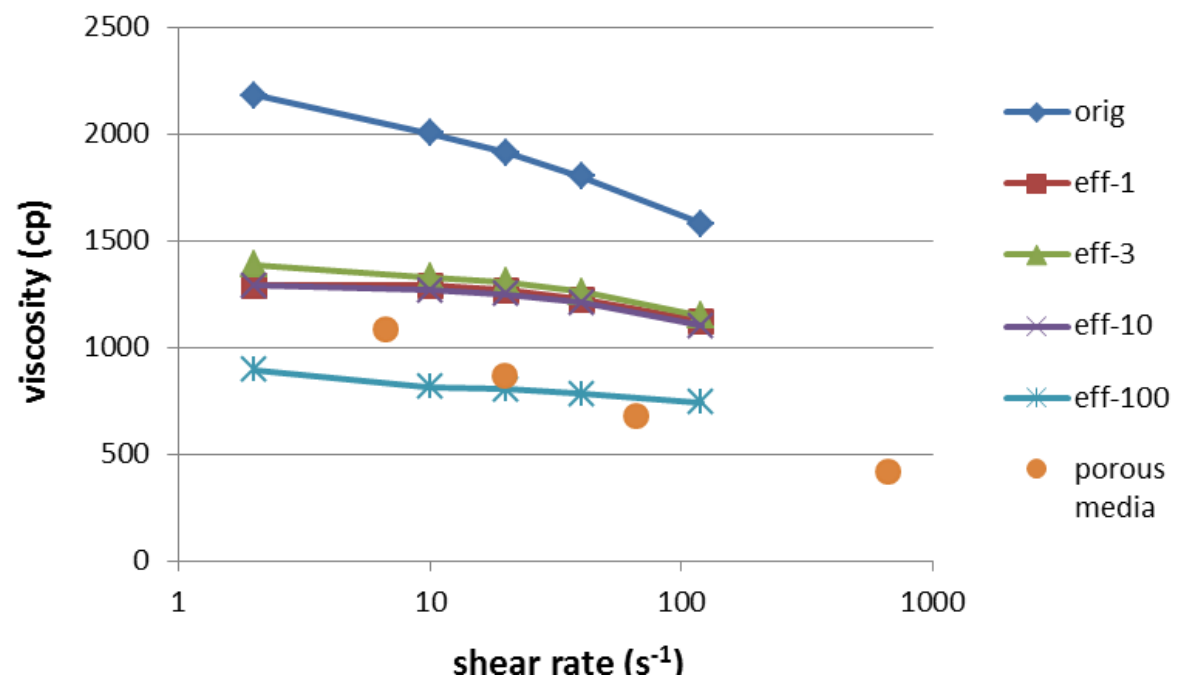

Fig. 3.20- Viscometer-measured viscosit of the emulsion effluents entheimer sandstone I. 
In Figure 3.20, the effective viscosities of the emulsion calculated from coreflood experiments were also included, shown as orange dots. Their corresponding shear rates were calculated using correlating parameter $u /(\phi k)^{0.5}$ (Seright et al., 2010). Compared to the effluent viscosities measured by viscometer, the effective viscosity results obtained from coreflood experiments were roughly in the same range. The emulsion demonstrated higher extent of shear-thinning during passing through the core than during viscometer tests, likely due to the water breakout in the corefloods, which further reduced the apparent viscosity of the emulsion. During measurements by viscometer, the emulsion retained its integrity and did not breakdown like in corefloods.

To demonstrate the effect of co-existing water with emulsion on pressure drop while flowing through porous media, a two-phase Darcy flow calculation was conducted compared to single oil phase Darcy flow:

For single phase oil, $q_{o}=\frac{\Delta p A k_{o}}{L \mu_{o}}$

Therefore, $\Delta p=\frac{q L}{A\left(\frac{k_{o}}{\mu_{o}}\right)}$

For two phase flow of both oil and water,

$$
\begin{aligned}
& q_{o}=\frac{\Delta p A k_{o}}{L \mu_{o}} \\
& q_{w}=\frac{\Delta p A k_{w}}{L \mu_{w}} \\
& q=q_{o}+q_{w}
\end{aligned}
$$




$$
\text { Therefore, } \Delta p=\frac{q L}{A\left(\frac{k_{o}}{\mu_{o}}+\frac{k_{w}}{\mu_{w}}\right)}
$$

With the same flow rate and the same core dimensions, the pressure drops differ between single phase flow and two phase flow by the mobility factors in equation 1 and 2. It has to be noted that $\frac{k_{o}}{\mu_{o}}$ in these two equations are not the same, as relative permeability of oil changes with water saturation, and the two equations are associated with conditions with or without free water. Given a typical relative permeability diagram (which is the same as used in our simulations) as shown in Figure 3.21, the mobility factor of $\left(\frac{k_{o}}{\mu_{o}}+\frac{k_{w}}{\mu_{w}}\right)$ in two phase flow can be calculated for any given oil viscosity.

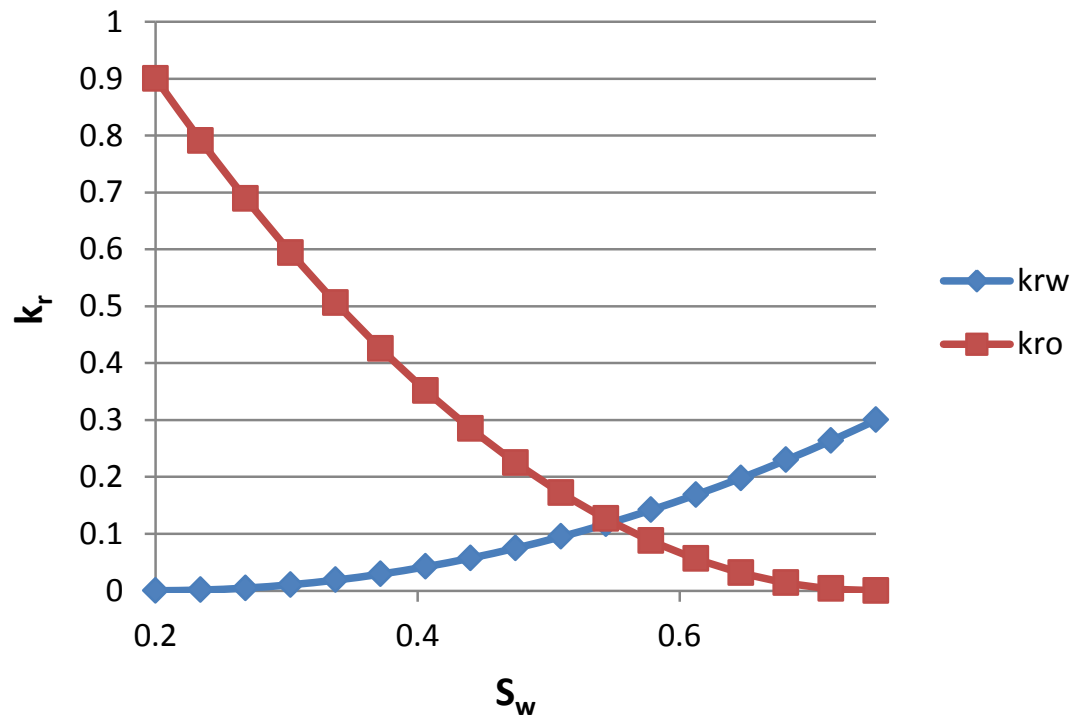

Fig. 3.21 - Typical relative permeability curves. 


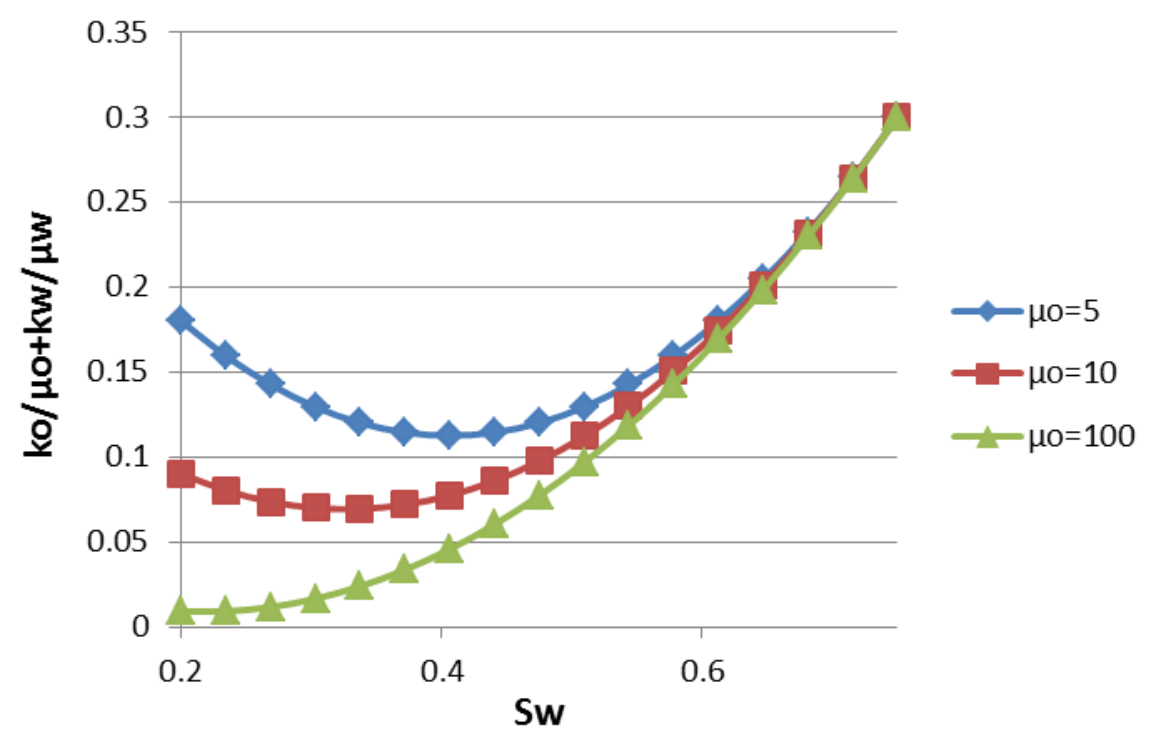

Fig. 3.22 - Mobility factor curves in two phase flow.

The values for $\left(\frac{k_{o}}{\mu_{o}}+\frac{k_{w}}{\mu_{w}}\right)$ were calculated at different water saturations for three different oil viscosities: $5 \mathrm{cp}, 10 \mathrm{cp}$ and $100 \mathrm{cp}$. The water viscosity was assumed to be 1 cp. For simplicity, unit absolute permeability was assumed so that $k_{o}=k_{r o}$ and $k_{w}=k_{r w}$. The results of $\left(\frac{k_{o}}{\mu_{o}}+\frac{k_{w}}{\mu_{w}}\right)$ for these three oil viscosity conditions are shown in Figure 3.22. At relatively low oil viscosities ( $5 \mathrm{cp}$ and $10 \mathrm{cp}$ ), the mobility factor peaked at single phase flow points (the two end points) and had a minimum value in the middle where two phase flow occurred. On the other hand, for a more viscous oil (100 cp), the mobility factor was the lowest at residual water saturation - any point that had higher 
water saturation resulted in higher mobility. Therefore, for a highly viscous oil-external emulsion in our case, its mobility would most likely increase as co-existing water concentration goes up. That is why water breakout not only reduces the viscosity of emulsion, but also affects the total mobility of the emulsion by two-phase flow.

\subsubsection{Bentheimer sandstone 12}

The porosity and permeability of the 12 "L Bentheimer sandstone core was characterized to be 0.170 and $1000 \mathrm{md}$, respectively. After the injection rates were translated into pump rates and the emulsion flow experiments were conducted, the effluents were analyzed. The free water content of the effluents were found to be $4 \%$, $5 \%, 10 \%$ and $25 \%$ at injection rate of $1 \mathrm{ft} / \mathrm{d}, 3 \mathrm{ft} / \mathrm{d}, 10 \mathrm{ft} / \mathrm{d}$ and $100 \mathrm{ft} / \mathrm{d}$, respectively.

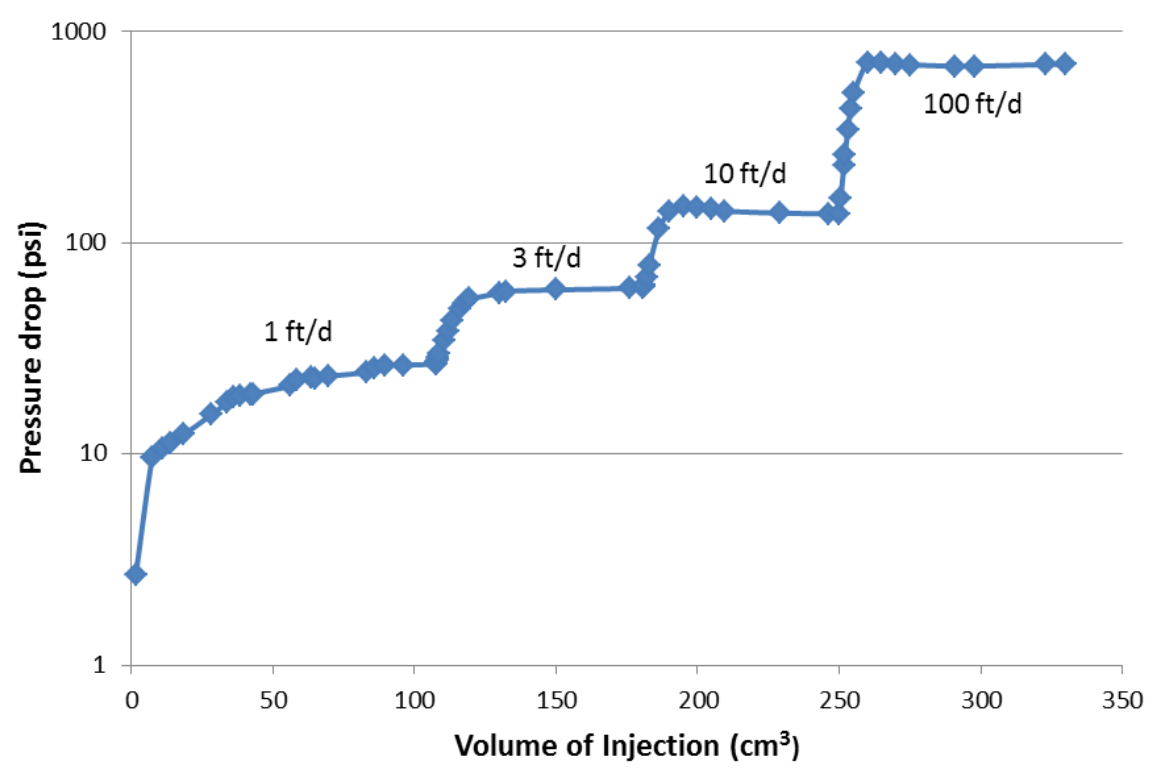

Fig. 3.23 - ressure rofile for emulsion in ection 12 entheimer sandstone 
The pressure profile was also obtained, shown in Figure 3.23. From the stabilized pressure drop values at each rate, the effective viscosity of the emulsion was also calculated, shown in Figure 3.24.

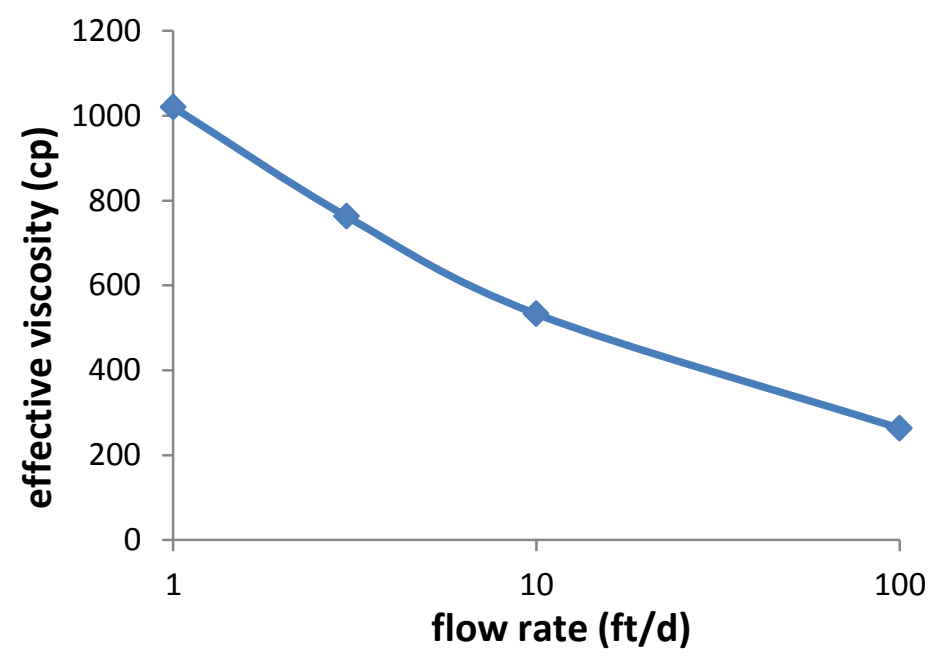

Fig $32-\mathrm{f}$ fecti $\mathrm{e}$ is cosit of the emulsion 12 entheimer sandstone

The viscosities of the emulsion effluents were also measured by viscometer, shown in Figure 3.25. The viscosity profile of the effluents at $1 \mathrm{ft} / \mathrm{d}$ and $3 \mathrm{ft} / \mathrm{d}$ were very similar, because of the similar amount of water breakdown from the emulsion. Compared to the original emulsion, about $40 \%$ of the original viscosity was lost for these two cases. The effluent at $10 \mathrm{ft} / \mathrm{d}$ lost about $50 \%$ of its original viscosity after passing through this core. At the highest injection rate $100 \mathrm{ft} / \mathrm{d}$, the amount of free water broke 
out of the emulsion was as high as $25 \%$, and the emulsion effluent lost over $70 \%$ of its original viscosity.

Compared to viscosities measured by viscometer, the effective viscosities obtained from corefloods (orange dots) again demonstrated higher extent of shear thinning: the effective viscosity at $100 \mathrm{ft} / \mathrm{d}$ was as low as $263 \mathrm{cp}$ in corefloods, while the viscosity of effluent at this rate was measured to be above $500 \mathrm{cp}$. This could also be explained by the effect of two phase flow discussed earlier.

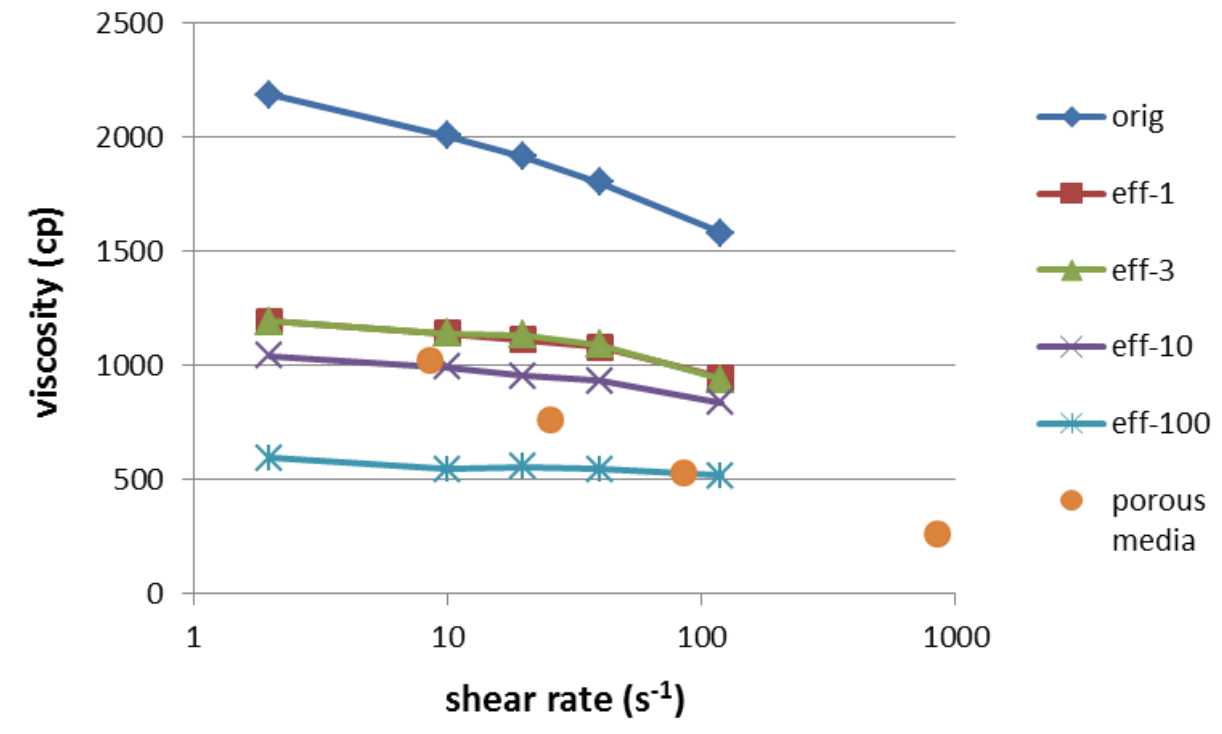

Fig 325- Viscometer-measured iscosit of the emulsion and effluents 12 Bentheimer sandstone I. 
The purpose of using different core lengths to conduct the e e riment was to e tra olate the emulsion ro e rties a ssing through the formation, in which case the tra e ling distance would e much longer Com ar ed to the entheimer sandstone case, the 12 core caused larger e tents of water $\mathrm{r}$ eakdown at all in ection rates oth the effecti e is cosit calculated from the ressure dro and the iscomete r-measured iscosit of the effluents from the 12 core were found to e less than that from the L core. However, the inconsistency in rock properties between the two tests made it hard to conclude anything from the core length point of view. Therefore, cores of similar properties need to be used to reveal the effect of traveling distance on emulsion breakdown.

\subsubsection{Late Corefloods}

Bentheimer sandstone cores cut from the same block of rock were used to conduct our later corefloods, in the aim of finding a relationship between the traveling distance of the emulsion and its breakdown. Kaminsky (Kaminsky et al., 2010) reported that similar amount of free water $r$ oke out of the emulsion for a $r$ ing core lengths e tween 05 and $25 \mathrm{ft}$, for a e r similar emulsion s stem created with crude oil and nano a rticles Therefore, we used and 12 entheimer cores of similar $\mathrm{r}$ o e rties to conduct the emulsion flow experiment to see whether they would yield the same amount of water breakdown.

The procedures of the late corefloods were modified from the early corefloods: the injection rates were set to be $1 \mathrm{ft} / \mathrm{d}, 3 \mathrm{ft} / \mathrm{d}, 10 \mathrm{ft} / \mathrm{d}$ and finally back to $1 \mathrm{ft} / \mathrm{d}$. The 
highest rate was chosen to be $10 \mathrm{ft} / \mathrm{d}$ as the proceeding rate of the emulsion is likely to stay below this rate in a field application. After the step-wise increase of injection rates, the rate was set to be $1 \mathrm{ft} / \mathrm{d}$ in the last step, to further verify whether there is any blockage effect from the emulsion injection by looking at the pressure profile.

The highest fluid velocity happens in the near wellbore region. The further away from the wellbore, the slower the fluid front moves. Therefore an estimate of the fluid velocity at the wellbore would give a reasonable value for our maximum flow rate in the corefloods. If we assume the injection rate to be $50 \mathrm{bbl} / \mathrm{d}$, and the well radius and height to be $0.25 \mathrm{~m}$ and $5 \mathrm{~m}$, respectively, and reservoir porosity to be 0.35 , then the fluid velocity at the wellbore can be calculated:

$$
q=\left(50 b b l / d \times 0.159 m^{3} / b b l\right) /(2 \times 3.14 \times 0.25 m \times 5 m \times 0.35)=2.9 m / d=9.5 f t / d
$$

The injection rate or the well properties may vary, but for a viscous fluid like this, the rate should not go very high limited by the injection pressure, and the wells can be designed properly to accommodate the fluid velocity.

\subsubsection{Bentheimer sandstone 12}

The porosity and permeability of the 12 " L Bentheimer sandstone core II was characterized to be 0.153 and $730 \mathrm{md}$, respectively. After the injection rates were translated into pump rates and the emulsion flow experiments were conducted, the effluents were analyzed. The free water content of the effluents was found to be $5 \%, 6 \%$ and $10 \%$ at injection rate of $1 \mathrm{ft} / \mathrm{d}, 3 \mathrm{ft} / \mathrm{d}$ and $10 \mathrm{ft} / \mathrm{d}$, respectively. The pressure profile was also obtained, shown in Figure 3.26. The same as the pressure profiles from early 
corefloods, the pressure leveled off at any fixed rate of injection. In the final step, when the injection rate was set to be $1 \mathrm{ft} / \mathrm{d}$, which was the same as the rate set at the beginning, the pressure drop declined even below the original pressure drop. At this point, about 10 PV of emulsion has been injected through the core. Therefore, the emulsion was further proven to be non-plugging.

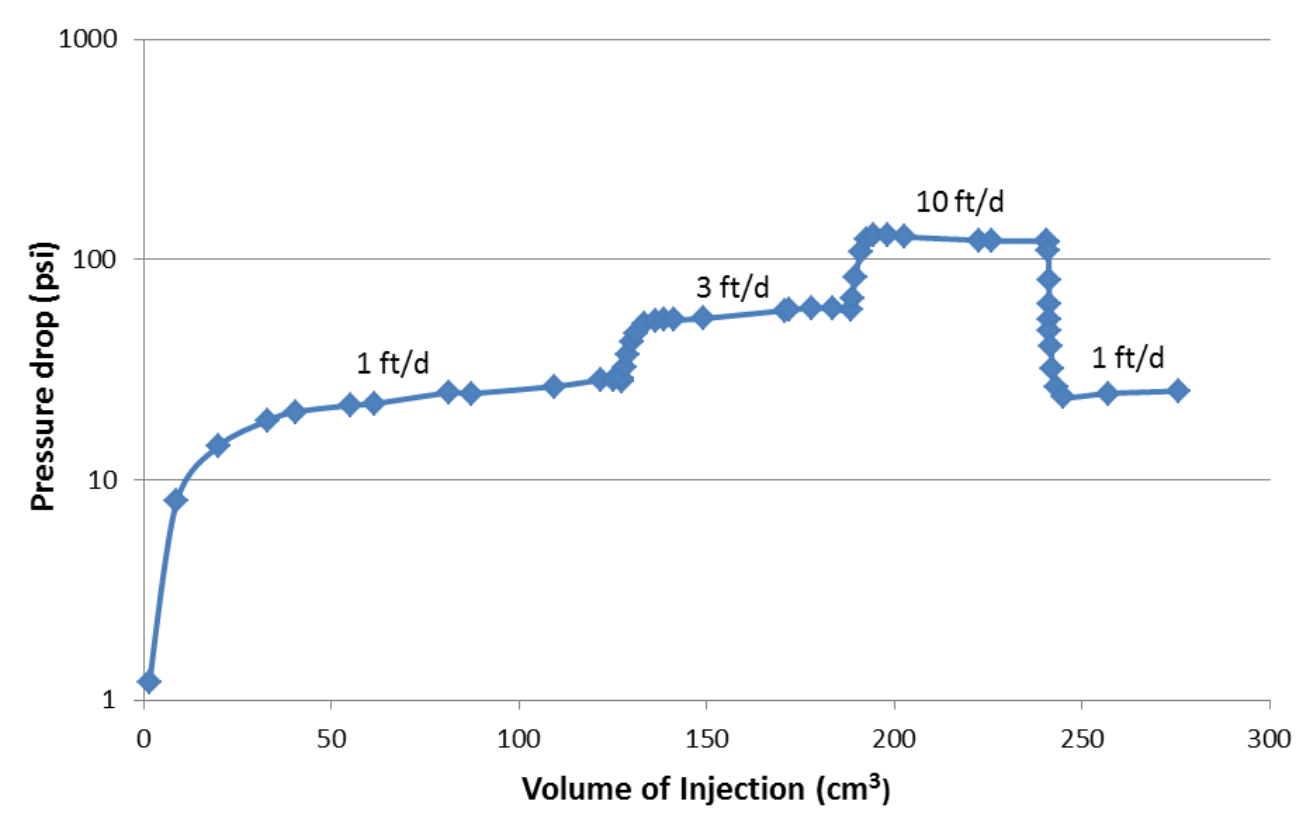

Fig 32 - ressure rofile for emulsion in ection 12 entheimer sandstone

From the stabilized pressure drop values at each rate, the effective viscosity of the emulsion was also calculated, shown in Figure 3.27. Compared to the values obtained from the 12 "L Bentheimer sandstone core A in the early corefloods, the 
effective viscosity values were a little lower, due to lower core permeability and slightly higher water breakout.

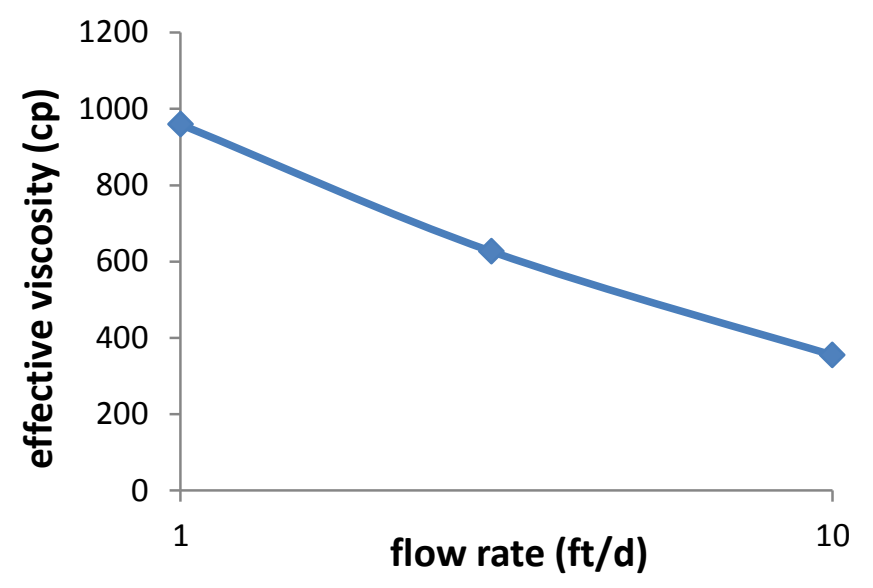

Fig. 3.27-Effective viscosity of the emulsion 12 entheimer sandstone

A picture of the Bentheimer sandstone core was taken right after the emulsion flow experiment, shown in Figure 3.28. For better illustration, the core was broken into pieces and the fresh surfaces could be seen. The emulsion appeared very homogeneous through the core, and no visible water drops were seen on any surface. As a matter of fact, the free water fraction within the core would be much smaller than that in the effluent, as the free water break out of the emulsion had a much higher velocity than the rest of emulsion traveling through the core, due to its much higher mobility compared to the oily emulsion phase. 


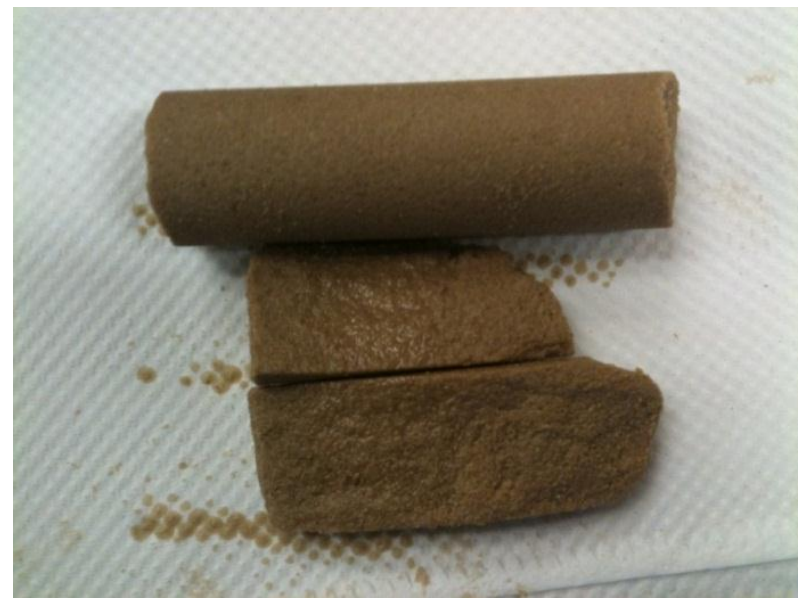

Fig. 3.28- Bentheimer sandstone core right after emulsion flow experiment.

\subsubsection{Bentheimer sandstone}

The porosity and permeability of the 6 " L Bentheimer sandstone core was characterized to be 0.152 and $620 \mathrm{md}$, respectively. After the injection rates were translated into pump rates and the emulsion flow experiments were conducted, the effluents were analyzed. The free water content of the effluents was found to be $3 \%, 9 \%$ and $16 \%$ at injection rate of $1 \mathrm{ft} / \mathrm{d}, 3 \mathrm{ft} / \mathrm{d}$ and $10 \mathrm{ft} / \mathrm{d}$, res ec ti e 1 Com a red to the 12 core, at injection rates of $3 \mathrm{ft} / \mathrm{d}$ and $10 \mathrm{ft} / \mathrm{d}$, the water breakout of this 6 "L core was even greater. Also compared to Bentheimer sandstone A (6 "L), which was tested in the early corefloods, the water breakout of this core at these two rate were more than tripled. This abnormally high water breakdown for this core B might be explained by its lower permeability. To verify the measurements though, the same test need to be repeated (see 2.3.4.3). 
The pressure profile was also obtained, shown in Figure 2.29. The same pattern was found here: the pressure leveled off at any fixed rate of injection. Again in the final step, when the injection rate was set to be $1 \mathrm{ft} / \mathrm{d}$, the pressure drop declined back to the pressure drop at the first stage. Therefore, the emulsion was again proven to be nonplugging.

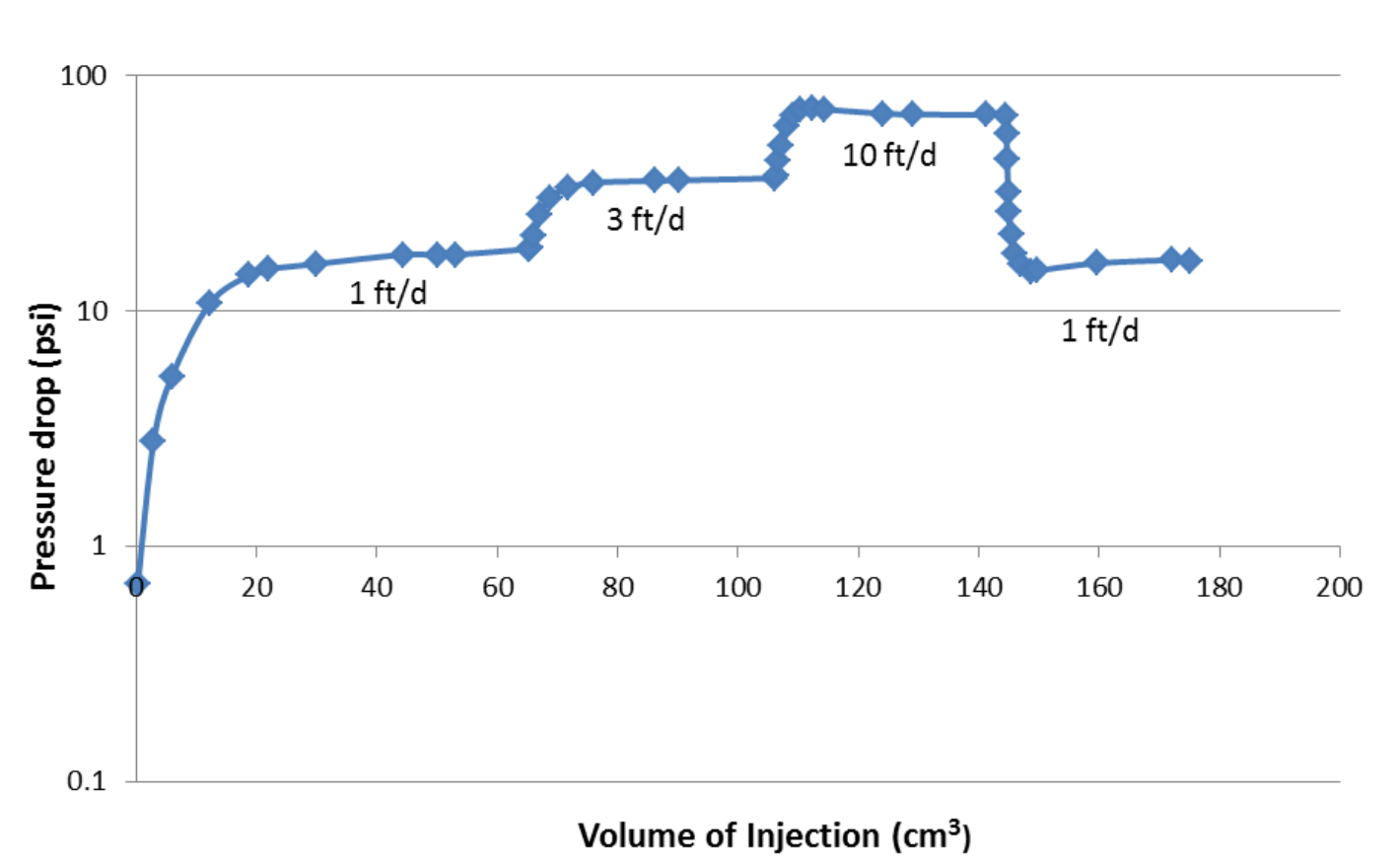

Fig. 3.29 - r essure rof ile for emulsion in ection entheimer sandstone

From the stabilized pressure drop values at each rate, the effective viscosity of the emulsion was also calculated, shown in Figure 3.30. 


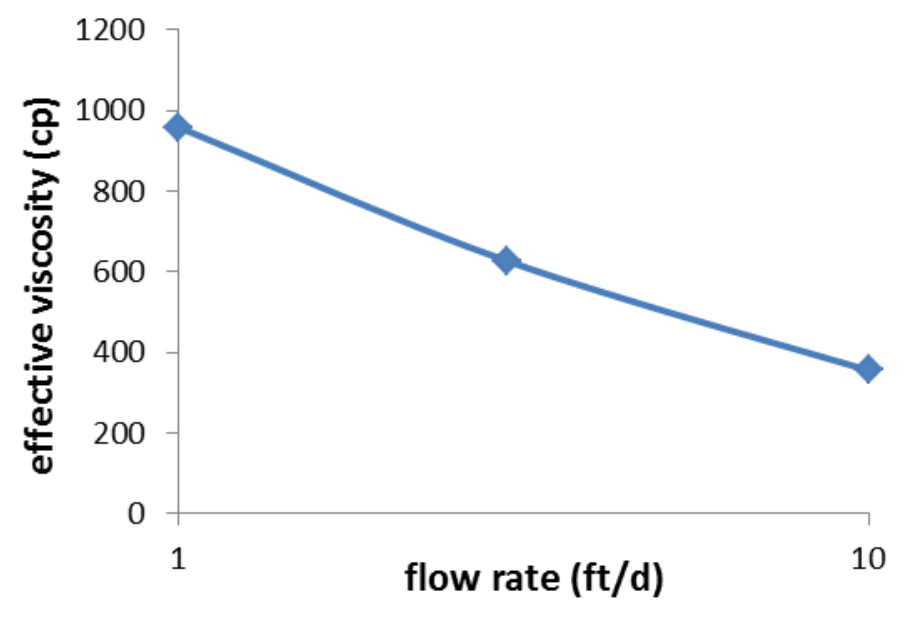

Fig. 3.30 - Effective viscosity of the emulsion entheimer sandstone

\subsubsection{Bentheimer sandstone $\quad 12$}

The porosity and permeability of the 6 " L Bentheimer sandstone core was characterized to be 0.205 and $2420 \mathrm{md}$, respectively. After the injection rates were translated into pump rates and the emulsion flow experiments were conducted, the effluents were analyzed. The free water content of the effluents was found to be $3 \%, 5 \%$ and $7 \%$ at injection rate of $1 \mathrm{ft} / \mathrm{d}, 3 \mathrm{ft} / \mathrm{d}$ and $10 \mathrm{ft} / \mathrm{d}$, respectively.

The pressure profile was also obtained, shown in Figure 3.31. From the stabilized pressure drop values at each rate, the effective viscosity of the emulsion was also calculated, shown in Figure 3.32. 


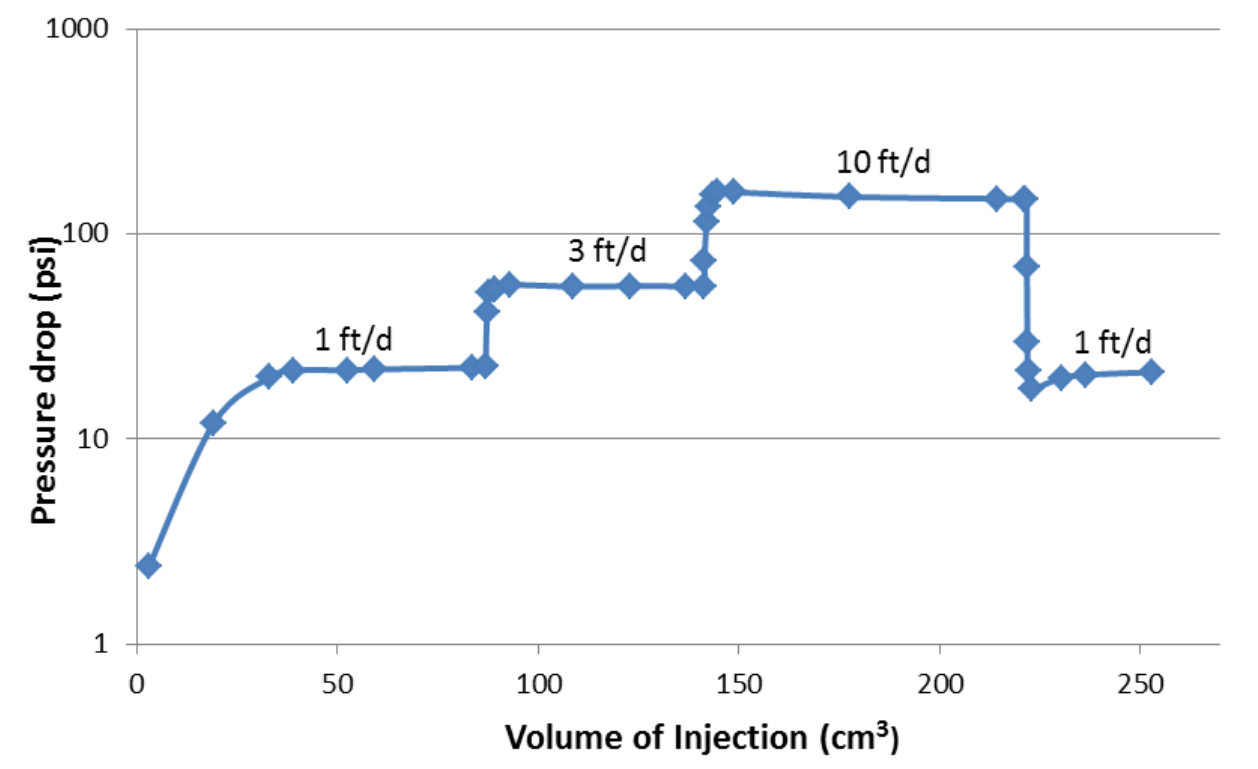

Fig $331-\mathrm{r}$ essure rof ile for emulsion in ection 12 entheimer sandstone III.

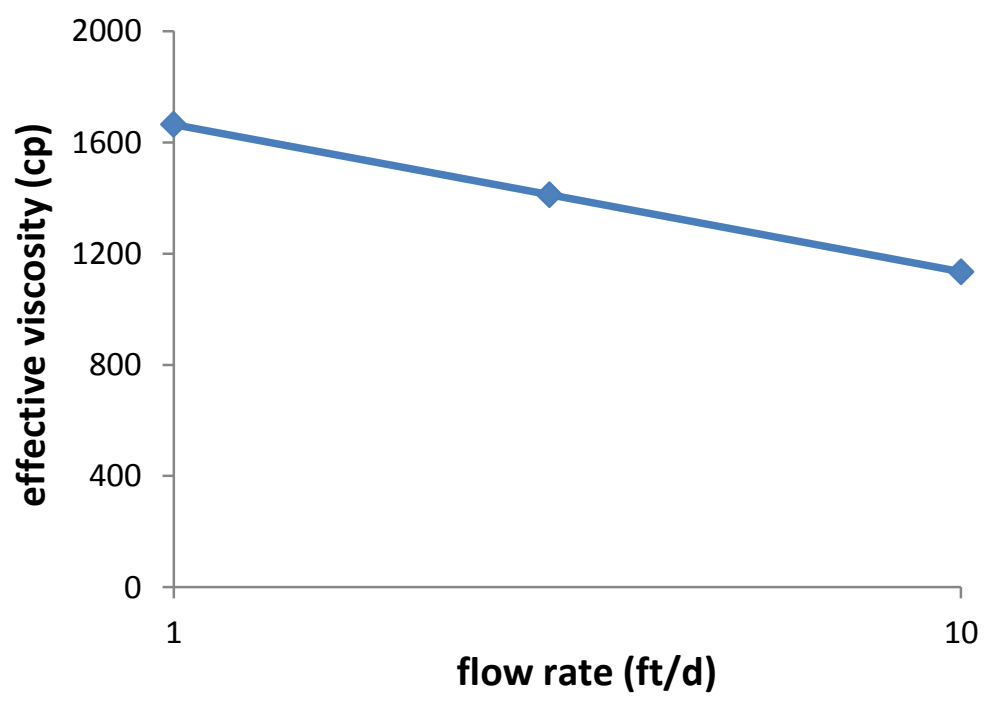

Fig 332 - f fecti e is cosit of the emulsion 12 entheimer sandstone 


\subsubsection{Bentheimer sandstone}

The porosity and permeability of the 6 " L Bentheimer sandstone core was characterized to be 0.191 and $960 \mathrm{md}$, respectively. After the injection rates were translated into pump rates and the emulsion flow experiments were conducted, the effluents were analyzed. The free water content of the effluents was found to be $2 \%, 6 \%$ and $8 \%$ at injection rate of $11 \mathrm{ft} / \mathrm{d}, 3 \mathrm{ft} / \mathrm{d}$ and $10 \mathrm{ft} / \mathrm{d}$, respectively.

The pressure profile was also obtained, shown in Figure 3.33. From the stabilized pressure drop values at each rate, the effective viscosity of the emulsion was also calculated, shown in Figure 3.34.

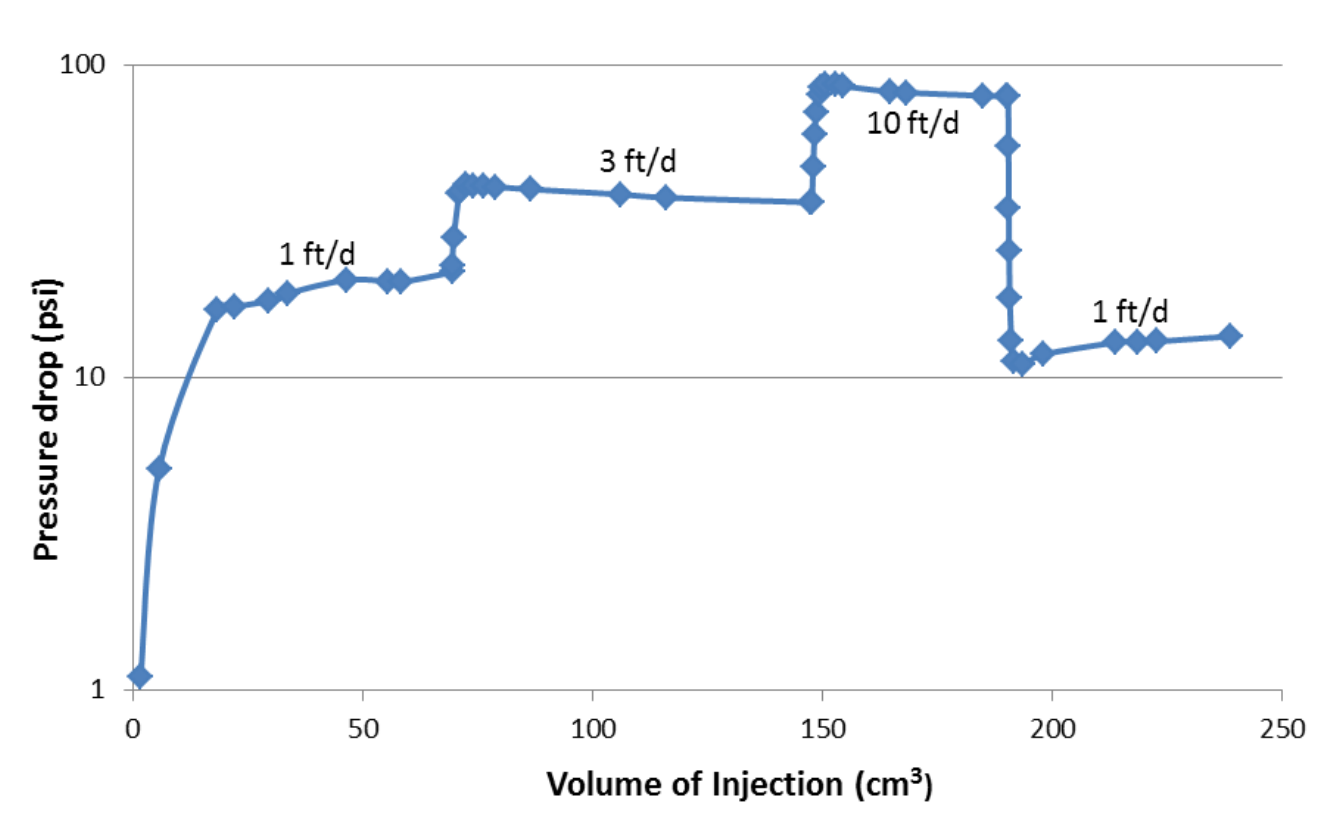

Fig. 3.33 - pressure profile for emulsion in ection entheimer sandstone 


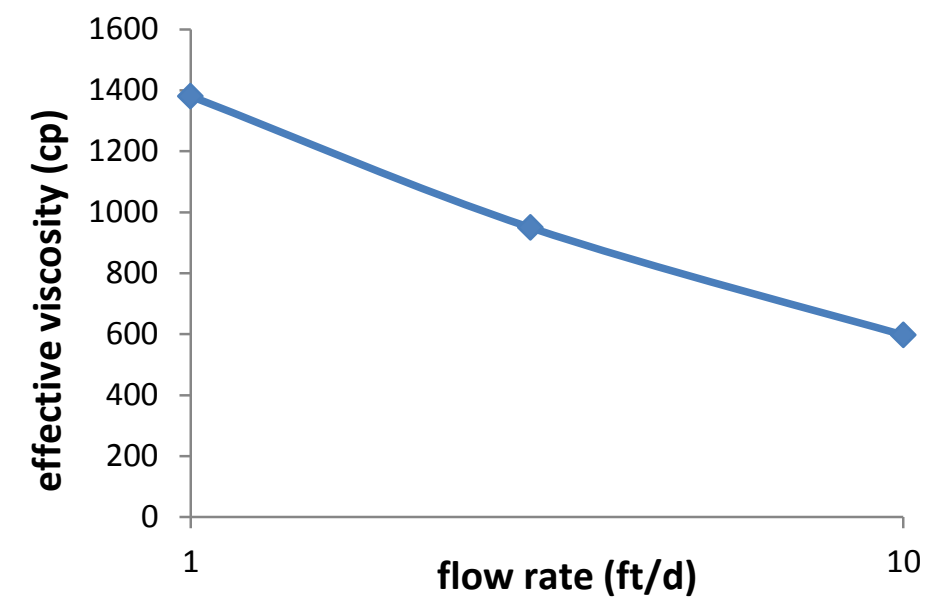

Fig 33 - f fecti e is cosit of the emulsion entheimer sandstone

\subsubsection{Corefloods with Sandpacks}

Sand a cked slimtu es of 3 ' and ' 1 engths were re a red for emulsion flow tests Similar procedures were taken for preparation of the coreflood system, except no overburden pressure could be applied for the slimtubes. The injection rates were also modified to start with $3 \mathrm{ft} / \mathrm{d}$, in order to accelerate these time consuming processes. Injection rates followed the order of $3 \mathrm{ft} / \mathrm{d}, 6 \mathrm{ft} / \mathrm{d}, 9 \mathrm{ft} / \mathrm{d}$, and finally back to $3 \mathrm{ft} / \mathrm{d}$ for both sandpack cases.

\subsubsection{Slimtu e A $3^{\prime}$}

The porosity of the sand pack was estimated in two ways in order to eliminate possible errors.

First, Based on the volume of sand: 
The ulk olum e of the sand a ck is equal to the olum e within the slimtu e The inner diameter of the slimtu e was measured to e 018 , therefore the bulk volume was about $14.68 \mathrm{~cm}^{3}$. The weight of the empty tube and sand-filled tube was measured to be $164.78 \mathrm{~g}$ and $188.90 \mathrm{~g}$, respectively. Knowing the matrix density of silica sand $2.65 \mathrm{~g} / \mathrm{cm}^{3}$ and the bulk volume of the tube, the porosity of the sand pack could be obtained:

$$
\phi=1-\frac{\operatorname{Vol}(\text { matrix })}{\operatorname{Vol}(\text { bulk })}=1-\frac{\left(m_{s}-m_{e}\right) / \rho_{s}}{\operatorname{Vol}(\text { bulk })}=1-\frac{(188.90 \mathrm{~g}-164.78 \mathrm{~g}) /\left(2.65 \mathrm{~g} / \mathrm{cm}^{3}\right)}{14.68 \mathrm{~cm}^{3}}=0.380
$$

Second, Based on the volume of brine:

The weight of the dry sand-filled tube and water saturated tube was measured to be $188.90 \mathrm{~g}$ and $194.19 \mathrm{~g}$, respectively. Knowing the density of brine $1.02 \mathrm{~g} / \mathrm{cm}^{3}$, the porosity of the sand pack could be obtained:

$$
\phi=\frac{\operatorname{Vol}(\text { pore })}{\operatorname{Vol}(\text { bulk })}=\frac{\left(m_{b}-m_{s}\right) / \rho_{b}}{\operatorname{Vol}(\text { bulk })}=\frac{(194.19 \mathrm{~g}-188.90 \mathrm{~g}) /\left(1.02 \mathrm{~g} / \mathrm{cm}^{3}\right)}{14.68 \mathrm{~cm}^{3}}=0.353
$$

There is a slight difference between the two results. An average between those two values was taken which resulted in an estimation of porosity of 0.37 . With the porosity determined, the rate of injection from pump could be determined based on the assigned velocity values in the slimtube.

$$
\begin{aligned}
& 3 f t / d=\frac{\left(3.1416 \times 0.178^{2} \times 1.27^{2}\right) \mathrm{cm}^{2} \times(30.48 \times 3) \mathrm{cm} \times 0.37}{24 \times 60 \mathrm{~min}} \approx 0.004 \mathrm{~cm}^{3} / \mathrm{min} \\
& 6 \mathrm{ft} / d \approx 0.008 \mathrm{~cm}^{3} / \mathrm{min} \\
& 9 \mathrm{ft} / d=0.012 \mathrm{~cm}^{3} / \mathrm{min}
\end{aligned}
$$


After the slimtube was connected to the coreflood system as the coreflood cell, brine was injected through at fixed rate of $5 \mathrm{ml} / \mathrm{min}$ to test its permeability. The pressure drop stabilized around 82.7 psi. Therefore the permeability of the sand pack could be estimated:

$$
\begin{aligned}
& k=\frac{q \mu l}{A \Delta p} \\
& =\frac{\left(5 \mathrm{ml} / \mathrm{min} \times 10^{-6} \mathrm{~m}^{3} / \mathrm{ml} \times 1 / 60 \mathrm{~min} / \mathrm{s}\right) \times\left(1 \times 10^{-3} \mathrm{~Pa} \cdot \mathrm{s}\right) \times\left(30.48 \times 3 \times 10^{-2} \mathrm{~m}\right)}{3.1416 \times\left(0.178 \times 1.27 \times 10^{-2}\right)^{2} \times(82.7 \mathrm{psi} \times 6894 \mathrm{~Pa} / \mathrm{psi})} \\
& =8.3 \times 10^{-12} \mathrm{~m}^{2} \\
& =8300 \mathrm{md}
\end{aligned}
$$

After the test of permeability, the injectant was switched to emulsion from brine. The emulsion was first injected at the lowest rate $3 \mathrm{ft} / \mathrm{d}$, until the movable brine originally in the core was completely displaced by emulsion, which could be judged from fixed percentage of water in the effluent, and stable pressure drops along the slimtube. Afterwards the rate was set to be $6 \mathrm{ft} / \mathrm{d}$ and $9 \mathrm{ft} / \mathrm{d}$ consecutively and finally back to $3 \mathrm{ft} / \mathrm{d}$. Several pore volumes of fluid were injected through the sand pack at each rate to ensure stabilized flow at that rate, and effluents were collected at each rate after stabilization.

The water breakout from the emulsions was measured from the effluents collected at each rate. Free water content was found to be $<<1 \%,<1 \%$ and $4 \%$, respectively at injection rate of $3 \mathrm{ft} / \mathrm{d}, 6 \mathrm{ft} / \mathrm{d}$ and $9 \mathrm{ft} / \mathrm{d}$. Despite the great length of transport, the emulsion breakdown from flowing through the sand pack was very little. This further proved the well-maintained stability of the emulsion in high permeability reservoirs. 
The pressure profile was also obtained, shown in Figure 3.35. The same as the pressure profiles from sandstone corefloods, the pressure leveled off at any fixed rate of injection. In the final step, when the injection rate went back to be $3 \mathrm{ft} / \mathrm{d}$, the pressure drop declined to values close to the pressure drop in the first step. The non-plugging feature of the emulsion was further verified.

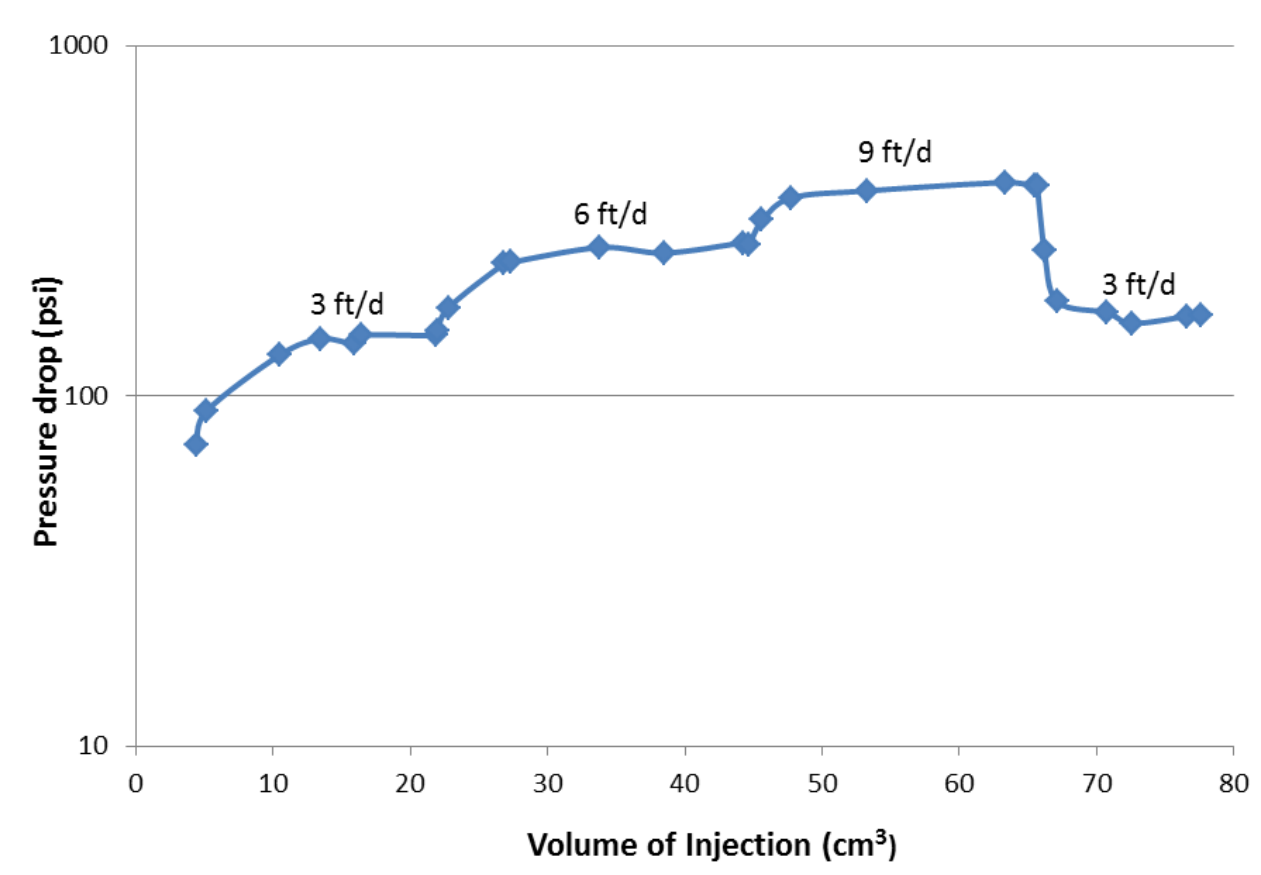

Fig. 3.35- ressure rofile for emulsion in ection $3^{\prime}$ sand a cked slimtu e

From the stabilized pressure drop value at each injection rate, the effective viscosity of emulsion at that rate was calculated. The results are shown in Figure 3.36. From this Figure, the shear thinning behavior of the emulsion was almost negligible. 


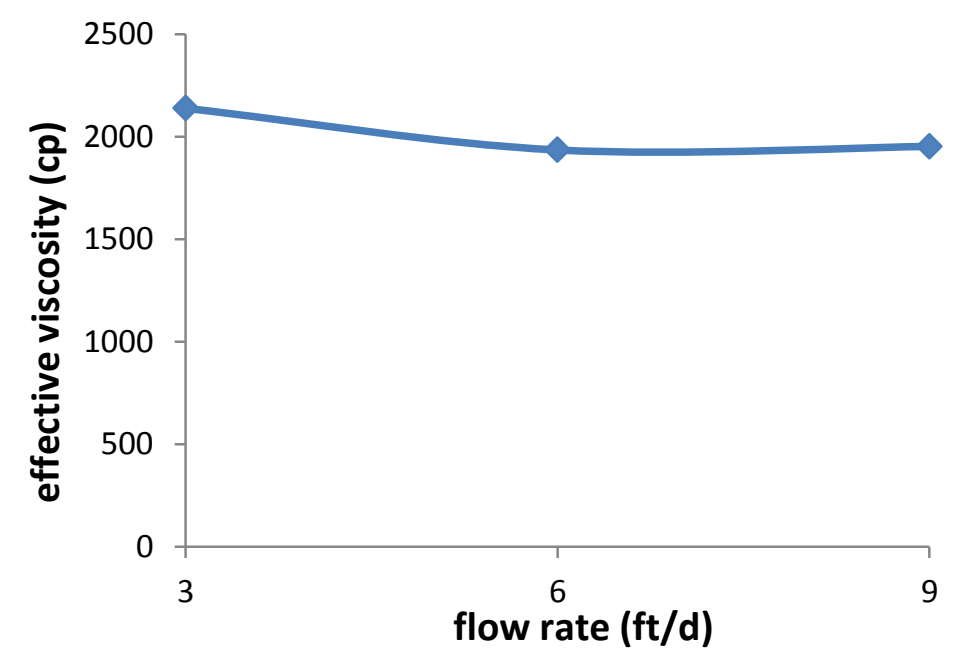

Fig. 3.36- Effective viscosity of the emulsion $3^{\prime}$ sand acked slimtu e

The viscosities of the emulsion effluents were also measured by viscometer, shown in Figure 3.37. The original emulsion before injection was also measured by viscometer at the same time and shown in this figure. As expected, the viscosity of the original emulsion was the highest, and the effluents collected at $3 \mathrm{ft} / \mathrm{d}, 6 \mathrm{ft} / \mathrm{d}$ and $9 \mathrm{ft} / \mathrm{d}$ had decreasing viscosities, because of higher and higher water breakout from the emulsion. Roughly $10 \%, 15 \%$ and $24 \%$ of the original viscosity was lost for the effluents collected at the three injection rates. 


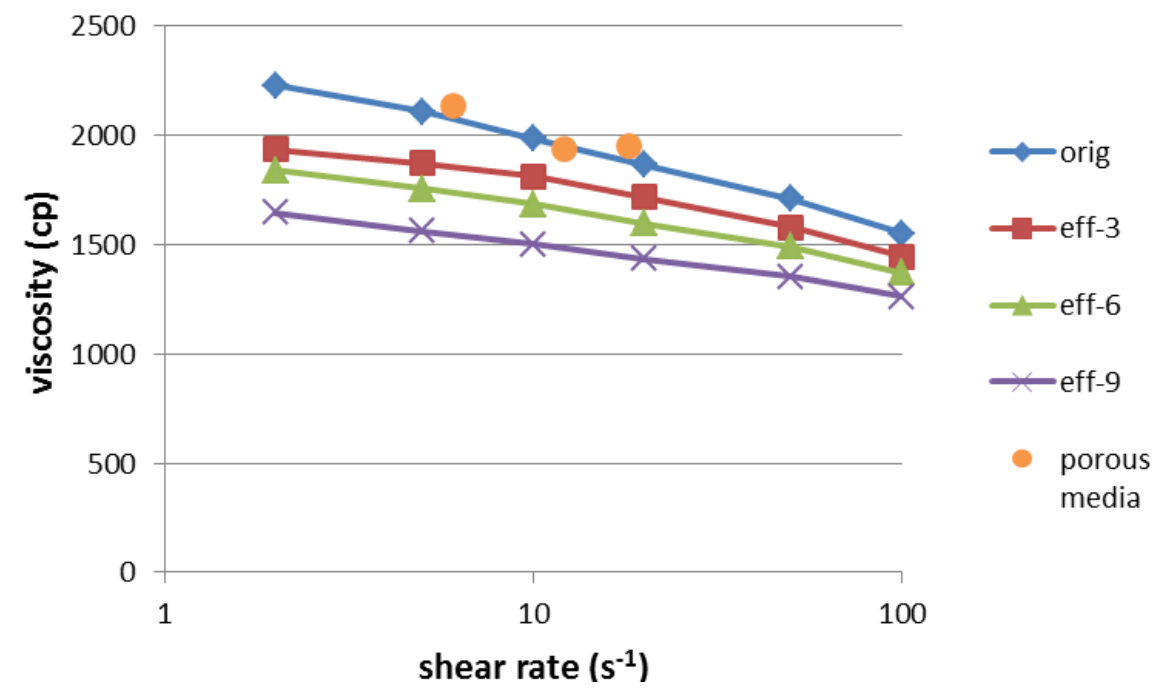

Fig. 3.37- Viscometer-measured iscosit of the emulsion effluents $3^{\prime}$ sand a cked slimtube.

The effective viscosity of the emulsion calculated from coreflood experiments were included in Figure 3.37, shown as orange dots. Opposite to the observation from earlier corefloods, the effective viscosities obtained from current corefloods showed higher viscosities compared to viscosities measured by viscometer - they almost o e rla e $\mathrm{d}$ with the isc osit cur e of the original emulsion Also, the "shear thinning" trend observed in earlier coreflood experiments was not obvious in this case - the effective viscosity curve was quite flat. This result seemed to conflict with the explanation by two phase flow, but possible explanations could be the setup of experiment. Since no overburden pressure was applied to the sand pack, the confinement pressure the sand body experience was largely dependent on fluid injection pressure. In other words, the higher the injection rate, the higher pressure experienced by the sand 
particles. Therefore, during emulsion injection, the sand pack might have become more and more tightly packed, and this would very likely decrease the permeability of the sand pack. Decrease of the sand pack permeability will lead to overestimate of the effective viscosity of emulsion.

\subsubsection{Slimtube B '}

The orosit and e rmea il it of the ' sand a cked slimtu e was estimated to be 0.37 and $7600 \mathrm{md}$, respectively. After the injection rates were translated into pump rates and the emulsion flow experiments were conducted, the effluents were analyzed for emulsion breakdown. The free water content of the effluents was found to be $<1 \%, 1 \%$ and $7 \%$ at injection rate of $3 \mathrm{ft} / \mathrm{d}, 6 \mathrm{ft} / \mathrm{d}$ and $9 \mathrm{ft} / \mathrm{d}$, respectively.

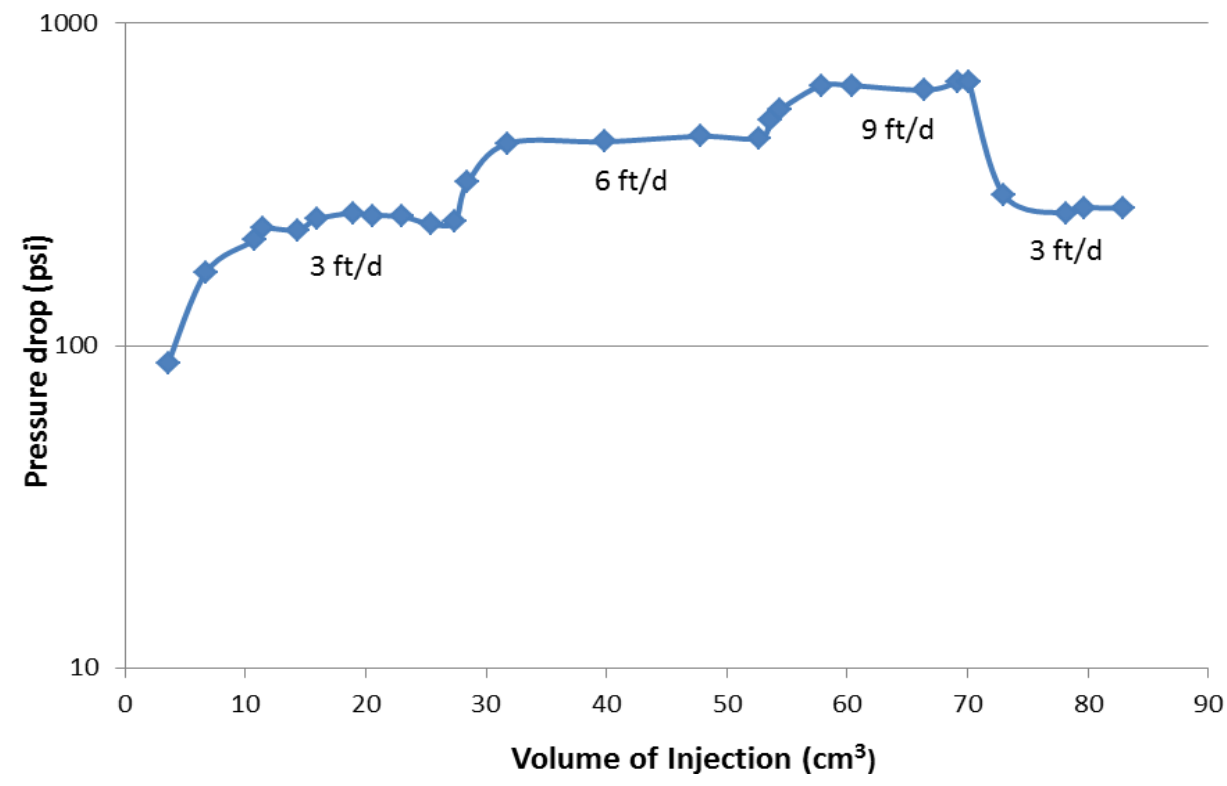

Fig. 3.38 - ressure rof ile for emulsion in ection ' sand a cked slimtu e 
The pressure profile was obtained during the coreflood experiment, shown in Figure 3.38. Comparable to all earlier results, the pressure drop stabilized at each fixed rate of injection. From those values, the effective viscosity of emulsion at each injection rate was also calculated, shown in Figure 339 Similar to the $3^{\prime}$ sand acked slimtu e case, of the emulsion demonstrated very little shear thinning behavior from the effective viscosity calculations. It has to be noted that in sand pack experiments the flow rates had a narrower range than that in corefloods, and the effective shear was also smaller due to higher permeability and porosity.

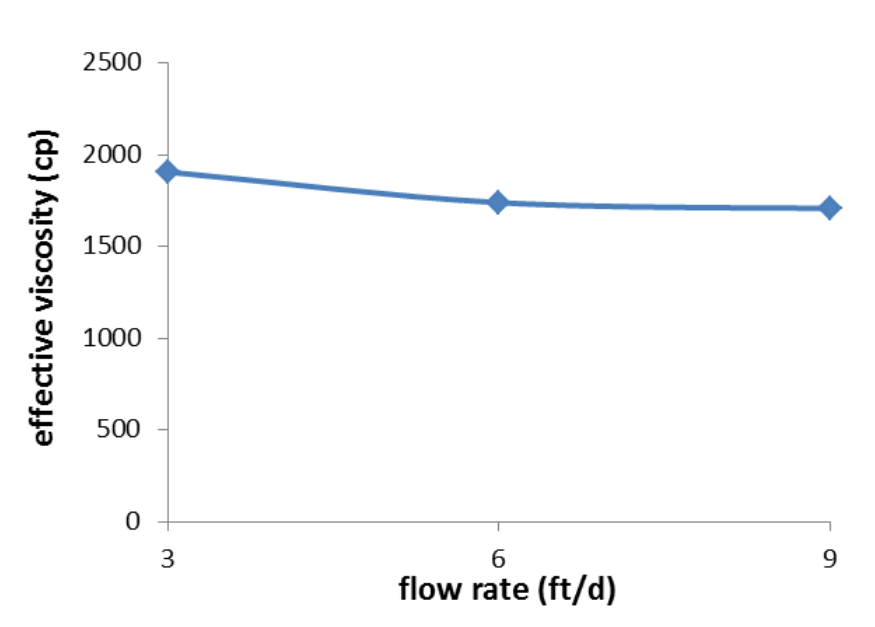

Fig. 3.39 - f fecti e is cosit of the emulsion ' sand acked slimtu e

The viscosities of the emulsion effluents were also measured by viscometer, shown in Figure 3.40. The viscosity of the effluents collected at $3 \mathrm{ft} / \mathrm{d}$ and $6 \mathrm{ft} / \mathrm{d}$ had 
similar viscosities. Roughly $20 \%$ of the original viscosity was lost for the effluents collected at these two rates. The effluent collected at $9 \mathrm{ft} / \mathrm{d}$ had the largest water breakout, therefore its viscosity was the lowest - about $40 \%$ of the original viscosity was lost after passing through the tube at $9 \mathrm{ft} / \mathrm{d}$.

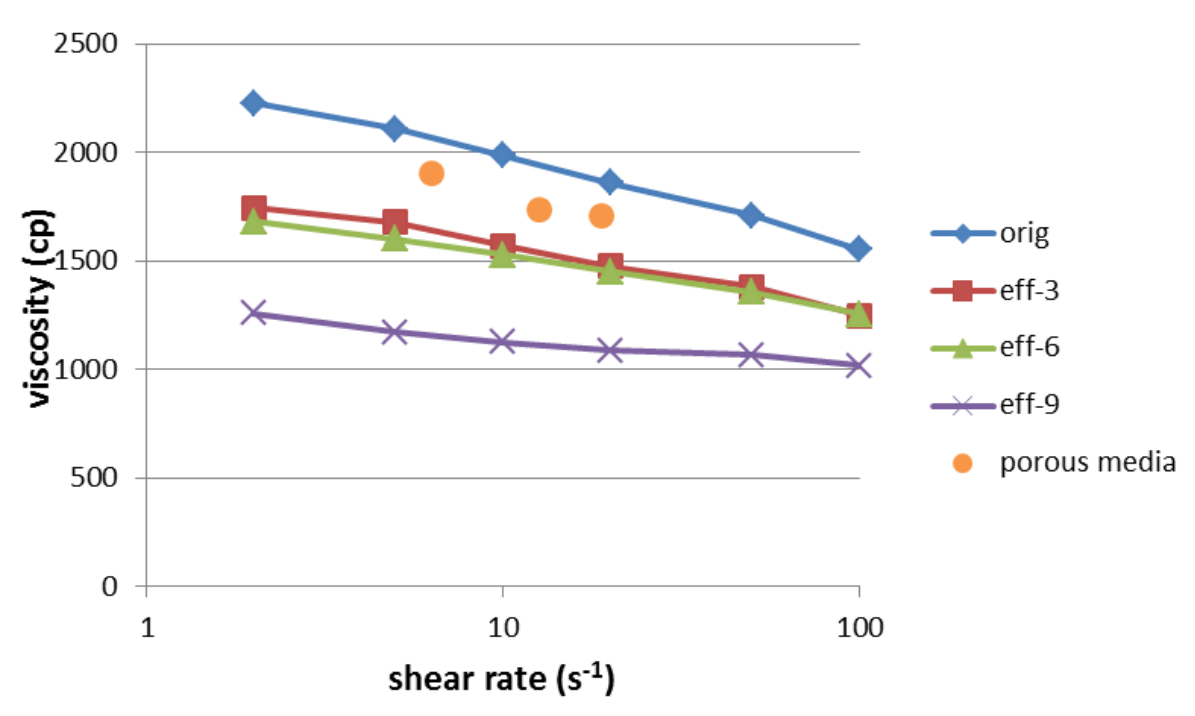

Fig. 3.40 - Viscometer-measured iscosit of the emulsion effluents ' sand a cked slimtube.

The effective viscosity of the emulsion calculated from coreflood experiments were also included in Figure 3 0, shown as orange dots Similar to the $3^{\prime}$ sand a cked slimtube case, the effective viscosities calculated from coreflood experiments showed higher viscosities compared to the viscosities measured by viscometer, and the curve 
was almost flat. As discussed before, this was likely due to experiment setup. However, the viscosities obtained by the two methods were roughly in the same range. This allows us to approximate emulsion properties in porous media from bench tests. 


\section{CHAPTER IV}

\section{SIMULATION STUDIES}

\subsection{General Description}

Numerical study on emulsion flooding a homogeneous heavy oil reservoir was conducted using black oil model with CMG STARS. A 1/8 of a five-spot well pattern was used for this study. Since the emulsion was oil-external, and no plug-off effect was observed during emulsion flow experiments, the emulsion was simply treated as singlephase oil. The breakdown effect of the emulsion was simulated as a co-injection of water together with this oil, to take into account of free water breakout from the emulsion while passing through porous media. This is a reasonable assumption as most water breakout will occur near the wellbore region where flow rates are the highest.

Some major input parameters for the reservoir and fluid properties are listed in Table 4.1. The drainage area was $1 / 8$ of 2.5 acres, and the netpay was $20 \mathrm{ft}$. The porosity and horizontal permeability were set to be 0.3 and $5000 \mathrm{md}$, respectively. The vertical permeability was set to be $1 / 10$ of the horizontal permeability. Since this is a nonthermal process, a tem erature of $90{ }^{\circ} \mathrm{F}$ was a li ed for oth in ected fluids and the formation. The heavy oil was considered to have a viscosity of $1000 \mathrm{cp}$ at this temperature. The emulsion viscosity and free water breakout were set to be $1000 \mathrm{cp}$ and $10 \%$, respectively. Among these parameters, the emulsion viscosity, free water breakout, heavy oil viscosity, reservoir porosity and permeability were set to different values in the sensitivity analyses part. 


\begin{tabular}{|ll|}
\hline \multicolumn{2}{|c|}{ TABLE 4.1 RESERVOIR AND FLUID PROPERTIES } \\
\hline Drainage area & $1 / 8 \mathrm{of} 2.5$ acres \\
Netpay & $20 \mathrm{ft}$ \\
Porosity & 0.30 \\
Horizontal permeability & $5000 \mathrm{md}$ \\
Vertical permeability & $500 \mathrm{md}$ \\
Initial oil saturation & 0.8 \\
Temperature & $90{ }^{\circ} \mathrm{F}$ \\
Heavy oil viscosity & $1000 \mathrm{cp}$ \\
Emulsion viscosity & $1000 \mathrm{cp}$ \\
Emulsion breakdown & $10 \%$ (free water breakout) \\
\hline
\end{tabular}

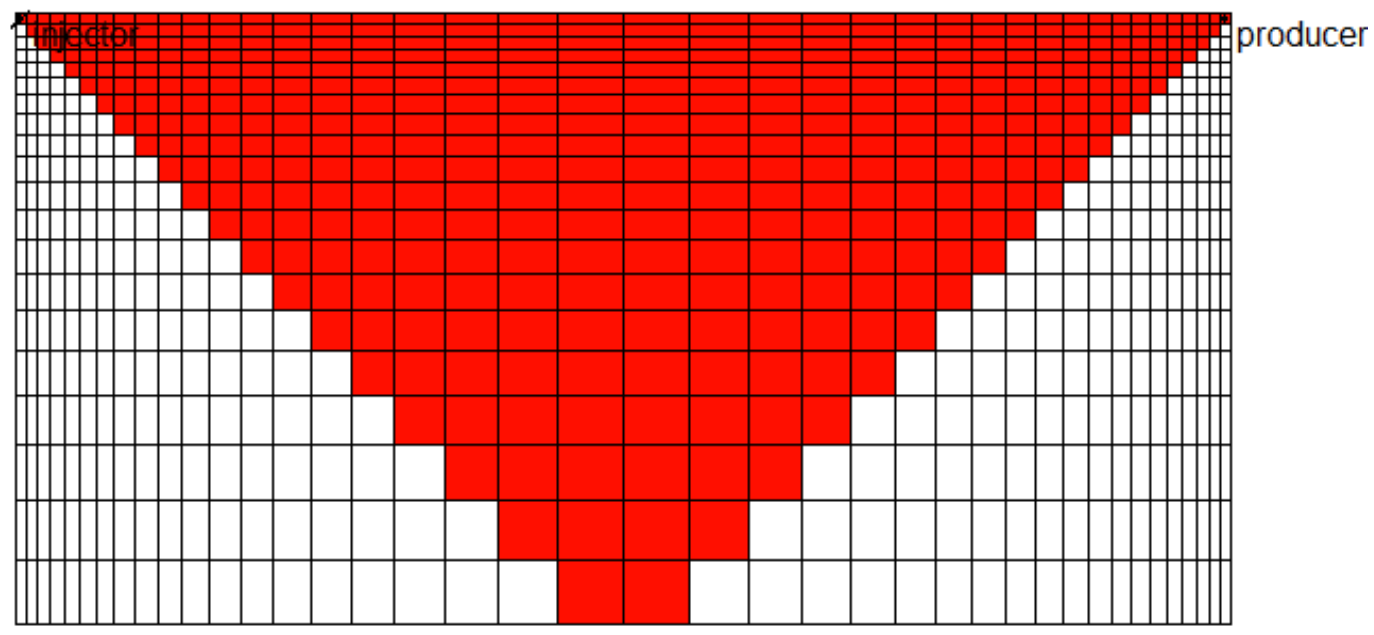

Fig. 4.1- (a) 2D view of the gridblocks from top; (b) 3D view of the gridblocks. 


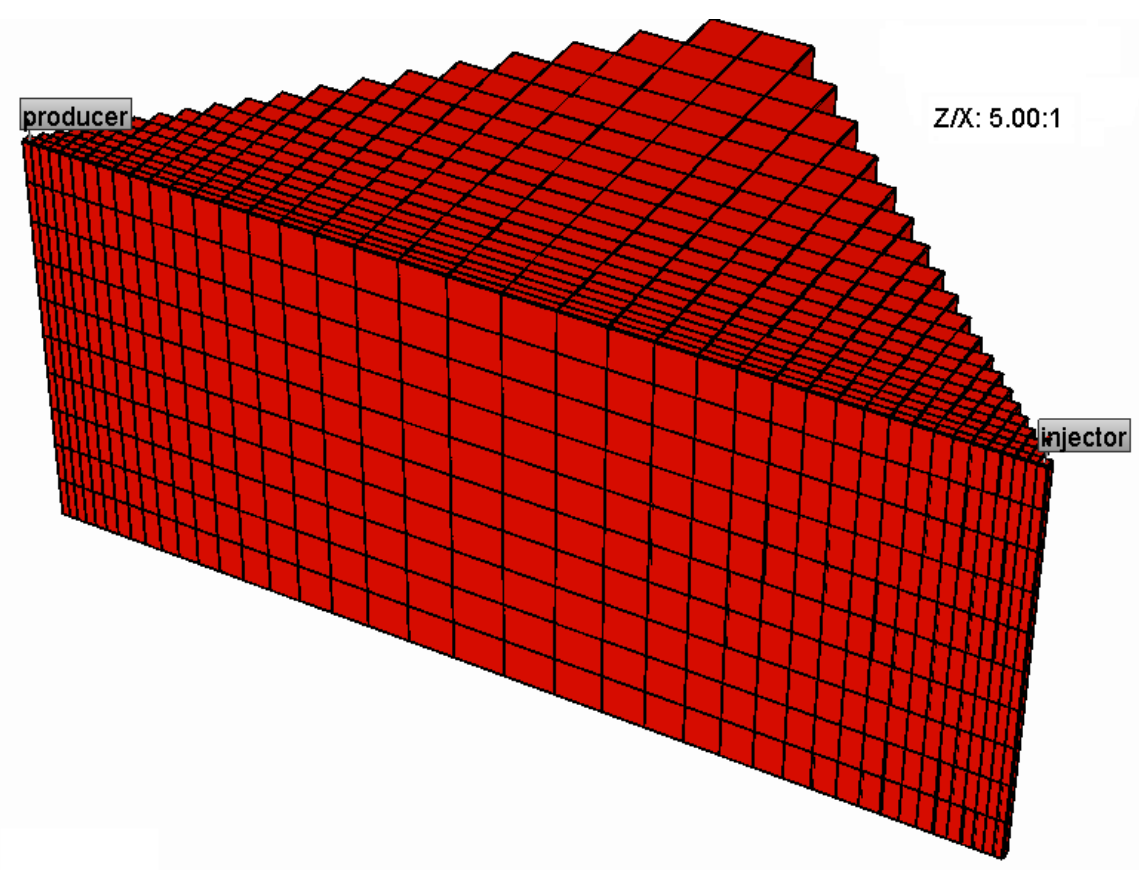

Fig. 4.1 Continued

The 3D simulation model is shown in Figure 4.1(a) and (b). A total of $40 \times 20 \times 10$ Cartesian grids were built and only the red ones were assigned with porosity and permeability values, and the bordering grid blocks were assigned with half of the porosity for normal grids, in order to take into account of the boundary effect.

The operation constraints were set to be the same for all simulation cases: the maximum bottom hole pressure (BHP) for the injection well was $1400 \mathrm{psi}$, and the maximum injection rate was $50 \mathrm{bbl} / \mathrm{d}$; the minimum BHP of the production well was set to be $230 \mathrm{psi}$, and there was no constraint on the production rate. During simulation, those limits will soon be reached and the wells will operate under these values. For the 
injection well, since there are constraints on both pressure and injection rate, the stricter one between these two is the active constraint.

\subsection{Water Flooding}

Simulation on water flooding was conducted as a base case for comparison.

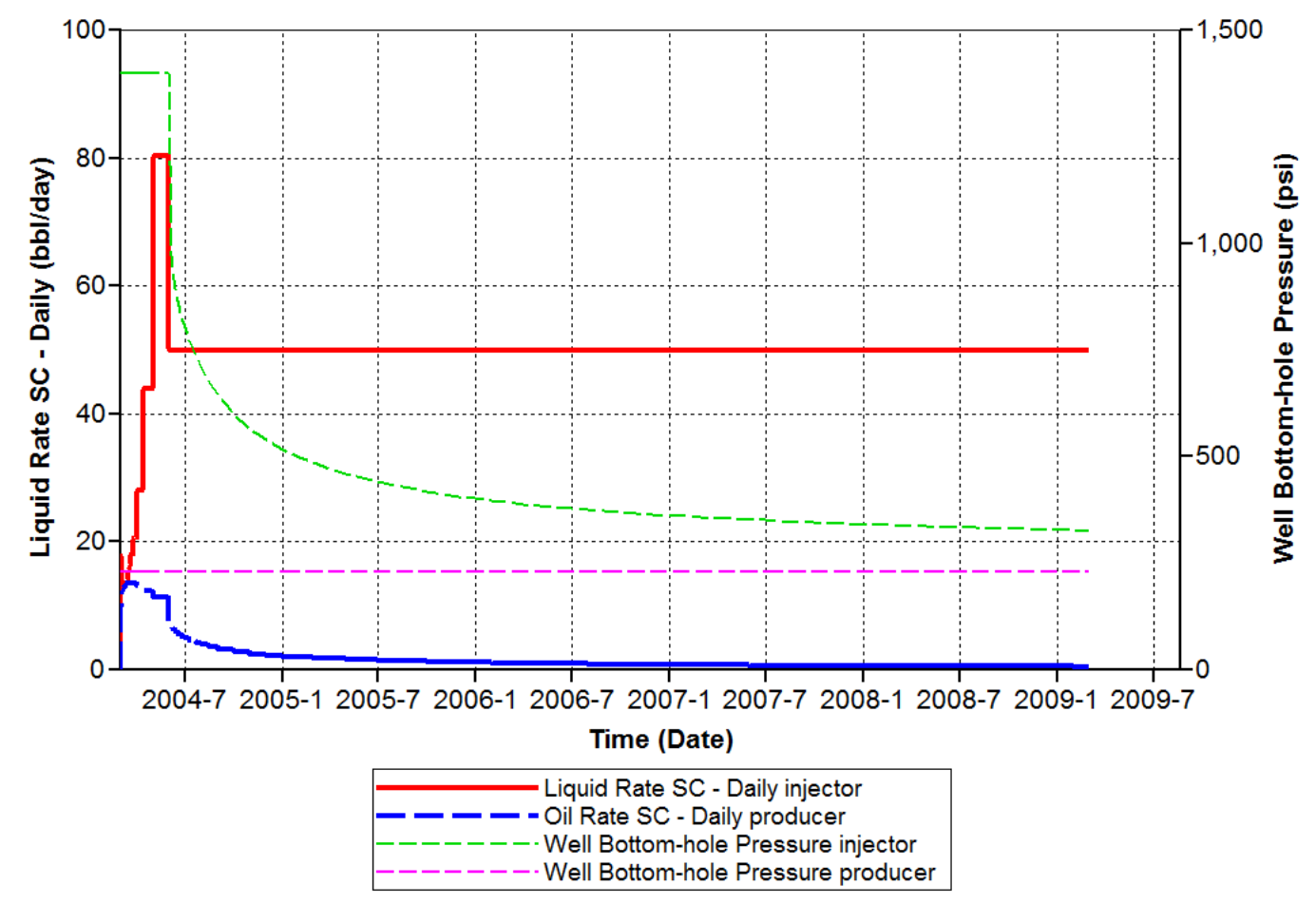

Fig. 4.2- Liquid rates and well BHPs in water flooding.

The BHP and fluid rates of the production and injection wells are shown in Figure 4.2. At the beginning, the injection well was operating under the pressure limit 
1400 psi. As more water was injected into the reservoir, the injectivity increased and the injection rate also went up. When the injection rate exceeded $50 \mathrm{bbl} / \mathrm{d}$, it fell back rapidly and the well started to operate under the rate limit $50 \mathrm{bbl} / \mathrm{d}$. The BHP at the injection well started to drop after this point. The BHP of the production well was kept at $230 \mathrm{psi}$ the whole time. The total liquid rate at the production well was almost the same as that of the injection well thus not shown in this figure. The oil rate peaked at the beginning of water flooding, and then it dropped rapidly after water breakthrough.

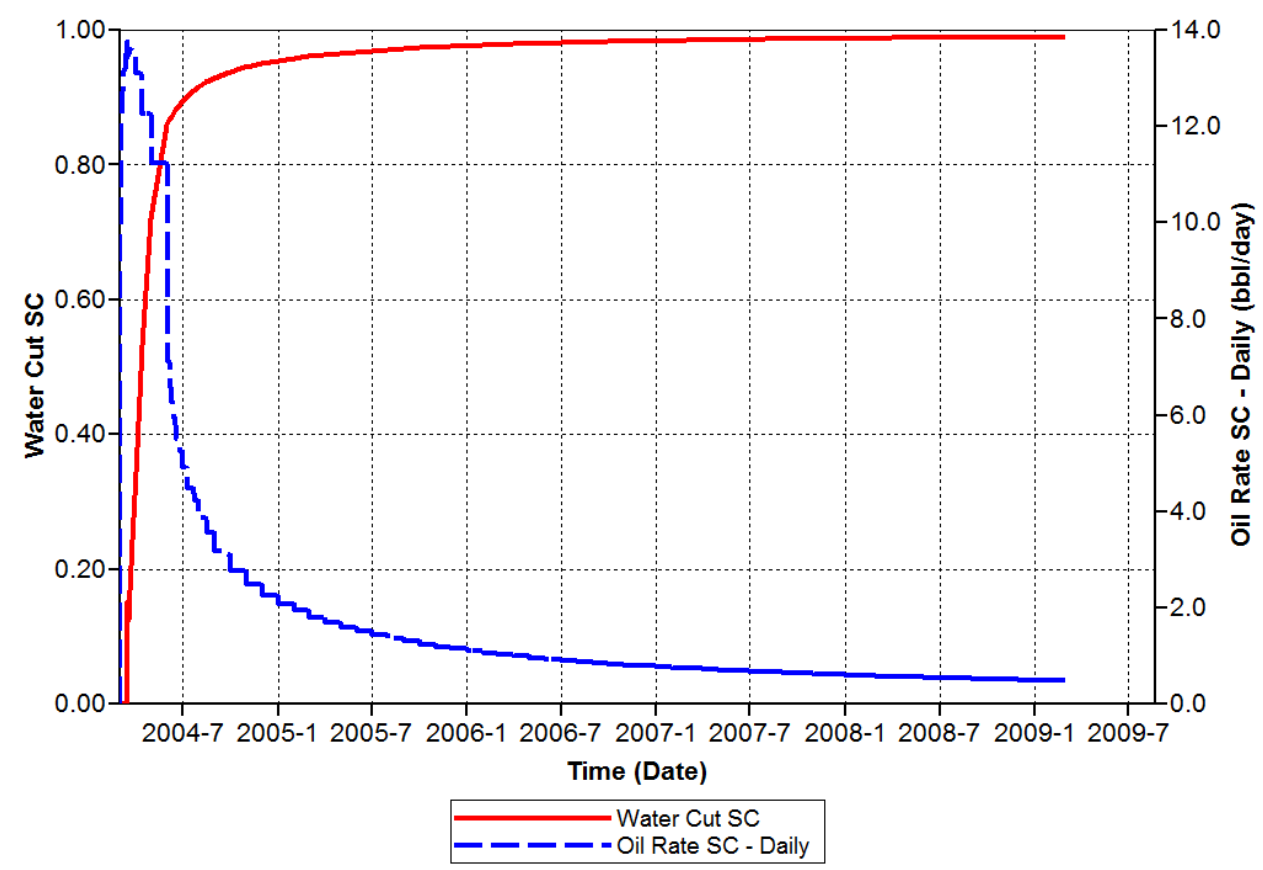

Fig. 4.3- Water cut in water flooding. 
Figure 4.3 shows the water cut at the production well, together with the oil rate of production. The water cut increased rapidly - within a year after the water injection, the water cut had increased above $95 \%$. In an actual case this water flooding project would have been terminated within a year if we decide the limit for water cut to be around $95 \%$.

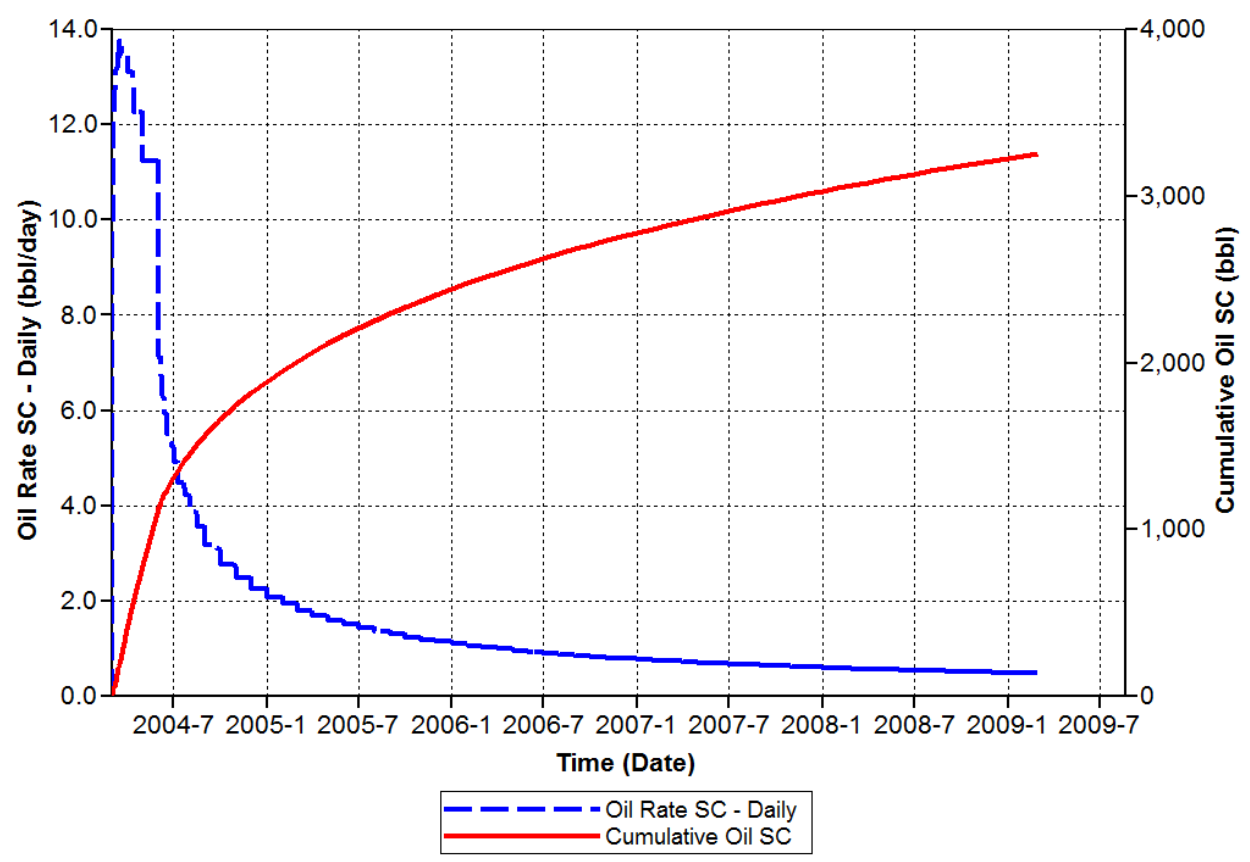

Fig. 4.4- Cumulative oil production in water flooding.

The cumulative oil production is shown in Figure 4.4. About 2000 barrels of oil had been produced after one ear's water flooding The original oil in lac e OO of the $1 / 8$ of 2.5 -acre field is calculated as: 
$O O I P=\frac{7758 A h \phi\left(1-S_{w}\right)}{B_{o}}=\frac{7758 \times 1 / 8 \times 2.5 \times 20 \times 0.3 \times 0.8}{1}=11637(b b l)$

Therefore, about $17 \%$ of the OOIP was recovered when the WOC reached above $95 \%$.

The recovery performance curve relating the fraction of oil recovered and the pore volumes of fluid injected was plotted, shown in Figure 4.5. Oil recovery at unit pore volume water injection was only $16 \%$, and this value increased very slowly to less than $30 \%$ after over 6 pore volumes of water being injected.

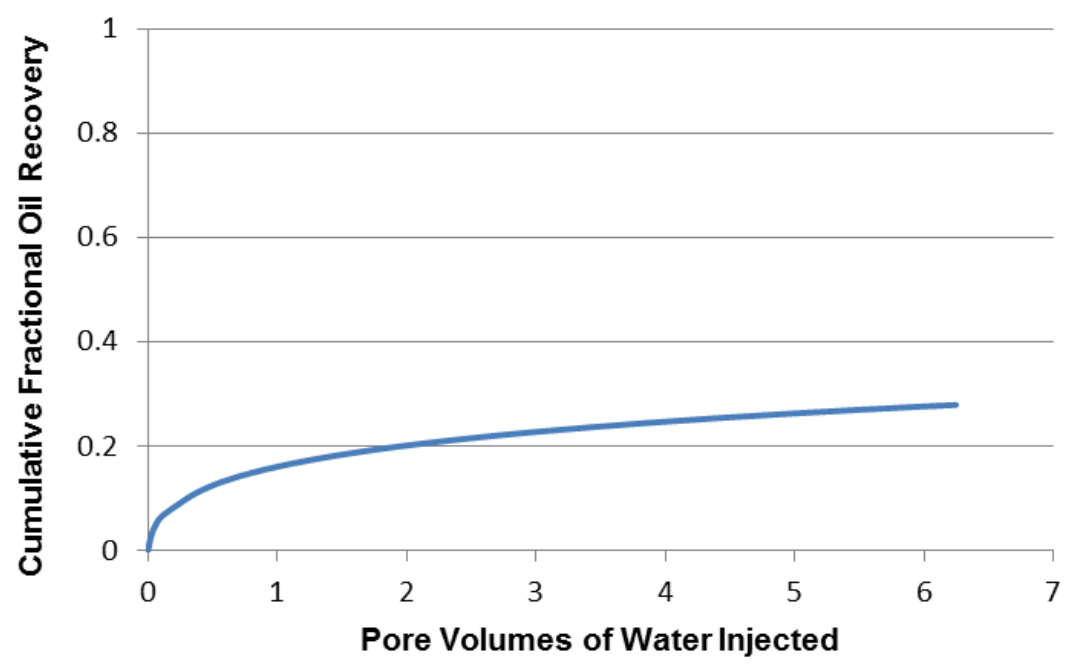

Fig. 4.5- Recovery performance for water flooding.

To better illustrate the flood pattern, a 3D view of the oil saturation after two years is shown in Figure 4.6. The gravity segregation between water and oil was not severe in this case, due to a combination factor of small gravity difference (the oil was 84 
assigned a density of $\left.60 \mathrm{lb} / \mathrm{ft}^{3}\right)$, thin pay zone (20 ft), and restrained vertical permeability (500 md).

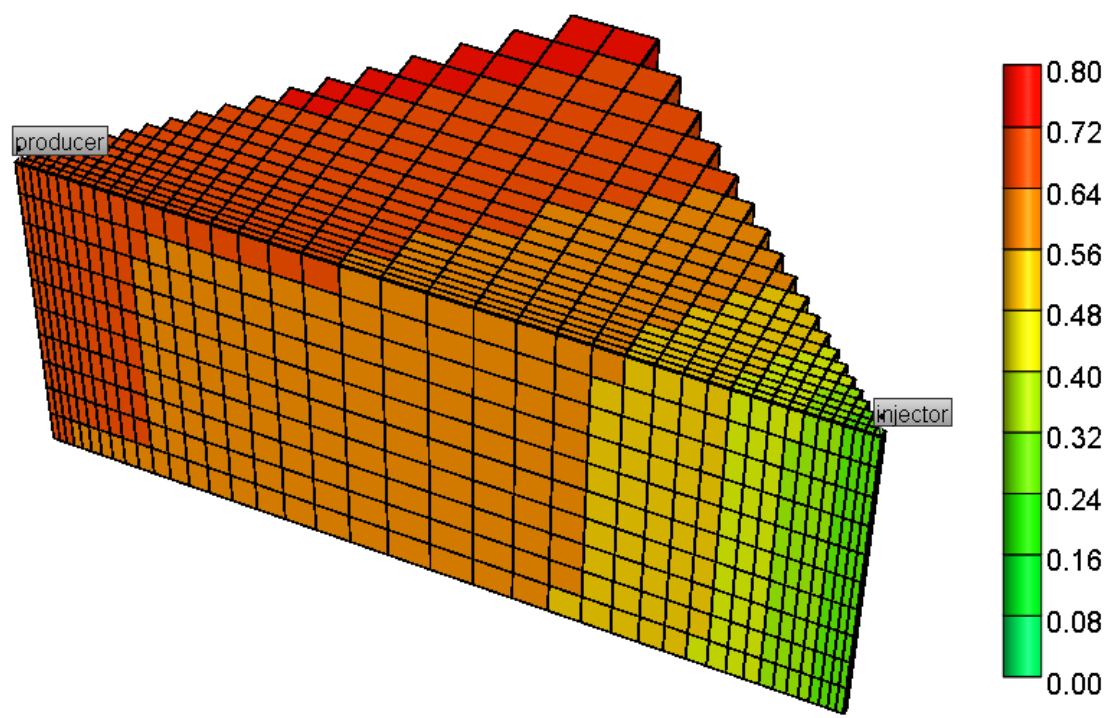

Fig. 4.6 - Oil saturation after two years of water flooding.

The high viscosity of oil caused very adverse mobility ratio between oil and water, therefore water channeled through between the injection and production well soon after water injection. Once the channels were created, water would flood through those zones much more easily than the rest of reservoir, due to high water mobility in the water flooded zones. This is the main reason why heavy oil reservoirs have very low recovery in a water flooding process. When there is heterogeneity in the reservoir, the channeling effect would be even worse. 
The simulation results were verified through conservation of fluid volume in the reservoir by the reviewing the output file. For example, at two years of water flooding, the amount of each component in the reservoir was taken from the output file, shown in Table 4.2.

\begin{tabular}{|llccc|}
\hline \multicolumn{4}{|c}{ TABLE 4.2 RESERVOIR FLUID QUANTITIES IN WATER FLOODING } \\
\hline & & Initial Total & Current Total & Net Inj/Prod \\
$\mathrm{H}_{2} \mathrm{O}$ & $(\mathrm{lbmo})$ & $5.65 \mathrm{E}+04$ & $1.05 \mathrm{E}+05$ & $4.87 \mathrm{E}+04$ \\
oil & $(\mathrm{lbmo})$ & $8.51 \mathrm{E}+03$ & $6.66 \mathrm{E}+03$ & $-1.85 \mathrm{E}+03$ \\
emulsion & $(\mathrm{lbmo})$ & $0.00 \mathrm{E}+00$ & $0.00 \mathrm{E}+00$ & $0.00 \mathrm{E}+00$ \\
\hline
\end{tabular}

The "initial total" column indicates the amount of each component in the reser oir at time 0 , and the "current total" column shows the amount of fluid at current time - two ears after water flooding The "net in / rod" s e cifies the difference between the amounts of fluid injected and produced, which is equal to the difference e tween the "current total" and "initial total" for that fluid n our simulation, the densit of both crude oil and emulsion was assigned to be $60 \mathrm{lb} / \mathrm{ft}^{3}$, and the molecular weight for crude oil and emulsion was assumed to be $460 \mathrm{~g} / \mathrm{mol}$ and $300 \mathrm{~g} / \mathrm{mol}$, respectively. By converting the unit from lbmo into bbl, the volume of each fluid component within the reservoir was obtained, shown in Table 4.3. 


\begin{tabular}{|c|c|c|c|c|}
\hline \multicolumn{5}{|c|}{ TABLE 4.3 RESERVOIR FLUID BARRELS IN WATER FLOODING } \\
\hline & & Initial Total & Current Total & Net Inj/Prod \\
\hline $\mathrm{H}_{2} \mathrm{O}$ & (bbl) & $2.92 \mathrm{E}+03$ & $5.43 \mathrm{E}+03$ & $2.52 \mathrm{E}+03$ \\
\hline oil & (bbl) & $1.16 \mathrm{E}+04$ & $9.10 \mathrm{E}+03$ & $-2.52 \mathrm{E}+03$ \\
\hline emulsion & (bbl) & $0.00 \mathrm{E}+00$ & $0.00 \mathrm{E}+00$ & $0.00 \mathrm{E}+00$ \\
\hline
\end{tabular}

The volume increase of water equaled to the volume decrease of oil in the reservoir $(2.52 \mathrm{E}+03 \mathrm{bbl})$. This amount was also equal to the cumulative oil production at two years from the production data shown earlier. Therefore, the conservation of volume in our simulation was verified.

\subsection{Emulsion Flooding}

Before presenting the simulation results of emulsion flooding, some limitations of our simulation need to be discussed. First of all, the emulsion was approximated as a Newtonian fluid of fixed viscosity. In reality, the emulsion would be slightly shearthinning, and its viscosity would decrease as it flows through porous media by breaking out water.

Secondly, the amount of emulsion breakdown was set to be a fixed value in the simulation, and this breakdown was simply treated as co-injection of water - emulsion breakdown was assumed to occur instantaneously and completely at the injection well. In reality, the emulsion breaks down gradually as it travels through the reservoir (although the emulsion breakdown would be the most intense near the wellbore region 
where the emulsion has the highest velocity). This limitation is also related to the first one mentioned above, as the emulsion breakdown has effect on the rheological behavior of the emulsion phase itself. Because the proceeding rate of the injected fluid is very slow (except near the wellbore region) in emulsion flooding, and given the high horizontal permeability in the simulated reservoir, the amount of emulsion breakdown is likely to stay very low and the assumptions should not be too far from reality. In fact, sensitivity analyses on emulsion viscosity and amount of water breakout conducted later were intended to partially resolve the two limitations mentioned above.

Thirdly, the mixing between the oil and emulsion was not controlled in our simulation. In STARS, fluid flow is simulated based on its phase. Since both oil and emulsion were set to e "oleic" in our simulation, the would mo e together arc 's law with the oil phase flow. Also the two components were fully mixed in each grid lock following linear mi ing rule $\left.\ln \mu_{\mathrm{o}}=\Sigma_{\mathrm{i}}\left[\mathrm{x}_{\mathrm{i}} \cdot \ln \mu_{\mathrm{oi}}\right)\right]$. In reality, the two components do not necessarily mix in such a way. With those limitations discussed, the simulation conditions and results for emulsion flooding are presented and compared with the base case of water flooding in the followings. 


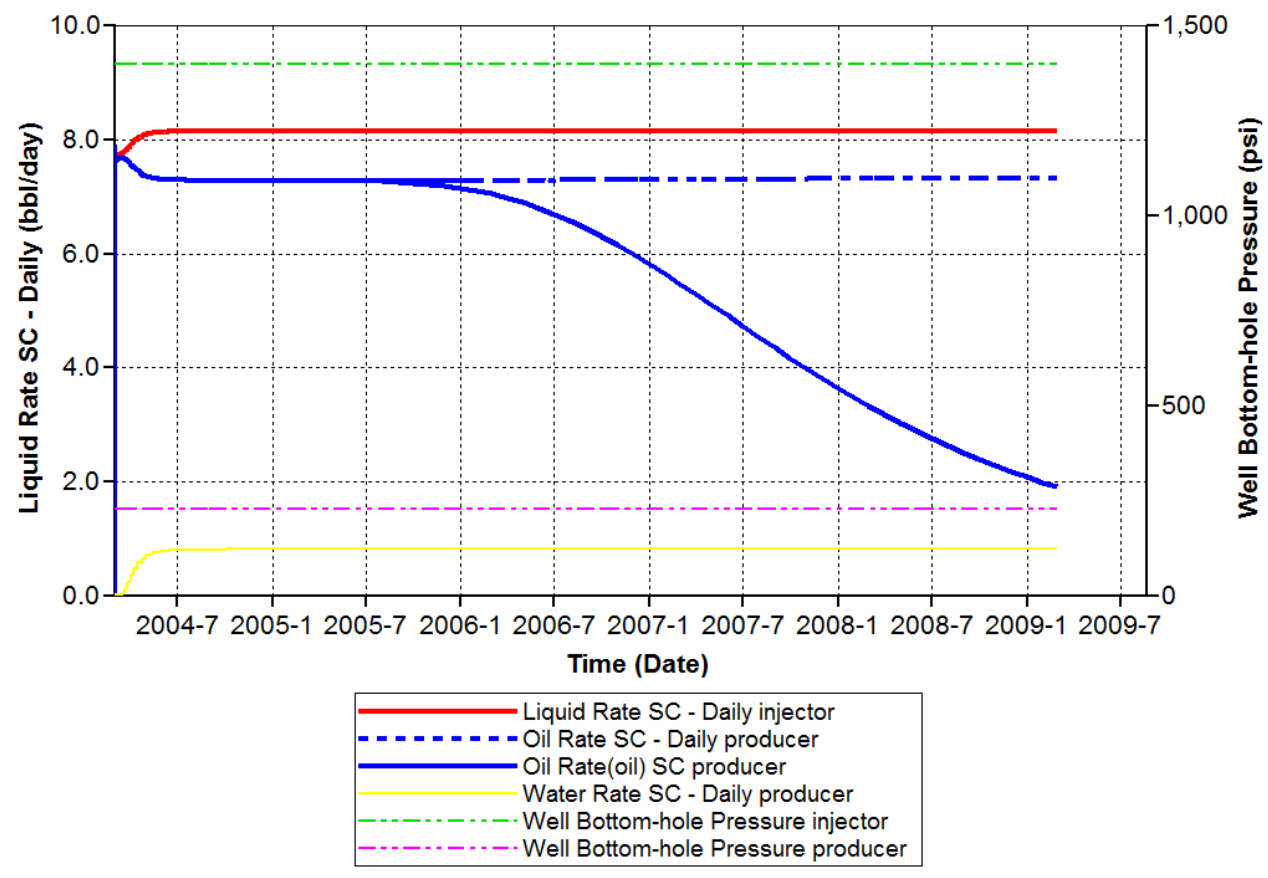

Fig. 4.7- Liquid rates and well BHPs in emulsion flooding.

The BHP and fluid rates of the production and injection wells are shown in Figure 4.7. Different from the water flooding case, the injection pressure remained constant at 1400 psi through the emulsion flooding, as the liquid injection rate always remained under the rate limit $50 \mathrm{bbl} / \mathrm{d}$. The liquid injection rate included $90 \%$ of emulsion, which was simply treated as an oil phase, and $10 \%$ water, which was included to emulate the water breakout from the emulsion. The emulsion had a viscosity of 1000 cp in this case.

For the daily oil rate of production curves shown in blue, the dashed line indicates the total rate of crude oil and emulsion, while the solid curve indicates the rate of crude oil. At the beginning of emulsion flooding, only crude oil was produced in the 
oil phase. After 2 years of flooding, breakthrough of emulsion was observed in the production well, shown as a separation of the two blue curves. The difference between the two curves was the production rate of the emulsion. Because of the operation cost and possible difficulties in separating the emulsion from crude, the emulsion flooding project may be terminated between 2 to 4 years after the starting of project. During the process, water production rate quickly reached $0.8 \mathrm{bbl} / \mathrm{d}$ and remained constant through the rest of emulsion flooding. This injected water had little effect on the oil phase flow after its breakthrough and was steadily produced at the production well - the viscosity of water is very low compared to the oil phase.

The oil production rate in emulsion flooding was compared with that in water flooding, shown in Figure 4.8. In water flooding, the oil production rate peaked around 10 14 bbl/d for the beginning 3 4 months, while in the emulsion flooding case, the oil production maintained a stable rate of $7 \sim 8 \mathrm{bbl} / \mathrm{d}$ for about 2 years. Although the emulsion has much higher viscosity than water, which in turn would lead to much lower injectivity and thus lower liquid production, the maximum oil production was not dramatically different for the two cases. This is because the oil production rate is controlled by both the viscosity of the injected fluid and the crude oil in place. 


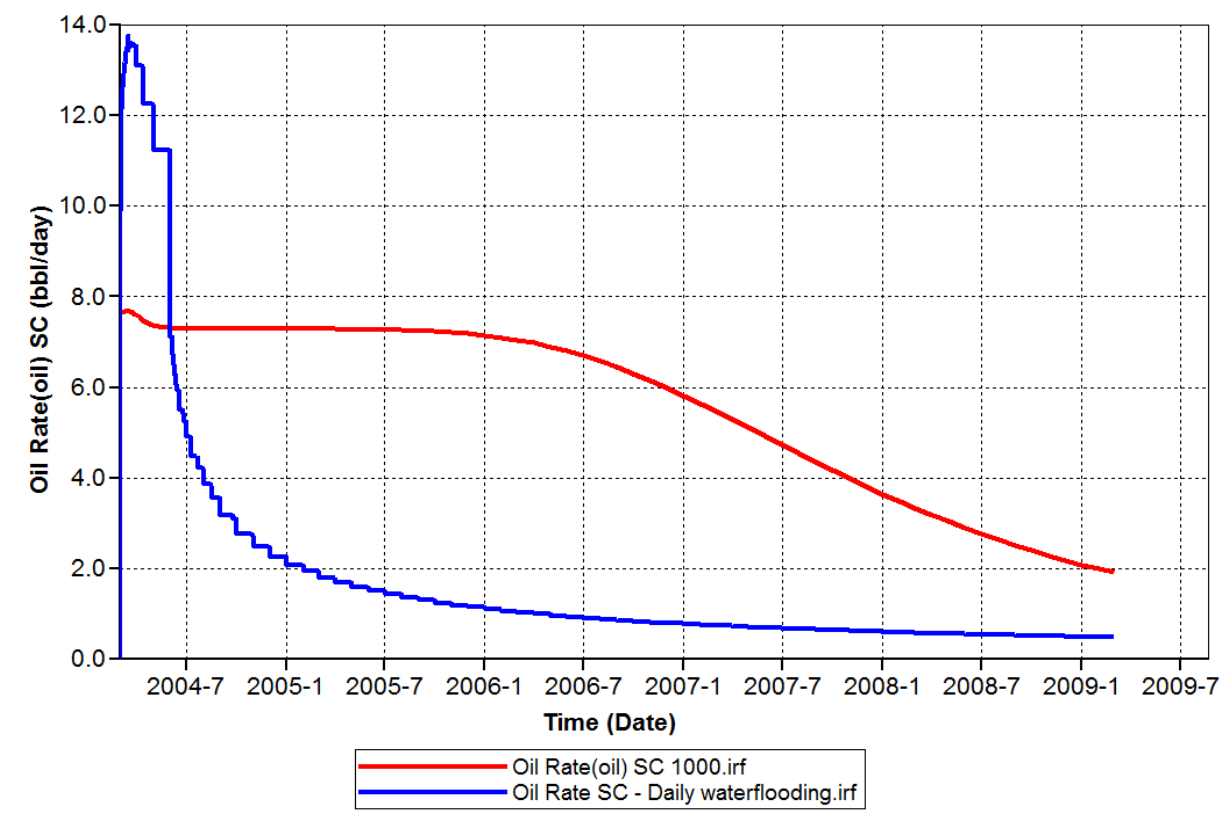

Fig. 4.8 - Comparison between emulsion flooding and water flooding: oil production rate.

The liquid injection rate in emulsion flooding was also compared with that in water flooding, shown in Figure 4.9. Although given the same operation constraints, the liquid injection rate in water flooding exceeded that in emulsion flooding greatly, due to high injectivity of water. Water Cut in emulsion flooding was also compared with that in water flooding, shown in Figure 4.10. The water cut in water flooding was greatly higher than that in emulsion flooding. 


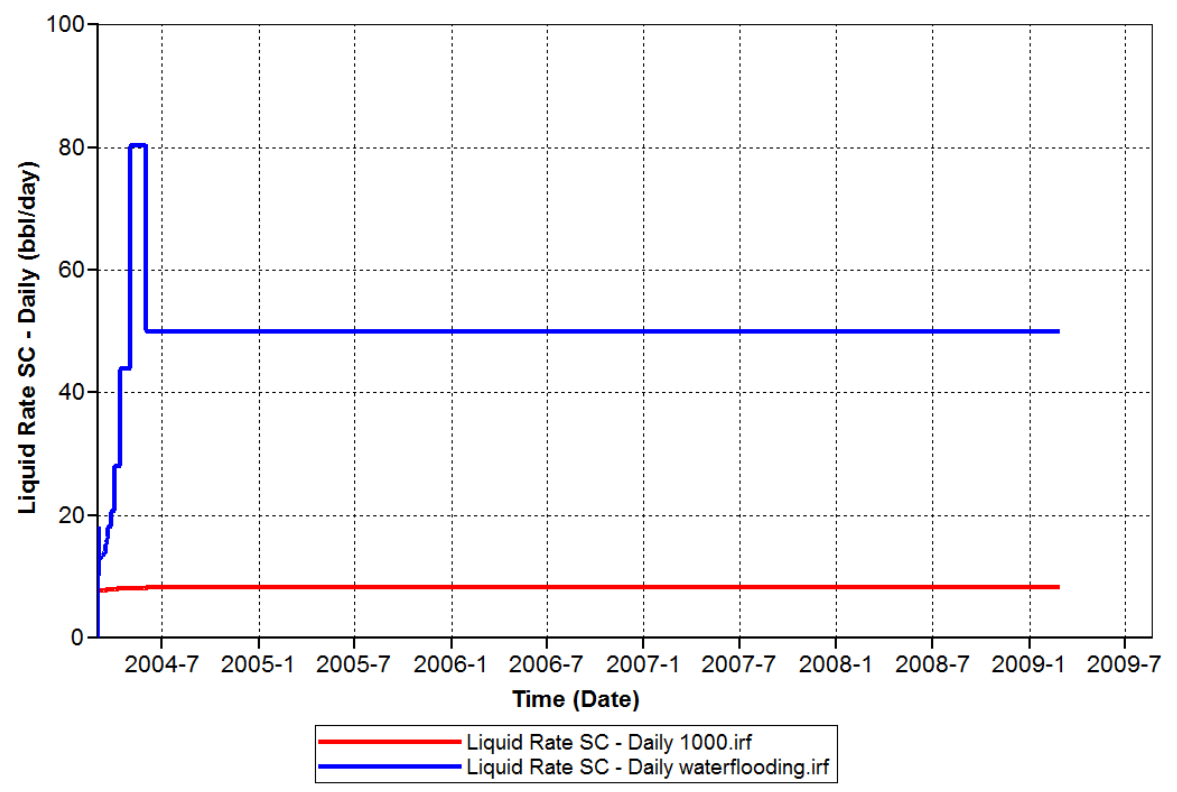

Fig. 4.9- Comparison between emulsion flooding and water flooding: liquid injection rate.

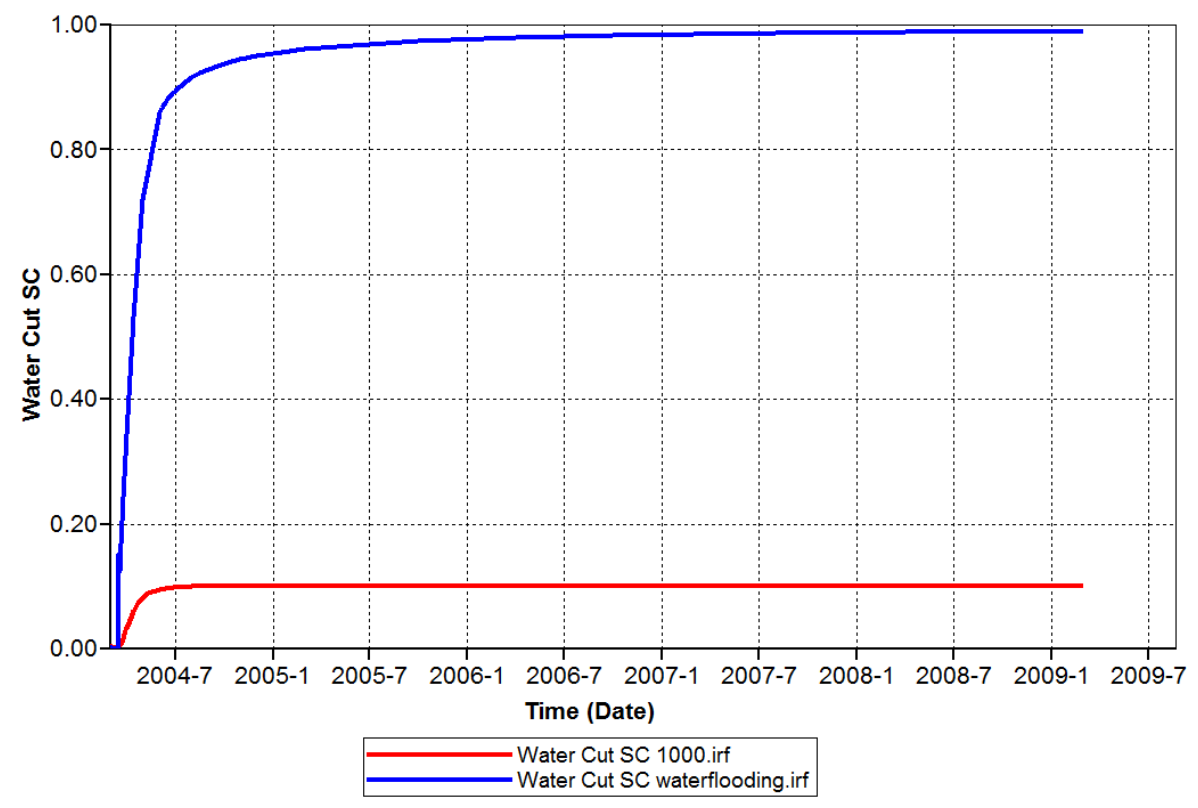

Fig. 4.10 - Comparison between emulsion flooding and water flooding: water cut. 
Cumulative oil production in emulsion flooding was also compared with that in water flooding, shown in Figure 4.11. Due to higher oil rates at the beginning, cumulative oil production in water flooding exceeded that in emulsion flooding during the first 8 months. However, after 8 months, the cumulative oil production curve for emulsion flooding increased steadily, while the curve for water flooding flattened. Within 2 years of production, the cumulative oil in emulsion flooding had doubled the amount in water flooding. Toward the end of simulation, the cumulative oil production in emulsion flooding had quadrupled the amount in water flooding.

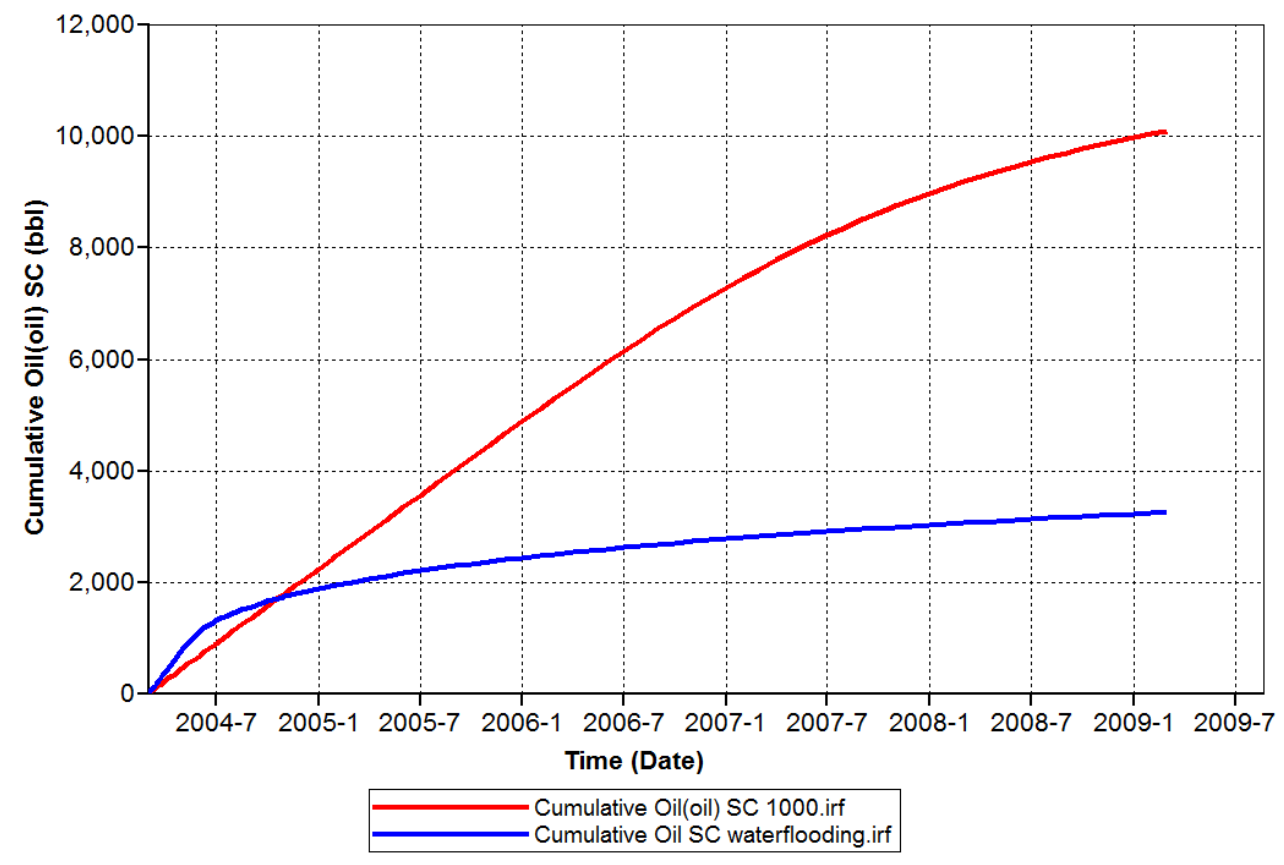

Fig. 4.11- Comparison between emulsion flooding and water flooding: cumulative oil production. 
Oil recovery performance in emulsion flooding was also compared with that in water flooding, shown in Figure 4.12. At unit pore volume of emulsion injection, the cumulative fractional oil recovery was over $85 \%$. This value was over five times of the cumulative fractional oil recovery at unit pore volume of fluid injection in water flooding.

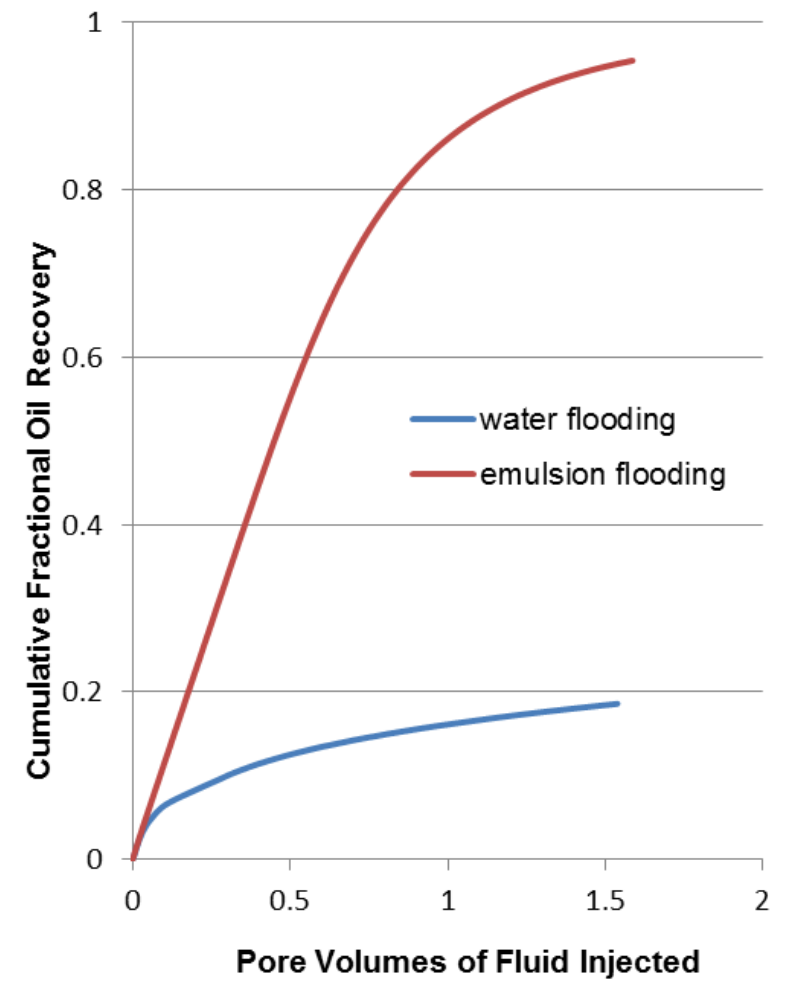

Fig. 4.12- Comparison between emulsion flooding and water flooding: oil recovery performance. 
To better illustrate the flood pattern of emulsion flooding, a 3D view of the crude oil fraction after two years is shown in Figure 4.13. The emulsion displaced the heavy crude uniformly with a stable front. The miscibility between emulsion and heavy oil caused almost 0 crude oil fraction in the emulsion flooded zone. The flood pattern in emulsion flooding is close to piston-like, and is very different from the displacement pattern in water flooding shown in Figure 4.6. Because the density of both crude oil and emulsion was set to be $60 \mathrm{lb} / \mathrm{ft}^{3}$, no gravity segregation was observed in the simulation results. The density of $60 \mathrm{lb} / \mathrm{ft}^{3}$ for emulsion was directly obtained from experimental measurements, while the crude oil density could be flexible depending on the reservoir. If the density were different between the oil and emulsion, the displacing front would be less uniform and the recovery performance would be slightly worse.

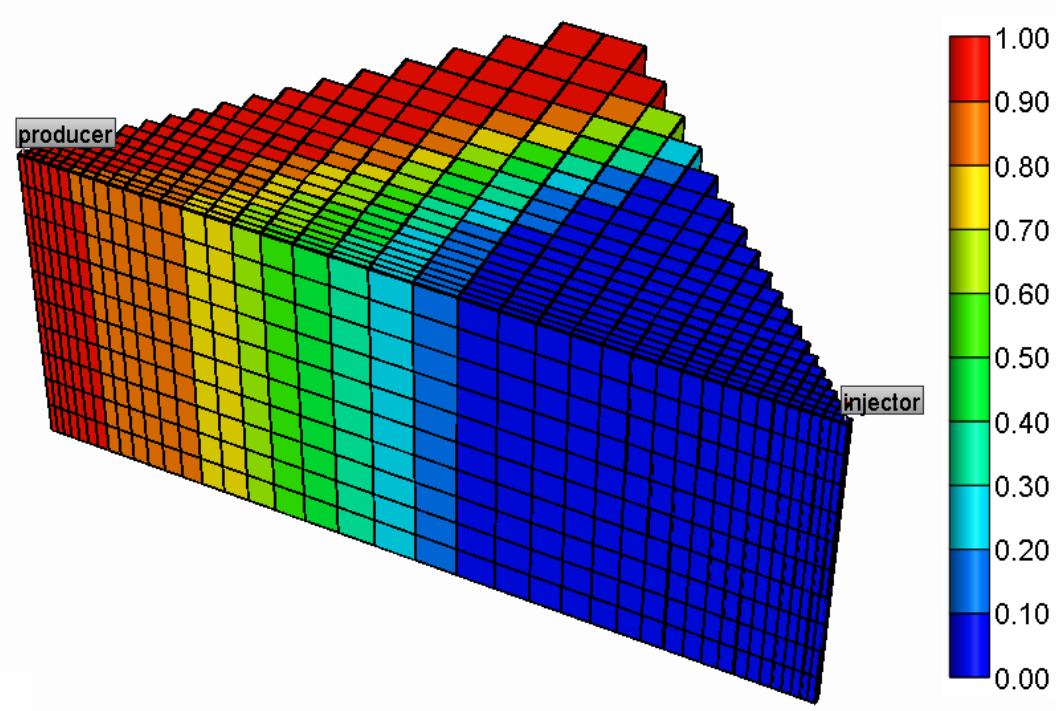

Fig. 4.13 - Crude oil fraction after two years in emulsion flooding. 
Similar to the water flooding case, the simulation results of emulsion flooding were verified through conservation of fluid volume in the reservoir by the reviewing the output file. For example, at two years of emulsion flooding, the amount of each component in the reservoir was taken from the output file, shown in Table 4.4.

\begin{tabular}{|c|c|c|c|c|}
\hline & & Initial Total & Current Total & Net Inj/Prod \\
\hline $\mathrm{H}_{2} \mathrm{O}$ & (lbmo) & $5.65 \mathrm{E}+04$ & $5.71 \mathrm{E}+04$ & $6.25 \mathrm{E}+02$ \\
\hline oil & (lbmo) & $8.51 \mathrm{E}+03$ & $4.59 \mathrm{E}+03$ & $-3.91 E+03$ \\
\hline emulsion & (lbmo) & $0.00 \mathrm{E}+00$ & $5.97 \mathrm{E}+03$ & $5.97 \mathrm{E}+03$ \\
\hline
\end{tabular}

By taking into account of the molecular weight and the density of each component, the unit was converted from lbmo into bbl so that the volume of each fluid within the reservoir was obtained, shown in Table 4.5.

\begin{tabular}{|c|c|c|c|c|}
\hline \multicolumn{5}{|c|}{ TABLE 4.5 RESERVOIR FLUID BARRELS IN EMULSION FLOODING } \\
\hline & & Initial Total & Current Total & Net Inj/Prod \\
\hline $\mathrm{H}_{2} \mathrm{O}$ & (bbl) & $2.92 \mathrm{E}+03$ & $2.95 \mathrm{E}+03$ & $3.23 \mathrm{E}+01$ \\
\hline oil & (bbl) & $1.16 \mathrm{E}+04$ & $6.28 \mathrm{E}+03$ & $-5.34 \mathrm{E}+03$ \\
\hline emulsion & (bbl) & $0.00 \mathrm{E}+00$ & $5.32 \mathrm{E}+03$ & $5.32 \mathrm{E}+03$ \\
\hline
\end{tabular}


The volume increase of emulsion $(5.32 \mathrm{E}+03 \mathrm{bbl})$ and water $(3.23 \mathrm{E}+01 \mathrm{bbl})$ equaled to the volume decrease of oil in the reservoir $(5.34 \mathrm{E}+03 \mathrm{bbl})$. This amount was also equal to the cumulative oil production at two years of emulsion flooding from the production data shown earlier. Therefore, the conservation of volume was verified. Also to be noticed, the amount of water accumulated in the reservoir was two orders of magnitude smaller than that of emulsion, due to its much higher mobility in the reservoir. This on the other hand indicates that almost all the crude oil recovered was due to displacement by emulsion although water co-injection constituted $10 \%$ of the total fluid injected.

\subsection{Sensitivity Analyses}

Several parameters were chosen to conduct sensitivity analyses, including emulsion viscosity, water breakout fraction, heavy oil viscosity, reservoir porosity and permeability.

\subsubsection{Emulsion Viscosity}

Because the emulsion viscosity is sensitive to its water fraction, different viscosities can be achieved by adjusting the water oil ratio in the emulsion. Also during the process of flowing through the reservoir, the emulsion may lose some of its original viscosity. Therefore it is useful to simulate the emulsion flooding process with different emulsion viscosities. Four different values: $200 \mathrm{cp}, 500 \mathrm{cp}, 1000 \mathrm{cp}$ and $2000 \mathrm{cp}$ were 
used in our simulations to cover the viscosity range observed in coreflood experiments. All other parameters were set as defaults listed in Table 4.1.

Figure 4.14 indicates the oil production rates for emulsion flooding under different emulsion viscosities. The oil rates from water flooding were also plotted in this figure for comparison. All the curves from emulsion flooding had a long period of high production rates followed by relatively smooth declines, while the curve for water flooding peaked at the beginning for only a few months and then had a sharp decline. Among the four different emulsion flooding cases, the lowest viscosity of $200 \mathrm{cp}$ resulted in the highest oil rate, but also had the earliest emulsion breakthrough and oil rate decline.

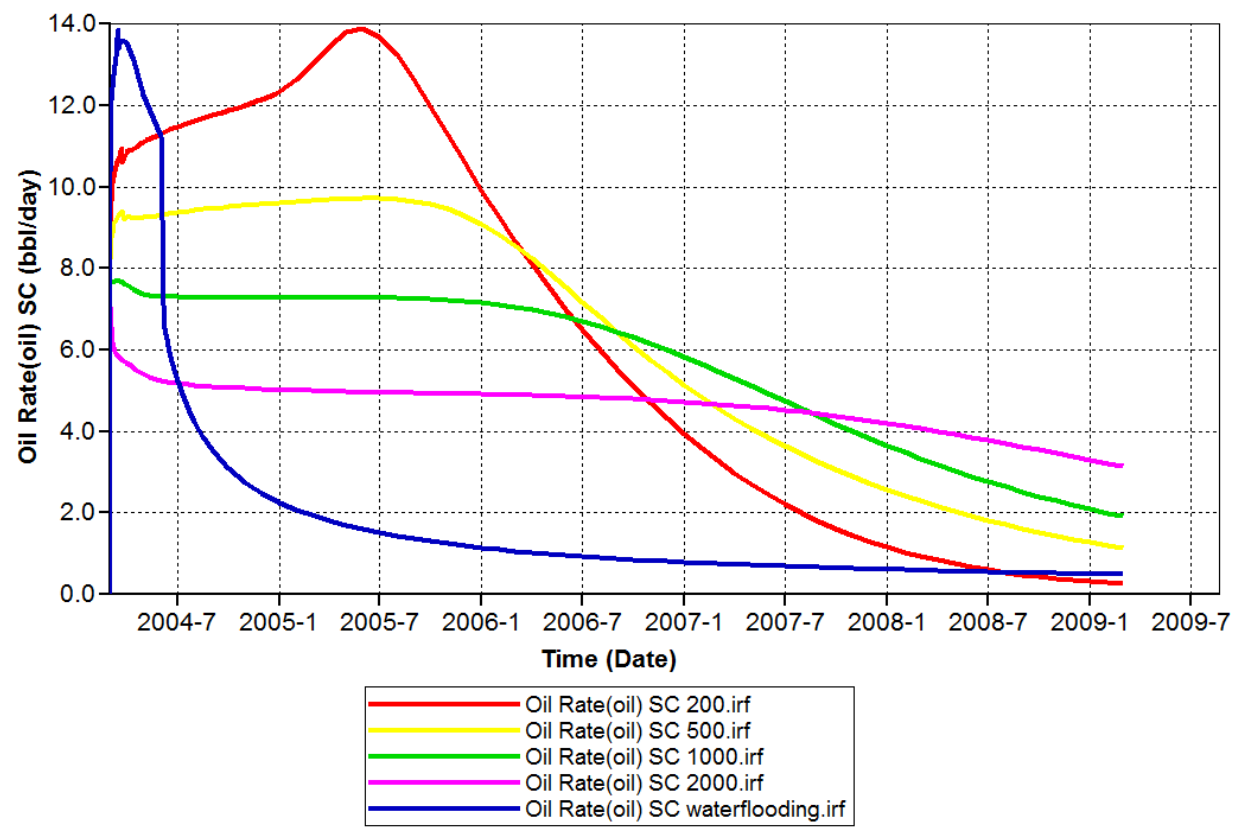

Fig. 4.14- Oil production rates under different emulsion viscosities. 


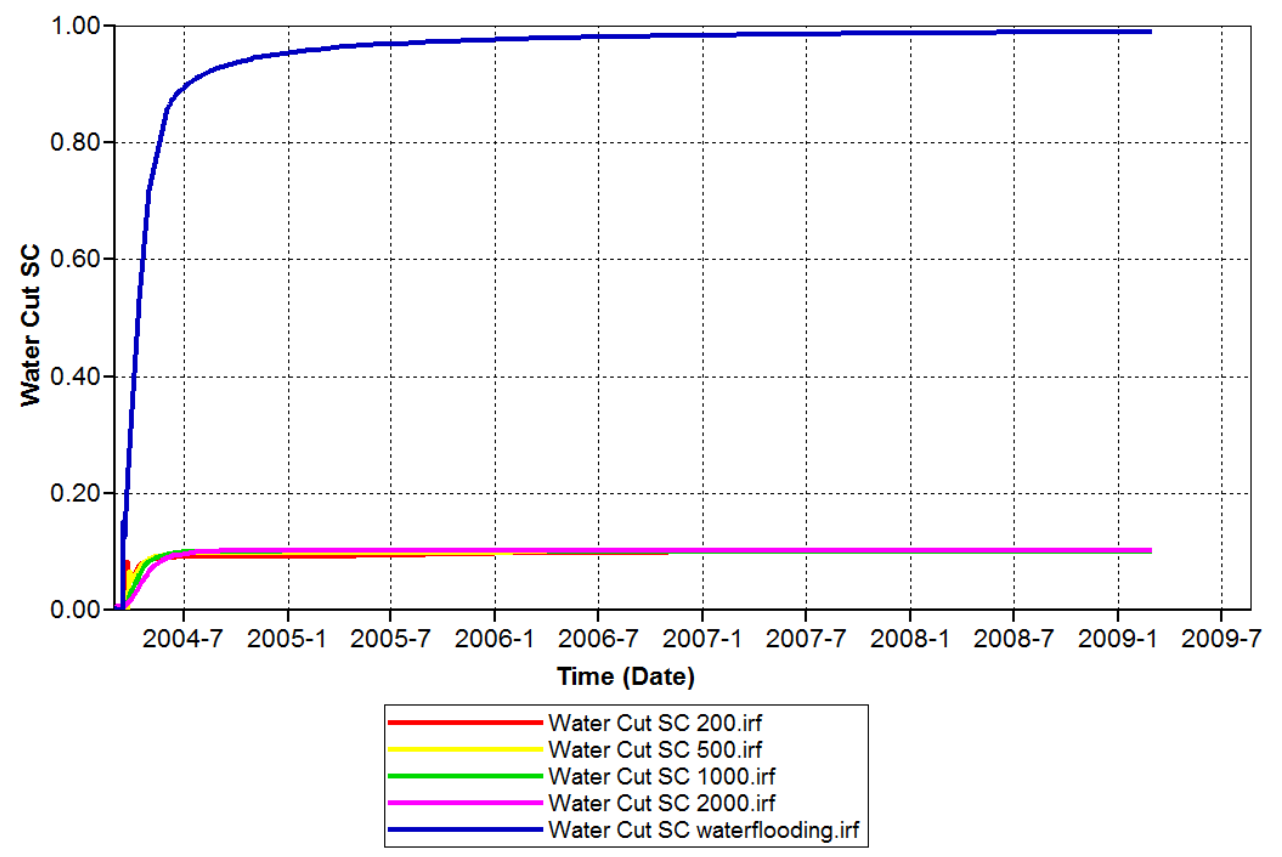

Fig. 4.15- Water cut under different emulsion viscosities.

The water cut in the produced liquids for all the simulation cases as well as water flooding are shown in Figure 4.15. Compared to the high water cut in the water flooding case, all the emulsion flooding cases were very similar in water cut - the four curves almost overlapped from this figure. 


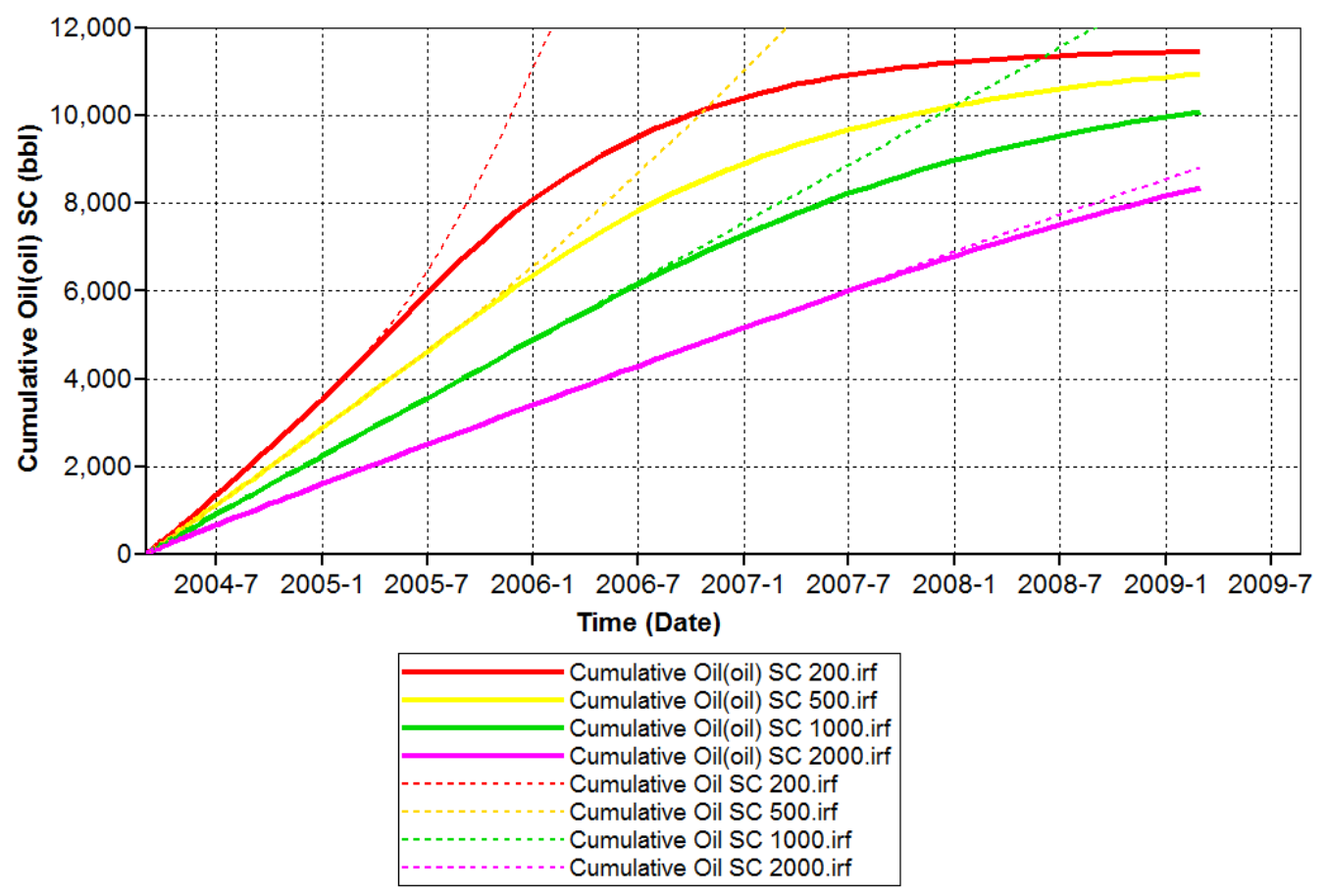

Fig. 4.16- Cumulative oil productions under different emulsion viscosities.

The cumulative oil productions under different emulsion viscosities were also compared, shown in Figure 4.16. The fine dashed lines indicate the total oil (phase) rate from the production well, including the emulsion. Therefore the points that the solid curves separate from the dashed lines are the points where emulsion broke through. As seem from this figure, the highest cumulative oil production curve corresponded to the lowest emulsion viscosity $-200 \mathrm{cp}$. However, the $200 \mathrm{cp}$ case had the lowest cumulative oil production at emulsion breakthrough. The project should be terminated not long after emulsion breakthrough because of lower displacement efficiencies afterwards and technical difficulties in separating crude oil. Although the lower emulsion viscosities 
lead to higher rates of oil production, the displacement pattern was somewhat less favorable, due to less mobility control. An optimum emulsion viscosity should be targeting the crude oil viscosity and not too far below.

\subsubsection{Emulsion Breakdown}

The emulsion will break down to some extent flowing in porous media, especially in tighter reservoirs. As mentioned before, the highest shear in the reservoir were experienced near wellbore, therefore co-injection of water was applied to simulate the emulsion breakdown. To study the effect of the extent of emulsion breakdown, four values for free water breakout were chosen: $5 \%, 10 \%, 20 \%$ and $60 \%$. The first three values were reasonable expectations obtained from coreflood experiments, and the $60 \%$ was included to indicate the maximum amount of water breakout possible since the emulsion itself contained $60 \%$ water. All other parameters were set as default values.

Figure 4.17 shows the liquid injection rates and oil production rates at different water breakout percentages from emulsion. As the water co-injection percentage (water breakout) increased, the total liquid injectivity also increased, consequently the highest water breakout resulted in the highest liquid rates of injection. However, the oil production rates were very similar among these four cases. 


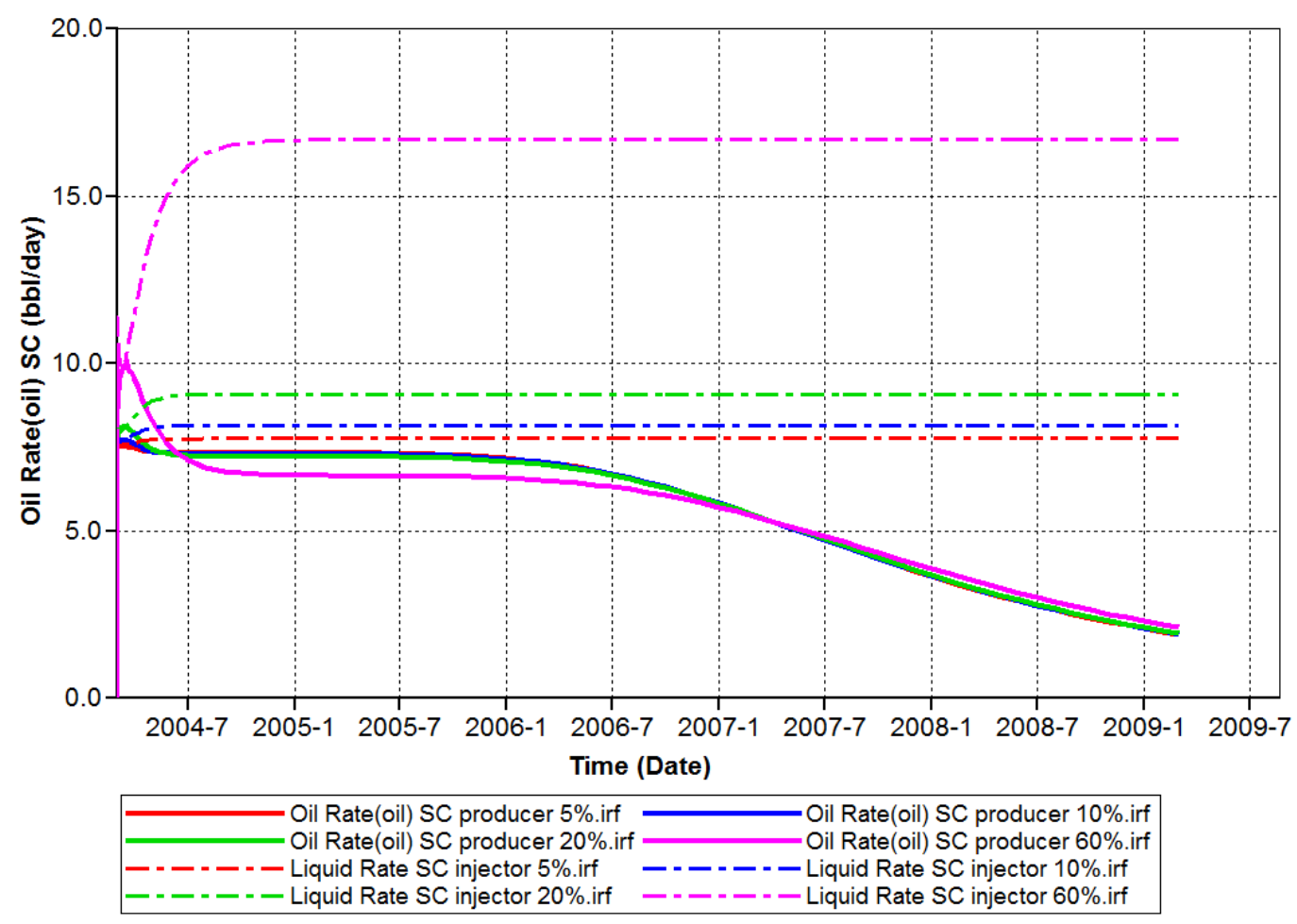

Fig. 4.17- Injection and production rates at different emulsion breakdown.

Figure 4.18 indicates the water cut values in the produced fluid. Water cut in the producer soon equaled the water cut from the injector, and remained stable through the emulsion flooding process. Therefore, the amount of free water breakout had little effect on crude oil production, only resulting different amount of water production. With the target emulsion viscosity maintained, the lower the emulsion breakdown, the more efficient the process is. However, the emulsion viscosity is highly dependent on the amount of water breakout form the emulsion, especially for cases with high water breakouts. The purpose of conducting sensitivity analyses on water breakout here was to 
simply illustrate the insignificant effect of water co-injection in terms of oil recovery, and did not consider the viscosity dependence on water breakout.

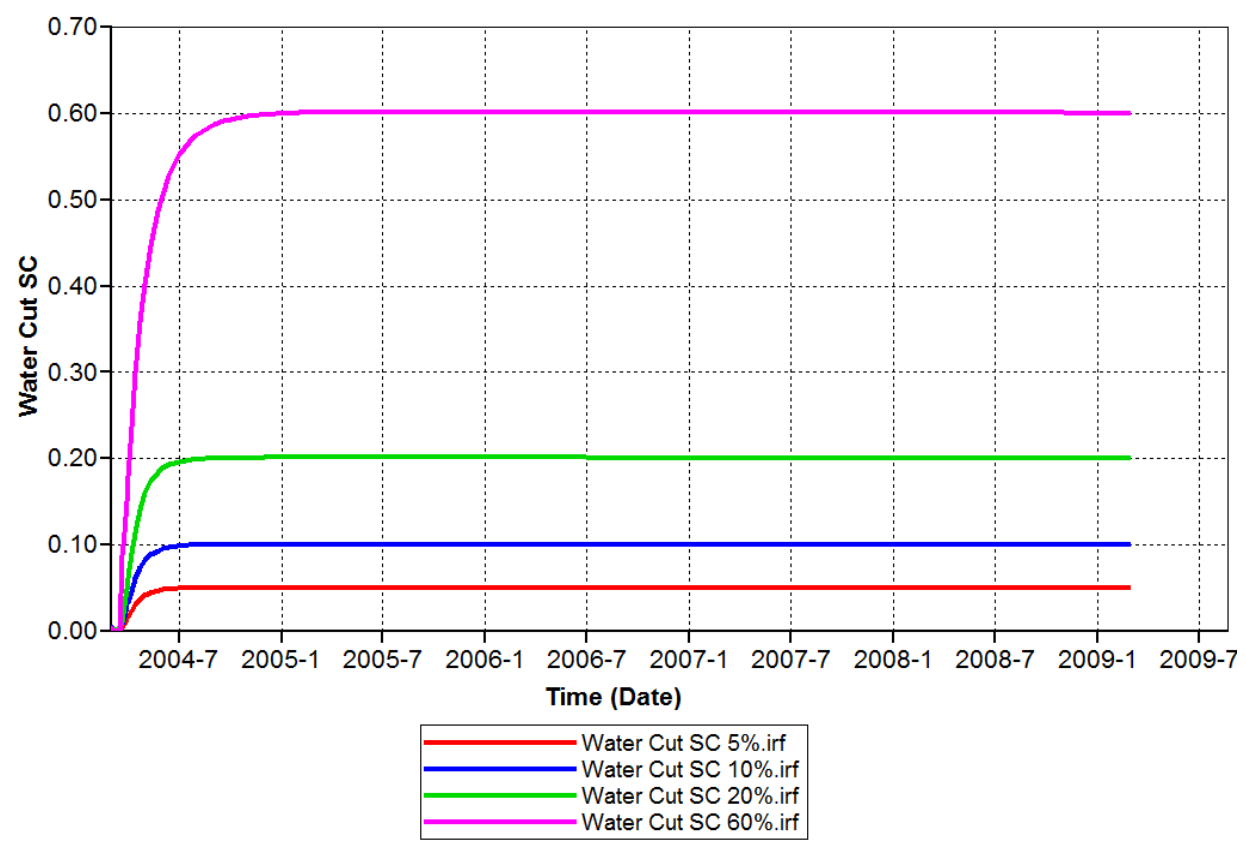

Fig. 4.18 - Water cut in the produced fluids at different emulsion breakdown.

\subsubsection{Crude Oil Viscosity}

The viscosity of crude oil in the reservoir would affect its production significantly. Here we studied several emulsion flooding cases with different crude oil viscosity values: $200 \mathrm{cp}, 500 \mathrm{cp}, 1000 \mathrm{cp}$ and $2000 \mathrm{cp}$. All other parameters were set as default values from Table 4.1. 


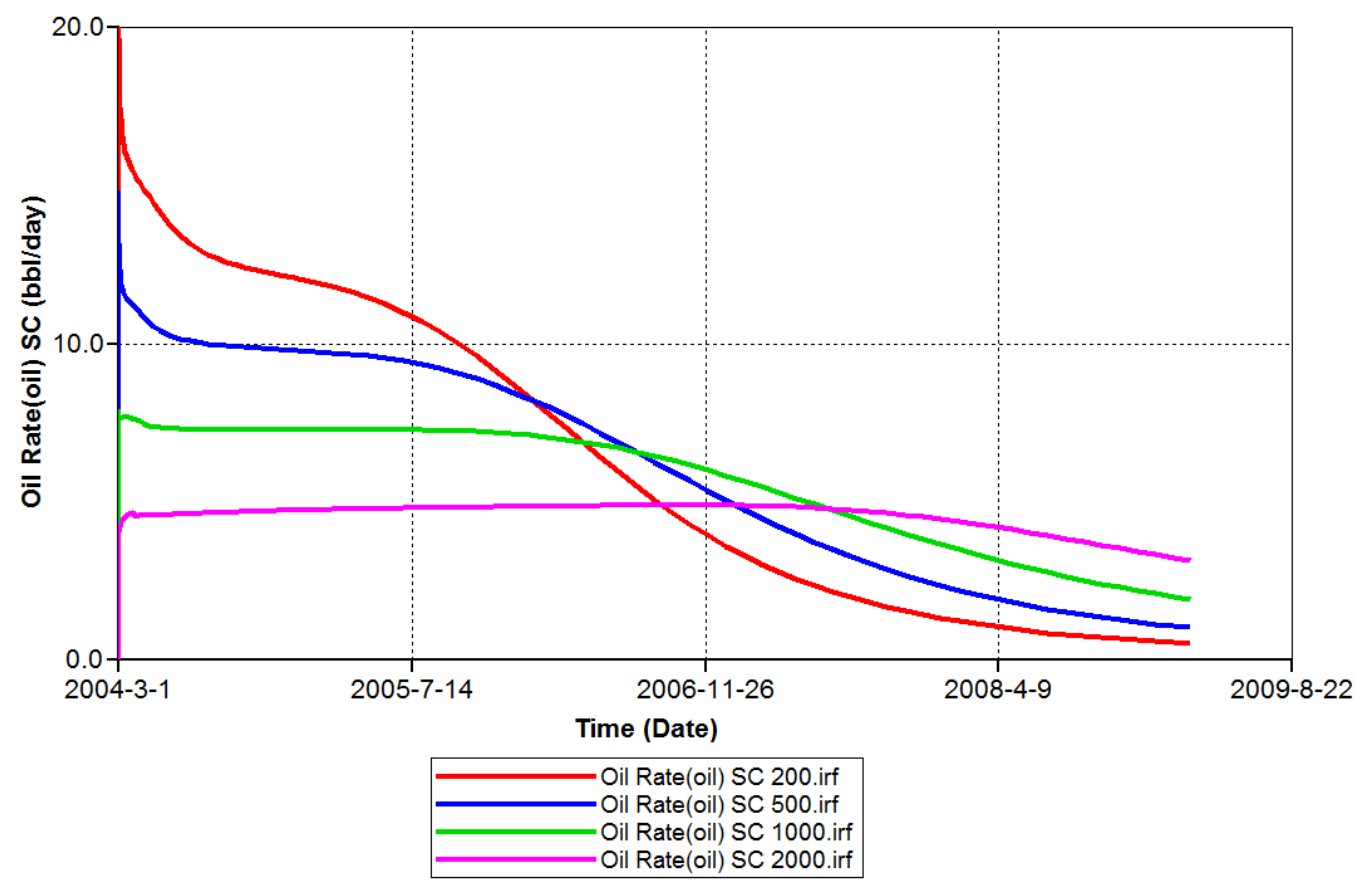

Fig. 4.19- Oil production rates for reservoirs with different crude oil viscosities.

Figure 4.19 indicates the oil production rates for all four cases: the lower the reservoir oil viscosity, the higher the production rate. The lowest viscosity case corresponded to the earliest decline, because of its earliest reservoir depletion. Actually for the two lowest crude oil viscosity cases, the emulsion viscosity which was set to be $1000 \mathrm{cp}$, was not an optimal choice. The drive fluid viscosity should be targeting the viscosity of fluid to be displaced and not go too far above. If the emulsion viscosities were given similar values to the crude viscosities, the oil rates for the $200 \mathrm{cp}$ and $500 \mathrm{cp}$ cases would be even higher. 
For the two highest crude oil viscosity cases, the oil production rates from the $1000 \mathrm{cp}$ oil reservoir did not quite double that from the $2000 \mathrm{cp}$ oil reservoir, because of the same viscosity of emulsion during injection. For high oil viscosity reservoirs, it might be a good idea to inject emulsions that are somewhat less viscous, in order to obtain reasonably high production rates.

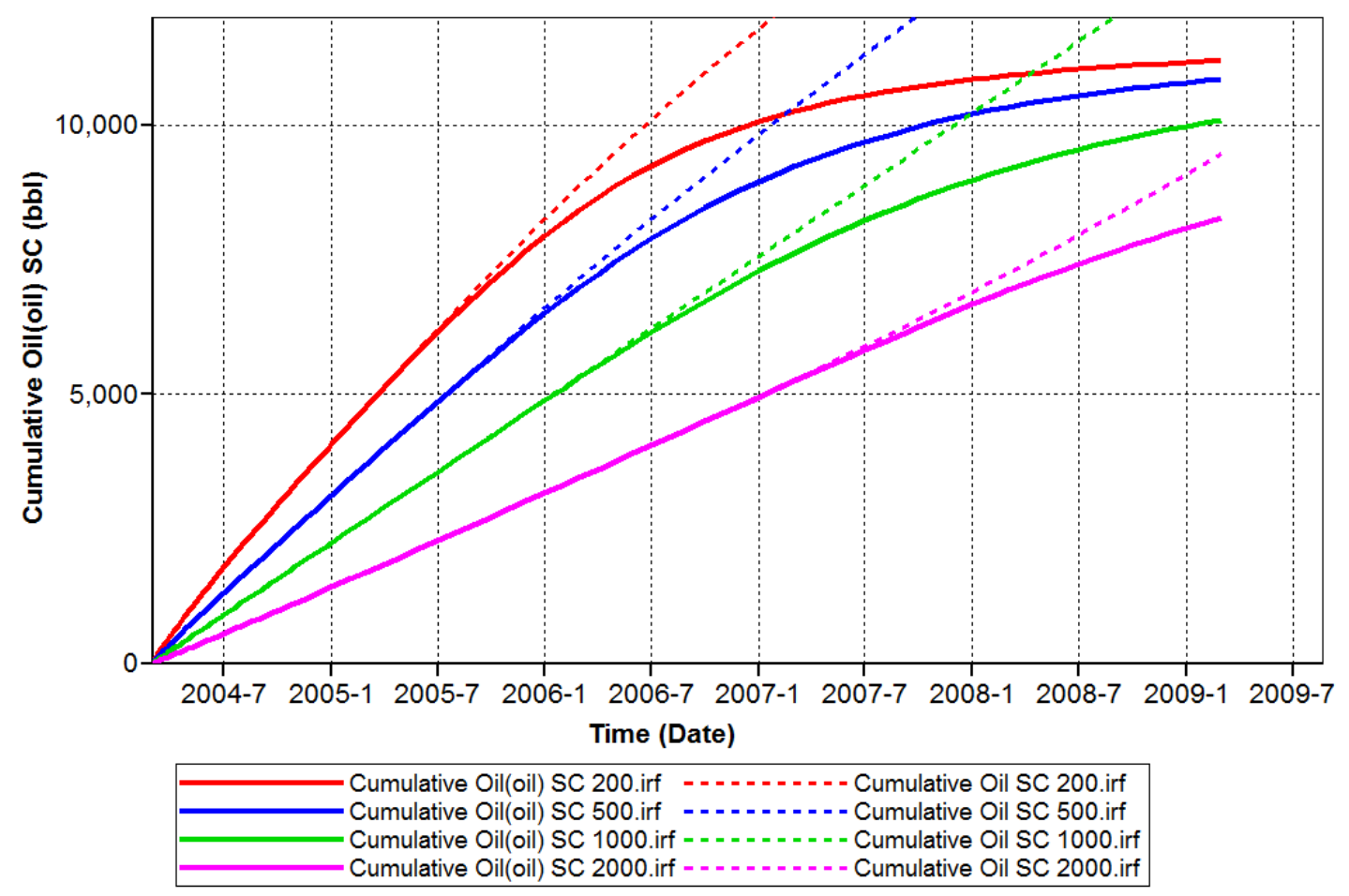

Fig. 4.20- Cumulative oil productions for reservoirs with different crude oil viscosities. 
The cumulative oil productions for the four cases were also compared, shown in Figure 4.20. The highest cumulative oil production corresponded to the lowest reservoir oil viscosity. This figure had similar trend to Figure 4.16, but in this figure, the lowest reservoir oil viscosity also lead to the highest cumulative oil production at emulsion breakthrough (the points where the solid lines separated from the dotted lines), because there was the most sufficient mobility control for the lowest crude oil viscosity case, given the same drive fluid.

\subsubsection{Reservoir Porosity}

To study the effect of reservoir porosity on emulsion flooding performance, three porosity values were chosen: $0.2,0.3$ and 0.4 . All other parameters were kept as default values.

The daily production and cumulative production of crude oil for these three conditions are shown in Figure 4.21 and Figure 4.22, respectively. In Figure 4.21, the three curves almost overlapped during the first one or two years, but resulted in the earliest decline for the lowest porosity case. In Figure 4.22, the same cumulative oil production was observed at the beginning one or two years, but the case with the lowest porosity corresponded to the lowest cumulative oil production toward the end of simulation. Different reservoir porosity caused little difference in the early oil production profiles, but the lowest porosity reservoir contained the least OOIP, thus lead to the earliest depletion of reservoir. 


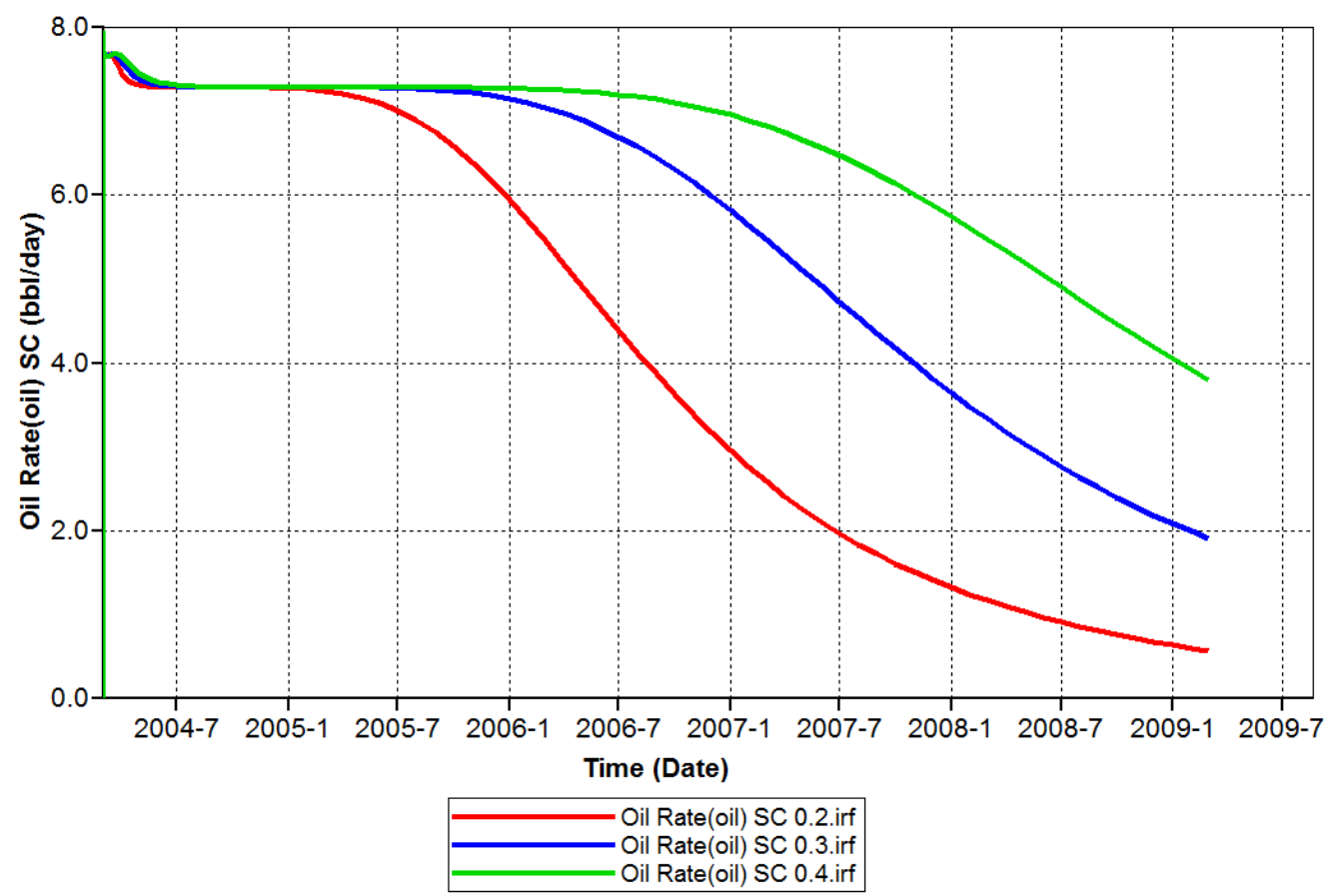

Fig. 4.21- Oil production rates for reservoirs with different porosities. 


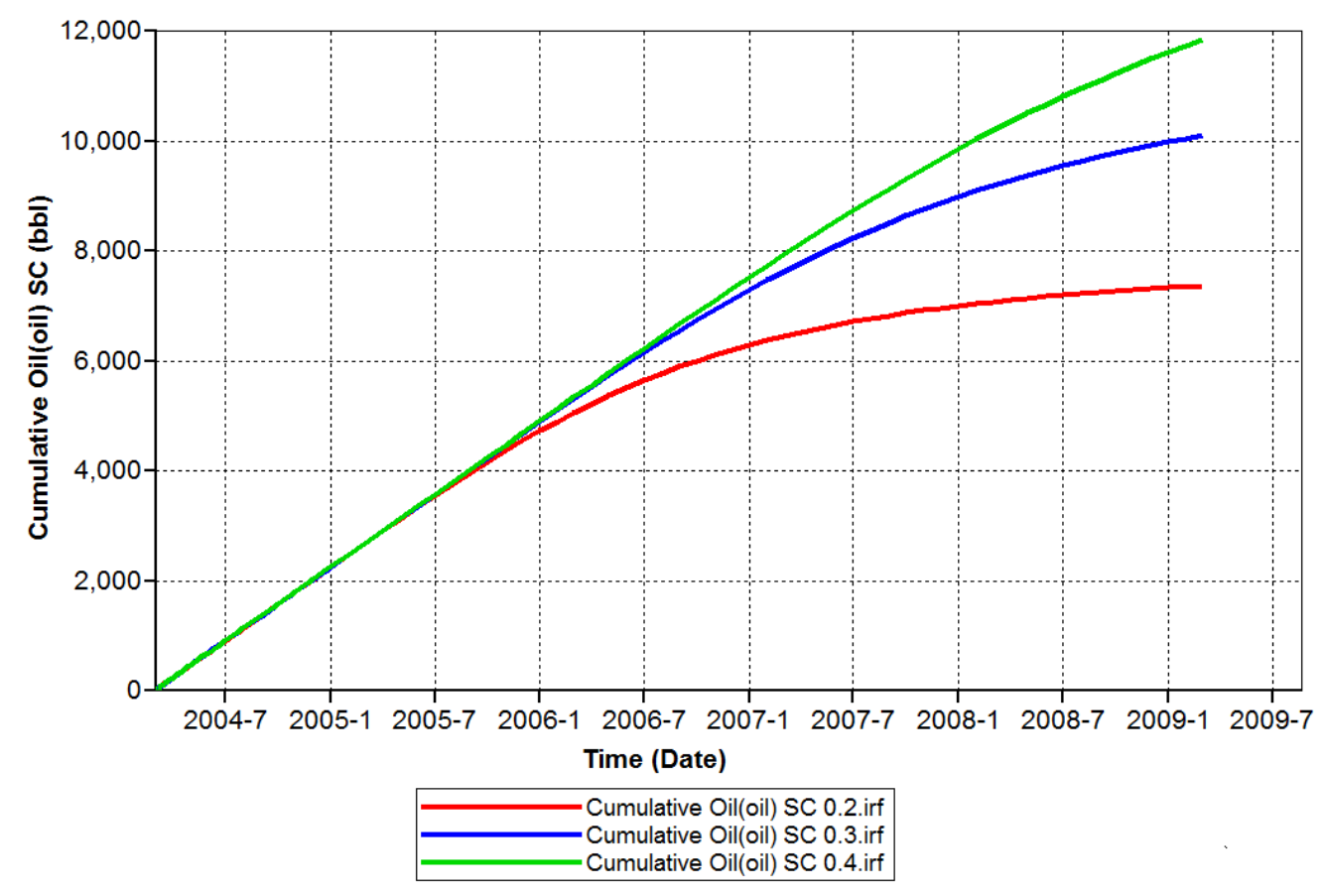

Fig. 4.22 - Cumulative oil productions for reservoirs with different porosities.

\subsubsection{Reservoir Permeability}

To study the effect of reservoir permeability on emulsion flooding performance, three horizontal permeability values were chosen: $2500 \mathrm{md}, 5000 \mathrm{md}$ and $8000 \mathrm{md}$. The vertical permeability was kept to be $1 / 10$ of the horizontal permeability for all three cases. All other parameters were kept as default values shown in Table 4.1. The daily productions of crude oil for these three conditions are shown in Figure 4.23. The oil production rate was roughly proportional to the reservoir permeability until emulsion breakthrough. After emulsion breakthrough, the total produced oil (oil phase including emulsion) would remain constant, but the crude oil production started to drop, shown as a decline in the curves. 


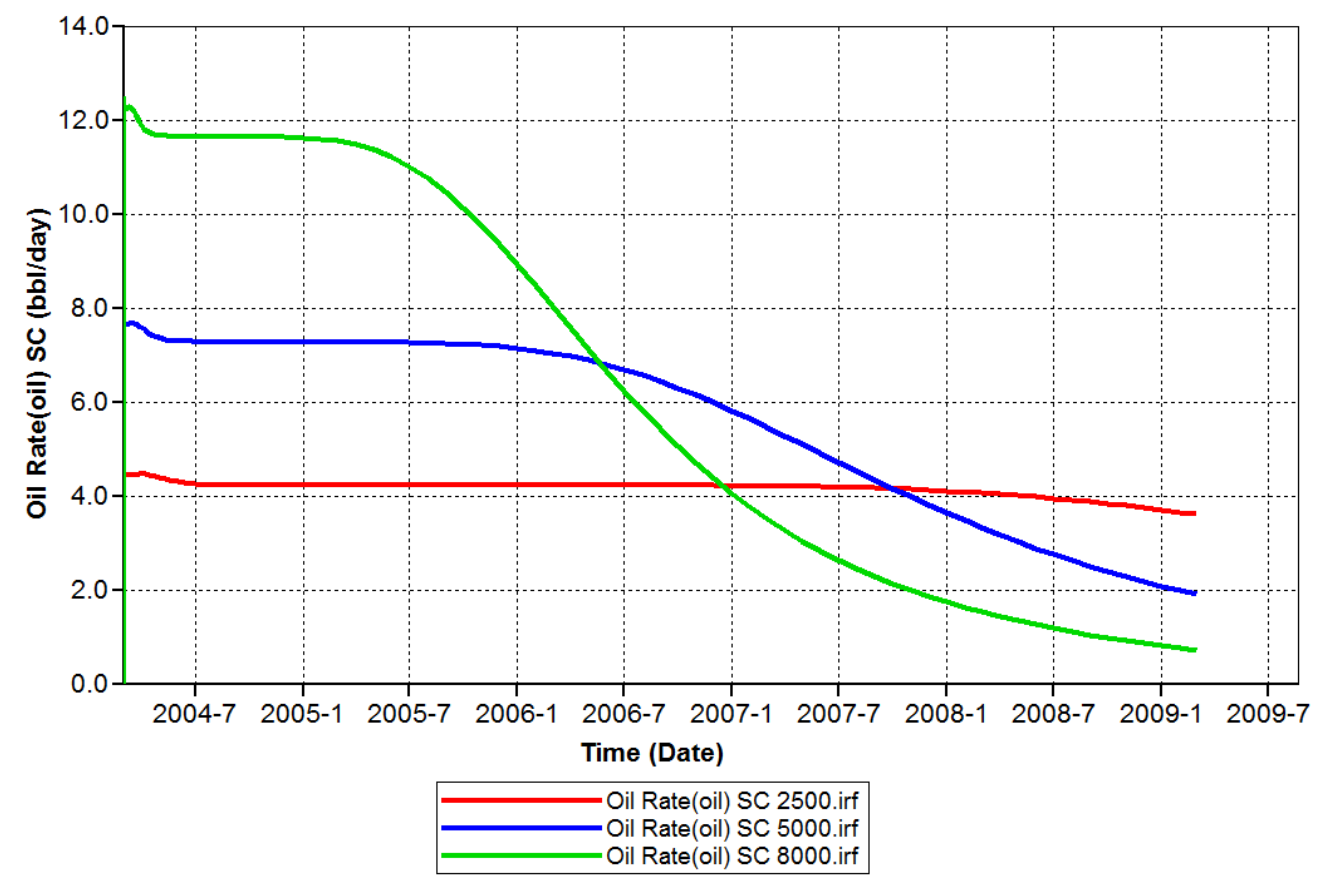

Fig. 4.23- Oil production rates for reservoirs with different permeabilities.

The cumulative oil productions of crude oil for the three reservoir permeability conditions are shown in Figure 4.24. The dashed lines indicate total oil production (both crude oil emulsion) and the solid curves are crude oil only. Although crude oil was produced at different rates, the cumulative productions reached very similar values at emulsion breakthrough, since all these three cases had the same OOIP and their displacement patterns were very similar. 


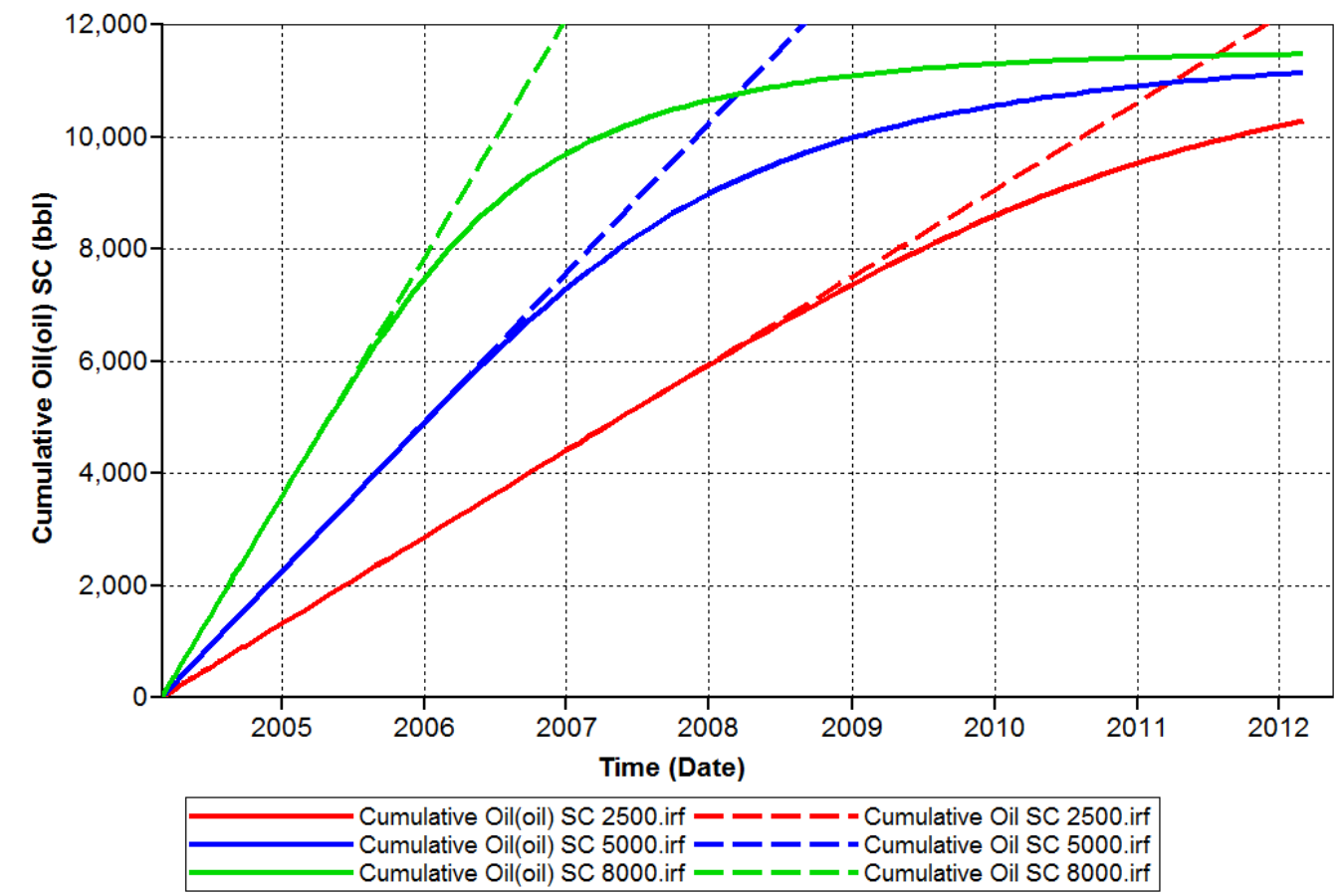

Fig. 4.24-Cumulative oil productions for reservoirs with different permeabilities.

\subsection{Emulsion Flooding in a Water-flooded Reservoir}

To find out the possibility of emulsion flooding a water-flooded reservoir, the reservoir was first operated under water flooding for a year, and then switched to emulsion flooding from that point. As shown before, after one year of water flooding, the process had become extremely inefficient. When the injectant was switched to emulsion, positive responses on both oil production and water cut were seen after a few months. 


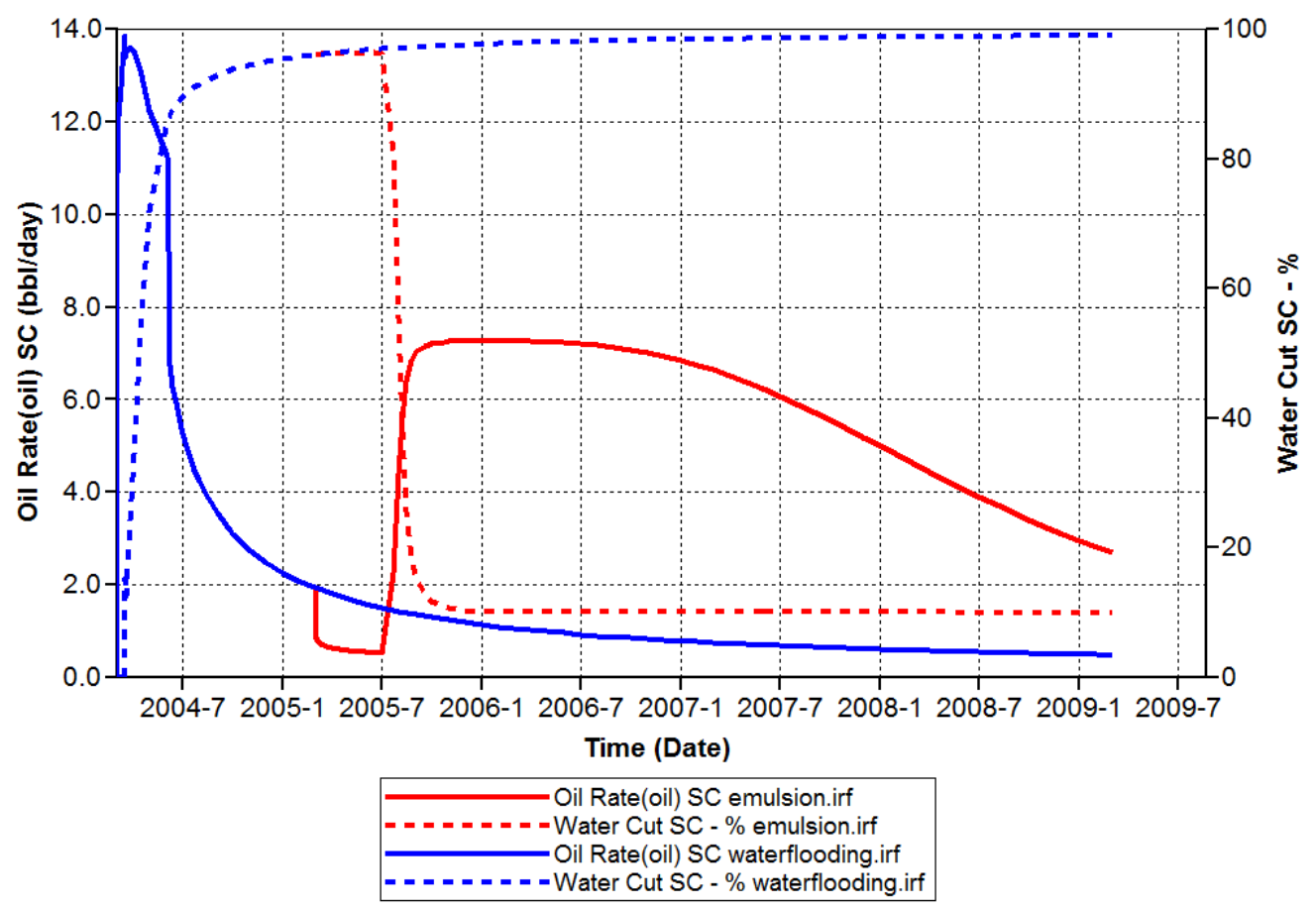

Fig. 4.25- Oil rate and water cut at the production well for emulsion flooding after water flooding.

Figure 4.25 indicates the oil production rate and water cut responses from emulsion flooding after one year's water flooding At the end of water flooding, the oil rate had dropped below $2 \mathrm{bbl} / \mathrm{d}$, and water cut had gone above $95 \%$. Without any further EOR methods, the oil rate would keep falling and water cut keep increasing, shown as blue curves in this figure. However, when emulsion flooding started to take over at the end of water flooding, first there was a negative response of oil rate for about 4 months, and then the rate went up straight to about $7 \mathrm{bbl} / \mathrm{d}$ and last for nearly two years. The water cut response was interrelated: there was not any noticeable response at the 
beginning 4 months of emulsion injection, and then water cut dropped rapidly to about $10 \%$.

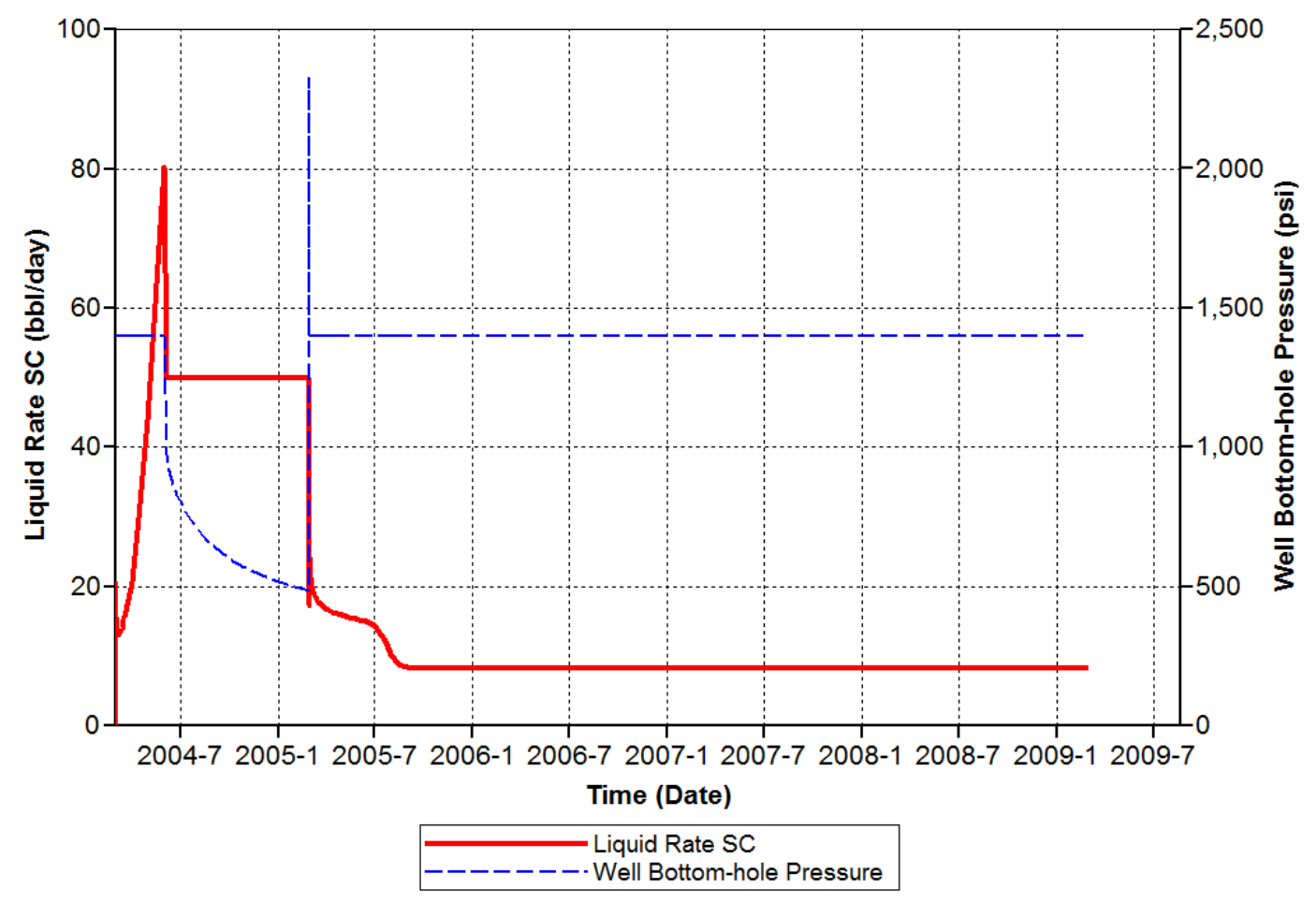

Fig. 4.26- Total liquid rate and BHP at the injection well for emulsion flooding after water flooding.

Total liquid injection rate and BHP at the injection well during this process is shown in Figure 4.26. With this figure, the production responses from Figure 4.25 can be better explained. In Figure 4.25, the oil rate drop at the beginning of emulsion flooding was due to a sudden decrease of liquid injection rate (limited by the injection pressure), and the negligible water cut response within that period of time indicates no change in 
liquid flow toward the production well - the movable water injected into the reservoir within the first year was being depleted by emulsion injection during the first four months of emulsion flooding, because of its much higher mobility compared to heavy oil or emulsion.

After four months, very positive responses on both oil production and water cut were seen in Figure 4.25. Correspondingly, the injection rate decreased again at that time shown in Figure 4.26. As the movable water was depleted, the reservoir was filled with high-viscosity liquid again, and the injection rate of emulsion in turn went down.

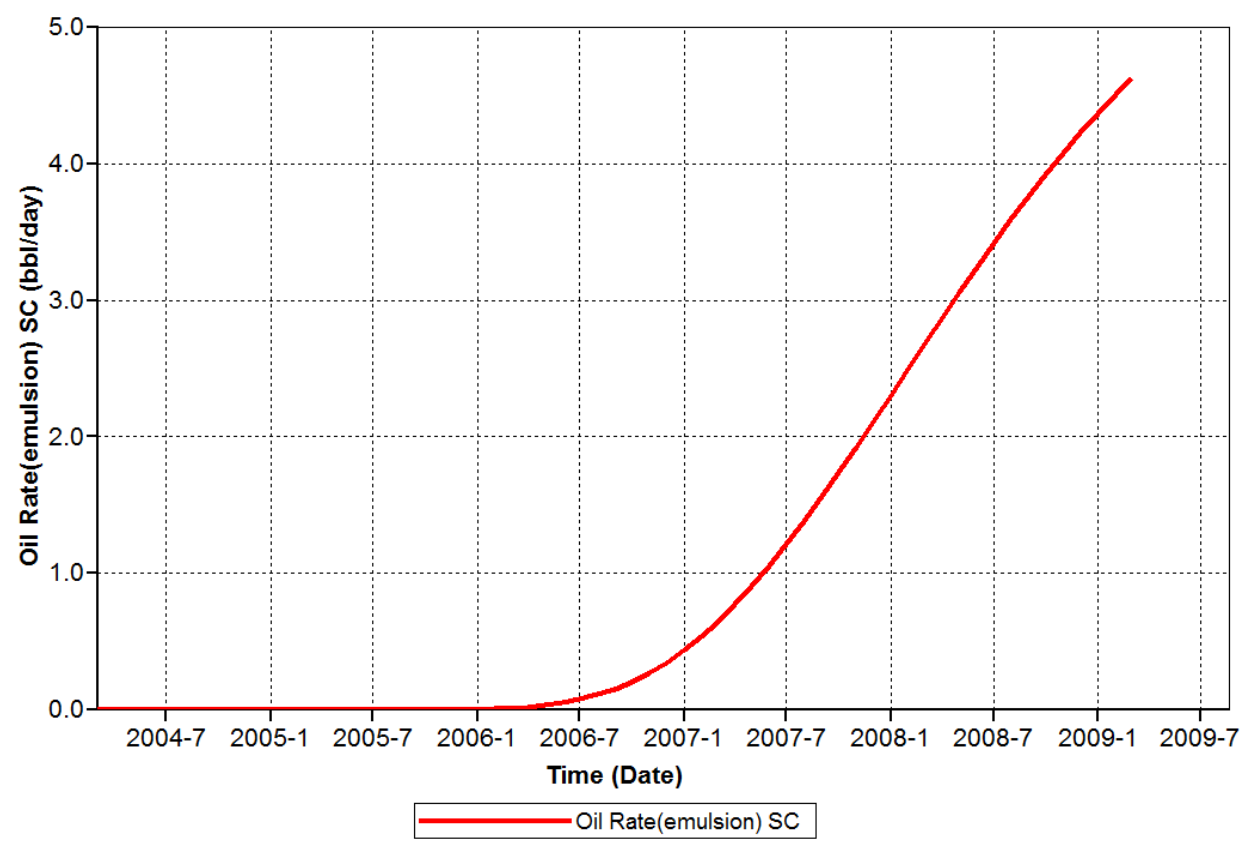

Fig. 4.27- Emulsion rate at the production well for emulsion flooding after water flooding. 
The production rate of emulsion was also analyzed, shown in Figure 4.27. Although water channels were created at the beginning of emulsion flooding, the emulsion injected did not appear in the production well until a year later. This means the injected emulsion did not "fill in" those water channels directl, instead it ushe $d$ hea oil forward into those water flooded zones and improved reservoir fluid distribution and thus the displacement pattern.

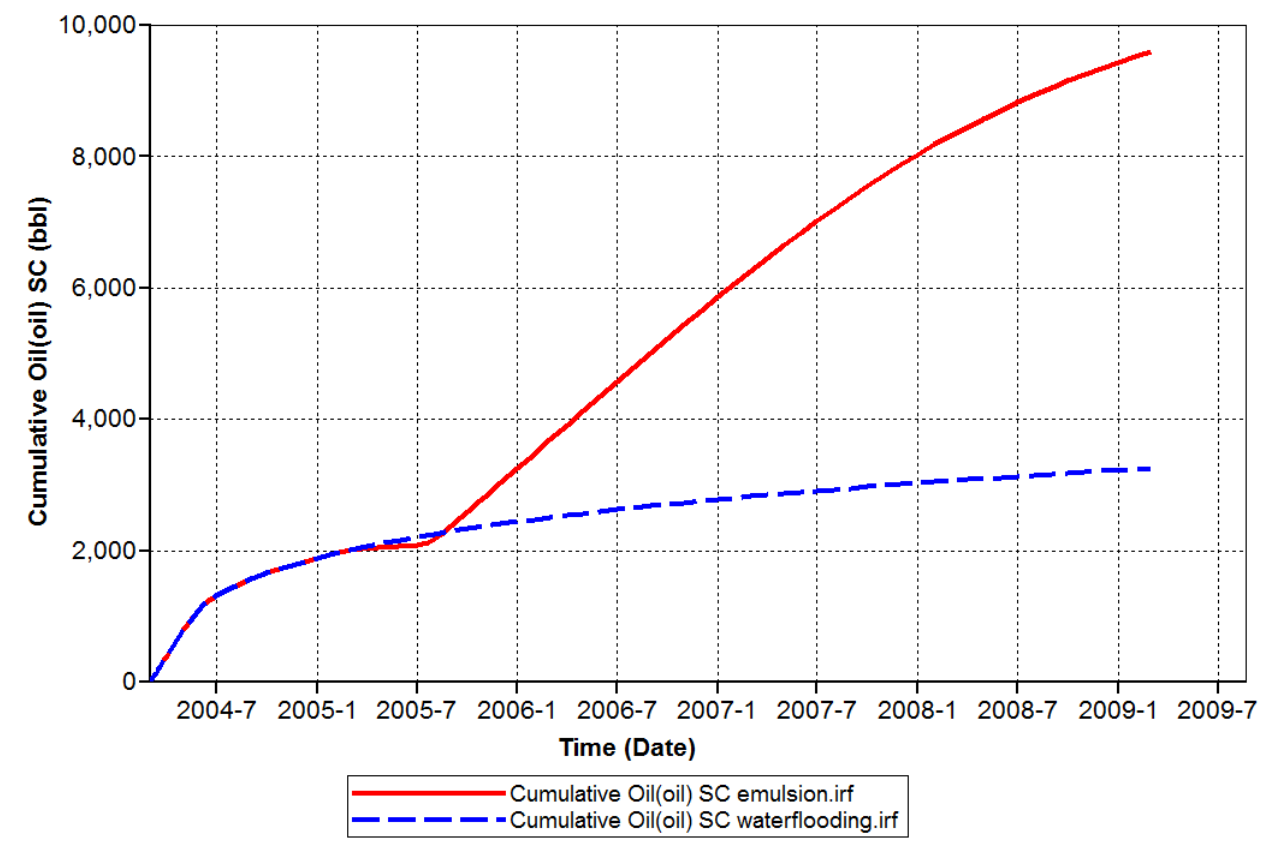

Fig. 4.28 - Cumulative oil production at the production well for emulsion flooding after water flooding. 
The cumulative oil production for this process is shown in Figure 4.28. The cumulative oil recovery at emulsion breakthrough at least doubled the amount at the end of water flooding. Toward the end of simulation, an incremental recovery of over $50 \%$ OOIP was achieved by emulsion flooding.

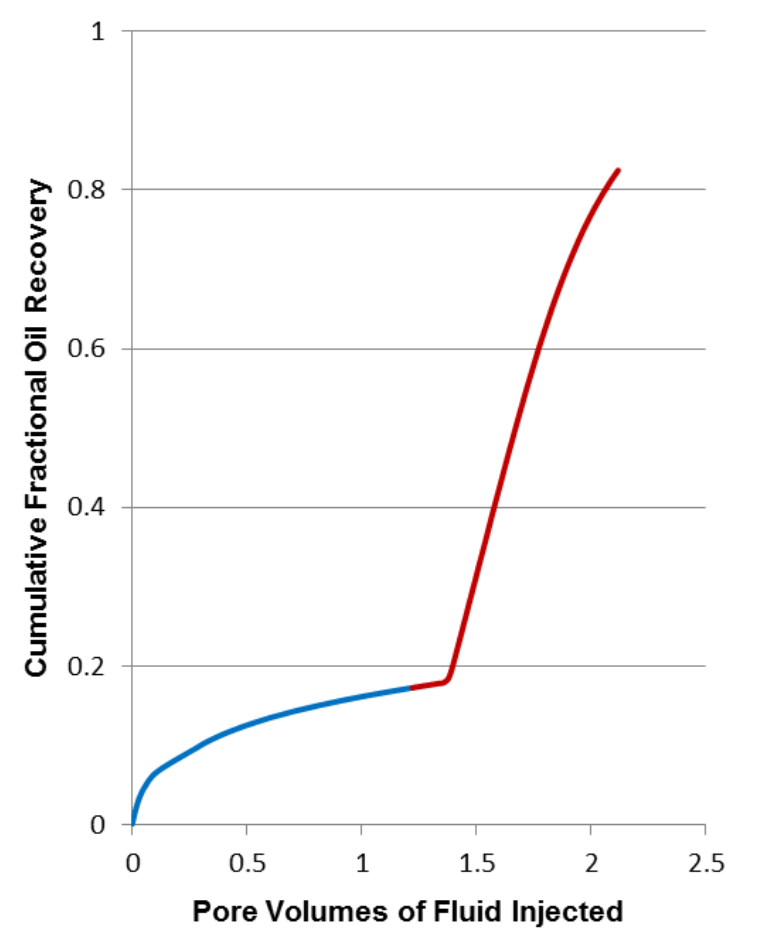

Fig. 4.29 - Recovery performance for emulsion flooding after water flooding.

The oil recovery performance for this process was also analyzed, shown in Figure 4.29. The blue part of the curve shows the performance during water flooding, while the red part indicates that after the injectant was switched to emulsion. The 
recovery efficiency became very low shortly after the beginning of water flooding. One year later, about 1.2 PV of water was injected, resulting in an oil recovery of $17 \%$ OOIP. At this point, emulsion flooding started to take place. The recovery performance was significantly improved after $0.15 \mathrm{PV}$ of emulsion being injected, and the high displacement efficiency lasted for 0.6 PV of emulsion injection, resulting in an additional oil recovery of over $50 \%$ OOIP.

Despite the low injectivity of the emulsion, the recovery rate of crude oil was reasonably high, even compared to the maximum rate during water flooding. More importantly, this high rate could last for a long period of time, resulting in a consistent steady increase of cumulative oil recovery. Because of the high efficiency of emulsion flooding, the water cut problem also diminished compared to water flooding. Overall speaking, emulsion flooding process demonstrated great potential in improved oil recovery even after water flooding. 


\section{CHAPTER V}

\section{ECONOMICS CALCULATIONS}

\subsection{Model Description}

The model for calculating economics in this dissertation is kept in a simple format. First, cash flow is calculated at the end of each month through production. The equation is given as:

\section{Cash Flow $=$ Revenue - Operating Costs}

In this equation, revenue corresponds to the sales of crude oil from production within each month, therefore equals to barrels of oil produced multiplied by the price of crude oil. The operating costs involves several terms: injection liquid, production liquid disposal, fixed daily cost, and capital investment. Among these terms, the liquid injection and production liquid disposal are based on the amount of liquid injected or produced. The fixed daily cost involves all other expenses that are independent of the amount of liquids and will be given a fixed value. The capital investment takes into account the expenses at the very beginning of a project and is only applied for the first month.

Then the net present value (NPV) can be calculated based on monthly cash flow using the following equation:

$$
N P V=\sum\left\lfloor\operatorname{cash} \text { flow } \times \frac{1}{\left(1+\frac{i}{12}\right)^{n}}\right\rfloor
$$


Where $i=$ Annual Interest Rate

These two equations were implemented in excel and calculations were conducted based on data from simulation results.

\subsection{Input Values}

\begin{tabular}{|ll|}
\hline \multicolumn{2}{|c|}{ TABLE 5.1 INPUT PARAMETERS FOR ECONOMICS } \\
\hline Capital cost (Water Flooding) & $\$ 500,000$ \\
Capital cost (Emulsion Flooding) & $\$ 800,000$ \\
Oil price & $\$ 80 / \mathrm{bbl}$ \\
Water price & $\$ 2 / \mathrm{bbl}$ \\
Emulsion Price & $\$ 15 / \mathrm{bbl}$ \\
Water disposal & $\$ 2 / \mathrm{bbl}$ \\
Emulsion separating cost & $\$ 10 / \mathrm{bbl}$ \\
Fixed operating cost & $\$ 500 / \mathrm{day}$ \\
Annual interest rate & $10 \%$ \\
\hline
\end{tabular}

The input parameters for economics calculations are listed in Table 5.1. The common parameters in water flooding and emulsion flooding were set to be the same values. Capital cost for water flooding and emulsion flooding were set to be $\$ 500,000$ 
and $\$ 800,000$, respectively. In emulsion flooding, an emulsion cost of $\$ 15 / \mathrm{bbl}$ was assumed, including the cost for used engine oil (purchase and transportation), water and mixing cost. Also, a cost of $\$ 10 / \mathrm{bbl}$ was assumed for emulsion separation from produced oil.

The liquid flow rates in water flooding and emulsion flooding are shown in Figure 5.1 and 5.2, respectively. These two figures were obtained from simulation results exported into excel sheets and plotted on a monthly basis. Zero time corresponded to the initial date of projects in simulation, which was set to be $03 / 01 / 2004$ for all cases. The periodic fluctuation was due to variable number of days in different months. The rates have been multiplied by 8 from the simulation results thus indicate the liquid flow rates within the whole 2.5 acre pattern.

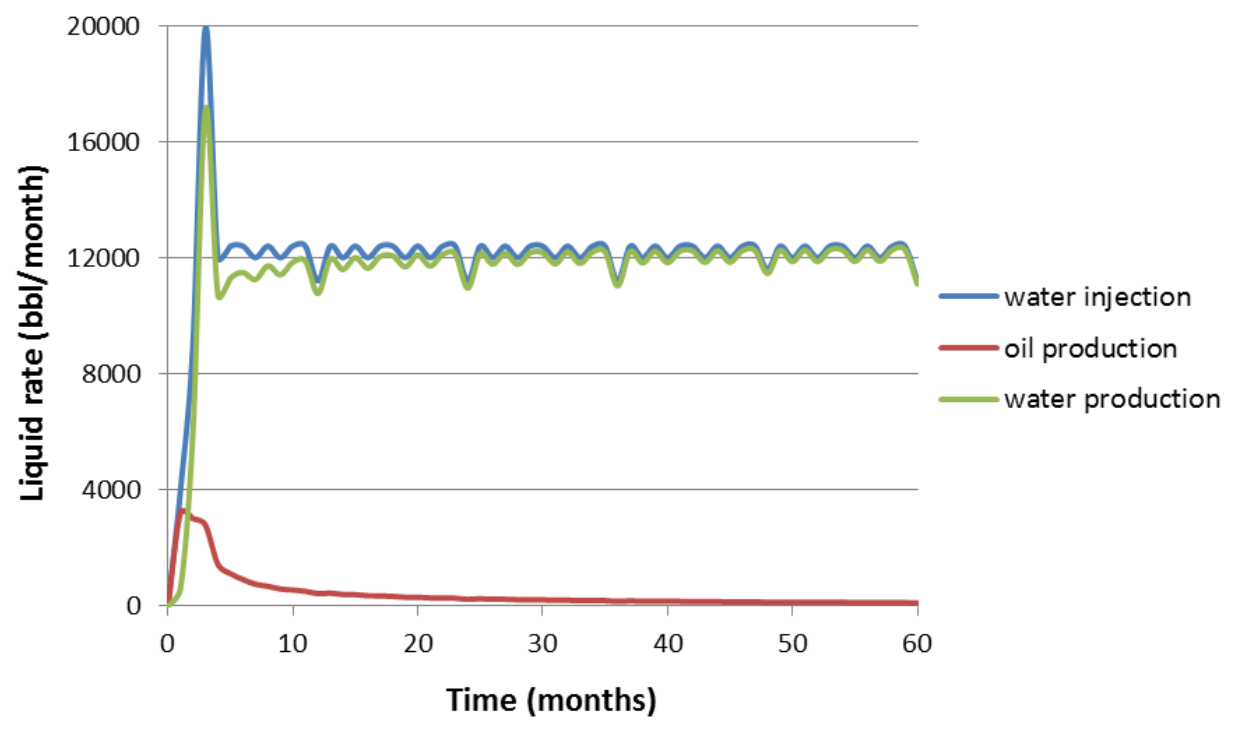

Fig. 5.1- Monthly liquid rates in water flooding. 


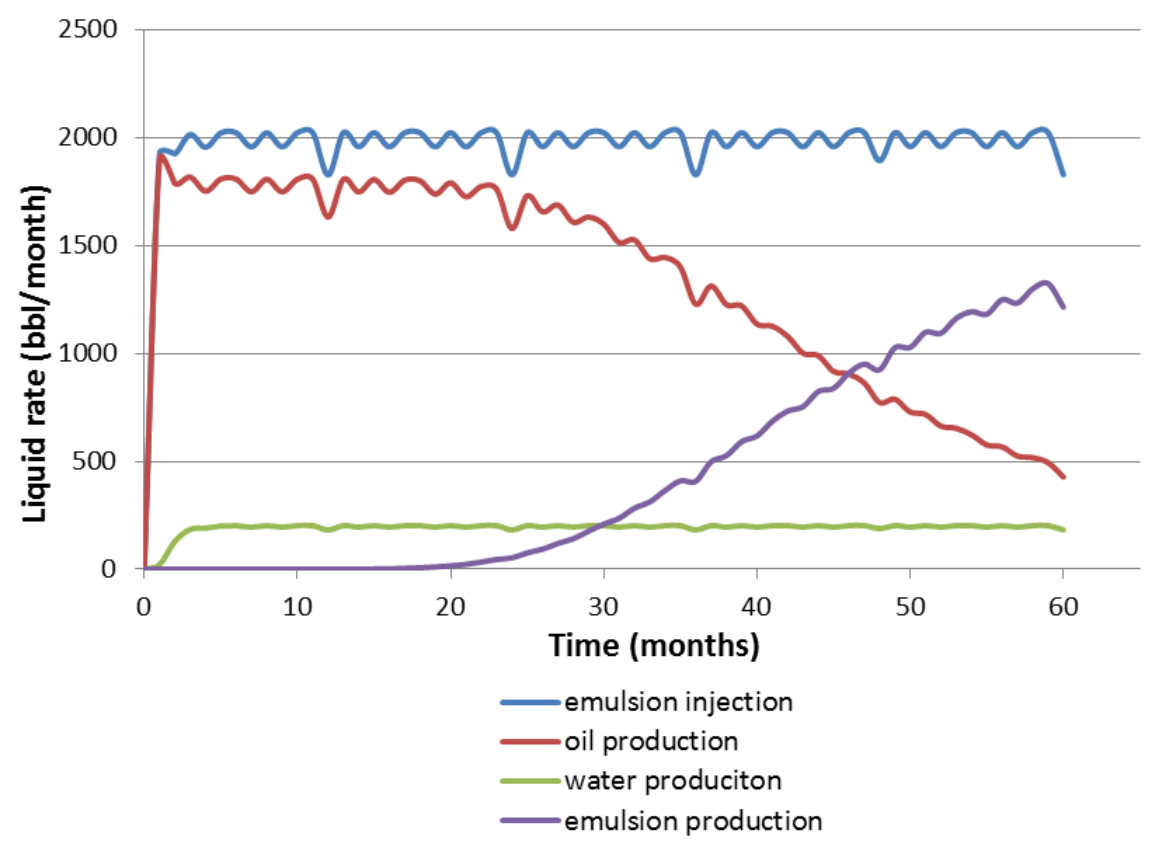

Fig. 5.2 - Monthly liquid rates in emulsion flooding.

\subsection{Results}

The cash flow for water flooding and emulsion flooding were calculated and shown in Figure 5.3. Both water flooding and emulsion flooding started with negative cash flow values, which were equal to the capital costs. Similar to oil production rates, the cash flow for water flooding peaked within the first few months of project and declined sharply to negative within a year, while the cash flow for emulsion flooding remained stably high for several years before falling below zero. Normally a project is terminated when cash flow goes down near zero. 


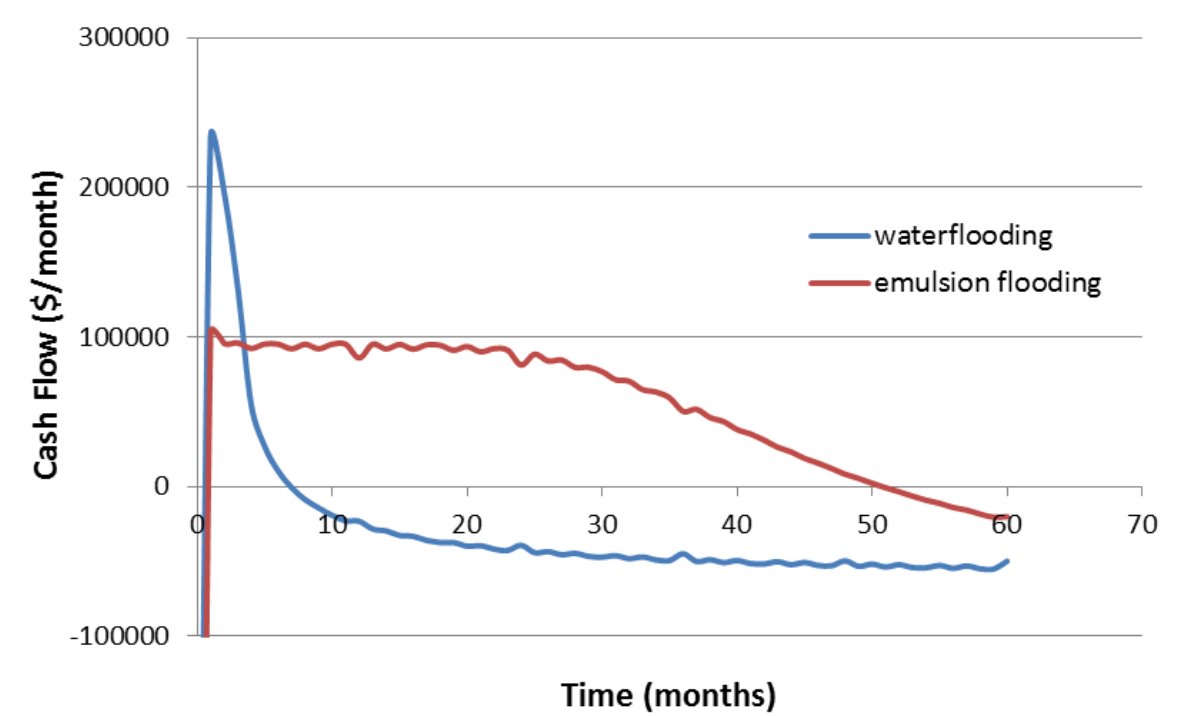

Fig. 5.3 - Cash flow for water flooding and emulsion flooding.

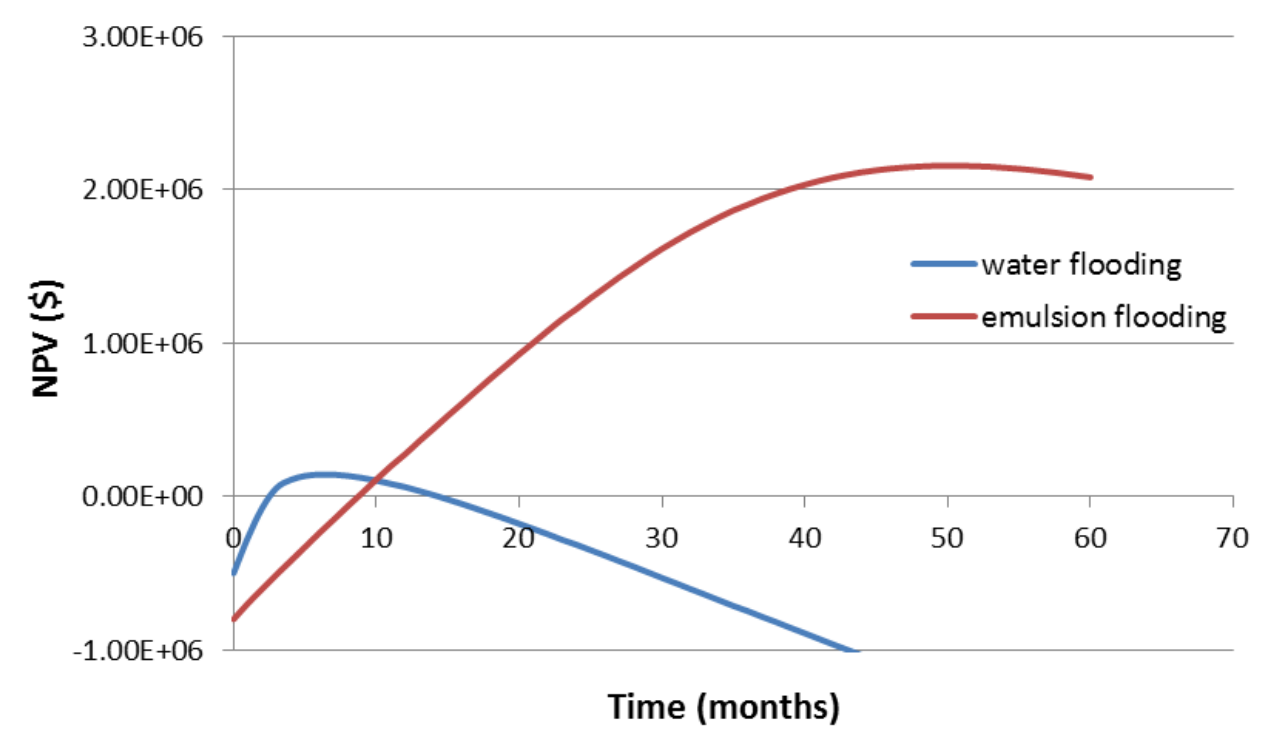

Fig. 5.4- NPV for water flooding and emulsion flooding. 
The NPV for water flooding and emulsion flooding were also calculated and shown in Figure 5.4. As NPV is simply an accumulation of cash flow by taking into account of interest rate, it increases as long as cash flow remains positive. The peak of the NPV curve is at the point where cash flow goes down to zero. The maximum NPV for water flooding was about $\$ 140,000$ - the economics for water flooding such a thin heavy oil reservoir was marginal. On the other hand, the maximum NPV for emulsion flooding was $\$ 2,200,000$. Compared to water flooding, the NPV for emulsion flooding was significantly higher. This significant improvement mainly comes from the enhanced production of heavy oil and much better controlled water cut.

\subsection{Sensitivity Analyses}

To combat the uncertainty of assigned values for input parameters, several parameters were chosen to conduct sensitivity analyses, including capital costs, water price, emulsion price, water disposal cost, fixed operating cost and annual interest rate. The viscosity of the injected emulsion was also analyzed for sensitivity as this is a major parameter to control in emulsion flooding projects.

\subsubsection{Capital Costs}

In this part the capital costs for water flooding and emulsion flooding were assumed to be $\$ 1,000,000$ and $\$ 1,600,000$, respectively. Compared to the capital costs in

Table 5.1, both values were doubled. All other values were the same as given in Table 5.1. 


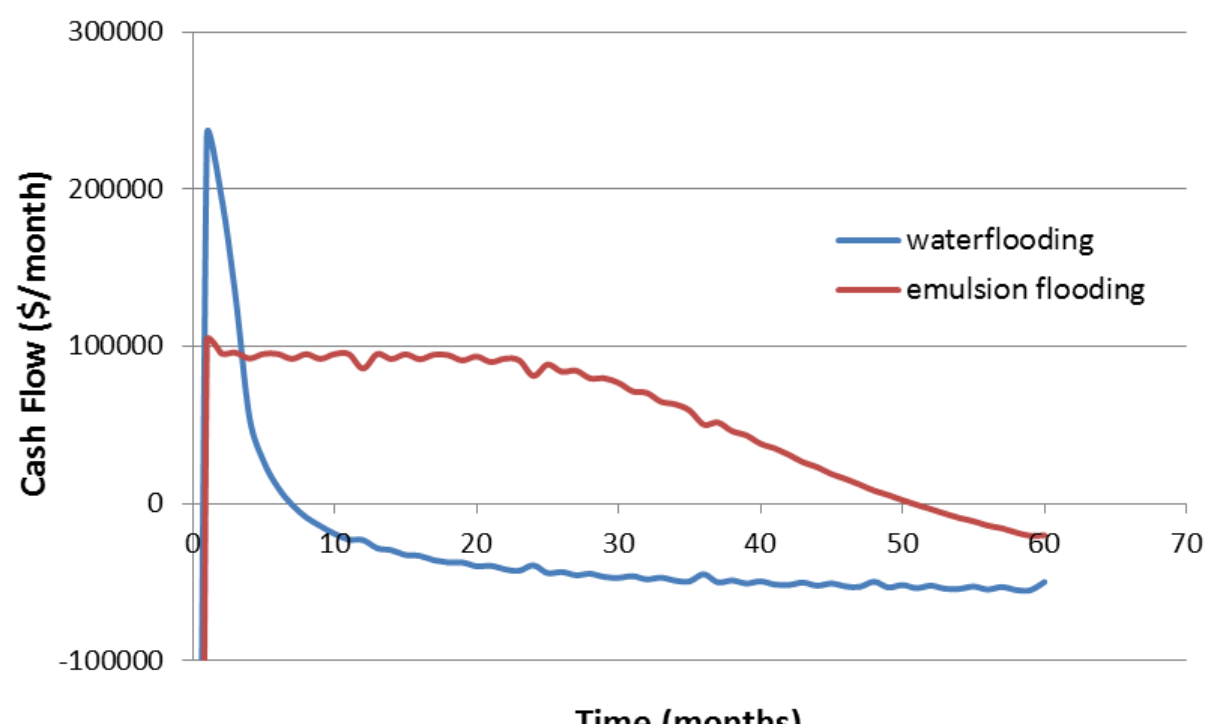

Fig. 5.5- Sensitivity analyses of capital costs on cash flow.

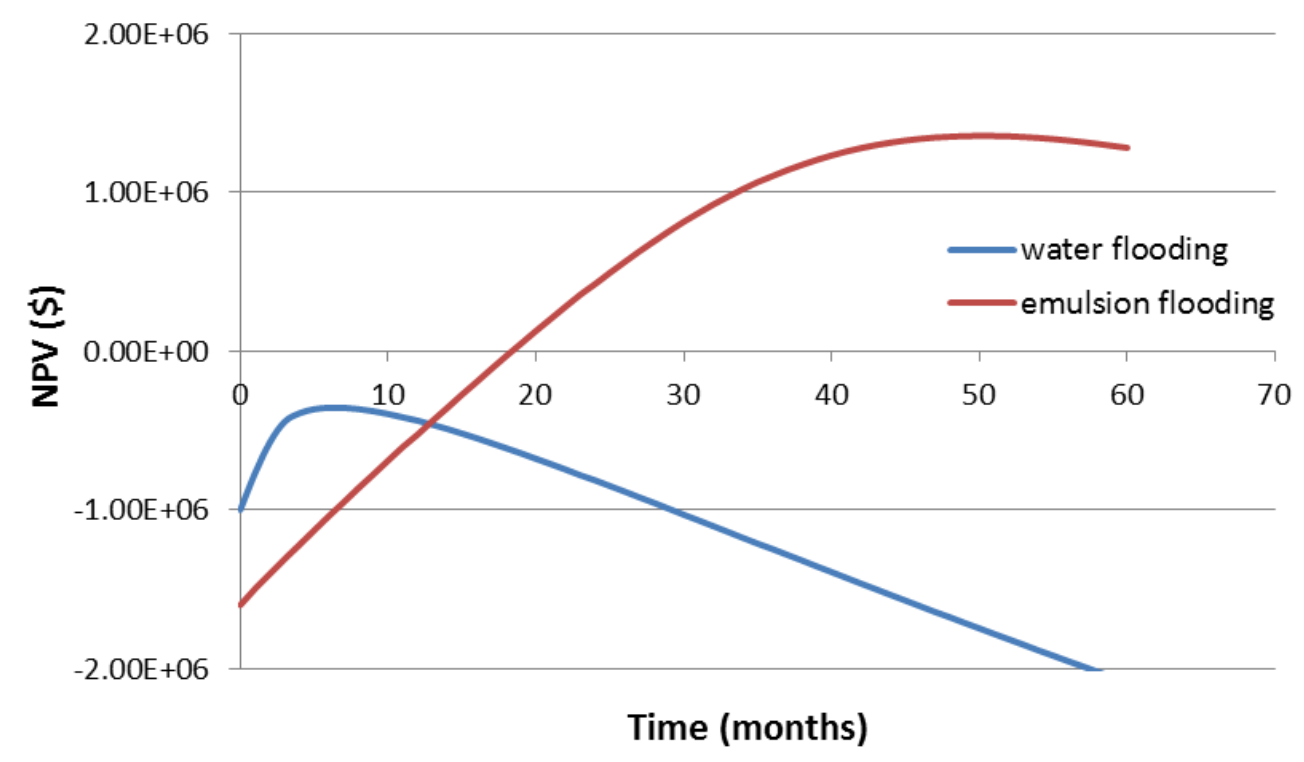

Fig. 5.6- Sensitivity analyses of capital costs on NPV. 
The cash flow and NPV curves under the new capital costs were plotted in Figure 5.5 and 5.6. Figure 5.5 is different from Figure 5.3 only in the very beginning: the cash flows were doubled at time zero because of capital costs. In Figure 5.6, the NPV for water flooding never exceeded 0 - water flooding was not an economical process under the current input parameters. On the other hand, the NPV for emulsion flooding reached a maximum value of $\$ 1,400,000$ - the increased capital cost of $\$ 800,000$ could be directly subtracted from the previous NPV. Also, compared to the NPV curve in the previous case, the capital cost in this case required much longer time to pay off: about 18 months.

\subsubsection{Water Price}

Water price was assigned to be $\$ 1 / b b l, \$ 2 / b b l$ and $\$ 4 / b b l$ for sensitivity analysis. All other parameters were kept the same as in Table 5.1.

The cash flow and NPV curves for water flooding are shown in Figure 5.7 and 5.8, respectively. As water price went up, both cash flow and NPV values decreased, and the project had to be terminated at an earlier time. Economics of water flooding was quite sensitive to the price of water, especially in the later stages when water injection reached maximum and oil recovery efficiency became very low. 


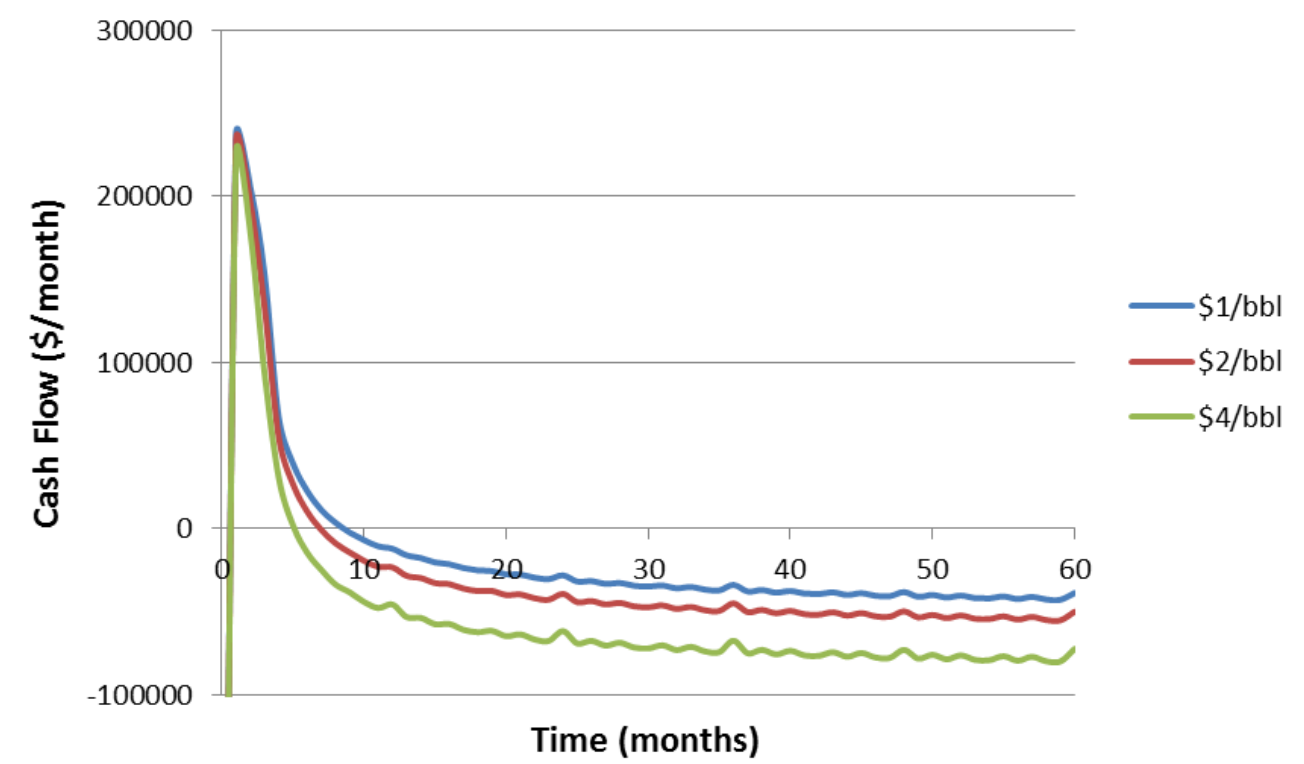

Fig. 5.7- Sensitivity analyses of water price on cash flow in water flooding.

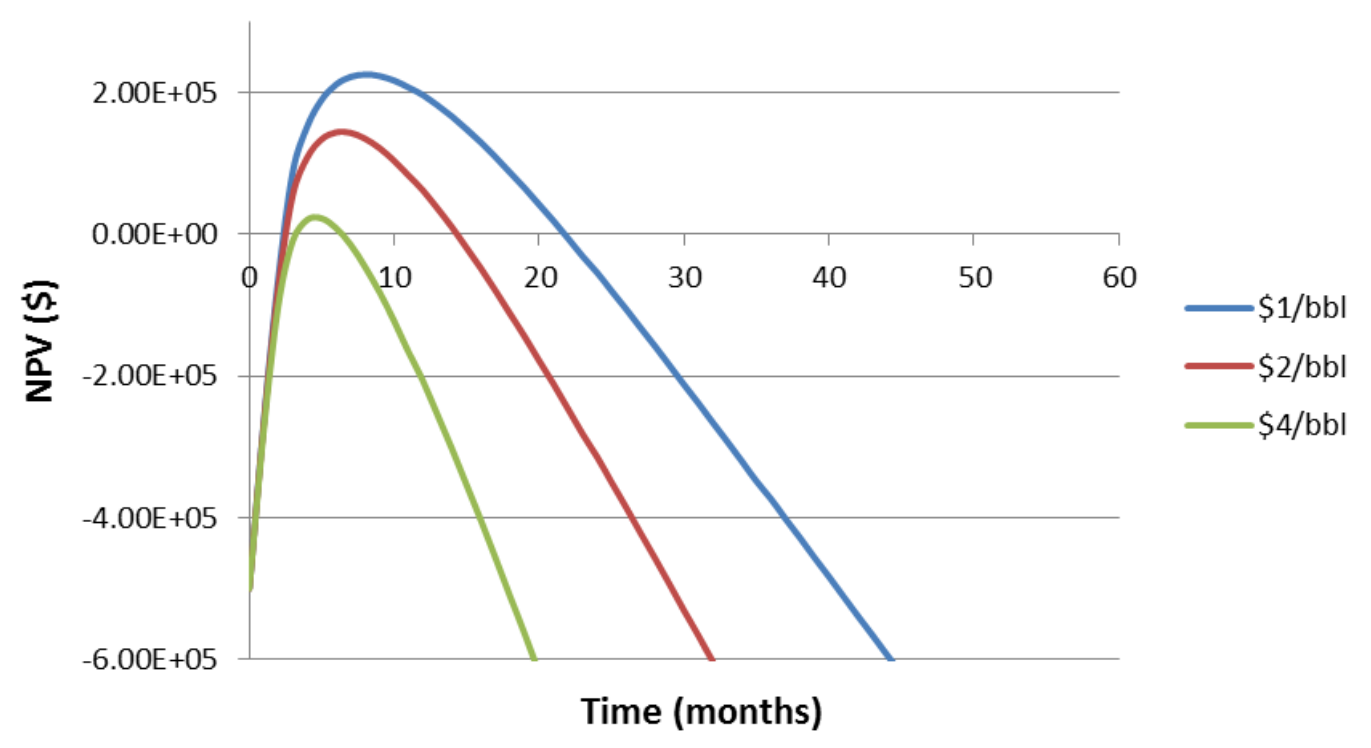

Fig. 5.8 - Sensitivity analyses of water price on NPV in water flooding. 
In emulsion flooding, no water is being injected directly so the cash flow and NPV curves will not be affected by the water price, and their figures will remain the same as in Figures 5.3 and 5.4. The price of water does have some influence on emulsion cost, as the emulsion consists of $60 \%$ water. However, water cost only contributes to a small part of the cost for generating emulsions. In our calculations, the unit cost for emulsion $(\$ 15 / \mathrm{bbl})$ is much higher than that for water. Therefore, the economics of emulsion flooding will not be sensitive to the price of water in general cases.

\subsubsection{Emulsion Price}

As mentioned before, the cost of emulsion included used engine oil purchase and transportation, water cost and mixing cost. The cost for purchasing used engine oil can be as low as 0 , as used engine oil is collected mainly for environmental issues. The cost for transportation could vary depending on the distance and transportation techniques. To the extent of my knowledge, the cost for transporting a barrel of oil by railcar would be around $\$ 10$ to $\$ 20$. Mixing cost is difficult to evaluate at this point, but this type of emulsification has been conducted in the field and proven doable (Kaminsky et al., 2010). If we assume the mixing cost ranges from $\$ 5$ to $\$ 15$ per barrel, by taking into account of oil and water costs, the overall cost for emulsion would be approximately between $\$ 10 / \mathrm{bbl}$ to $\$ 25 / \mathrm{bbl}$. In this sensitivity study, three values of $\$ 10 / \mathrm{bbl}, \$ 15 / \mathrm{bbl}$ and $\$ 25 / \mathrm{bbl}$ were used for cash flow and NPV calculations. All other parameters were kept the same values as shown in Table 5.1. 


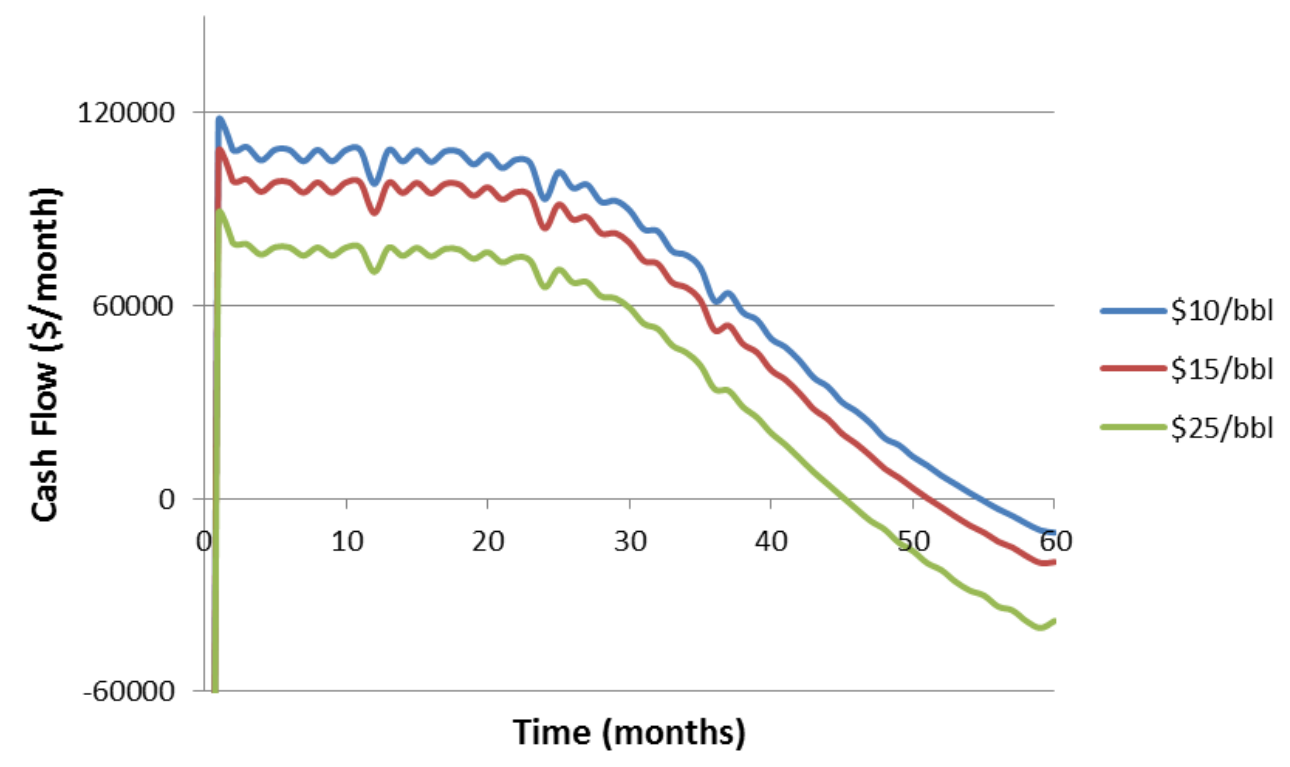

Fig. 5.9- Sensitivity analyses of emulsion price on cash flow in emulsion flooding.

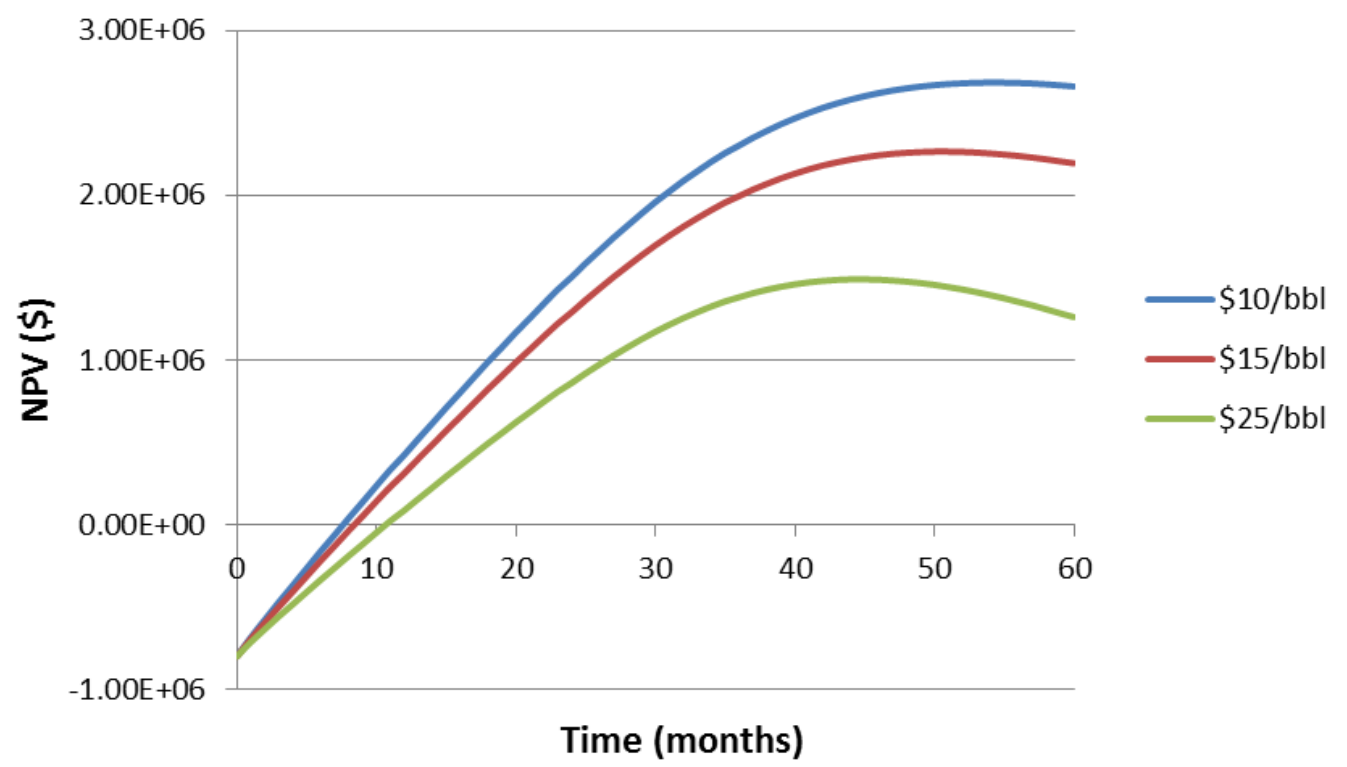

Fig. 5.10- Sensitivity analyses of emulsion price on NPV in emulsion flooding. 
The calculation results on cash flow and NPV are shown in Figure 5.9 and 5.10, respectively. As expected, economics of emulsion flooding process is quite sensitive to the emulsion price. Similar to the sensitivity analyses of water price in water flooding, increasing emulsion price will result in lower profits of the emulsion flooding process and an earlier termination of the project.

\subsubsection{Water Disposal Cost}

Water disposal cost was chosen to be $\$ 1 / \mathrm{bbl}, \$ 2 / \mathrm{bbl}$ and $\$ 4 / \mathrm{bbl}$ for sensitivity analyses. All other parameters were kept the same as in Table 5.1.

The cash flow and NPV curves for water flooding are shown in Figure 5.11 and 5.12, respectively. Higher cost for water disposal resulted in lower values of cash flow and NPV, and earlier termination of the project. Similar to the effect water price, water disposal cost had large effect on the economics of water flooding especially at later stages. After water breakthrough, the water cut increased constantly and became one major cost for the project.

The cash flow and NPV curves for emulsion flooding are shown in Figure 5.13 and 5.14, respectively. All three curves almost overlapped in both figures. Although the emulsion flooding process involved water disposal, the amount of water produced was very small. Therefore, the economics was very insensitive to the cost of water disposal for an emulsion flooding process. 


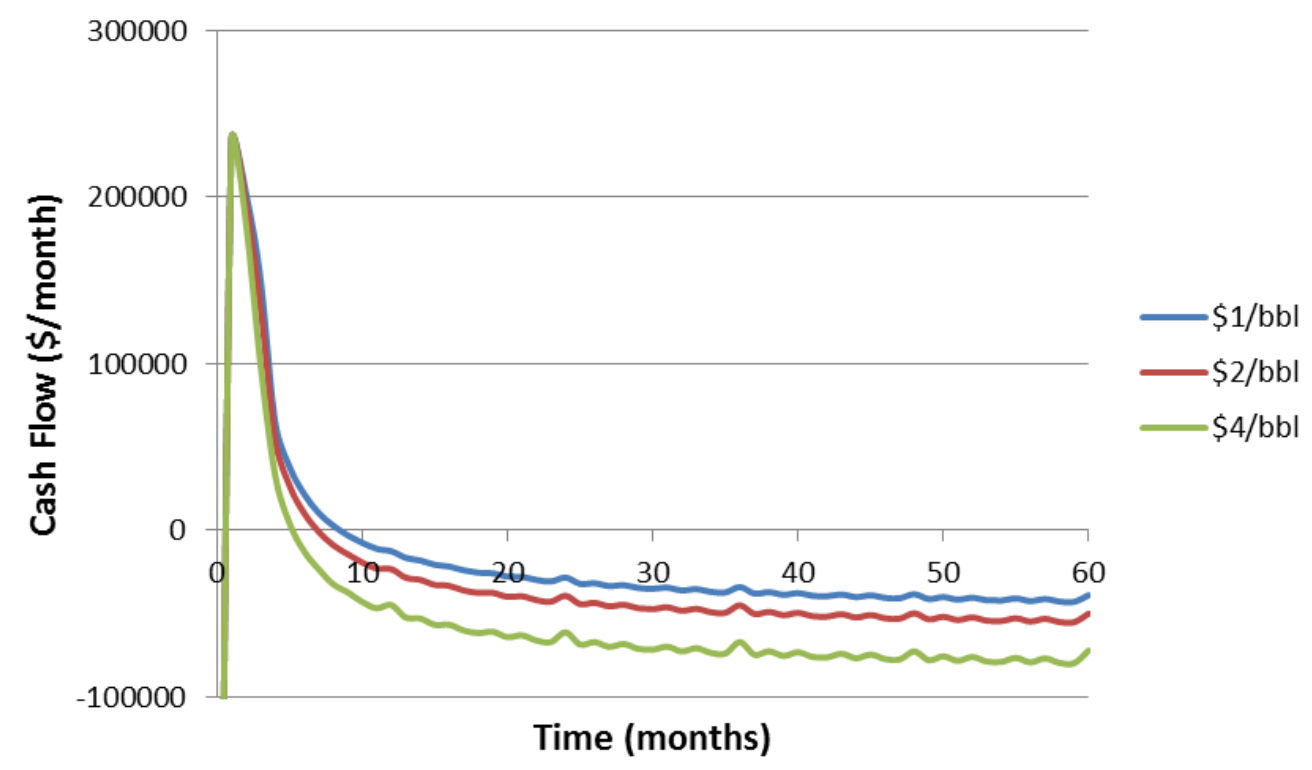

Fig. 5.11- Sensitivity analyses of water disposal cost on cash flow in water flooding.

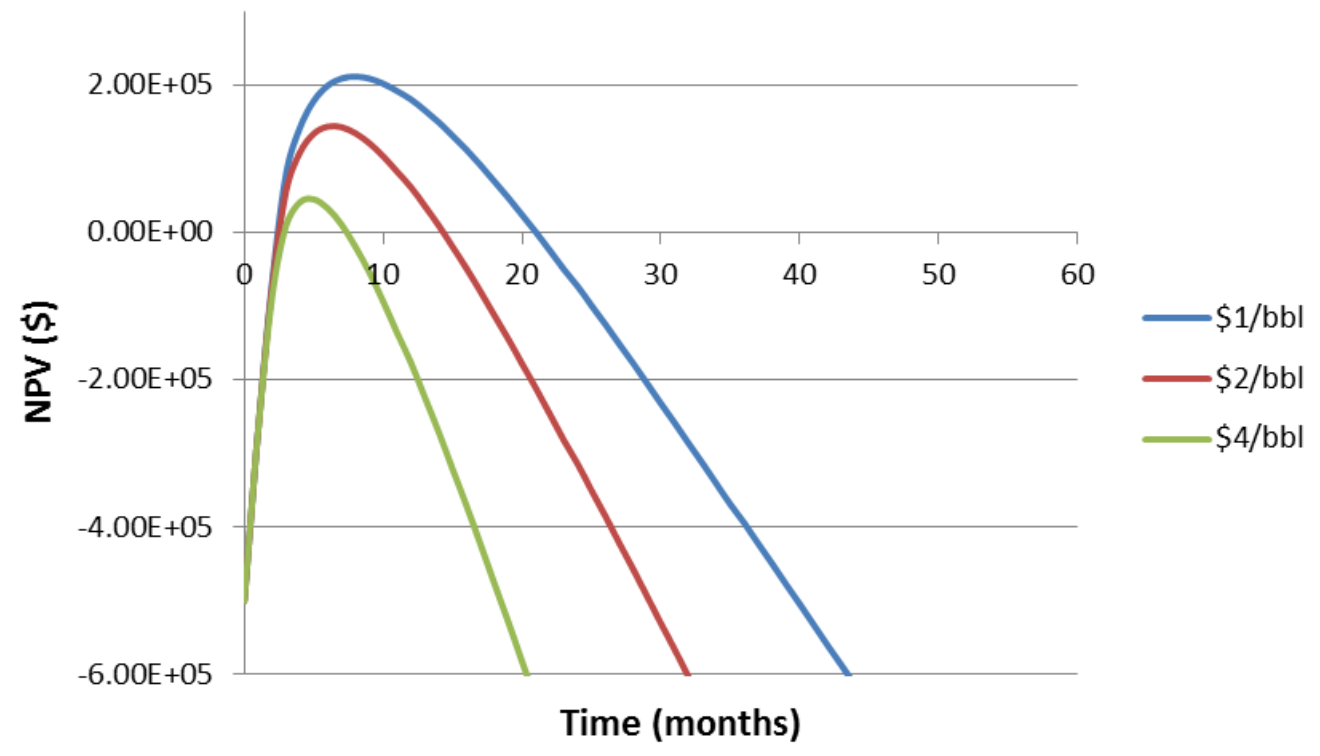

Fig. 5.12 - Sensitivity analyses of water disposal cost on NPV in water flooding. 


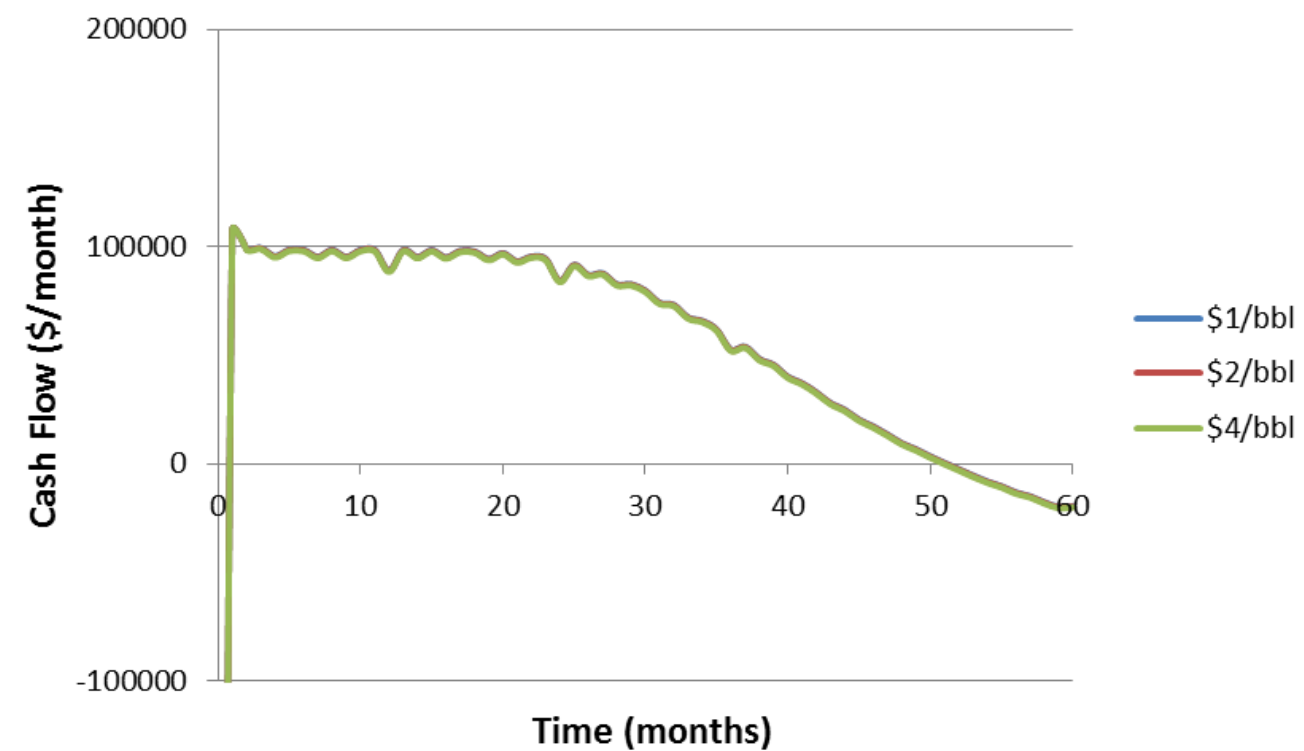

Fig. 5.13 - Sensitivity analyses of water disposal cost on cash flow in emulsion flooding.

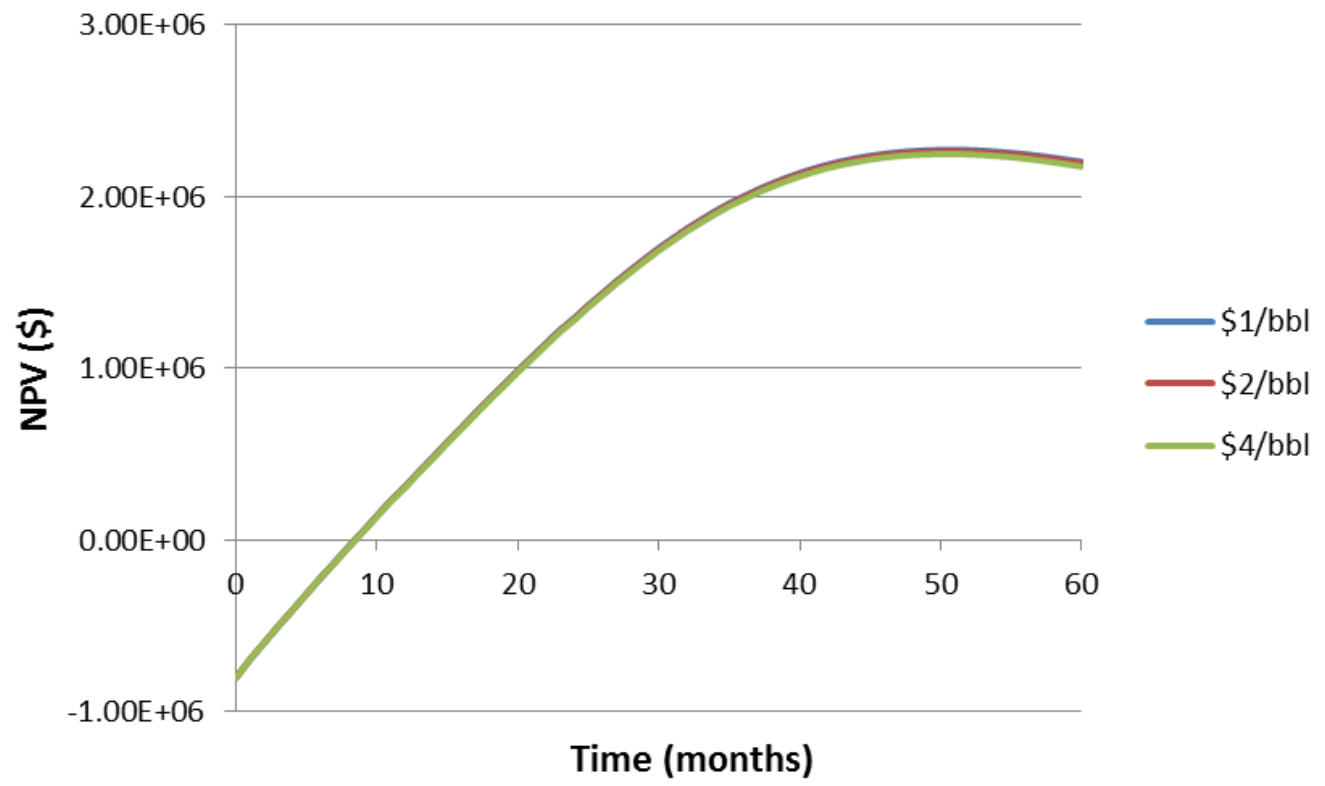

Fig. 5.14- Sensitivity analyses of water disposal cost on NPV in emulsion flooding. 130 


\subsubsection{Fixed Operating Cost}

Fixed operating cost was chosen to be $\$ 300 / \mathrm{d}, \$ 500 / \mathrm{d}$ and $\$ 1000 / \mathrm{d}$ for sensitivity analyses. The influences of operating cost on cash flow for water flooding and emulsion flooding are shown in Figure 5.15 and 5.16, respectively. As expected, higher operation cost will lead to less profits and earlier project termination. The sensitivity analyses of operating cost on NPV for water flooding and emulsion flooding were also conducted, shown in Figure 5.17 and 5.18, respectively. Generally speaking the operation cost will have a larger effect on emulsion flooding than water flooding because of the longer duration of an emulsion flooding project.

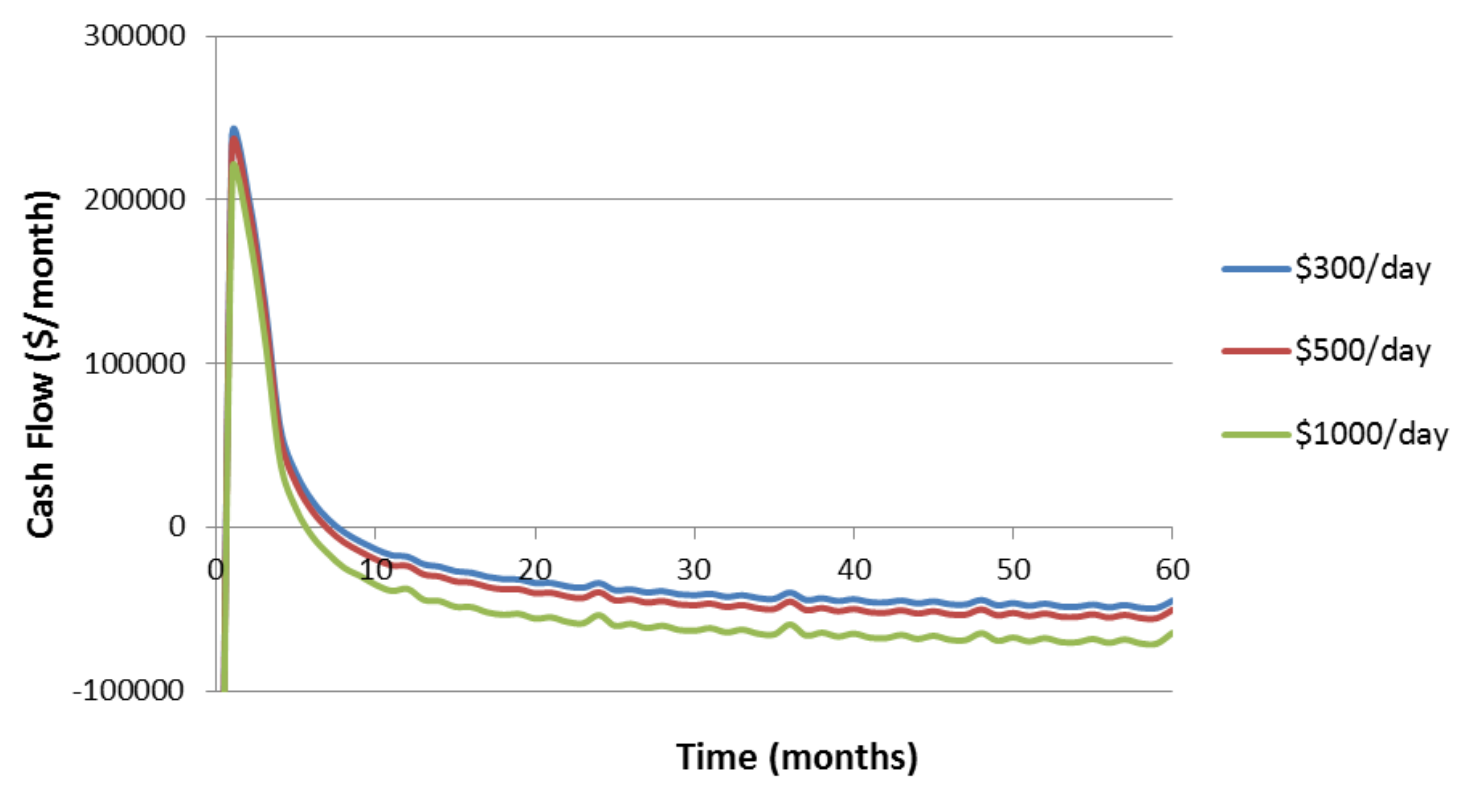

Fig. 5.15- Sensitivity analyses of operating cost on cash flow in water flooding. 


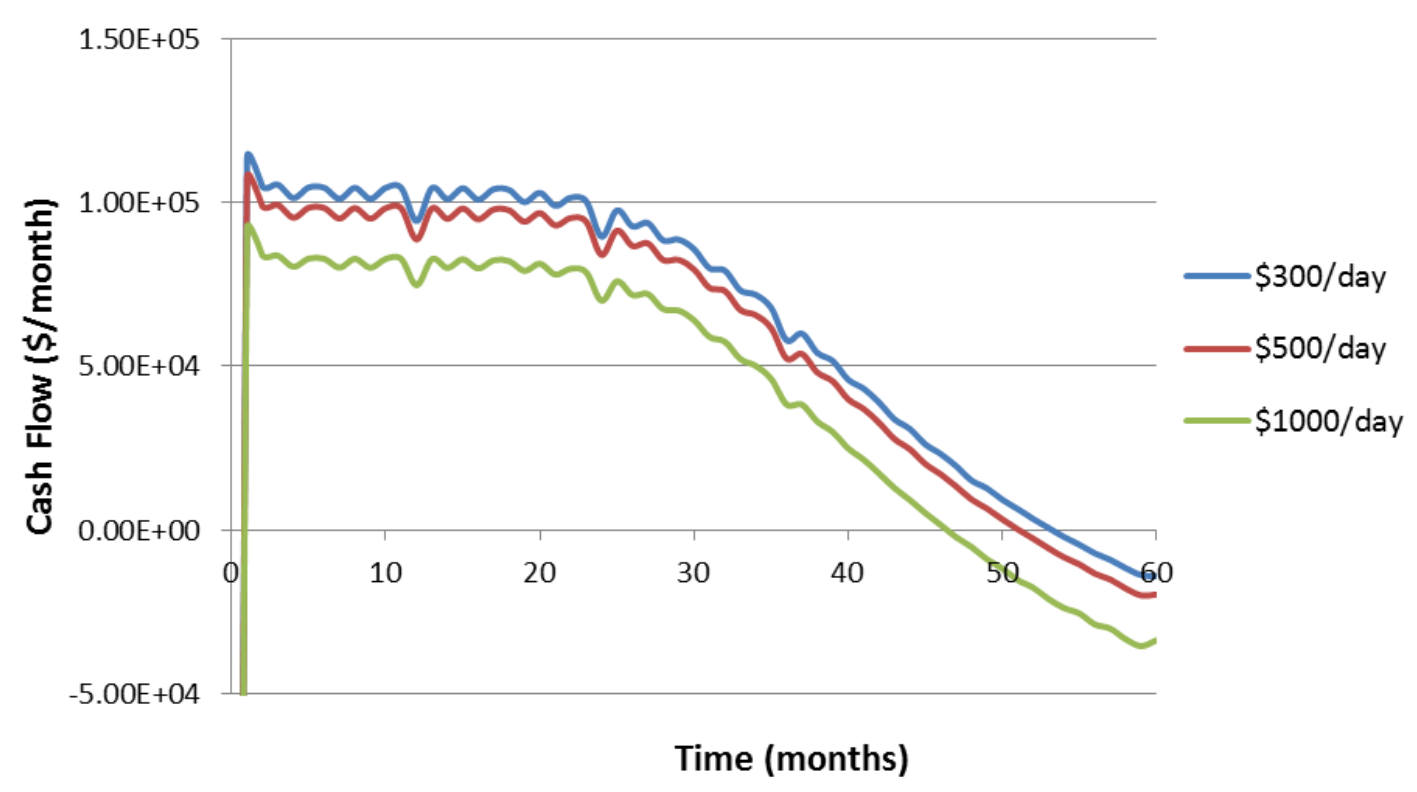

Fig. 5.16- Sensitivity analyses of operating cost on cash flow in emulsion flooding.

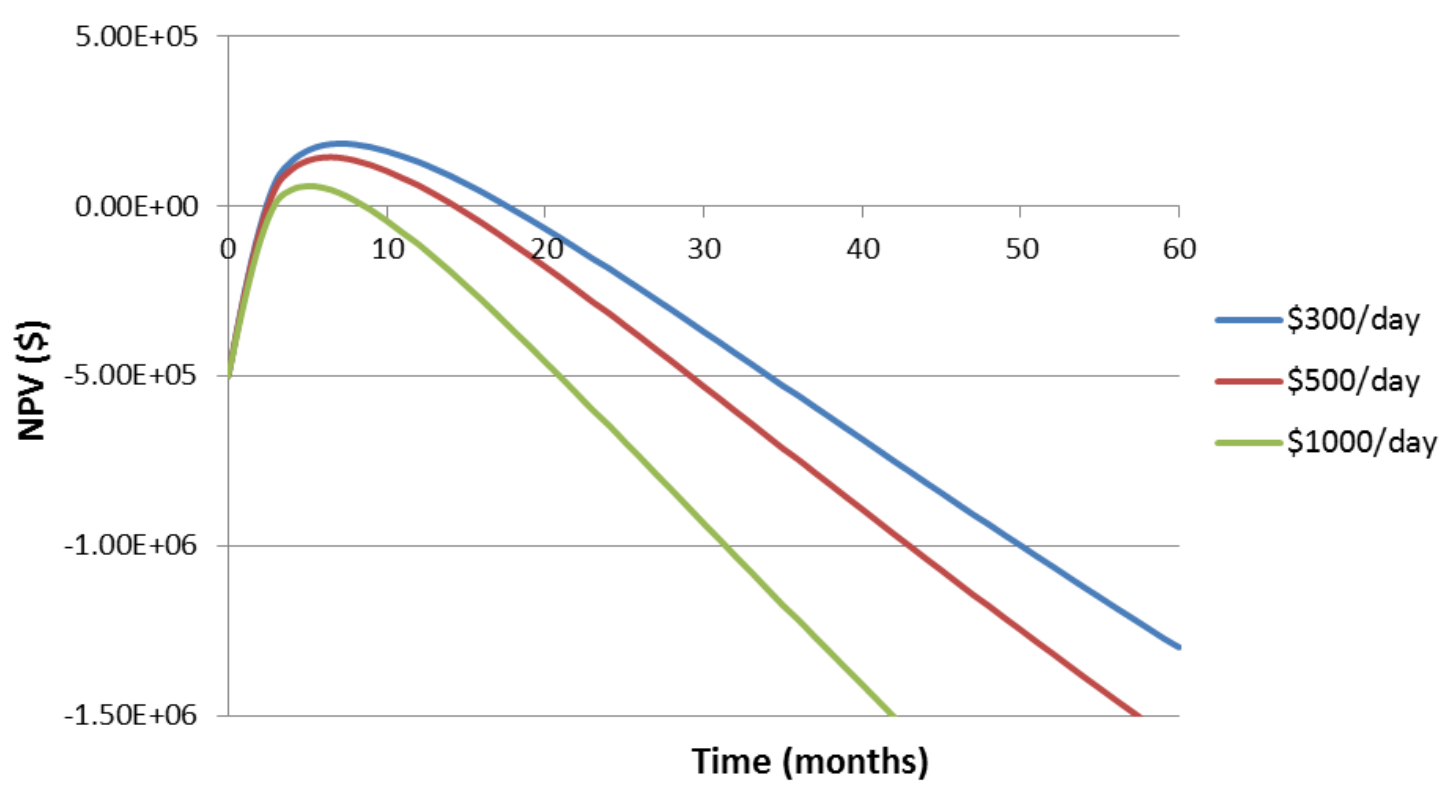

Fig. 5.17- Sensitivity analyses of operating cost on NPV in water flooding. 


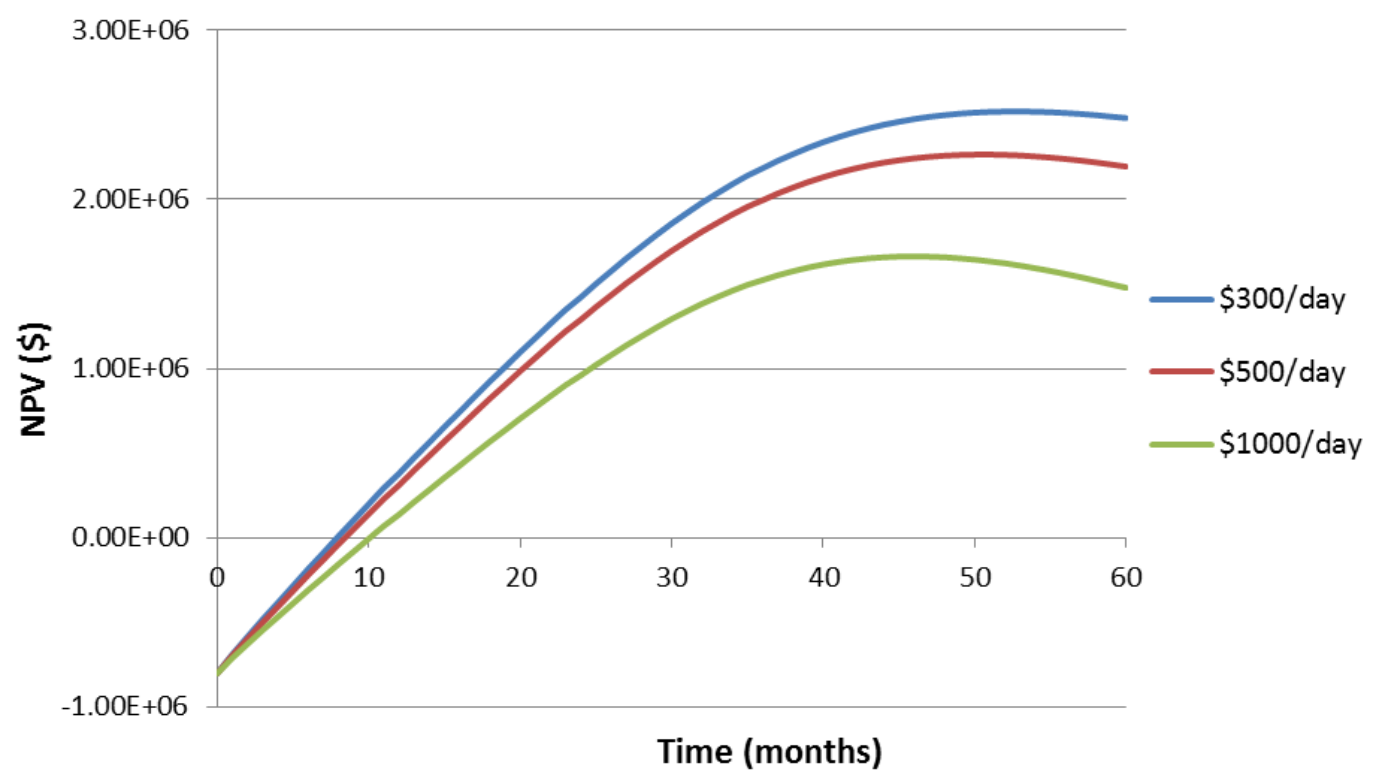

Fig. 5.18 - Sensitivity analyses of operating cost on NPV in emulsion flooding.

\subsubsection{Annual Interest Rate}

To demonstrate the influence of annual interest rate, $6 \%, 8 \%$ and $10 \%$ were chosen to conduct NPV calculations. Cash flow has nothing to do with interest rate, therefore will not be affected. The NPV curves for water flooding and emulsion flooding under these three different interest rates are shown in Figure 5.19 and 5.20, respectively. Higher interest rates lead to decreased values of NPV, but their influence on economics was very small for both cases. The NPV curves at different interest rates almost overlapped among each other. The emulsion flooding case showed a relatively larger effect of the annual interest rate on NPV, due to the longer duration of this method. 


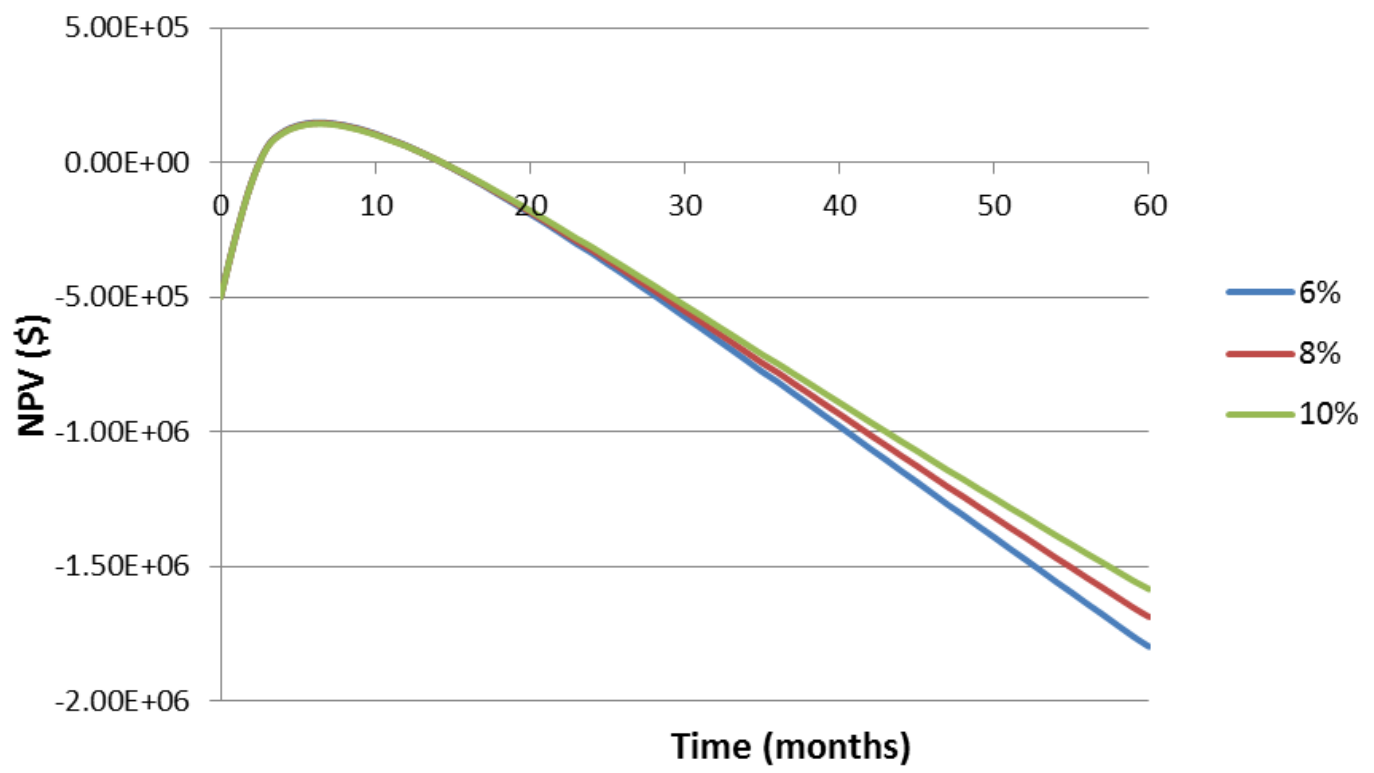

Fig. 5.19- Sensitivity analyses of annual interest rate on NPV in water flooding.

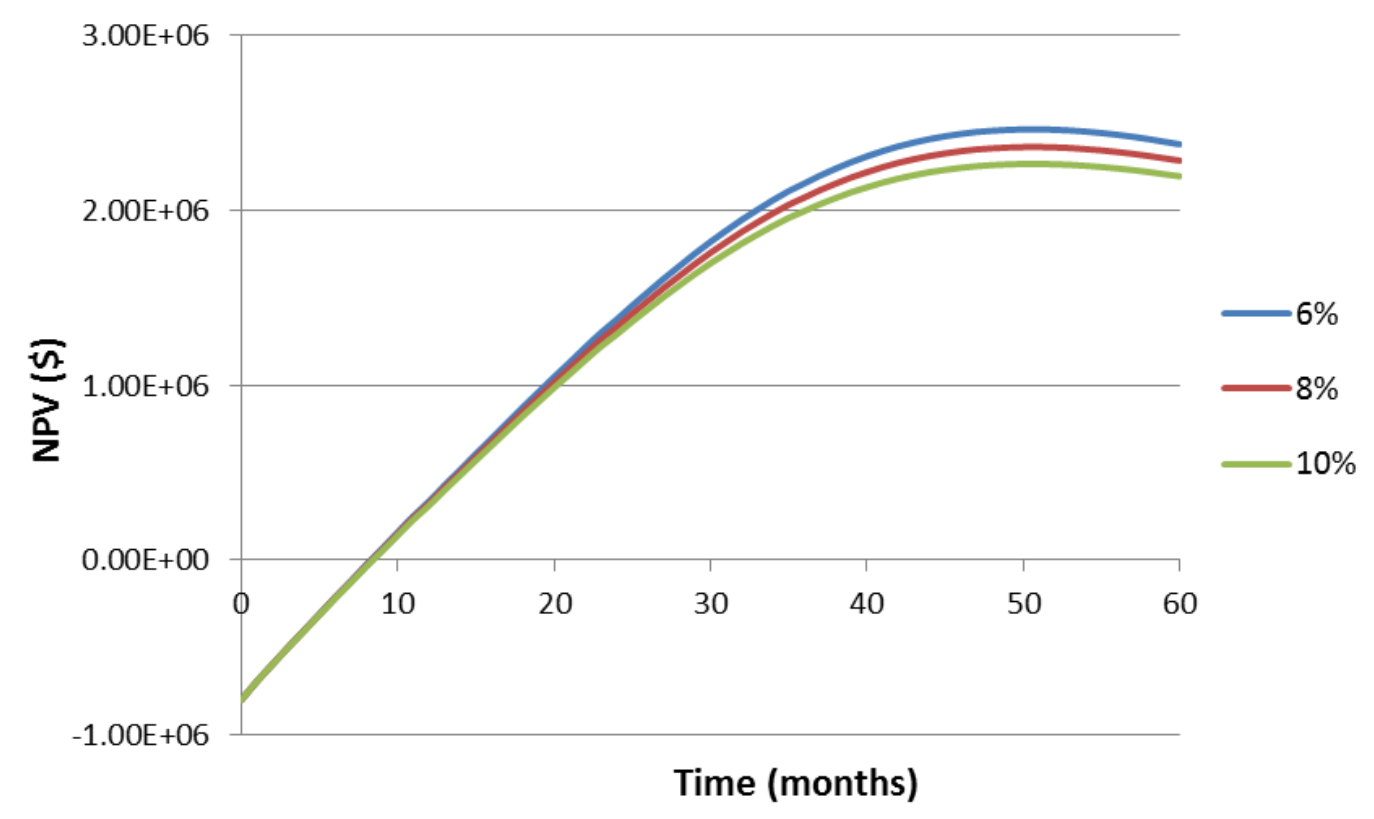

Fig. 5.20 - Sensitivity analyses of annual interest rate on NPV in emulsion flooding. 


\subsubsection{Emulsion Viscosity}

As a major parameter to control for a given reservoir, emulsion viscosity was chosen to conduct sensitivity analyses to better demonstrate its effect on economics. The same viscosity values of $200 \mathrm{cp}, 500 \mathrm{cp}, 1000 \mathrm{cp}$ and $2000 \mathrm{cp}$ were chosen as in the simulations. The results on cash flow and NPV are shown in Figure 5.21 and 5.22, respectively.

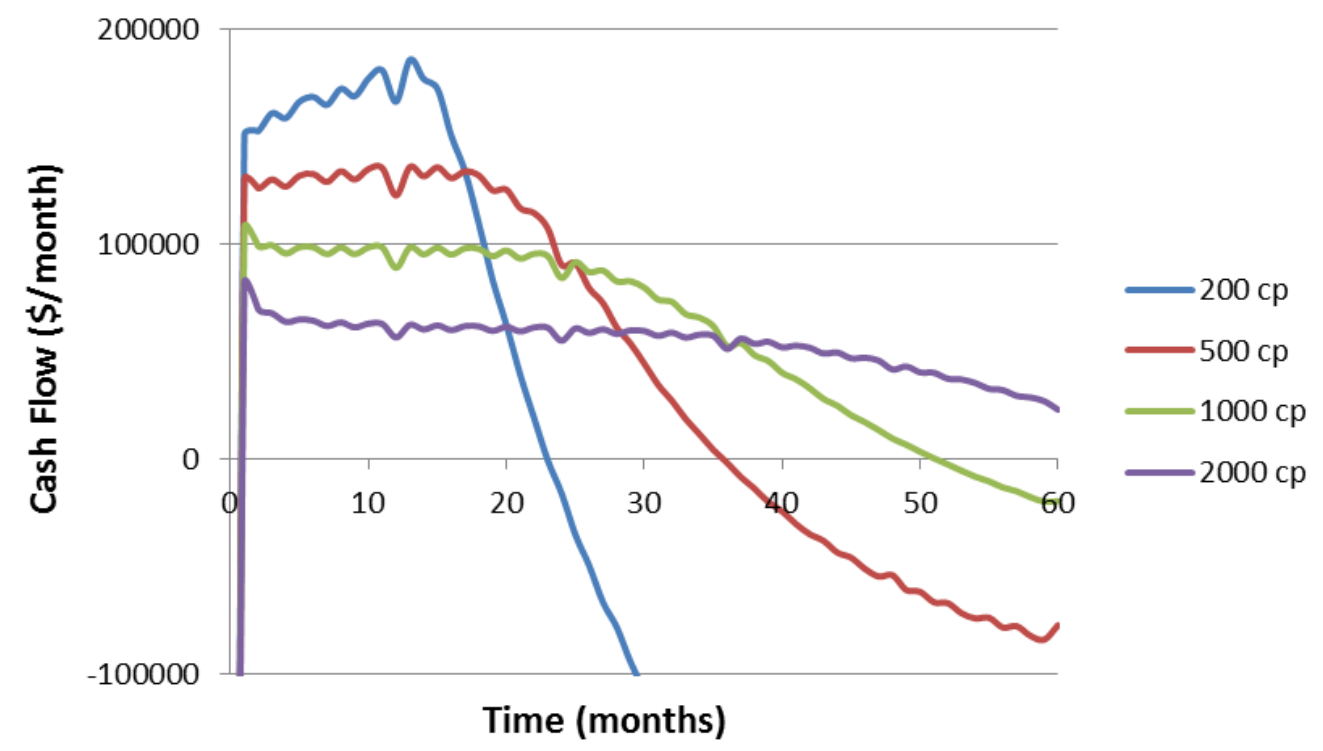

Fig. 5.21- Sensitivity analyses of emulsion viscosity on cash flow in emulsion flooding.

From Figure 5.21, the cash flow had the highest value for the lowest viscosity case, but the duration of this high value was also the shortest. Smaller viscosity of the 
emulsion resulted in better injectivity and thus the highest oil recovery rate at the beginning of project, but faster and higher amount of oil emulsion mixing occurred at the production well due to less mobility control provided by the emulsion.

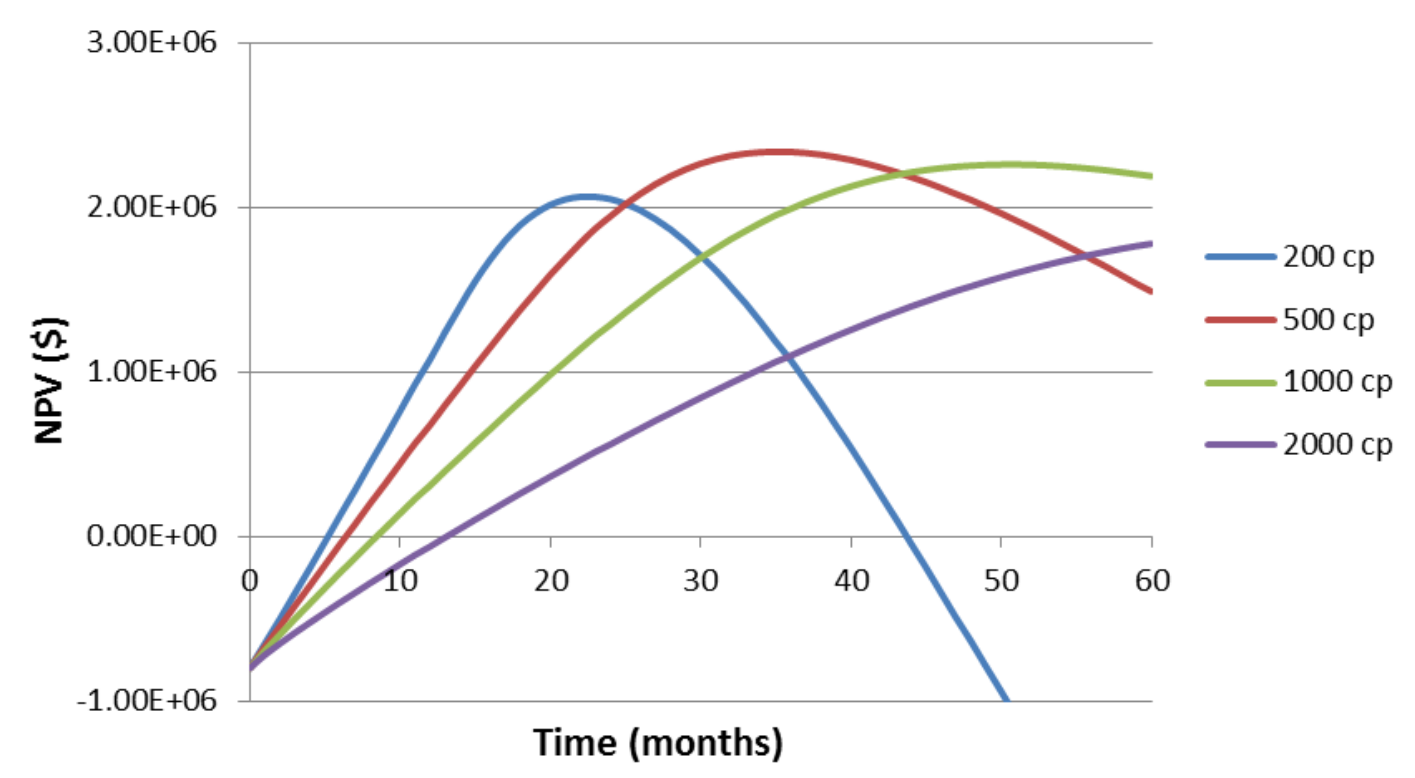

Fig. 5.22 - Sensitivity analyses of emulsion viscosity on NPV in emulsion flooding.

The overall comparison can be better demonstrated by NPV curves shown in Figure 5.22. From this figure, the maximum NPV was clearly shown to be the $500 \mathrm{cp}$ emulsion case among the four cases. When the emulsion viscosity is low, the displacement pattern gets poorer. On the other hand, if the emulsion viscosity is too high, oil recovery will be very slow and the interest rate will have a bigger negative 
effect on the economics because of the longer duration. Therefore, optimum viscosity should be decided by balancing those two factors. Since the NPV is affected by many other parameters, the best way to decide on emulsion viscosity is to conduct a sensitivity analysis based on other given parameters. In this case, the optimal emulsion viscosity was found to be around half of the crude oil viscosity (500 cp) in order to maximize the profit.

\subsection{Emulsion Flooding in a Water-flooded Reservoir}

Economics calculations on emulsion flooding in a water-flooded reservoir were conducted to evaluate the potential of this process in a reservoir that has been abandoned after water flooding. The capital cost in this case would be additional facility cost to generate and inject emulsions, which was assumed to be $\$ 300,000$. All other input parameters are kept the same as listed in Table 5.1.

The liquid rates in this process as input for conducting economics analyses are shown in Figure 5.23. All these curves were obtained from simulation results (see 4.5 in dissertation) that were exported into excel sheets and plotted on a monthly basis. Zero time corresponded to the initial date of emulsion flooding, which was set to be 03/01/2005 in simulation, when the reservoir had already been produced under water flooding for a year. All liquid rates in Figure 5.23 have been multiplied by 8 from the simulation results thus indicate the total rates within the whole 2.5 acre pattern. 


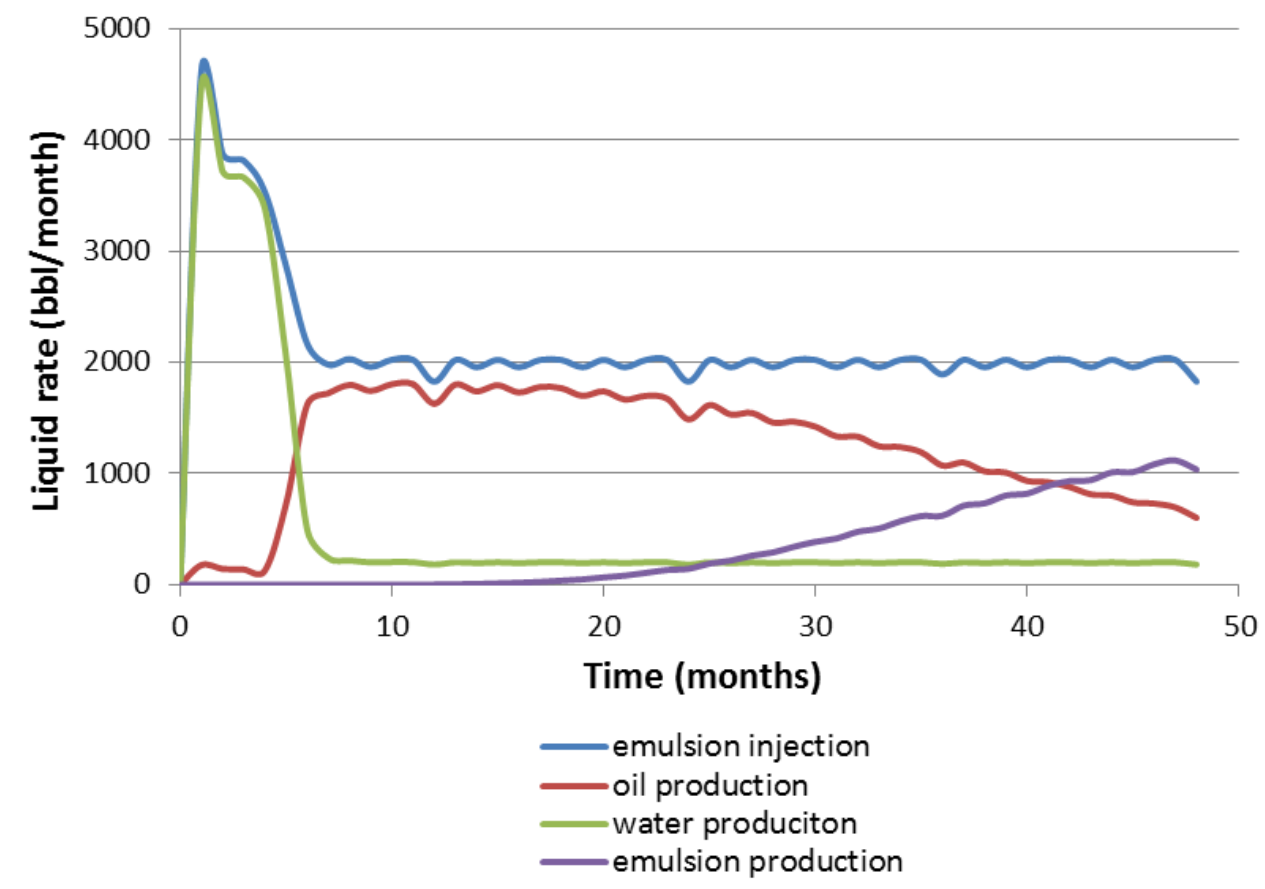

Fig. 5.23 - Monthly liquid rates during emulsion flooding in a water-flooded reservoir.

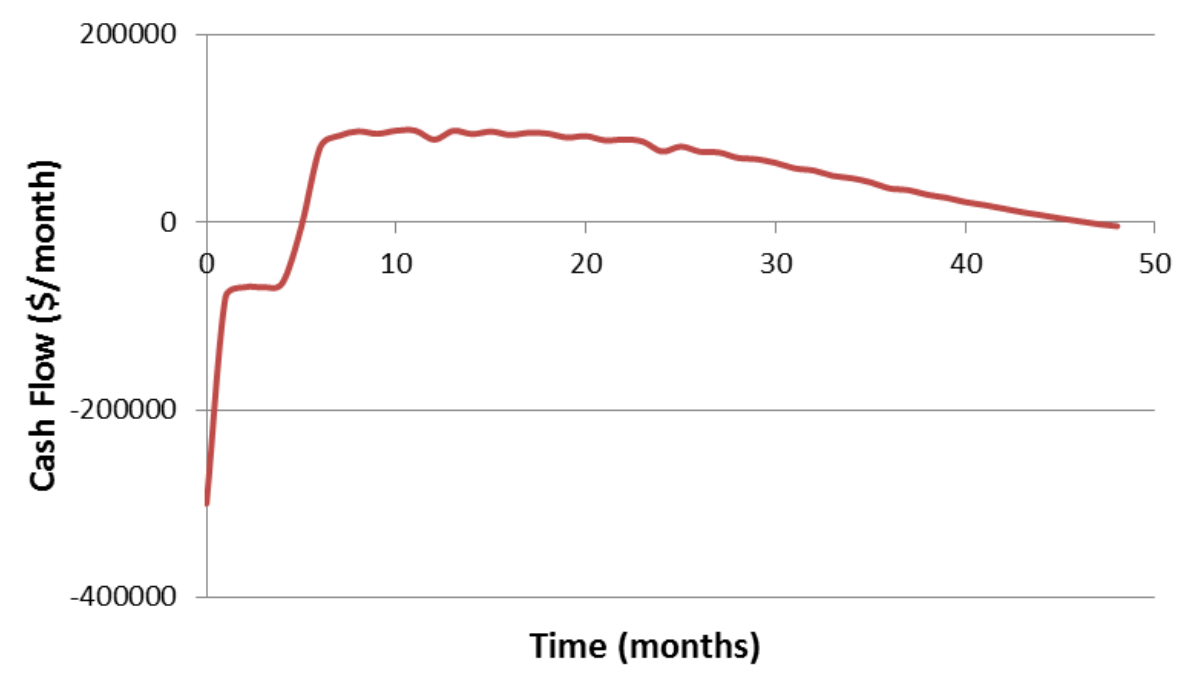

Fig. 5.24 - Cash flow for emulsion flooding in a water-flooded reservoir. 
The cash flow for this process were calculated and shown in Figure 5.24. The cash flow curve started at $-\$ 300,000$, which was equal to the amount of capital investment. Then the cash flow remained negative for five months and turned positive at the $6^{\text {th }}$ month. During this period of time, little oil was produced and most of the free water in the reservoir was being depleted, because of its much higher mobility than the oil phase. After the initial five months, oil rate went up rapidly to nearly 2000 bbl/month, coupled with a dramatic decrease of water production. Correspondingly, the cash flow became positive, and remained positive for another three years, until the oil production declined below economical rates.

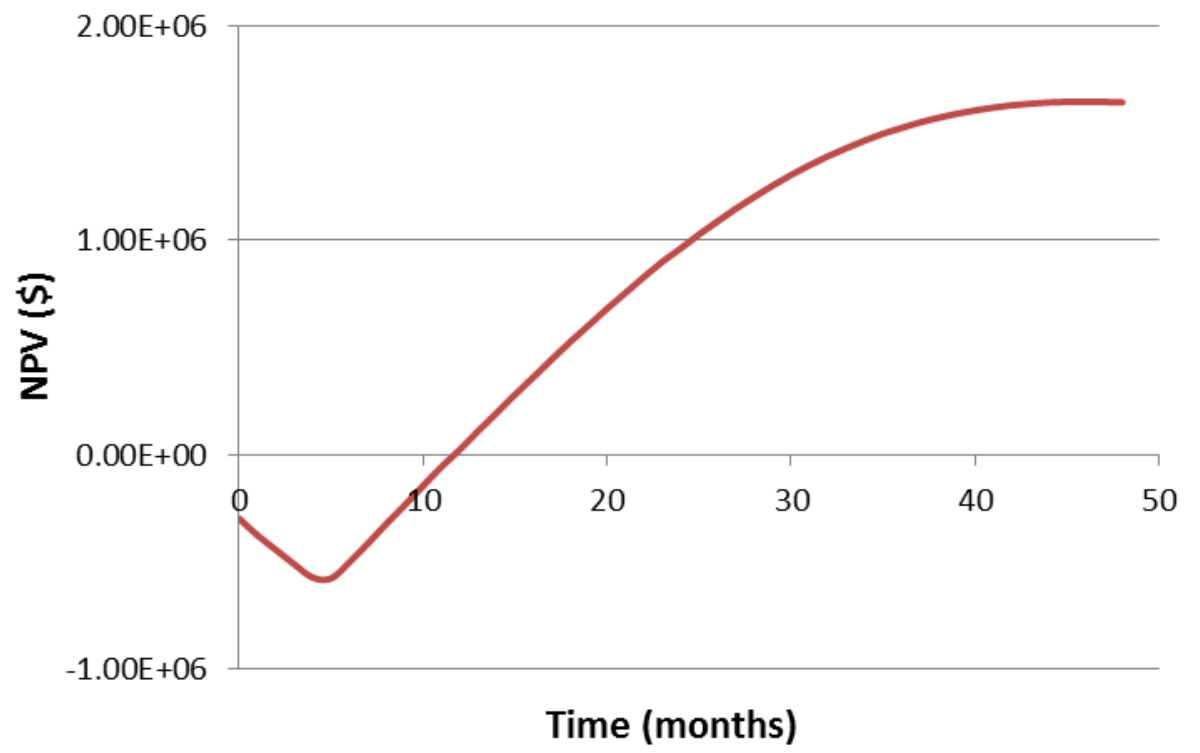

Fig. 5.25- NPV for emulsion flooding in a water-flooded reservoir. 
The NPV curve for this process was also obtained and shown 5.25. The NPV declined from the initial $-\$ 300,000$ to $-\$ 655,000$ during the first five months, and began to improve afterwards. It turned positive after a year of emulsion flooding, and kept on increasing to a maximum value of $\$ 1,600,000$. This value proves the highly positive economics of this process in a water-flooded reservoir - given an abandoned reservoir after water flooding that has $0 \mathrm{NPV}$, the emulsion flooding technique can improve its value to $\$ 640,000 /$ acre with all the parameters assumed in this case. 


\section{CHAPTER VI}

\section{SUMMARY AND CONCLUSIONS}

\subsection{Summary}

A new candidate of drive fluid for heavy oil recovery was invented and tested by a series of experiments. This new fluid is an emulsion system made of two inexpensive components: used engine oil and brine. The stability of the emulsion was proven by microscopic imaging and better understood by interfacial tension measurements and soot particle size analyses. Viscosity measurements were also conducted for emulsions of different water cut under various conditions.

An emulsion that contained $60 \%$ brine and $40 \%$ used engine oil was further investigated in a number of coreflood experiments, to verify its stability and flow properties in porous media. Several type of sandstone cores and two sand-packed slimtubes were used in these coreflood experiments, and the emulsion was injected at several rates in each experiment. Under each experimental condition, the emulsion breakdown was analyzed, and the stabilized pressure drop was recorded, from which the effective viscosity of the emulsion was calculated.

Based on the experimental results, numerical simulations were conducted on emulsion flooding in a heavy oil reservoir. Because of the oil-external nature of the emulsion and little plug-off effects from flowing through porous media, the emulsion was simply treated as heavy oil, and the emulsion breakdown effect was included by coinjection of water with this oil in simulation. Input parameters such as emulsion 
viscosity and water breakout fractions were chosen based on experiments and sensitivity analyses were conducted on those parameters to include their uncertainties. Simulation results were compared with water flooding in terms of oil rate, water cut and cumulative oil production. Emulsion flooding in a water-flooded reservoir case was also studied in our simulations.

Finally, economics calculations were performed based on simulation results. Cash flow and NPV curves for emulsion flooding were obtained and compared with those for water flooding. Sensitivity analyses of certain input parameters were also conducted. Economics of emulsion flooding in a water-flooded reservoir were also calculated to reveal the potential of this method for abandoned reservoirs from water flooding.

\subsection{Conclusions}

Based on our experimental studies, the following conclusions are made:

1. Stable $\mathrm{W} / \mathrm{O}$ emulsions were generated with used engine oils simply by mixing in brine under shear. No surfactant or any other chemicals were required in the emulsification process.

2. Up to $75 \%$ brine by volume could be mixed into used engine oil to form emulsions. Beyond this brine fraction, water existed as separate a separate phase from the emulsion. 
3. The viscosity of the emulsion increased with increasing water fraction. A wide range of viscosity from $102 \mathrm{cp}$ to $104 \mathrm{cp}$ was covered for emulsions of $20 \%$ to $70 \%$ water cut.

4. At low water cut $(<40 \%)$, the emulsion was a Newtonian fluid; at higher water cut the emulsion was shear thinning.

5. Used engine oil emulsions were macroemulsions. However, they were very stable, as evident from the fact that no phase separation occurred after six months and water droplet size remained fairly constant.

6. The stability of the emulsion was related to the presence of soot particles in used engine oil and certain additives in engine oil.

7. An emulsion of $60 \%$ water cut had viscosities around $2000 \mathrm{cp}$ at room temperature, and was recommended as drive fluid for heavy oil displacement.

8. This emulsion passed through sandstone/sand without plugging off the porous media, as evident from constant pressure drops along the core at constant rates of injection, and similar pressure drop to the beginning of experiment after many pore volumes of emulsion passing through.

9. This emulsion broke down to some extent by flowing through cores, and the amount of water breakout depended on core properties and the flow rate.

10. Breakdown of emulsion resulted in reduced viscosities of the emulsion, and could cause lower effective viscosity due to two-phase flow.

11. In high permeability matrixes (>1000 md), emulsion breakdown was less than $10 \%$ at moderate rates of injection in all experiments. In sand packs 
(permeability around $8000 \mathrm{md}$ ), emulsion breakdown from flowing through the matrix was less than $1 \%$ at rates up to $6 \mathrm{ft} / \mathrm{d}$.

12. Effective viscosities of the emulsion calculated from coreflood experiments revealed $0 \sim 10 \%$ viscosity reduction from viscometer-measured viscosity of the original emulsion (before injection) in sand packs, and larger extents of reduction in sandstone cores. Calculated effective viscosities were comparable to viscometer measurements.

Based on the experimental results, the emulsion was approximated as an oil phase (and co-injection of a certain fraction of water) in numerical simulations of heavy oil displacement, and economics calculations were conducted from the simulation results. Major conclusions from simulations and economics calculations are drawn as follows:

1. Emulsion flooding in a heavy oil reservoir was highly effective compared to water flooding: oil production rate maintained at a reasonably high value until close to crude oil depletion in the reservoir; water cut was dramatically reduced through the process; cumulative oil production nearly quadrupled the amount from water flooding at the end of simulation.

2. Economics calculations of emulsion flooding was highly positive, revealing an increase of over $\$ 2,000,000$ in NPV for a 2.5 acre pattern of a thin bed reservoir compared to that for water flooding. 
3. Oil production rates were controlled by the crude oil viscosity at the beginning of injection, and later more dominated by the viscosity of injectant. The emulsion viscosity needs to be carefully designed to maximize the NPV.

4. Emulsion flooding was found to be effective in water-flooded reservoirs. Simulation results showed an incremental oil recovery of over 50\% OOIP, and economics calculations demonstrated an incremental NPV of $\$ 640,000 /$ acre for this thin bed reservoir. 


\section{REFERENCES}

Adams, D.M. 1982. Experiences with Waterflooding Lloydminster Heavy-Oil Reservoirs. SPE Journal of Petroleum Technology 34 (8): 1643-1650.

Alikhan, A.A. and Farouq Ali, S.M. 1983. Current Status of Nonthermal Heavy Oil Recovery. Paper SPE 11846 presented at the SPE Rocky Mountain Regional Meeting, Salt Lake City, Utah, 22-25 May.

Breston, J.N. 1958. Oil Recovery by Heat from in Situ Combustion. SPE Journal of Petroleum Technology 10 (8): 13-17.

Bragg, J.R. 1999. Oil Recovery Method Using an Emulsion. US Patent 5927404.

Bragg, J.R. 2000. Oil Recovery Method Using an Emulsion. US Patent 6068054.

Bragg, J.R. and Varadaraj, R. 2006. Solids-Stabilized Oil-in-Water Emulsion and a Method for Preparing Same. US Patent 6988550.

Breslin, M. 2010. Used Oil: An Often Overlooked Resource. http://www.americanrecycler.com/0110/used002.shtml.

Bryan, J.L. and Kantzas, A. 2007. Enhanced Heavy-Oil Recovery by Alkali-Surfactant Flooding. Paper SPE 110738 presented at the SPE Annual Technical Conference and Exhibition, Anaheim, California, 11-14 November.

Bryan, J.L. and Kantzas, A. 2008. Improved Recovery Potential in Mature Heavy Oil Fields by Alkali-Surfactant Flooding. Paper SPE 117649 presented at the SPE/PS/CHOA International Thermal Operations and Heavy Oil Symposium, Calgary, Alberta, Canada, 20-23 October.

Bryan, J. and Kantzas, A. 2009. Potential for Alkali-Surfactant Flooding in Heavy Oil Reservoirs through Oil-in-Water Emulsification. Journal of Canadian Petroleum Technology 48 (2): 37-46.

Chopra, S. and Lines, L. 2008. Special Section - Heavy Oil. The Leading Edge (Society of Exploration Geophysicists) 27 (8): 1104-1106.

D'Elia-S, R. and Ferrer-G, J. 1973. Emulsion Flooding of Viscous Oil Reservoirs. Paper SPE 4674 presented at the Fall Meeting of the Society of Petroleum Engineers of AIME, Las Vegas, Nevada, 30 September-3 October. 
Drillet, V. and Defives, D. 1991. Clay Dissolution Kinetics in Relation to Alkaline Flooding. Paper SPE 21030 presented at the SPE International Symposium on Oilfield Chemistry, Anaheim, California, 20-22 February.

Du, Y. and Guan, L. 2004. Field-Scale Polymer Flooding: Lessons Learned and Experiences Gained During Past 40 Years. Paper SPE 91787 presented at the SPE International Petroleum Conference in Mexico, Puebla Pue., Mexico, 7-9 November.

Edinga, K.J., McCaffery, F.G., and Wytrychowski, I.M. 1980. Cessford Basal Colorado a Reservoircaustic Flood Evaluation. SPE Journal of Petroleum Technology 32 (12): 2103-2110.

Farouq Ali, S.M., Figueroa, J.M., Azuaje, E.A. et al. 1979. Recovery of Lloydminster and Morichal Crudes by Caustic, Acid and Emulsion Floods. Journal of Canadian Petroleum Technology 18 (1): 53-59.

Gondouin, M. and Fox III, J.M. 1991. The Challenge of West Sak Heavy Oil: Analysis of an Innovative Approach. Paper SPE 22077 presented at the International Arctic Technology Conference, Anchorage, Alaska, 29-31 May.

Harmsen, G.J. 1971. Oil Recovery by Hot-Water and Steam Injection. Paper WPC14228 presented at the World Petroleum Congress, Moscow, USSR, 13-18 June.

Huc, A.Y. 2011. Heavy Crude Oils: From Geology to Upgrading an Overview. Paris: Editions Technip.

Isaacs, E.E. and Chow, R.S. 1992. Practical Aspects of Emulsion Stability. ed. Schramm, L.L. Emulsions: Fundamentals and Applications in the Petroleum Industry. Washington, DC: American Chemical Society.

Jennings Jr., H.Y., Johnson Jr., C.E., and McAuliffe, C.D. 1974. A Caustic Waterflooding Process for Heavy Oils. SPE Journal of Petroleum Technology 26 (12): 1344-1352.

Johnson Jr., C.E. 1976. Status of Caustic and Emulsion Methods. SPE Journal of Petroleum Technology 28 (1): 85-92.

Joseph N. Breston, T.L. 1958. Oil Recovery by Heat from in Situ Combustion. SPE Journal of Petroleum Technology 10 (8): 13-17.

Kaminsky, R.D., Wattenbarger, R.C., Lederhos, J. et al. 2010. Viscous Oil Recovery Using Solids-Stabilized Emulsions. Paper SPE 135284 presented at the SPE Annual Technical Conference and Exhibition, Florence, Italy, 19-22 September. 
Kang, X., Zhang, J., Sun, F. et al. 2011. A Review of Polymer EOR on Offshore Heavy Oil Field in Bohai Bay, China. Paper SPE 144932 presented at the SPE Enhanced Oil Recovery Conference, Kuala Lumpur, Malaysia, 19-21 July.

Kaplan, I.R., Lu, S.T., Alimi, H.M. et al. 2001. Fingerprinting of High Boiling Hydrocarbon Fuels, Asphalts and Lubricants. Environmental Forensics 2: 231248.

Khatib, A.K., Earlougher, R.C., and Kantar, K. 1981. $\mathrm{CO}_{2}$ Injection as an Immiscible Application for Enhanced Recovery in Heavy Oil Reservoirs. Paper SPE 9928 presented at the SPE California Regional Meeting, Bakersfield, California, 25-27 March.

Kokal, S.L. 2005. Crude Oil Emulsions: A State-of-the-Art Review. SPE Production \& Operations 20 (1): 5-13.

Kumar, R., Dao, E.K., and Mohanty, K.K. 2010. Emulsion Flooding of Heavy Oil. Paper SPE 129914 presented at the SPE Improved Oil Recovery Symposium, Tulsa, Oklahoma, 24-28 April.

Lam, S.S., Russell, A.D., Lee, C.L. et al. 2012. Production of Hydrogen and Light Hydrocarbons as a Potential Gaseous Fuel from Microwave-Heated Pyrolysis of Waste Automotive Engine Oil. International journal of hydrogen energy 37: 5011-5021.

Leonard, J. 1986. Increased Rate of EOR Brightens Outlook. Oil and Gas Journal 84 (15): 77-101.

Liebe, H.R. and Butler, R. 1991. A Study of the Use of Vertical Steam Injectors in the Steam-Assisted Gravity Drainage Process. Paper presented at the Annual Technical Meeting, Banff, 21-24 April.

Mai, A., Bryan, J., Goodarzi, N. et al. 2009. Insights into Non-Thermal Recovery of Heavy Oil. Journal of Canadian Petroleum Technology 48 (3): 27-35.

Mashava, P.M., Alonge, I.E., and Mlenga, F. 1989. Chemistry from Waste Products: Fractional Distillation of Used Engine Oil. Journal of Chemical Education 66 (12): 1042.

McAuliffe, C.D. 1973a. Crude-Oil-Water Emulsions to Improve Fluid Flow in an Oil Reservoir. SPE Journal of Petroleum Technology 25 (6): 721-726. 
McAuliffe, C.D. 1973b. Oil-in-Water Emulsions and Their Flow Properties in Porous Media. SPE Journal of Petroleum Technology 25 (6): 727-733.

Mohnot, S.M., Bae, J.H., and Foley, W.L. 1987. A Study of Mineral/Alkali Reactions. SPE Reservoir Engineering 2 (4): 653-663.

Nelson, R.C., Lawson, J.B., Thigpen, D.R. et al. 1984. Cosurfactant-Enhanced Alkaline Flooding. Paper SPE 12672 presented at the SPE Enhanced Oil Recovery Symposium, Tulsa, Oklahoma, 15-18 April.

Novosad, Z. and Novosad, J. 1984. Determination of Alkalinity Losses Resulting from Hydrogen Ion Exchange in Alkaline Flooding. SPE Journal 24 (1): 49-52.

Owens, W.D. and Suter, V.E. 1965. Steam Simulation for Secondary Recovery. Journal of Canadian Petroleum Technology 4 (4): 227-235.

Picha, M.S. 2007. Enhanced Oil Recovery by Hot $\mathrm{CO}_{2}$ Flooding. Paper SPE 105425 presented at the SPE Middle East Oil and Gas Show and Conference, Kingdom of Bahrain, 11-14 March.

Reid, T.B. and Robinson, H.J. 1981. Lick Creek Meakin Sand Unit Immiscible $\mathrm{CO}_{2}$ Waterflood Project. SPE Journal of Petroleum Technology 33 (9): 1723-1729.

Saner, W.B. and Patton, J.T. 1986. $\mathrm{CO}_{2}$ Recovery of Heavy Oil: Wilmington Field Test. SPE Journal of Petroleum Technology 38 (7): 769-776.

Scott, G.R., Collins, H.N., and Flock, D.L. 1965. Improving Waterflood Recovery of Viscous Crude Oils by Chemical Control. Journal of Canadian Petroleum Technology 4 (4): 243-251.

Selby, R., Alikhan, A.A., and Ali, S.M.F. 1989. Potential of Non-Thermal Methods for Heavy Oil Recovery. Journal of Canadian Petroleum Technology 28 (4): 45-59.

Seright, R.S., Fan, T., Wavrik, K.E. et al. 2011. New Insights into Polymer Rheology in Porous Media. SPE Journal 16 (1): 35-42.

T-Taissi, A. and Raminsky, K. 2007. Hydrogen Production from Used Lubricating Oils. Catal Today 129 (365): 71.

Wassmuth, F.R., Green, K., Hodgins, L. et al. 2007. Polymer Flood Technology for Heavy Oil Recovery. Paper presented at the Canadian International Petroleum Conference, Calgary, Alberta, 12-14 June. 
Wassmuth, F.R., Green, K., Arnold, W. et al. 2009. Polymer Flood Application to Improve Heavy Oil Recovery at East Bodo. Journal of Canadian Petroleum Technology 48 (2): 55-61.

Xie, J., Chung, B.C., and Leung, L. 2008. Design and Implementation of a Caustic Flooding EOR Pilot at Court Bakken Heavy Oil Reservoir. Paper SPE 117221 presented at the SPE/PS/CHOA International Thermal Operations and Heavy Oil Symposium, Calgary, Alberta, Canada, 20-23 October.

Zaitoun, A., Tabary, R., Fossey, J.P. and Boyle, T. 1998. Implementing a Heavy-Oil Horizontal-Well Flood in Western Canada. Paper presented at the the Seventh UNITAR International Conference on Heavy Crude and Tar Sands, Beijing, China, 27-30 October. 